\title{
Anti-TGF- $\beta$-Antikörper und Öffnung der Blut-Hirn-Schranke - Evaluation neuer Optionen zur Behandlung hochmaligner Gliome im Tiermodell
}

\section{Dissertation}

zur Erlangung des mathematisch-naturwissenschaftlichen Doktorgrades

„Doctor rerum naturalium“

der Georg-August-Universität Göttingen

vorgelegt von

Petra Hülper

aus Emden 
D 7

Referent: Prof. Dr. Ernst A. Wimmer

Koreferent: Jun. Prof. Dr. Ralf Heinrich

Tag der mündlichen Prüfung: 27.10.2009 


\section{Inhaltsverzeichnis}

$1 \quad$ Einleitung ................................................................................................................. 1

1.1 Hirntumoren .................................................................................................................

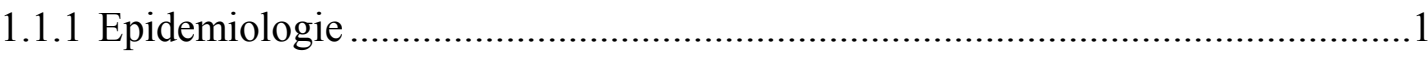

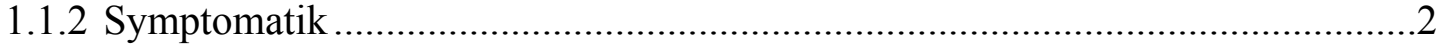

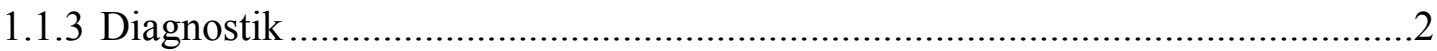

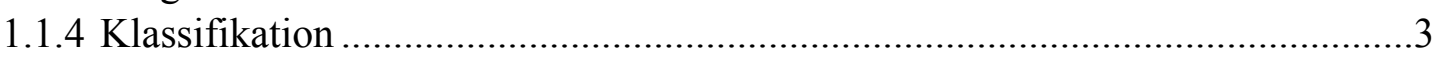

1.1.5 Tumorgenese des Glioblastoms ……………………………………….....

1.1 .6 Prognose

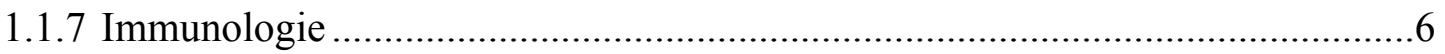

1.1 .8 Gefäßversorgung ............................................................................................

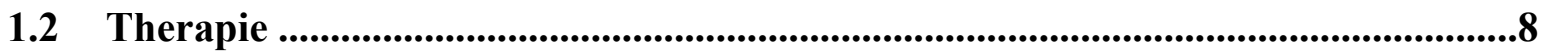

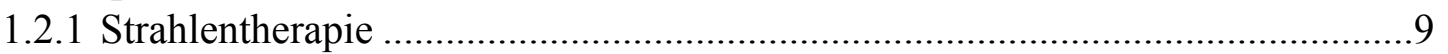

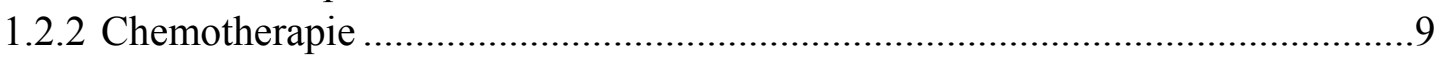

1.3 Alternative Therapieansätze.........................................................................................10

1.3.1 Überwindung der BHS............................................................................... 10

1.3.1.1 Die Blut-Hirn-Schranke _................................................................11

1.3.1.2 Methoden zur Überwindung der BHS .............................................12

1.3.1.3 Alkylglycerine.............................................................................13

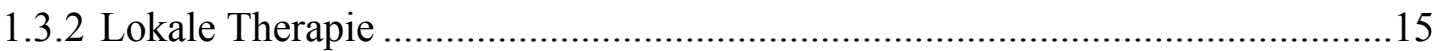

1.3.3 molecular targeted-Therapie.........................................................................15

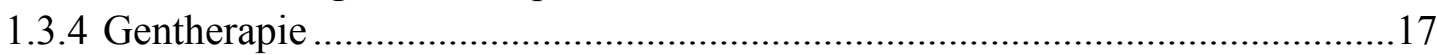

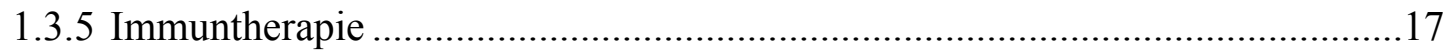

1.4 Transforming growth factor beta (TGF- $\beta$ ) …................................................18

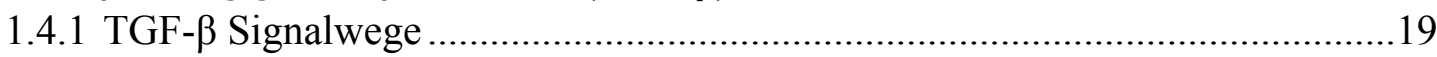

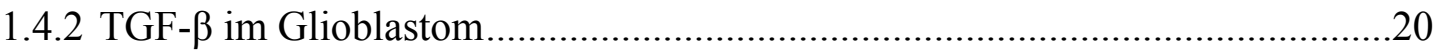

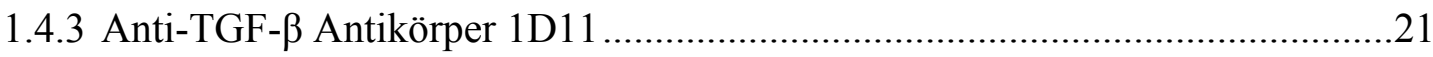

1.5 Optical imaging...............................................................................................................22

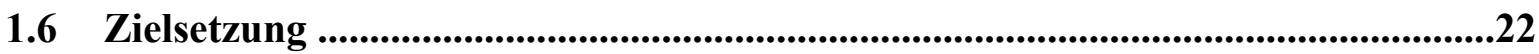

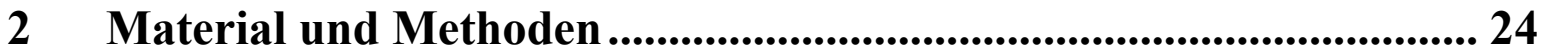

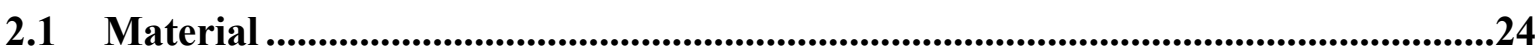

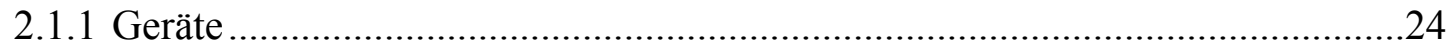

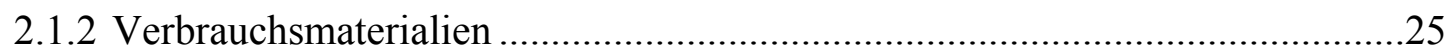

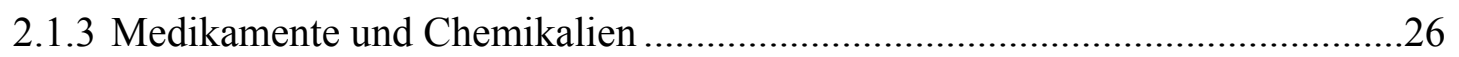

2.1.3.1 Alkylglycerine...............................................................................26

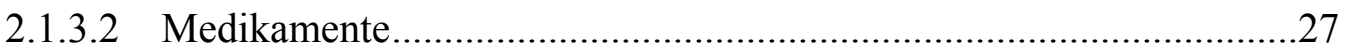

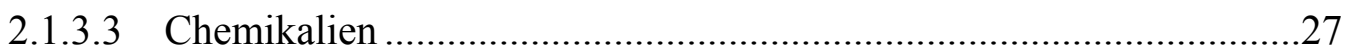

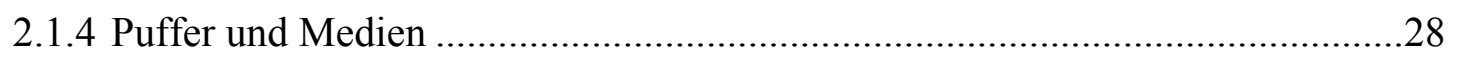

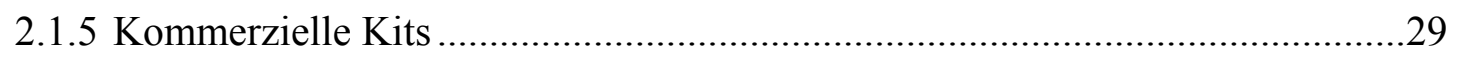

2.1.6 Antikörper und Proteine.........................................................................29

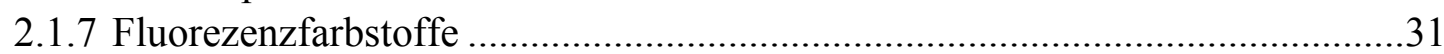

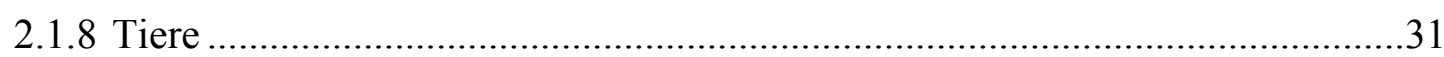

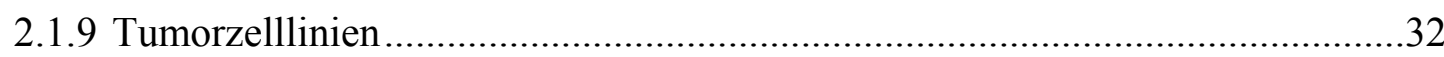

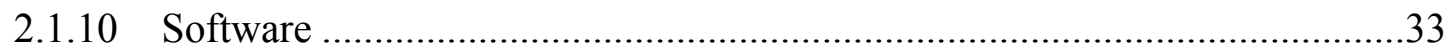


2.2 Methoden. .34

2.2.1 Kopplung der Fluoreszenzfarbstoffe RB200 oder Cy5.5

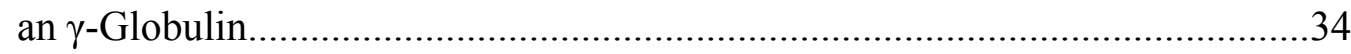

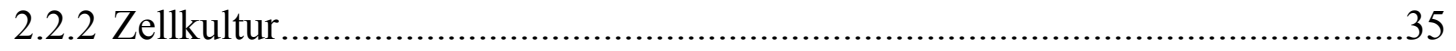

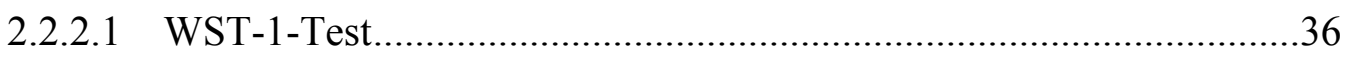

2.2.2.2 Gewinnung und Aufkonzentrierung von konditioniertem

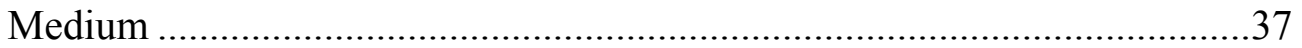

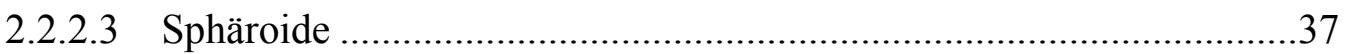

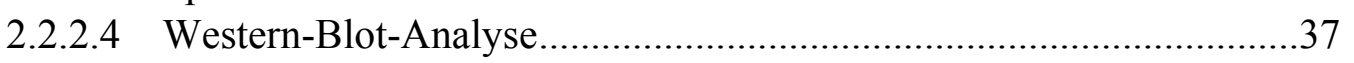

2.2.2.5 ELISA (enzyme-linked immunosorbent assay) ................................39

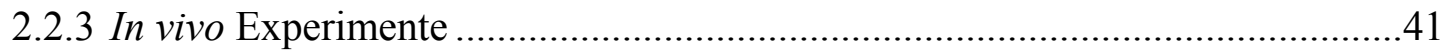

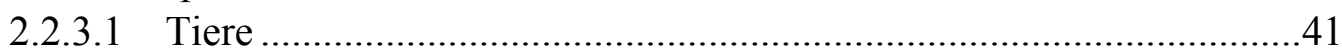

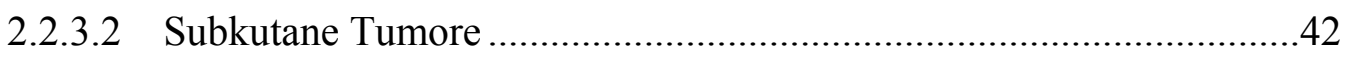

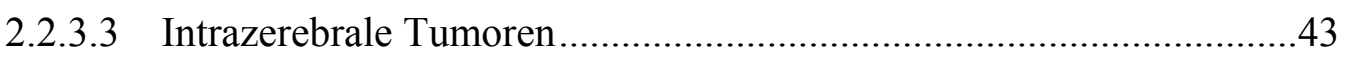

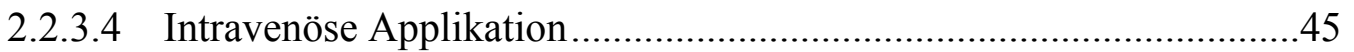

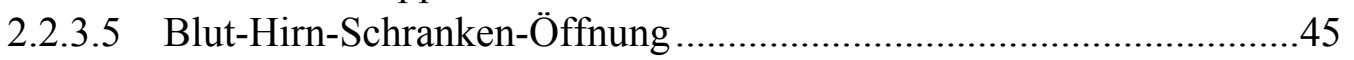

2.2.3.6 Fluoreszenzmessungen mit dem eXplore Optix System......................47

2.2.4 Gewinnung zuvor markierter Peritonealmakrophagen ....................................50

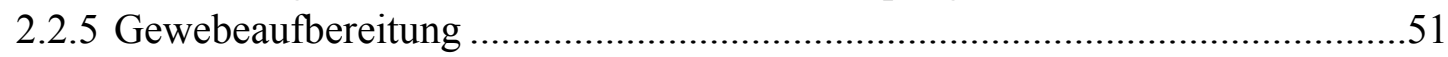

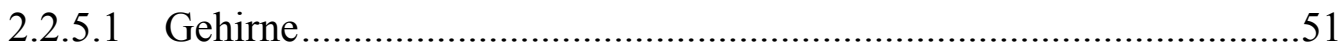

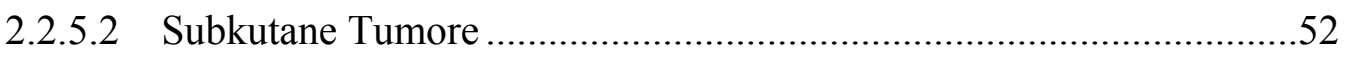

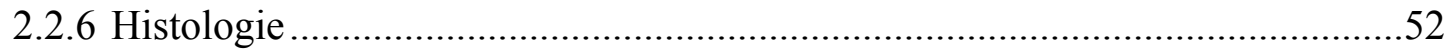

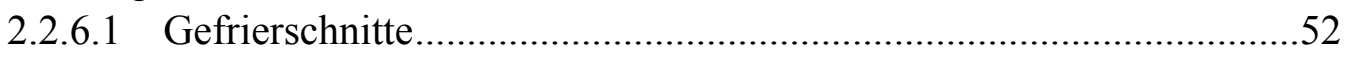

2.2.6.2 Immunfluoreszenzfärbung von Gefrierschnitten ..............................53

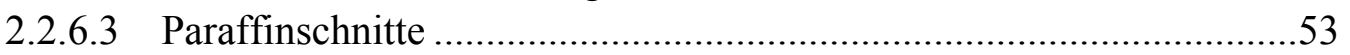

2.2.6.4 Färbungen von Paraffinschnitten .....................................................53

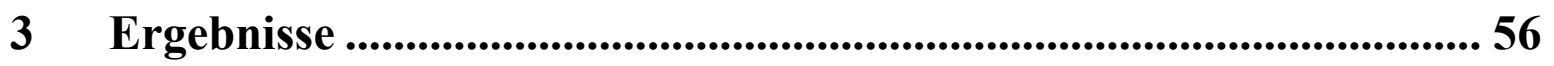

3.1 Spezifische Bindung von AF680 1D11 Antiköper an von

U87MG Tumorzellen sezerniertes TGF-ß.........................................................56

3.2 TGF- $\beta 2$ Produktion von U87MG und GL261 Zellen .........................................57

3.3 Einfluss von TGF- $\beta 2$ auf die Vitalität und Proliferation von Gliomzellen in der Zellkultur .............................................................................58

3.4 1D11-Behandlung s.c. Tumoren....................................................................59

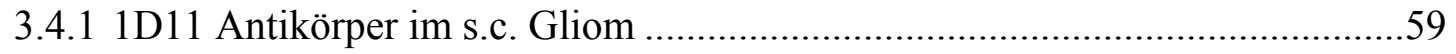

3.4.2 Behandlung subkutaner U87MG-Tumoren in nu/nu-Mäusen

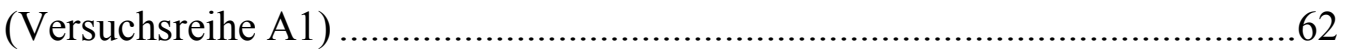

3.4.3 Behandlung subkutaner U87MG-Tumoren in nu/nu-Mäusen

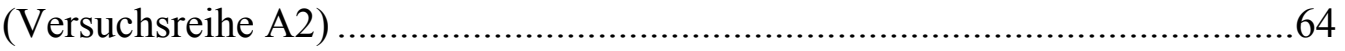

3.4.4 Behandlung subkutaner GL261-Tumoren in Black/6-Mäusen

(Versuchsreihe B) ...........................................................................66

3.4.5 Behandlung subkutaner GL261-Tumoren in nu/nu-Mäusen

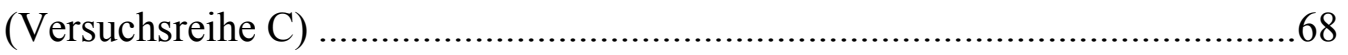

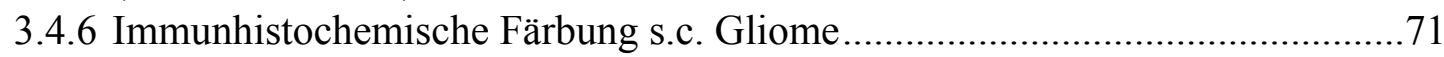

3.4.6.1 Immunhistochemische Färbung proliferierender Zellen....................71

3.4.6.2 Immunhistochemische Färbung apoptotischer Zellen .......................73 
3.4.6.3 Immunfluoreszenzfärbung von Gefäßendothelzellen .........................77

3.4.6.4 Immunhistochemische Färbung von Makrophagen ............................78

3.5 Einfluß von humanem, rekombinantem TGF- $\beta$ auf das Einwandern von Peritonealmakrophagen in GL261-Sphäroide ..............................................82

3.6 1D11 im intrazerebralen Gliom .........................................................................82

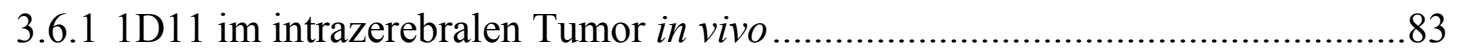

3.6.2 1D11 im intrazerebralen Tumor in der Fluoreszenzmikroskopie .......................84

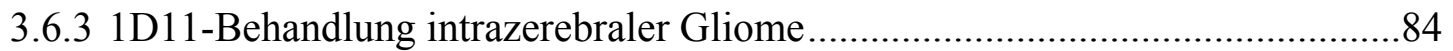

3.7 Globulin-Anreicherung im Mausgehirn nach Öffnung der BHS .........................87

3.7.1 Kurzzeitversuche zur Öffnung der BHS mit mikroskopischer

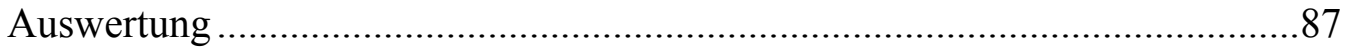

3.7.1.1 HG-Konzentrationsabhängige Öffnung der BHS .............................88

3.7.1.2 Öffnung der BHS mit i.v. Gabe von fluoreszierenden

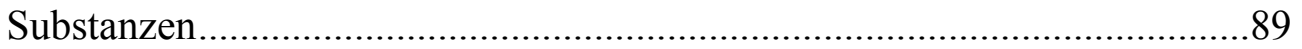

3.7.2 Langzeitversuche zur Öffnung der BHS mit mikroskopischer

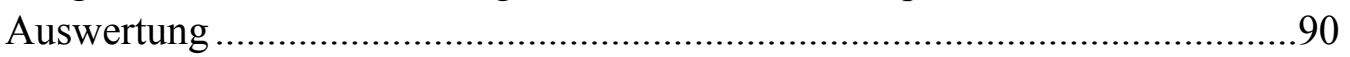

3.7.3 $\gamma$-Globulin-Anreicherung im Glioblastom-tragenden Gehirn

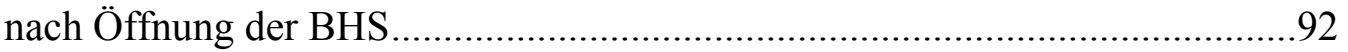

3.7.4 eXplore Optix-basierte Darstellung von intrazerebralem

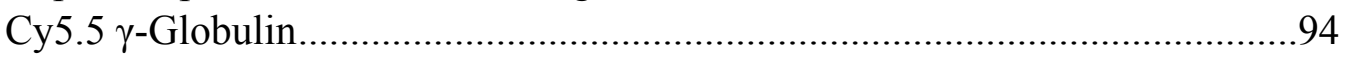

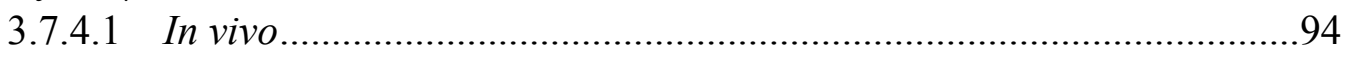

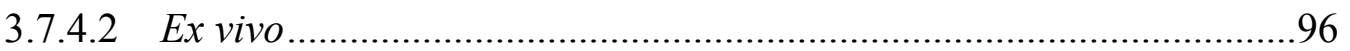

3.7.5 eXplore Optix-basierte Darstellung von intrazerebralem AF680 1D11 ............97

3.7.5.1 In vivo und ex vivo Fluoreszenzintensitäten.....................................98

3.7.5.2 Fluoreszenzanregungs-Lebensdauer (LT) ......................................98

4 Diskussion........................................................................................... 100

4.1 Vor- und Nachteile der Implantation von Gliomzellen aus der Zellkultur .......100

4.2 Anreicherung von 1D11 in Gliomen der Maus................................................102

4.3 Einfluß der 1D11-Behandlung auf subkutane Gliome......................................105

4.3.1 Einfluß der 1D11-Behandlung auf die extrazelluläre Matrix ..........................107

4.3.2 Einfluß der 1D11-Behandlung auf die Glykoproteinproduktion ......................108

4.3.3 Einfluß der 1D11-Behandlung auf die Proliferation.......................................109

4.3.4 Einfluß der 1D11-Behandlung auf die Angiogenese ........................................110

4.3.5 Einfluß der 1D11-Behandlung auf das Immunsystem ...................................112

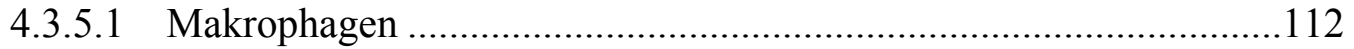

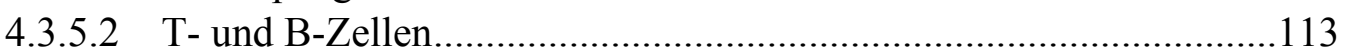

4.4 1D11-Behandlung intrazerebraler Gliome.................................................114

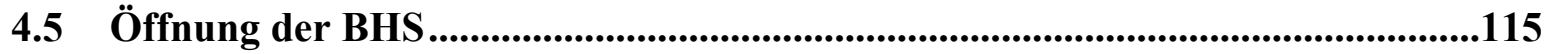

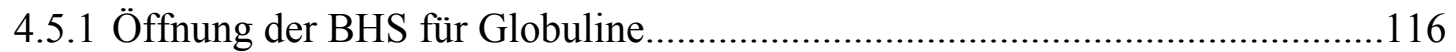

4.5.2 Bewertung der Lebensdauer der Fluorochromanregung..................................119

4.5.3 Öffnung der BHS im Glioblastom-tragenden Gehirn .........................................120

4.5.4 Öffnung der BHS im Vergleich zu convection enhanced delivery ...................121

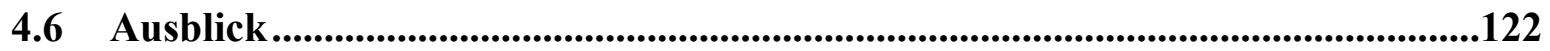

$5 \quad$ Zusammenfassung................................................................................. 124 
6 Literaturverzeichnis............................................................................ 126

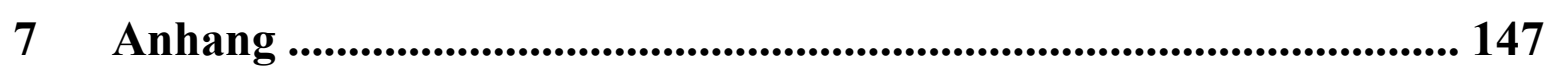

7.1 Abkürzungen .......................................................................................................147 


\section{Einleitung}

Die erfolgreiche Behandlung von Hirntumoren ist bei Kindern, wie bei Erwachsenen trotz aller Fortschritte in der Medizin auch heute noch schwierig (Kalifa und Grill 2005, Khatua und Jalali 2005). Im Gegensatz $\mathrm{zu}$ guten Therapieerfolgen bei der Behandlung verschiedener Entitäten extrakranieller solider Tumoren und Leukämien haben intrazerebrale Tumoren häufig noch eine schlechte Prognose (Furnari et al., 2007, Finlay und Zacharoulis 2005, Kelli 1999). Die Ursache hierfür liegt in der ausgeprägten Heterogenität von Gehirntumoren und der Existenz der Blut-Hirn-Schranke (BHS) im Gehirngefäßendothel (Doolittle et al. 2005, Löscher und Potschka 2005, Regina et al. 2001).

\subsection{Hirntumoren}

\subsubsection{Epidemiologie}

Hirntumoren sind alle malignen und benignen Neoplasien des zentralen Nervensystems (ZNS). Mit einem Anteil von $2 \%$ aller Tumorneuerkrankungen in Deutschland nimmt diese Gruppe im Erwachsenenalter einen eher kleinen Anteil ein. Die Glioblastome machen mit $50 \%$ aller hirneigenen Tumoren im Erwachsenenalter die größte Gruppe aus.

Im Gegensatz dazu stellen bei Kindern Tumoren des ZNS mit 22,6 \% (Jahresbericht 2007, Kinderkrebsregister, Mainz) nach den Leukämien die größte Gruppe dar. In Deutschland erkranken jedes Jahr etwa 400 von 100000 Kindern an einem Tumor des ZNS. Bei Kindern und Jugendlichen unter 15 Jahren liegt der Anteil der Gliome an allen Tumoren bei etwa $7 \%$. Das Glioblastom besitzt die höchste Mortalität aller Krebserkrankungen bei Kindern (Kaatsch et al., 2001).

Das Risiko an einem Gliom zu erkranken ist vermutlich von exogenen Faktoren weitgehend unabhängig. Bisher konnte nur für Belastung mit ionisierender Strahlung in mehreren Studien ein erhöhtes Risiko für die Entwicklung von Tumoren sicher nachgewiesen werden (Ohgaki u. Kleihues, 2005 a, 2005 b, Schuz, 2001).

Endogene Risikofaktoren sind erbliche Tumorsyndrome, wie die Neurofibromatose Typ I (Inzidenz von 1:3000 bis 1:4000) und II, die tuberöse Sklerose, das Turcot-Syndrom und das Li-Fraumeni-Syndrom (Ohgaki u. Kleihues, 2005 a).

Altersabhängig treten bestimmte Hirntumorvarianten häufiger auf. Im ersten Lebensjahr entstehen vor allem Tumoren des Plexus chorioideus und Teratome, während im Klein- 
und Schulkindalter Gliome und embryonale Tumoren typisch sind. Bei Kleinkindern mit einem Durchschnittsalter von 4 Jahren und Jugendlichen über 15 Jahren treten gehäuft Medulloblastome auf. Mit zunehmendem Alter in fallender Häufigkeit treten bis zum 20. Lebebsjahr Ependymome auf. Das mittlere Erkrankungsalter für Kinder mit zerebellären Astrozytomen liegt bei 6,8 Jahren (Kaatsch et al. 2001).

Auch die Rassenzugehörigkeit hat einen Einfluß auf das Erkrankungsrisiko. Weiße erkranken unterschiedlichen Studien zufolge doppelt so häufig an Glioblastomen, wie Schwarze oder Asiaten (Fan et al., 1992, Christensen et al. 2003).

\subsubsection{Symptomatik}

Intrakranielle Tumoren führen häufig $\mathrm{zu}$ einer Hirndrucksteigerung mit den damit verbundenen Symptomen. Kopfschmerzen sind mit $50 \%$ das häufigste Erstsymptom (Forsyth u. Ponser, 1993). Weitere typische Symptome der intrakraniellen Drucksteigerung sind Erbrechen, Nackensteife, Wesensänderung und Lethargie. Bei Säuglingen kann ein Perzentilensprung bei der Messung des Kopfumfanges auffallen. Ältere Kinder zeigen häufig eine Stauungspapille als Zeichen des erhöhten Hirndrucks.

Weitere Krankheitserscheinungen sind fokale oder generalisierte Krampfanfälle, Gefühlsstörungen (van Breemen et al., 2007) oder Lähmungen, die durch tumorbedingte Beeinträchtigung der entsprechenden Hirnregion entstehen (Armstrong et al., 2004).

\subsubsection{Diagnostik}

In den Jahren 2000 bis 2007 lag für Kinder unter 15 Jahren die 5-JahresÜberlebenswahrscheinlichkeit nach Diagnosestellung je nach Morphologie der Tumore für ZNS-Tumoren bei 50\% (WHO-Grad III-IV(s. 1.1.4)) (Deutsches Krebsregister, Mainz 2004). Während gute Fortschritte bei der nachhaltigen Behandlung extracranieller Tumoren gemacht wurden, blieben Behandlungserfolge ähnlichen Ausmaßes für Hirntumoren bislang aus (Stupp et al., 2006, Bleyer, 1999). Um therapeutische Maßnahmen planen und Behandlungserfolge auswerten und vergleichen zu können, müssen geeignete bildgebende Verfahren genutzt werden. Die Computertomographie stellte lange Zeit die initiale Bildgebung dar. Knochenbeteiligung, Kalzifikation, Blut und Gewebedichte können hiermit gezeigt werden. Das Hirnparenchym, insbesondere kleinere Strukturen wie Metastasen sind jedoch in der Computertomographie schlecht beurteilbar (Urbach und Solymosi, 2003). Deshalb stellt die Magnet-Resonanz-Tomographie (MRT) inzwischen die Standardmethode zur Diagnose von Hirntumoren dar. Anatomische Details wie kortikale 
Läsionen, Ödeme, und infiltratives Tumorwachstum lassen sich erkennen (Catalaa, 2006). Mittels MR-Spektroskopie kann Tumorgewebe von normalem Gehirngewebe unterschieden werden (Sibtain et al., 2007). Mittels Perfusions-MRT kann die Strömung des Blutes durch das Gewebe berechnet werden (Gass et al., 2000). Diffusionsgewichtetes MRT kann Gewebeveränderungen wie Ischämien in frühen Stadien zeigen, ist aber anfällig für Bewegungsartefakte (Sartor et al, 2003).

Protonenmagnetresonanzspektroskopie ermöglicht den Nachweis biologisch wichtiger Moleküle im Gehirn. So kann beispielsweise Cholin nachgewiesen werden, dessen Konzentration im Gehirn bei gesteigerter Mitoserate erhöht ist (Hollingworth et al., 2006).

Die Positronenemissionstomographie kann zur genaueren Abgrenzung und zur Diagnose von Stoffwechselprodukten und der Malignität eines Tumors eingesetzt werden (Popperl et al., 2006).

\subsubsection{Klassifikation}

Zur genaueren Eingruppierung von Hirntumoren ist eine histologische Untersuchung nötig. Von der Welt-Gesundheits-Organisation (WHO) wurde 1979 eine Einteilung der Hirntumoren in Klassen eingeführt. Im Wesentlichen erfolgte die Eingruppierung anhand immunhistochemischer Merkmale, die allgemein akzeptiert werden, und den zurzeit besten prognostischen Marker darstellen. Darin werden Gliome nach histologischen Eigenschaften in Grad I bis IV unterteilt, wobei Grad IV Gliome die Tumoren mit der höchsten Malignität darstellen. Eine Übersicht über die Einteilung der Gliome nach der WHO-Klassifikation und deren Histopathologie zeigt Tabelle 1. Der Übergang von benignen zu malignen Formen ist in der Realität fließend. Dabei nimmt die aktuelle Klassifikation der WHO (Louis et al., 2007) auch Erkenntnisse der Zytogenetik (Kleihues u. Cavenee, 2000 a) und der (molekularen) Genetik mit auf. 
Tabelle 1: Übersicht über die Einteilung der Gliome nach der WHO-Klassifikation, verändert (Glas et al., 2007, Tonn et al., 2004)

\begin{tabular}{|c|c|c|}
\hline WHO-Bezeichnung & WHO-Grad & Histopathologie \\
\hline Pilozytisches Astrozytom & I & $\begin{array}{l}\text { Geringe Zelldichte, } \\
\text { bipolare“pilozytische"Zellen, } \\
\text { Rosenthal-Fasern }\end{array}$ \\
\hline Niedrig-malignes Astrozytom & II & $\begin{array}{l}\text { Geringe bis mäßige Zelldichte, } \\
\text { fibrilläre oder gemistozytische } \\
\text { Astrozyten, einige Mitosen, geringe } \\
\text { nukleäre Atypien }\end{array}$ \\
\hline $\begin{array}{l}\text { Niedrig-malignes } \\
\text { Oligodendrogliom und } \\
\text { Oligoastrozytom }\end{array}$ & II & $\begin{array}{l}\text { Typische Honigwabenstruktur, } \\
\text { geringe Zellatypien, wenige Mitosen } \\
\text { bzw. Mischform }\end{array}$ \\
\hline Ependymom & II & $\begin{array}{l}\text { Wenig differenzierte Zellen, echte } \\
\text { und perivaskuläre Rosetten }\end{array}$ \\
\hline Anaplastisches Astrozytom & III & $\begin{array}{l}\text { Große Zelldichte, mäßige bis starke } \\
\text { Zell-und Kernpleomorphie, } \\
\text { zahlreiche Mitosen }\end{array}$ \\
\hline $\begin{array}{l}\text { Anaplastisches Oligodendrogliom } \\
\text { und Oligoastrozytom }\end{array}$ & III & $\begin{array}{l}\text { Zusätzlich typische } \\
\text { Honigwabenstruktur } \\
\text { bzw.Mischformen }\end{array}$ \\
\hline Anaplastisches Ependymom & III & $\begin{array}{l}\text { Wenig differenzierte Zellen, echte } \\
\text { Rosetten und Pseudorosetten, } \\
\text { Mitosen, Gefäßproliferation, } \\
\text { Nekrosen }\end{array}$ \\
\hline $\begin{array}{l}\text { Glioblastom (Glioblastoma } \\
\text { multiforme, GBM) }\end{array}$ & IV & $\begin{array}{l}\text { Hohe Zelldichte, Pleomorphie, } \\
\text { zahlreiche atypische Mitosen, } \\
\text { ausgedehnte Nekrosen, erhebliche } \\
\text { Gefäßproliferation }\end{array}$ \\
\hline Medulloblastom & IV & $\begin{array}{l}\text { Große Zelldichte, wenig } \\
\text { differenzierte, zytoplasmaarme } \\
\text { Zellen, viele Mitosen, auch } \\
\text { Apoptosen, Ausbildung von Rosetten }\end{array}$ \\
\hline
\end{tabular}

\subsubsection{Tumorgenese des Glioblastoms}

In Vertebraten gehen die Hauptzelltypen des ZNS, Neurone und Gliazellen vom embryonalen, aus dem Neuroektoderm entstandenen Neuroepithel des Neuralrohrs aus. Im Gegensatz zu Neuronen behalten die Gliazellen ihre Fähigkeit zur Proliferation. Die meisten adulten Hirntumoren gehen von Zellen glialer Herkunft aus und sind unter dem Begriff Gliome zusammengefasst (Kleihues et al., 2002). Glioblastome sind heterogene, hochmaligne, aggressive Gliome des ZNS mit dem WHO-Grad IV (Maher et al., 2001, 
Jung et al., 1999). Sie zeichnen sich durch weitläufige Infiltration und Zerstörung des gesunden Hirngewebes, ein ausgeprägtes Migrationsvermögen, sowie ein schlechtes Ansprechen auf traditionelle therapeutische Ansätze aus. Histopathologisch weisen Glioblastome ein pleomorphes Zellbild, eine hohe Zelldichte mit Mitosen, Kernatypien, Nekrosen und Gefäßneubildung auf (Kleihues et al., 2002). Es gibt Belege dafür, dass Glioblastome aus Astrozyten oder astrozytären Vorläuferzellen, eventuell neuronalen Stammzellen, entstehen (Uhrbom et al., 2002). Man unterscheidet primäre, de novo aus Vorläuferzellen entstandene von sekundären, aus niedrigmalignen Astrozytomen entstandene Glioblastome (Tso et al., 2006, Kleihues und Ohgaki, 1999). Primäre Glioblastome sind typisch für ältere Patienten (im Mittel 55 Jahre), wohingegen sich sekundäre vorwiegend bei jungen Erwachsenen (30-45 Jahre) über einen Zeitraum von 4-5 Jahren aus niedriggradigen Astrozytomen entwickeln (Kleihues und Cavenee, 2000 b). Diese Subtypen unterscheiden sich grundlegend auf molekularer Ebene und weisen ein unterschiedliches Muster an Mutationen auf. Für das primäre Glioblastom sind Amplifikationen oder aktivierende Mutationen des Epidermal Growth Factor ReceptorGen (EGFR-Gens) typisch, während für sekundäre Glioblastome Mutationen des p53-Gens kennzeichnend sind (Kleihues et al., 2002, Reifenberger und Collins, 2004). Diese Unterschiede spiegeln sich nur geringfügig in der Prognose wieder und haben keinen Einfluss auf die Histologie (Ohgaki et al., 2004). Seit einigen Jahren werden innerhalb eines Tumors verschiedene Tumorzelltypen unterschieden. So gibt es „ausdifferenzierte“ Tumorzellen, sowie zu unendlicher Proliferation befähigte Tumorstammzellen (Reya et al., 2001, Yuan et al., 2004).

Das Glioblastom besteht nicht ausschließlich aus Tumorzellen. Neben gefäßbildenden Zellen befinden sich auch Mikrogliazellen im Tumor (Badie und Schartner, 2001). Aktivierte Mikrogliazellen schütten verschiedene Faktoren, wie z.B. Cytokine und Proteasen aus, die direkt oder indirekt die Tumorprogression beeinflussen (Wesolowska et al., 2008, Sliwa et al., 2007, Watters et al., 2005). Auch Zellen des Immunsystems wandern in den Tumor ein. Die vom Glioblastom abgegebenen Cytokine können auch Makrophagen derart beeinflussen, dass sie das Tumorwachstum fördern (Umemura et al., 2008, Talmadge et al., 2007).

\subsubsection{Prognose}

Eine individuelle Prognose des Krankheitsverlaufs zu stellen ist schwierig, da sich die klinischen Verläufe verschiedener Patienten erheblich unterscheiden. Bisher ist es trotz intensiver Bemühungen noch nicht gelungen, zuverlässige molekulare Marker für Glioblastome zu etablieren, die mit dem Therapieansprechen oder einer bestimmten 
Prognose korrelieren (Glas et al., 2007). Als prognostische Marker wurden unter Anderem die Proliferationsfraktion (Moskowitz et al., 2006) und der p53-Status beschrieben (Ichimura et al., 2004, Chozick et al., 1994).

Einen wichtigen Fortschritt stellt die Analyse des Methylierungsstatus des Promotors der $\mathrm{O}^{6}$-Methylguanin-Desoxyribonucleinsäure (DNA) -Methyltransferase dar, der die Transkription des wichtigsten Resistenzfaktors für eine alkylierende Chemotherapie reguliert. Glioblastome, die $\mathrm{O}^{6}$-Methylguanin-DNA-Methyltransferase aufgrund einer Hypermethylierung des Promotors nur schwach exprimieren, zeigen ein besseres Ansprechen auf eine alkylierende Chemotherapie und eine deutlich bessere Prognose (21.7 Monate mittleres Überleben nach Diagnosestellung anstatt 14,6 Monate) nach kombinierter Radiochemotherapie (Hegi et al., 2005).

Eine erst seit einigen Jahren angewandte Technik zur Charakterisierung von Tumoren sind Micro-Array Analysen. Mittels dieser kann das Transkriptom verschiedener Glioblastome detailliert analysiert werden. Es können so Gruppen aus den untersuchten Gliomen, bei denen die gleichen Gene exprimiert sind gebildet werden, sogenannte Expressionscluster (Phillips et al., 2006, Glinsky et al., 2005, Freije et al., 2004). In einer großen Studie mit 252 Gliomen des WHO-Grades III und IV wurden drei Expressionsmuster gefunden, die sich prognostischen Gruppen zuordnen ließen. In der prognostisch günstigeren Gruppe waren Gene für neuronale Differenzierung überexprimiert. Mesenchymale Marker und Gene, die die Proliferation begünstigen, waren in den Gruppen überexprimiert, die ein schlechteres Überleben zeigten (Phillips et al., 2006).

\subsubsection{Immunologie}

Eine Besonderheit der Gliome ist, dass sie sich im immunprivilegierten Raum des ZNS entwickeln. Im Gehirn sind sowohl die angeborene, als auch die adaptive Immunabwehr eingeschränkt (Walker et al., 2003).

Die Ausbildung des immunpreviligierten Raumes geht auf zwei Mechanismen zurück. Zum Einen erschwert die BHS, die vom Gehirngefäßendothel ausgebildet wird, den Übertritt von Plasmaproteinen, wie Komplementproteinen und immunkompetenten Zellen, wie naive Lymphozyten, natürliche Killerzellen (NK-Zellen) und Makrophagen aus dem Blut ins Gehirn (Friese et al., 2004). Zum Anderen hat das ZNS kein lymphatisches System. Somit können antigenpräsentierende Zellen wie dendritische Zellen nicht über die Lymphbahnen in die lymphatischen Organe gelangen um dort eine Immunantwort zu erwirken. Im Gehirn selbst fehlen daher antigenpräsentierende Zellen. Mikrogliazellen und Astrozyten können zwar Antigene zur Initiierung einer T-Zellantwort präsentieren, sind 
aber ineffizient. Zudem werden im ZNS MHC-Klasse-I und II-Moleküle, die zur Antigenpräsentierung nötig sind, nur schwach exprimiert (Weller und Fontana, 1995). Somit ist auch die Antitumorantwort des Immunsystems im Gehirn geringer, als sie im übrigen Körper wäre (Schweitzer et al., 2001).

Zudem haben Gliome verschiedene Strategien, um der Antitumorantwort des Immunsystems zu entkommen. Beispielsweise werden Immunsuppressive Moleküle, wie Interleukin-10, oder CD70 von ihnen überexprimiert (Friese et al., 2004, Wischusen et al., 2002).

Ein schon lange bekanntes, von Glioblastomzellen überexprimiertes und sezerniertes Cytokin ist der Transforming Growth Factor- $\beta$ (TGF- $\beta$ ). Er ist einer der wichtigsten immunsuppressiven Faktoren und verantwortlich für verschiedene immunsupprimierende Wirkungen (Weller und Fontana, 1995, Jachimczak et al., 1993, Wrann et al., 1987). TGF$\beta$ reguliert zusätzlich auch Proliferation (Seoane, 2006), Tumorzellmigration und Angiogenese im Glioblastom (s.1.4.2). Durch Verteilung der immunsuppressiven Moleküle im gesamten Organismus, kann es beim Patienten neben einer lokalen Immunsuppression auch zu einer systemischen Immundefizienz kommen. Diese äußert sich klinisch durch Lymphopenie und eingeschränkte T-Zellfunktion (Platten et al., 2001).

\subsubsection{Gefäßversorgung}

Bei der Entstehung von Tumoren, ist die Versorgung mit Nährstoffen und Sauerstoff durch Diffusion nur über kurze Distanzen bis zum versorgenden Blutgefäß gewährleistet. Daher ist voluminöses Tumorwachstum über eine Größe von $2 \mathrm{~mm}^{3}$ nur möglich, wenn der Tumor sich seine Blutversorgung sichert (angiogenic switch) (Folkman, 1990). Glioblastome induzieren eine ausgeprägte Neovaskularisierung (Angiogenese) (Fischer et al., 2005).

Der Hypoxie-induzierbare Faktor 1 (Hifl), der in den meisten soliden Tumoren exprimiert wird, wird durch Oxidation mit Sauerstoff inaktiviert und über den VHLUbiquitin-Komplex degradiert. Im Falle von Sauerstoffmangel bleibt der Faktor aktiv und bindet an P300/CBP. Dies bewirkt die Aktivierung von Genen, die Hypoxia Response Elements enthalten. Der Faktor hat -nicht nur im Glioblastom- eine überragende Bedeutung für die Induzierung proangiogenetischer Faktoren wie vascular endothelial growth factor A (VEGFA) und deren Rezeptoren (Kargiotis et al., 2006, Fischer et al., 2005).

Die Angiogenese verläuft in mehreren Schritten. Die Tumorzellen an den Gefäßwänden leiten die Herunterregulierung der BHS-Eigenschaften ein und induzieren durch Sekretion von Proangiogenesefaktoren die Endothelzellproliferation. Diese Faktoren sind unter anderem VEGF, EGF, TGF- $\beta 2$ und Tumornekrosefaktor- $\alpha$ (TNF- $\alpha)$. Die VEGF-Familie 
besteht aus VEGF A-E und PDGF, wobei VEGFA der wichtigste Vertreter für die Haemangiogenese ist. Im Erwachsenen wird VEGF nur in Geweben exprimiert, die Gefäßneubildung aufweisen, also in heilenden Wunden und Plazenta. In Glioblastomen korreliert VEGF-Expression mit dem Malignitätsgrad. Die VEGF-Rezeptoren 1-3 gehören zu den Tyrosinkinase-Rezeptoren. Sie werden auf Gefäßendothel konstitutiv exprimiert. Rezeptor-Ligand-Bindung an der Endothelzellmembran führt $\mathrm{zu}$ einer erhöhten Gefäßpermeabilität, Proliferation und Migration der Endothelzellen. Das in Glioblastomzellen überexprimierte Angiopoetin-2 bewirkt durch Bindung an seinen auf Endothelzellen exprimierten Tie-2 Rezeptor dessen Dephosphorilierung, was in der Zelle zur Lockerung der Endothelzellkontakte führt. Sein Gegenspieler, das auch vom Glioblastom überexprimierte Angiopoetin-1 führt nach Bindung an den Tie-2 Rezeptor zu dessen Phosphorilierung und bewirkt die Ausreifung neugebildeter Gefäße. Das Gleichgewicht der verschiedenen angiogenen Faktoren ist im Glioblastom gestört, wodurch es häufig zur Bildung pathologischer Gefäße kommt. Dies kann zum Einen zur Ausbildung eines Hirnödems und erhöhtem Hirndruck führen und zum Anderen die Hypoxie durch schlechtere Perfusion verstärken (Kargiotis et al., 2006, Fischer et al., 2005).

\subsection{Therapie}

Die Behandlungsmethoden richten sich nach der histo-pathologischen Einordnung des jeweiligen Tumors, seiner Lokalisation, den Ergebnissen der bildgebenden Verfahren (Metastasierung), der molekularbiologischen Auswertung des Tumorgewebes und dem Alter des Patienten (Bouffet, 2000, Packer, 1999). Die Auswahl der Therapieprinzipien bei Kindern hat neben der Heilung (oder zumindest einer deutlichen Verlängerung der Überlebenszeit) auch die Vermeidung starker Nebenwirkungen und Schädigungen des sich entwickelnden Nervensystems zum Ziel (Kalifa u. Grill, 2005, Kelli 1999).

Wenn die Lokalisation es zulässt, wird zu Beginn der Behandlung eine chirurgische Resektion des Tumors durchgeführt, da sich für die meisten Tumorentitäten gezeigt hat, dass die Überlebenszeit mit dem Ausmaß der Resektion korreliert (Stummer et al., 2006, Hulshof et al., 2001).

Da Tumorzellen der meisten Gliome aber auch diffus ins umliegende Hirngewebe infiltrieren, ist eine mikroskopisch totale Resektion kaum möglich (Khatua u. Jalali, 2005). Daher können die Patienten durch chirurgische Entfernung alleine nicht langfristig geheilt werden. Ohne adjuvante Therapie kommt es fast immer zur Ausbildung eines Rezidivs durch erneutes Wachstum der im Hirn verbliebenen Tumorzellen. 


\subsubsection{Strahlentherapie}

An den chirurgischen Eingriff schließt sich meistens eine Strahlentherapie an. Sie gilt bei den meisten Hirntumoren als wirksam. Eine postoperative Strahlentherapie wirkt sich positiv auf das Langzeit-Überleben aus (Walker et al., 1978). Durch spezielle verbesserte Lagerungs- und Planungssysteme wird die Präzision der applizierten Strahlung bei gut abgrenzbaren Tumoren wesentlich erhöht, wodurch die Gesamtdosis gesteigert und die Dosis für normales Gewebe gesenkt werden konnte. Diese Fortschritte führten in vielen Fällen $\mathrm{zu}$ einer signifikanten Verlängerung der Überlebenszeit. Allerdings wird bei jüngeren Kindern, insbesondere unter 3 Jahren versucht, eine Bestrahlung zu vermeiden oder zumindest hinauszuzögern, da diese irreversible neuropsychologische und kognitive Defizite verursachen kann (Schmid et al., 2007).

\subsubsection{Chemotherapie}

Die Chemotherapie ist seit einigen Jahren eine weitere wichtige Therapieform zur Behandlung hochmaligner Hirntumoren. Die Chemotherapie führte nicht nur zur Verbesserung der Überlebensdauer, sondern auch zur Reduzierung der Bestrahlungsdosis (Perry et al., 1999). Jeder Tumor unterscheidet sich in seinem Ansprechen auf eine Chemotherapie.

Für fast alle kindlichen Hirntumoren existieren im deutschsprachigen Raum spezifische Studienprotokolle der GPOH (Gesellschaft für pädiatrische Onkologie und Hämatologie). Geprägt durch unterschiedliche Hypothesen über die Effektivität der systemischen Chemotherapie wurden in den letzten Jahren verschiedene Medikamente angewandt. Klassische Chemotherapeutika sind Nitrosoharnstoffe. Sie wurden bei Kindern mit malignen Gliomen erfolgreich eingesetzt (Stern und Raizer, 2006).

Kombinierte Therapieverfahren und neue Medikamente wie das oral zu verabreichende Temozolomid, konnten der Chemotherapie zwar einen festen Platz in der Glioblastomtherapie verschaffen und das Überleben steigern, aber keinen revolutionären Durchbruch bezüglich des Langzeitüberlebens erzielen. Im Vergleich zur zytostatischen Behandlung nicht-zerebraler Tumoren sind die Ergebnisse bei intrazerebralen Tumoren weiterhin enttäuschend (Reardon et al., 2006 a, Stupp et al., 2006). Hierfür sind hauptsächlich zwei Ursachen verantwortlich.

Zum Einen weisen viele Hirntumoren eine ausgeprägte Chemoresistenz auf (Bredel, 2001). Diese rührt daher, dass Gliome von einer heterogenen Gruppe von Zellen gebildet werden, von denen einige eine geringe mitotische Aktivität aufweisen (vermutlich Tumorstammzellen), wodurch nur ein Teil der Tumorzellen empfindlich auf die 
Chemotherapeutika reagiert, da deren Wirksamkeit meist von der Zellteilung abhängt. Alkylantien wie Temozolomid führen zum Einbau von Alkylgruppen in die DNA, welche die Replikation verhindern. Einige Tumore weisen fehlende Methylierung der Promotorregion des $\mathrm{O}^{6}$-Methylguanin-Methyltransferase-Enzyms auf (Hegi et al., 2005). Dadurch ist das DNA-Reparaturenzym in diesen Tumoren aktiv, entfernt die AlkylGruppen aus der DNA und verursacht somit eine Chemoresistenz.

Zum Anderen verhindert die Blut-Hirn-, bzw. Blut-Liquor-Schranke die ausreichende Diffusion von Medikamenten aus dem Blut ins Hirngewebe (Patel et al., 2009). Dies spielt bei den diffus wachsenden Gliomen eine große Rolle. Die durch Angiogenese neu entstandenen Tumorgefäße weisen zwar oft eine höhere Permeabilität auf als gesunde Gefäße und Kapillaren, aber in der Peripherie des Tumors und in peritumoralen gesunden Hirnabschnitten, in die schon maligne Zellen migriert sein können, ist die BHS oft noch intakt (Arismendi-Morollo u. Castellano, 2005, Donelli et al., 1992). Durch die BHS ist auch die therapeutische Nutzbarkeit vieler Peptide aufgrund der niedrigen Penetrationsrate ins Gehirn limitiert (Banks, 2008). Durch eine intraarterielle Gabe von Therapeutika oder eine Hochdosischemotherapie kann die Konzentration der Medikamente im Blut erhöht, und damit der Anteil des ins Gehirn diffundierenden Therapeutikums gesteigert werden. Dieses Vorgehen führt aber in der Regel zu verstärkten Nebenwirkungen. Im Tumor selber kann das Eindringen von Chemotherapeutika zusätzlich durch veränderte Perfusion, erhöhten Abstand der Kapillaren (Jain, 1990) und erhöhten Druck im Tumor (Michinton u. Tannock, 2006) erschwert sein.

\subsection{Alternative Therapieansätze}

Mit den herkömmlichen Therapiestrategien zur Behandlung von Glioblastomen wurden trotz großer Bemühungen noch nicht die gewünschten Erfolge erzielt. Daher werden seit Jahren neben den herkömmlichen, traditionellen auch innovative experimentelle Therapieansätze verfolgt.

\subsection{1 Überwindung der BHS}

Die BHS limitiert den Therapieerfolg bei der Behandlung maligner Gliome. Deshalb ist ein Gegenstand der Forschung, die Durchlässigkeit der BHS für Therapeutika zu erhöhen. 


\subsubsection{Die Blut-Hirn-Schranke}

Bereits 1885 machte Ehrlich die Beobachtung, dass nach intravenöser (i.v.)-Injektion von Farbstoffen in Tiere, mit Ausnahme des Gehirns, alle Körpergewebe Färbung aufwiesen (Ehrlich, 1885). Bei Applikation von Farbstoff in den Liquorraum ließen sich die Farbstoffe hinterher nur im Gehirn Nachweisen, nicht aber im Blut oder anderen Organen. Als anatomisches Substrat der BHS konnten mit Hilfe von Elektronenmikroskopie die Kapillarendothelzellen identifiziert werden (Reese und Karnovski, 1967). Endothelzellen sind polare Zellen mit einer gefäßluminalen und einer abluminalen Seite. An den Kontaktstellen der einzelnen Endothelzellen finden sich Strukturen (Zonulae occludentes (Tight junctions)), die so dicht sind, dass praktisch kein parazellulärer Substanzaustausch zwischen den getrennten Kompartimenten möglich ist. Tight junctions (TJ) sind ein großer Molekülkomplex, der sich in und auf beiden Seiten der Membran befindet und Wechselwirkungen mit den TJ-Molekülen der benachbarten Zelle eingeht. In diesem Komplex identifizierte Moleküle sind unter anderem ZO-1 (Stevenson et al., 1986), ZO-2, Occludin (Furuse et al., 1993), junctional adhesion molecule (JAM) (Martin-Padura, 1998), Claudin-3 (Wolburg et al., 2003) Claudin-5, Claudin 12 (Nitta et al., 2003) und MAGI-1 (Hirabayashi et al., 2003). Eine weitere, aber schwächere Barriere stellen die Zonulae adhaerentes (Adherens Junctions) dar. Auf der luminalen Seite ist die Membran negativ geladen. Durch die TJ wird ein hoher transendothelialer elektrischer Widerstand (TEER) erreicht, was den Barriereeffekt für polare Substanzen unterstützt. In den Endothelzellen herrscht nur eine geringe Aktivität pinozytischer Vesikel. So wird der transendotheliale Transport gering gehalten. Zusätzlich ist die luminale Seite mit einer hohen Dichte an energieabhängigen Ionenpumpen und Efflux-Transportern, wie dem multidrug-resistance Protein oder P-Glycoprotein, ausgestattet. So können Stoffe, die passiv über Diffusion in die Endothelzellen gelangt sind, wieder hinausgeschleust werden (Deli, 2008, Golden und Pollack, 2003, Kemper et al., 2004). Eine große Zahl an selektiven Einwärtstransportern sorgt für die Beschaffung essentieller Moleküle, wie z.B. Glukose durch den Transporter GLUC-1 (McAllister et al., 2001, Pardridge et al., 1990).

Die Gehirnkapillaren sind umgeben von einer Basalmembran, Perizyten und aufgelagerten Astrozyten-Endfüßen (Abbildung 1, A), die eine weitere Barriere zwischen dem Kapillarlumen und dem Hirnparenchym darstellen. 

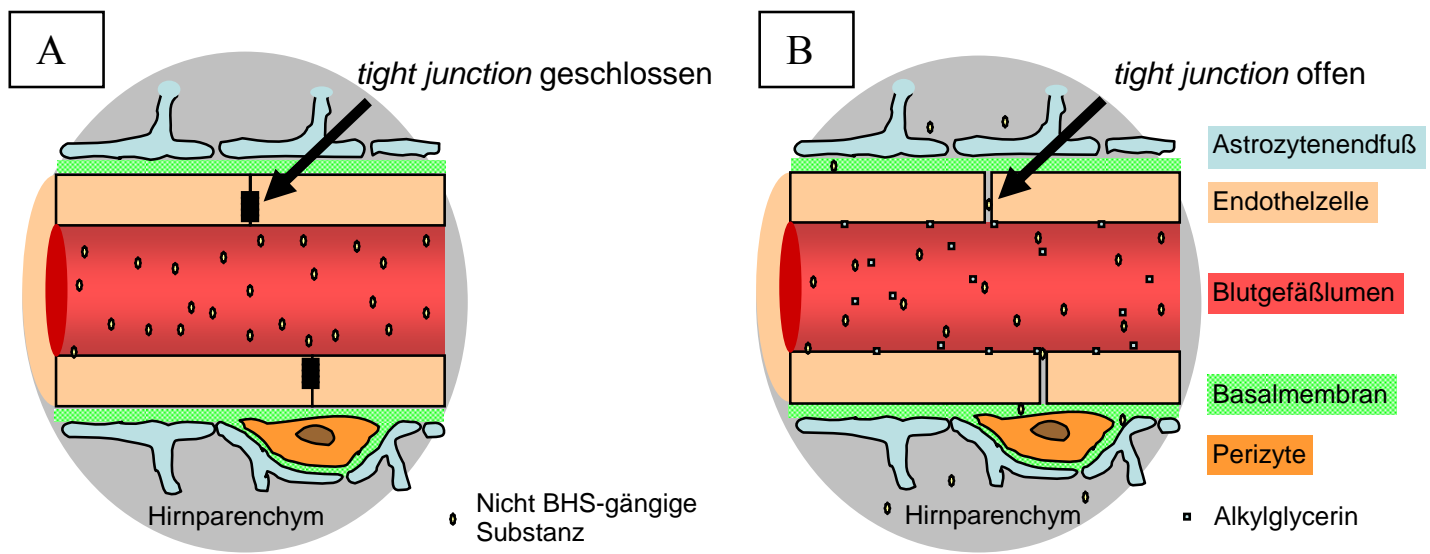

Abbildung 1: Schematische, vergrößerte Darstellung des Aufbaus einer Hirnkapillare. A) Die BHS führt zum Verbleib der nicht BHS-gängigen Substanz im Lumen der Kapillare. B) Erst nach Öffnung der BHS durch Alkylglycerine kann die Substanz durch die Zellzwischenräume ins Hirnparenchym diffundieren.

Von den Perizyten und Astrozytenfortsätzen in die Basalmembran abgegebene Botenstoffe bewirken in den Endothelzellen unter anderem die Ausbildung der beschriebenen BHS-Eigenschaften (Peppiatt et al., 2006, Abbott, 2006, Wolburg, 2006, Lai und Kuo 2005, Ramsauer et al., 2002).

Die BHS führt zum Erhalt des homeostatischen intrazerebralen Milieus und bewirkt einen Schutz des Gehirns vor dem Eindringen toxischer Substanzen (de Boer et al., 2003).

\subsubsection{Methoden zur Überwindung der BHS}

Für viele Erkrankungen des Gehirns sind in der Vergangenheit prinzipiell effektive Medikamente entwickelt worden, die aufgrund einer unzureichenden Penetration ins Hirngewebe keine Effekte zeigen (Neuwelt et al., 1999). Die Mechanismen zur Regulation von Transportvorgängen an der BHS sind noch immer unzureichend aufgeklärt. Die gesteigerte oder zielgerichtete Zufuhr von Medikamenten ins Hirngewebe ist deshalb ein Schwerpunkt in der experimentellen Neurologie. Es sind schon verschiedene Strategien entwickelt worden, um die Konzentration von Therapeutika im Gehirn zu erhöhen. Dabei kann entweder der transzelluläre oder der parazelluläre Durchtritt von Therapeutika über die BHS gesteigert werden.

Generell kann ein Molekül die BHS besser überwinden, je geringer das Molekulargewicht und je höher die Lipidlöslichkeit sind (Jong u. Huang, 2005). Eine Möglichkeit, den transzellulären Durchtritt durch die Endothelzellen zu ermöglichen, ist daher die Verwendung lipophiler Wirksubstanzen, die die BHS überwinden können (Reardon et al., 2006 a). Einen ähnlichen Ansatz stellt die Gabe von Nanopartikeln und 
Niosomen dar (Kreuter, 2004). Dabei wird die Substanz, die ins Gehirn gelangen soll, an Nanopartikel gebunden oder liposomal verpackt.

Viele Verbindungen, die aufgrund ihrer physiko-chemischen Eigenschaften die Endothelzellmembran zwar durchdringen, können durch Effluxtransportsysteme wie pGlycoprotein und multidrug resistance Proteine wieder aus den Endothelzellen ins Kapillarlumen zurücktransportiert werden (Deli, 2008, Golden und Pollack, 2003, Kemper et al., 2004). Aus diesem Grund ist eine weitere Möglichkeit zur Konzentrationssteigerung von Wirkstoffen im ZNS die Gabe von Substanzen, die den Rücktransport ins Blut verhindern. Medikamente, die Substrate für P-Glykoprotein sind, werden so durch Gabe von P-Glycoprotein-Blockern weniger schnell aus dem ZNS eliminiert (Fellner et al., 2002).

Die Entwicklung weiterer neuer BHS-gängiger Peptide, wie Angoipep-2 (Demeule et al., 2008), oder Transportvermittler, wie Substratgekoppeltes Glycosamin (Dhanikula et al., 2007) zeigt, dass hier noch keine optimale Lösung gefunden wurde.

Eine Methode den parazellulären Durchtritt von Molekülen durch die Gefäßwand ins Gehirn zu steigern, ist die Öffnung der BHS mittels intraarterieller Infusion einer hyperosmolaren (1,37 M) Mannitollösung (Neuwelt et al., 1985). Hierdurch werden die Hirnendothelzellen zum Schrumpfen gebracht, wobei sich die Zell-Zell-Kontakte weiten (Rapoport, 2000). Die osmotische Öffnung der BHS wurde schon erfolgreich im Tiermodell und bei Menschen mit hochmalignen Hirntumoren eingesetzt, um die Effektivität einer Chemotherapie zu erhöhen (Doolittle, 2000). Da die Methode schwer zu handhaben ist, ist sie bisher nur in wenigen Zentren angewendet worden.

Eine Steigerung der Permeabilität von Kapillaren in Hirntumoren konnte auch durch Stimulation von Bradykinin-Rezeptoren erreicht werden. Lobradimil ist ein in der Klinik bei Hirntumoren eingesetzter Bradykinin B2 Rezeptorantagonist (Warren et al., 2006, Borlogan u. Emerich, 2003), der die TJ weitet, und eine erhöhte Anreicherung von Zytostatika im Hirntumorgewebe hervorruft.

\subsubsection{Alkylglycerine}

Kurzkettige Alkohole verändern die physiko-chemischen Eigenschaften von Membranen. Schon vor über 20 Jahren konnte gezeigt werden, dass durch permeabilitätssteigernde Eigenschaften von Alkylglycerinen radioaktive Marker vermehrt in das Gehirn von Ratten gelangen (Unger et al., 1985).

Eine Bolusinjektion kurzkettiger Aklylglycerine in die Arteria carotis (A. carotis) wurde zur Öffnung der BHS im Tiermodell beschrieben (Erdlenbruch et al., 1998). Es konnte gezeigt werden, dass eine Bolusinjektion einer isoosmolaren Lösung in die A. carotis interna an den Gefäßen der ipsilateralen Hemisphäre des Hirns eine Öffnung der BHS 
bewirkt (Abbildung 1, B). Wie die osmotische ist auch die Alkylglycerin-vermittelte Öffnung reversibel. Die Stärke der Öffnung der BHS und der zeitliche Verlauf lassen sich durch Auswahl verschiedener Derivate, und deren Konzentration steuern (Erdlenbruch et al., 2000). Für Methotrexat (MTX) konnte nach Schrankenöffnung im Hirngewebe der ipsilateralen Hemisphäre im Vergleich zur kontralateralen Hemisphäre eine signifikante Anreicherung gemessen werden. Pentylglycerin führt zu einer kurzen Öffnung der BHS, die nach etwa 20 min wieder vorrüber ist. 2-O-Hexyldiglycerin (HG) führt zu einer Öffnung, die bis zu 15 min nach der Gabe zu- und dann langsam wieder abnimmt. Etwa 30 min nach Gabe ist die BHS wieder geschlossen (Erdlenbruch et al., 2003a). Die intraarterielle Verabreichung von $120 \mathrm{mM}$ 1-O-Pentylglycerin sowie von $75 \mathrm{mM} \mathrm{HG}$ zeigten im Tierversuch klinisch, laborchemisch und histopathologisch keine Anzeichen für Toxizität. Auch in Langzeitexperimenten konnten bei behandelten Tieren keine Zeichen für Toxizität der Alkylglycerine festgestellt werden. Bei Ratten mit Hirntumoren konnte mit diesen Derivaten eine erhöhte Konzentration von zusätzlich verabreichtem MTX im Tumorgewebe und im Tumorrandgebiet nachgewiesen werden. Diese Anreicherungen von Substanzen im Gesunden und tumortragenden Gehirn konnten mit Hilfe von NatriumFluorescein $(\mathrm{Na}-\mathrm{Fl})$ unter Einsatz von Fluoreszenzmikroskopie visualisiert werden. So konnte nach Öffnung der BHS auch der Durchtritt von größeren Molekülen, wie fluoreszenzmarkiertem Albumin und FITC-Dextran 40000 nachgewiesen werden.

Ein therapeutischer Effekt konnte nach einmaliger Chemotherapie mit Carboplatin oder Cisplatin nach Öffnung der BHS an gehirntumortragenden Ratten nachgewiesen werden (Rönz, 2007). Die Tiere wurden 7 Tage nach Tumorzellimplantation einmalig behandelt. Unbehandelte Kontrolltiere starben nach etwa 22 Tagen, mit Cisplatin therapierte Tiere lebten im Mittel 26 Tage und Tiere die Cisplatin mit Öffnung der BHS erhielten, lebten durchschnittlich 36 Tage.

In Versuchen mit extrahierten Kapillaren aus Schweinehirn konnte gezeigt werden, dass nach Zugabe von Alkylglycerinen Fluorescein aus dem umgebenden Medium parazellulär ins Lumen der Kapillaren eindringt. Diese Beobachtung stützt die Hypothese, dass Alkylglycerine die Dichtigkeit der TJ verringern (Erdlenbruch et al., 2003 b). Der genaue Mechanismus der Schrankenöffnung konnte noch nicht geklärt werden. Bislang wurde auch nicht untersucht, ob Moleküle $>150 \mathrm{kDa}$, wie Enzyme oder Antikörper nach der Öffnung der BHS mit Alkylglycerinen ins Gehirn eindringen können und wie lange sich auf diese Weise ins Gehirn eingebrachte Moleküle dort nachweisen lassen. 


\subsubsection{Lokale Therapie}

Ein weiterer Ansatz die BHS zu überwinden, ist die direkte Einbringung von Therapeutika ins Gehirn, wie beispielsweise in die Resektionshöhle von Tumoren als lokoregionale Therapie. Hier sind die Wirkstoffe direkt am Wirkort. Auch können höhere Dosen oder systemtoxische Substanzen eingesetzt werden, da ein Übertritt ins Blutgefäßsystem zu vernachlässigen ist.

In verschiedenen Studien wurden klassische Chemotherapeutika in bioabbaubare Substanzen eingebettet (Westphal et al., 2003) und in die Resektionshöhle eingebracht. Im Zuge der Biodegradierung dieser Substanzen wurden die Therapeutika nach und nach freigesetzt. Auf diese Weise kamen auch radioaktive ${ }^{125}$ I-Seeds zum Einsatz (Selker et al., 2002, Laperriere et al., 1998). Allerdings ließ sich das progressionsfreie Überleben der Patienten durch keine der Methoden wesentlich steigern. Zudem traten im Falle des ${ }^{125} \mathrm{I}$ Einsatzes noch strahlungsbedingte Nekrosen auf.

In der Radioimmuntherapie wurden auch radioaktiv markierte monoklonale Antikörper, die gegen tumorassoziiertes Tenascin gerichtet sind, lokal eingesetzt (Reardon et al., 2002, 2006 b). Hier konnte bei Patienten mit Glioblastom-Rezidiven ein erhöhtes Gesamtüberleben erreicht werden.

Weiterhin sind Mikroinfusionspumpen oder Katheter (convection enhanced delivery) zum Einsatz gekommen, die unterschiedliche Substanzen, wie Chemotheapeutika (Lidar et al., 2004), Genvektoren (Voges et al., 2003), tumorspezifische Toxin-Konjugate (Parney et al., 2005) oder Antisense-Oligonucleotide (Bogdahn et al., 2007) in die Resektionshöhle gepumpt haben. Von diesen Substanzen erbrachte die Behandlung mit AntisenseNucleotiden bisher die vielversprechendsten Ergebnisse.

\subsection{3 molecular targeted-Therapie}

In den letzten Jahren wurden im Glioblastom viele für die Malignität wichtige, genetische und molekulare Besonderheiten, sowie Signalwege und deren Aktivierungskaskaden beschrieben (Hutterer et al., 2006). Diese Kenntnisse erlauben den Einsatz von Therapeutika, die solche Moleküle gezielt hemmen, die Proliferation, Invasion oder Angiogenese steuern. Zum Beispiel wurde für die folgenden Wachstumsfaktoren und ihre Rezeptoren eine Funktion bei der Entstehung eines malignen Glioms beschrieben: PDGF/R (Platelet-Derived-Growth-Factor/-Receptor), EGF/R, FGF/R (Fibroblast-Growth-Factor/Receptor), VEGF/R (Vascular-Endothelial-Growth-Factor/-Receptor), IGF/R (InsulinGrowth-Factor/-Receptor), TGF- $\alpha$ (Transforming-Growth-Factor-alpha/-Receptor) und TGF- $\beta / \mathrm{R}$ (Transforming-Growth-Factor-Beta/-Receptor). Die meisten Rezeptoren für 
Wachstumsfaktoren besitzen Tyrosinkinase-Aktivität. Daher sind die Rezeptor Tyrosinkinasen die wichtigsten Ziele der molecular targeted Therapie (Sathornsumetee u. Rich, 2007, Newton, 2003).

In $67 \%$ der EGFR-positiven Tumoren ist der Rezeptor mutiert und dadurch konstitutiv aktiviert (Kuan et al., 2001). Die gängigen targeted Therapeutika sind monoklonale Antikörper und Inhibitoren mit geringer Molekülgröße (low-molecular-weight inhibitors). Einer von verschiedenen Antikörpern, die an den EGF-Rezeptor binden, ist Cetuximab. Er verhindert die Bindung von EGF und TGF- $\alpha$ und stimuliert die Rezeptorinternalisierung (Baselga, 2001).

PDGF induziert Wachstum und Angiogenese des Glioblastoms. Im gesunden Gehirn verursacht PDGF-Infusion das Gliom-ähnliche Wachstum von neuralen Stammzellen (Jackson et al., 2006). Ein in Phase I/II Studien eingesetzter Inhibitor ist Imatinib (Wen et al., 2006).

VEGFA ist der Schlüsselfaktor der Tumorhämangiogenese (s.1.1.8) und seine Expression korreliert mit der Malignität von Gliomen. Eine hohe Gefäßdichte im Gliom ist mit einer schlechten Prognose assoziiert (Oehring et al., 1999, Leon et al., 1996). Bevacizumab ist ein humanisierter Antikörper, der an den VEGF-Rezeptor bindet und bei Hirntumoren in Kombination mit Irinotecan eingesetzt wurde (Vredenburgh et al., 2007).

Es gibt auch verschiedene Tyrosinkinase-Inhibitoren, die FGF-Rezeptor-, IGFRezeptor- und TGF- $\beta$-Rezeptor-vermittelte Tyrosinkinase-Aktivität inhibieren. Bisher gibt es allerdings keine klinischen Anwendungen (Hutterer et al., 2006).

Andere Inhibitoren greifen in den durch die Rezeptor Tyrosinkinasen aktivierten intrazellulären Signalwegen ein. Ras/Raf/MEK und PI3K/Akt/mTOR sind die Schlüsselmoleküle dieser Signaltransduktionskaskaden. Tipifarnib, ein Ras-Inhibitor wurde bereits in klinischen Studien eingesetzt (Cloughesy et al., 2005). Temsirolimus ist ein mTOR-Inhibitor, der ebenfals schon in Studien am Patienten zu Einsatz kam (Galanis et al., 2005).

Zusammengefaßt gibt es eine Fülle von neuen molecular targeted Therapeutika, die schon an Menschen mit malignen Hirntumoren eingesetzt wurden. Die Fallzahlen sind allerdings klein. Viele weitere Inhibitoren sind noch in der Entwicklung (Sathornsumetee und Rich, 2008, Hutterer et al., 2006). Keiner dieser Inhibitoren oder Antikörper, die bisher in klinischen Studien getestet wurden, konnte eine durchgreifende Verbesserung in der Glioblastombehandlung erzielen. (Brandes et al., 2008, Norden et al., 2008).

$\mathrm{Da}$ nicht alle Gliome das gleiche Expressionsmuster zeigen, ist für eine verbesserte molecular targeted Therapie in Zukunft eine genaue molekulargenetische Charakterisierung jedes Glioms nötig. So könnte eine auf den individuellen Tumor abgestimmte Therapie mit einer Kombination aus Antikörpern, Inhibitoren, Strahlen- und 
Chemotherapie eingeleitet werden (Ermoian et al., 2009, Brandes et al., 2008, Norden et al., 2008, Sathornsumetee und Rich, 2008, Hutterer et al., 2006).

\subsubsection{Gentherapie}

Ein weiterer seit Jahren bekannter möglicher Therapieansatz ist die Gentherapie. Dabei kann durch Viren ein Stück DNA (z.B. ein bestimmtes Gen) in das Genom der Tumorzelle eingebaut werden. Die Zelle stellt dann die gewünschte Ribonucleinsäure (RNA) (oder das Protein) selbst her. Ein Beispiel hierfür ist die suicide gene therapy, die schon in Phase IIIStudien am Menschen eingesetzt wurde (Rainov, 2000, Stockhammer et al., 1997). Dabei wird das Retrovirus Herpes Simplex Virus type 1 lokal eingebracht, wo es die Glioblastomzellen mit dem Herpes-Simplex-Virus-Thymidinkinase-(HSVTk) Gen transduziert. Dieses Gen wird normalerweise nicht in Säugern exprimiert. HSVTk phosphoryliert nachfolgend systemisch verabreichtes Ganciclovir das dann die zelluläre DNA-Replikation inhibiert und zum Zelltod führt (Moolten, 1986).

Auch bei dieser Studie konnte kein signifikant längeres Überleben der Patienten erreicht werden als mit Radio-Chemotherapie (Rainov, 2000). Ein Grund hierfür mag die geringe Transduktionsrate im menschlichen Glioblastom von nur 1\% sein (Hutterer et al., 2006). Im Tiermodell sind auch schon lytische Viren erfolgreich eingesetzt worden. Wegen der unklaren Nebenwirkungen schreckt man jedoch noch davor zurück, diese beim Menschen einzusetzen.

Eine Gentherapie im weiteren Sinne ist die lokale Applikation von AntisenseOligonucleotiden in den Tumor. Durch Gabe von spezifisch für eine mRNA hergestellten Antisense-Oligonucleotiden greift man in den Translationsvorgang ein und verhindert spezifisch die Synthese eines bestimmten Moleküls in der Zelle (Hutterer et al., 2006). Ein Beispiel hierfür ist Gabe von spezifischen Antisense-Oligodeoxynucleotiden (AP12009), gegen humane TGF- $\beta 2$ mRNA die die TGF- $\beta 2$-Sekretion von Gliomzellen reduzieren (Schlingensiepen et al. 2006).

Diese ist also zusätzlich sowohl eine molecular targeted, als auch eine immunmodulatorische Therapie, da TGF- $\beta 2$ im Glioblastom als wichtigster, sezernierter Immunsuppressor gilt (s.1.1.7).

\subsubsection{Immuntherapie}

Immuntherapien zielen darauf ab, dass das körpereigene Immunsystem den Tumor bekämpft oder immunsuppressive Wirkungen der Hirntumorzellen antagonisiert. 
Die Gabe von Zytokinen wie Interleukin-2 (Boiardi et al., 1994, Merchant et al., 1990) oder Interferon- $\gamma$ (Wolff et al., 2006, Farkkila et al., 1994) zur Steigerung der unspezifischen Immunität zeigte toxische Nebenwirkungen und keine Wirksamkeit bei Gliomen.

Die ex-vivo-Stimulation von allogenen und autologen Lymphozyten und deren lokale Infusion in den Tumor zeigte ebenso keine Wirksamkeit (Zeltzer et al., 1999, Plautz et al., 1993) wie die Reinfusion von mit toten Tumorzellen vakzinierten und in vitro stimulierten zytotoxischen T-Lymphozyten (Solan et al., 2000). Zur Verbesserung der adoptiven T-ZellTherapie sind weitere Innovationen der ex vivo T-Zell-Manipulation vonnöten (Okada et al., 2009).

Die aktive Immuntherapie (Impfung) ist eine weitere Form der Immuntherapie. Dabei wurden mehrere Strategien verfolgt. Zum Einen wurden bestrahlte oder allogene Tumorzellen subkutan (s.c.) gespritzt (Okada et al., 2009). Zum Anderen wurde eine Impfung mit dendritischen Zellen durchgeführt. Hierbei werden aus Makrophagen des Patienten differenzierte dendritische Zellen s.c. appliziert, die mit dem inaktivierten Homogenat des resezierten Tumormaterials beladen wurden. Die dendritischen Zellen migrieren zu lokalen Lymphknoten und stimulieren zytotoxische T-Zellen und THelferzellen. Wenn so aktivierte T-Zellen dann die Tumorregion infiltrieren, können sie gezielt gegen die Tumorzellen vorgehen (De Vleeschouwer et al., 2008, De Vleeschouwer et al., 2005). Diese Therapie zeigt, genauso wie die TGF- $\beta$ Antisense-Therapie, bisher vor allem bei jüngeren Patienten sehr vielversprechende Erfolge.

\subsection{Transforming growth factor beta (TGF- $\beta)$}

Ein mögliches Ziel bei der Behandlung ist das in vielen Gliomen hochregulierte Zytokin TGF- $\beta 2$ (Kjellman et al., 2000, Piek et al., 1999, Gold, 1999). Während TGF- $\beta 1$ und 3 weniger stark exprimiert werden ist TGF- $\beta 2$ sowohl auf mRNA-Ebene als auch auf Proteinebene in hochmalignen Gliomen stark exprimiert. Die Stärke seiner Expression korreliert positiv mit dem Tumorgrad und der Tumorprogression (Kjellman et al., 2000). TGF- $\beta$ ist ein Mitglied einer großen, in der Evolution konservierten Familie von pleiotropen Zytokinen. 33 Mitglieder der Familie sind in Säugern bekannt. Darunter sind die drei Isoformen TGF- $\beta 1-3$, Activine und bone morphogenetic proteins (Schmierer und Hill, 2007, Shi u. Massague, 2003, Heldin et al., 1997). TGF- $\beta$ kann je nach Gewebe die unterschiedlichsten, teils gegenteiligen Wirkungen auf die Zielzellen haben. So kann TGF$\beta$ Proliferation und Differenzierung, Adhäsion und Migration und Apoptose oder Apoptoseresistenz vermitteln (Massague, 1998). Alle Liganden der TGF- $\beta$-Familie werden als inaktive dimere Proteine generiert, wovon im Golgi-Apparat jeweils das C-terminale 
aktive TGF- $\beta$-Molekül abgespalten wird (Dubois et al., 1995). Zunächst bleibt das TGF- $\beta$ Molekül noch mit dem N-Terminale Molekül, dem latent assoziierten Protein (LAP) assoziiert, welches durch Disulfid-Brücken an das latent bindende Proteine (LTBP) gebunden wird. Die LTBP sind Multidomänen-Glykoproteine, welche die Sezernierung und Speicherung im Interzellularraum vermitteln. In der extrazellulären Matrix (EZM) wird TGF- $\beta$ durch Abspaltung der bindenden Proteine aktiviert. Die Aktivierung in vivo wurde bisher durch Integrin $\alpha v \beta 6$ und Thrombospondin gezeigt. (ten Dijke u. Arthur, 2007, Rifkin, 2005).

\subsubsection{TGF- $\beta$ Signalwege}

TGF- $\beta 2$ und 3 werden im gesunden Gehirn in Astrozyten der weissen Substanz, wie auch in Neuronen des Kortex, Hippocampus, Striatium, Hirnstamms und des Kleinhirns exprimiert. TGF- $\beta 1$ wird in den Meningen und im Choroid Plexus exprimiert (Unsicker und Strelau, 2000), andere Expressionsorte für TGF- $\beta 1$ sind noch nicht endgültig geklärt (Mecha et al., 2008).

TGF- $\beta$ vermittelt seine zellulären Effekte indem es an einen Komplex aus transmembranen Typ I- und Typ II-Serin/Threonin Kinase Rezeptoren bindet. In Säugern gibt es fünf verschiedene Typ II-Rezeptoren und sieben verschiedene Typ I-Rezeptoren, auch als activin receptor-like kinases (ALKs) bezeichnet (Schmierer und Hill, 2007, Shi und Massague, 2003, Heldin et al., 1997). Durch die Bindung von TGF- $\beta$ wird ein heteromerer Komplex aus Dimeren von Typ I- und Typ II-Rezeptor gebildet. Der konstitutiv aktive Typ II-Rezeptor aktiviert den Typ I-Rezeptor an spezifischen Serin und Threonin-Resten in der intrazellulären Region durch Phosphorylierung. In den meisten Zellen läuft die Signalweiterleitung über den Typ II-Rezeptor und ALK5 (Goumans et al., 2002, Oh et al., 2000).

Reguliert wird die Anbindung von TGF- $\beta$ an die signalweiterleitenden Typ I- und Typ II-Rezeptoren durch Ligand-Binde-Proteine und Helfer-Typ III-Rezeptoren. Gut untersuchte Beispiele für Typ III-Rezeptoren sind Endoglin und Betaglycan (ten Dijke et al., 2008, ten Dijke und Arthur, 2000).

Durch Kombination der Rezeptortypen sind unterschiedliche Zellantworten inflolge der Bindung ein und desselben Liganden möglich.

Der aktivierte Rezeptor Typ I kann Rezeptor-regulierte Smads (R-Smads) an ihren zwei Serin-Resten am Carboxylende aktivieren. ALK 4 und 5 induzieren die Phosphorylierung von R-Smad2 und 3, während ALK1, 2, 3 und 6 R-Smad 1, 5 und 8 phosphorylieren. Die so aktivierten R-Smads formen mit Smad4 einen Komplex, der in den Nucleus gelangt. Hier können sie zusammen mit anderen Proteinen die Transkription von spezifischen 
Zielgenen regulieren. Inhibitor Smads, wie Smad 6 und 7 können die Aktivierung der RSmads inhibieren. Dies geschieht durch kompetitive Interaktion mit dem Typ I Rezeptor oder durch Anbindung von Ubiquitinligasen oder Phosphatasen, die den aktivierten Rezeptorkomplex jeweils zum Ziel für Proteasomen machen, oder ihn dephosphorylieren. Der Smad-Signalweg vermittelt tumorsuppressive Zellantworten wie Wachstumsarrest. (Schmierer und Hill, 2007, Shi und Massague, 2003, Heldin et al., 1997).

Der auch durch den Phosphorylierten Rezeptor Typ I aktivierte TRAF6-TAK1JNK/p38-Signalweg reguliert die Expression von Genen im Zusammenspiel mit dem Smad-Signalweg. Durch ihn kann sowohl Apoptose, als auch die Ausbildung eines mesenchymalen Phänotyps induziert werden (Yamashita et al., 2008).

Der aktivierte Rezeptor Typ I kann auch den Ras/Raf/Erk/MAPK-Signalweg aktivieren. Durch diesen werden Gene aktiviert die einen mesenchymalen Phänotyp ausmachen. Dieser Signalweg spielt im Tumor bei der TGF- $\beta$-vermittelten Metastasierung und Invasion eine Rolle (Lee et al., 2006, Thiery, 2003).

Die Signalweiterleitung kann auch über Rho-like GTPasen, wie RhoA, Rac und Cdc42 erfolgen. Wie die MAP Kinasen Signalwege spielt auch die Signalweiterleitung über RhoA eine Schlüsselrolle bei der Vermittlung eines mesenchymalen Phänotyps. Diese Signale können direkt an den Wirkort weitergeleitet werden und vermitteln so einen schnellen Effekt, z.B. Dynamik des Zytoskeletts und Lockerung des Kontakts von TJ (BarriosRodiles et al., 2005).

Letztlich gibt es noch den PI3K/Akt Signalweg, der durch den Typ-1 Rezeptor aktiviert werden kann. Dieser spielt als Hemmer des über Smads vermittelten Wachstumsarrests eine Rolle (Song et al., 2006).

\subsubsection{TGF- $\beta$ im Glioblastom}

Von Glioblastomzellen abgegebenes TGF- $\beta$ hat unterschiedliche Wirkungen auf die Tumorprogression (Platten et al., 2001).

Im Matrigel-Invasionsassay konnte gezeigt werden, dass TGF- $\beta 1$ und 2 die Expression von Matrix-Metalloproteinasen in Gliomzellen steigert und die Expression von Inhibitoren der Metalloproteinasen hemmt (Wick et al., 2001, Nakano et al., 1995). Die MatrixMetalloproteinasen degradieren die EZM und erlauben den Gliomzellen sich auszubreiten und das umliegende Hirnparenchym zu infiltrieren (Lakka et al., 2004, Uhl et al., 2004, Rao, 2003, Platten et al., 2001). Inhibition von TGF- $\beta$ reduziert die Migration von Gliomzellen (Wesolowska et al., 2008).

Mit steigender Malignität verliert die TGF- $\beta 1$ Expression an Bedeutung. TGF- $\beta 2$ wird weiterhin stark exprimiert und vermittelt seine Effekte. Wie auch in anderen Erkrankungen 
fungiert TGF- $\beta$ in niedrigmalignen Gliomen als Tumorsuppressor, während in hochmalignen Gliomen ein „switch“ zur TGF- $\beta$-vermittelten autokrinen (und parakrinen) Wachstumsstimulation stattfindet (Seoane, 2006, Jachimczak et al., 1996). Ein gestörtes Gleichgewicht zwischen dem Smad-Signalweg und dem MAPK-Signalweg wird, wie auch bei anderen malignen Zelltypen (Akhurst und Derynck, 2001) als eine mögliche Ursache für dieses Phänomen diskutiert (Nickl-Jockschat et al., 2007). Der Smad-Signalweg vermittelt hauptsächlich antiproliferative Effekte (Massague 1998). Mutationen des TGF- $\beta$ Rezeptors, der Smads oder anderer Effektoren der Signalkaskade werden für den Verlust des antiproliferativen Effekts von TGF- $\beta$ verantwortlich gemacht (Rich et al., 1999, Rich et al., 2001, Kjellman et al., 2000). Der TGF- $\beta$-aktivierte MAPK-Signalweg gilt als Induktor eines mesenchymalen Phänotyps (Derynck und Zhang, 2003, Teicher, 2001).

TGF- $\beta$ hat auch einen Angiogenese fördernden Effekt, indem es die Expression angiogener Faktoren, wie VEGF und basic fibroblast growth Faktor induziert (Akhurst and Derynck, 2001, Pepper, 1997, Koochekpour et al., 1996).

Das von Glioblastomzellen sezernierte TGF- $\beta$ hat nicht nur autokrinen Einfluß, sondern wirkt auch parakrin auf andere Zellen, die entsprechende Rezeptorproteine auf ihrer Oberfläche exprimieren.

So induziert TGF- $\beta 1$ die Synthese des Wachstumsfaktors Platelet-derived growth Faktor-A und B in Endothelzellen und in gefäßassoziierten Glattmuskelzellen (Dunn et al., 2000). Ein weiterer Mechanismus, mit dem TGF- $\beta$ die Angiogenese in Endothelzellen induziert ist die Hochregulierung von $\alpha_{v} \beta_{3}$ Integrin auf der Oberfläche von Endothelzellen, was zur Bindung und Aktivierung von Matrix-Metalloproteinasen führt, welche die EZM degradieren und somit den Endothelzellen das Einwandern in den Tumor ermöglichen (Platten et al., 2001).

Zudem spielt TGF- $\beta$ eine zentrale Rolle als immunsuppressives Cytokin. Es unterdrückt die Reifung und Antigenpräsentation dendritischer und anderer antigenpräsentierender Zellen, inhibiert Natural Killer (NK)-Zellen und verhindert die Aktivierung und Differenzierung von zytotoxischen T-Zellen (Friese et al., 2004, Friese et al., 2003, Weller and Fontana, 1995, Bodmer et al., 1989).

\subsubsection{Anti-TGF- $\beta$ Antikörper 1D11}

Der murine Antikörper 1D11 bindet die aktiven TGF- $\beta$-Isoformen 1, 2 und 3 und verhindert damit ihre Bindung an TGF- $\beta$-Rezeptoren (Dasch et al., 1998). So kann der Antikörper die durch TGF- $\beta$ ausgelöste Signaltransduktion verhindern.

In in vivo-Studien mit inravenös applizierten Nierenkarzinomzellen konnte die Behandlung mit 1D11 die Anzahl der Metastasen in der Lunge von Mäusen reduzieren (Liu 
et al., 2007 a). Auch bei der Behandlung von Brustkrebs im Mausmodell wurde der 1D11Antikörper schon erfolgreich eingesetzt (Nam et al., 2008). In der Zellkultur ist der Einfluß von 1D11 auf Endothelzellen nach Kultur in U87MG-konditioniertem Medium beschrieben (Pen et al., 2008). Der Effekt einer 1D11-Behandlung von Glioblastomen in vivo ist noch nicht untersucht worden.

\subsection{Optical imaging}

Für Patienten stehen schon viele nicht-invasive bildgebende Verfahren zur Verfügung mit denen man z. B. Tumoren im Gehirn darstellen kann (z.B. CT, MRT, PET, SPECT und andere). Auch in der Forschung nimmt der Einsatz von Bildgebungsverfahren in den letzten Jahren zu. Diese haben den Vorteil, dass Informationen im lebenden Tier nichtinvasiv ermittelt werden können. So kann ein biologischer Prozess in ein und demselben Tier über die Zeit genau verfolgt werden. Dadurch verringert sich auch die Zahl der für Versuche benötigten Tiere.

In vivo Fluoreszenzbildgebung ermöglicht die Realisierung von Zeitkinetiken fluoreszierender Proben im Tier. Durch Einsatz von fluoreszierenden Chromophoren, die im nahen Infrarotbereich zwischen $650 \mathrm{~nm}$ und $900 \mathrm{~nm}$ fluoreszieren, wird eine gute Gewebedurchdringung erreicht (Wessels et al., 2007, Gurfinkel et al., 2003). Auch ist die Autofluorezenz des Gewebes im Vergleich zu green fluorescent protein-basierten Messungen geringer. So können biologische Prozesse in vivo auch auf molekularer Ebene untersucht werden.

Das eXplore Optix-System ist sehr gut für die molekulare Bildgebung in lebenden Mäusen geeignet. Es ist ein laserbasiertes, optisch zeitauflösend im nahen Infrarotbereich messendes System. Es ermöglicht neben der Intensitätsmessung (Keren et al., 2008, Ma et al., 2007) auch die Messung der Fluoreszenzanregungslebensdauer (lifetime (LT)) für die eingesetzten Farbstoffe (Bloch et al., 2005). So kann Autofluoreszenz von spezifischen Fluoreszenzsignalen unterschieden werden. Durch die Möglichkeit der wiederholten Messung kann die Anreicherung und Eliminierung von fluoreszenzmarkierten Therapeutika (wie z.B. von Fluoreszenzmarkiertem 1D11) in Organen oder dem Tumor ermittelt werden.

\subsection{Zielsetzung}

Die Heilungsaussichten von Patienten mit Glioblastomen konnte in den vergangenen Jahren mit den zur Verfügung stehenden Therapiestrategien nicht wesentlich verbessert 
werden. Daher ist die erfolgreiche Behandlung maligner Hirntumoren auch weiterhin eine besondere Herausforderung an die moderne Onkologie.

So ist z.B. weder die Frage nach dem geeigneten Medikamenten-,,Cocktail“ für die einzelnen Gliomvarianten gekärt, noch eine allgemein gut verträgliche Methode zur BHSÜberwindung für einzelne Therapeutika etabliert.

Ziel dieser Arbeit ist, neue experimentelle Ansätze zur Behandlung maligner Gliome im Mausmodell zu evaluieren. Dies soll unter Verwendung von in vivo-Imaging, Fluoreszenzmikroskopie und verschiedenen Färbetechniken der Gewebe durchgeführt werden.

Es wird ein anti TGF- $\beta$ Antikörper (1D11) auf seine potentielle Anwendbarkeit als „molecular targeted““ Therapeutikum gegen maligne Gliome getestet. Dafür wird 1D11 sowohl in der Zellkultur, als auch im Mausmodell zur Behandlung implantierter Glioblastome eingesetzt. Der Antikörper bindet die TGF- $\beta$ Isoformen 1-3, und inhibiert damit deren Interaktion mit dem Rezeptor (Dasch et al., 1998). Die Langzeitapplikation dieses Antikörpers hat in gesunden Mäusen nur geringe Nebenwirkungen gezeigt (Ruzek et al., 2003).

Anreicherung und therapeutische Wirksamkeit des 1D11 Antikörpers auf die Tumorbildung soll zunächst in subkutan (s.c.) anwachsendenen Gliomen gezeigt werden, bevor die Anreicherung in intrazerebralen Tumoren visualisiert wird und diese behandelt werden.

Alkylglycerine eignen sich zur Öffnung der BHS. In gesunden Ratten wurde nach intraarterieller Applikation, sowie unter i.v. Langzeitbehandlung keine Anreicherung von Alkylglycerinen in Organen gezeigt und es sind keine Nebenwirkungen aufgetreten (Erdlenbruch et al., 2005). Es soll die Möglichkeit einer Erhöhung der Konzentration von Antikörpern im gesunden und tumortragenden Gehirn unter Anwendung von Alkylglycerinen zur Öffnung der BHS ermittelt werden. Darüberhinaus wird der Verbleib der Antikörper im Hirn genauer untersucht.

Diese Arbeit soll einen Beitrag zur Evaluation der Effektivität neuer Behandlungsstrategien zur Hirntumortherapie leisten. 


\section{Material und Methoden}

\subsection{Material}

\subsubsection{Geräte}

\begin{tabular}{|c|c|c|}
\hline Gerät & Modell & Hersteller \\
\hline Auflichtmikroskop & DMIRB & $\begin{array}{l}\text { Leica Microsystems, } \\
\text { Wetzlar }\end{array}$ \\
\hline Automatischer Pipettierer & Microlab m & $\begin{array}{l}\text { Hamilton, Bonaduz, } \\
\text { Schweiz }\end{array}$ \\
\hline Brutschrank & BBD6220 & $\begin{array}{l}\text { Haeraeus instruments, } \\
\text { Göttingen }\end{array}$ \\
\hline $\begin{array}{l}\text { Durchlicht-und } \\
\text { Fluoreszenzmikroskop }\end{array}$ & Leica 5000B & $\begin{array}{l}\text { Leica Microsystems, } \\
\text { Wetzlar }\end{array}$ \\
\hline Einbettstation & EG1160 & $\begin{array}{l}\text { Leica Microsystems, } \\
\text { Wetzlar }\end{array}$ \\
\hline Entwässerungsautomat & TP1020 & $\begin{array}{l}\text { Leica Microsystems, } \\
\text { Wetzlar }\end{array}$ \\
\hline Entwicklermaschine & Optimax Typ TR & $\begin{array}{l}\text { M.Schroeder Laborgeraete, } \\
\text { Heidelberg }\end{array}$ \\
\hline Gelkammer & Vertikale Minigelanlage & Biometra, Göttingen \\
\hline Implantationsspritze & $\begin{array}{l}\text { Microliter }{ }^{\mathrm{TM}} \\
\text { Syringes, } 10 \mu 1\end{array}$ & $\begin{array}{l}\text { Hamilton, Bonaduz, } \\
\text { Schweiz }\end{array}$ \\
\hline Infusionspumpe & Perfusor fm & B. Braun, Melsungen \\
\hline Kryomikrotom & LeicaCM3050S & $\begin{array}{l}\text { Leica Microsystems, } \\
\text { Wetzlar }\end{array}$ \\
\hline Mikrotiterplatten-Lesegerät & Sunrise & Tecan, Crailsheim \\
\hline Mikrotom & Leica RM2165 & $\begin{array}{l}\text { Leica Microsystems, } \\
\text { Wetzlar }\end{array}$ \\
\hline $\begin{array}{l}\text { NIR in vivo } \\
\text { Fluoreszenzmessgerät }\end{array}$ & eXplore Optix & ART, Montreal, Canada \\
\hline Operationsbesteck & $\begin{array}{l}\text { Pinzetten, Scheren, } \\
\text { Klemmen }\end{array}$ & $\begin{array}{l}\text { Carl Teufel GmbH \& Co, } \\
\text { Liptingen }\end{array}$ \\
\hline Operationsleuchte & Hanaulux, 2208 & Medap, Feldkirch \\
\hline Operationsmikroskop & OpMi-1 & Zeiss, Göttingen \\
\hline Partikelzähler & Beckman Coulter & Beckman, Cal, USA \\
\hline Pipettus & Easypet & $\begin{array}{l}\text { Eppendorf, Wesseling- } \\
\text { Berzdorf }\end{array}$ \\
\hline Semi-Dry-Blot Apparatur & Fastblot B44 & Biometra, Göttingen \\
\hline Spannungsgeber & EPS 3500 & $\begin{array}{l}\text { Pharmacia Biotech, } \\
\text { Freiburg }\end{array}$ \\
\hline Stereomikroskop & Leica MZFLIII & $\begin{array}{l}\text { Leica Microsystems, } \\
\text { Wetzlar }\end{array}$ \\
\hline
\end{tabular}




\begin{tabular}{|l|l|l|}
\hline Gerät & Modell & Hersteller \\
\hline Stereotaxiegerät & Modell 900 & $\begin{array}{l}\text { Kopf Instruments, Tujunga, } \\
\text { California }\end{array}$ \\
\hline Sterilbank & $\begin{array}{l}\text { Bio GARD Hood Class II } \\
\text { TYPE A }\end{array}$ & Sanford, Maine \\
\hline Zentrifuge & Biofuge 13, 5810R & $\begin{array}{l}\text { Eppendorf, Wesseling- } \\
\text { Berzdorf }\end{array}$ \\
\hline
\end{tabular}

\subsubsection{Verbrauchsmaterialien}

\begin{tabular}{|c|c|}
\hline Material & Hersteller \\
\hline 96-well Platten & Becton Dickinson, Heidelberg \\
\hline Centricon Filter, 10000 NMWL & Millipore, Schwalbach Theissungen \\
\hline Deckgläschen & Menzel-GmbH\&Co KG, Braunschweig \\
\hline Dialysierschlauch Visking, Type 20/32 & Serva, Heidelberg \\
\hline Einfrier-Einbettmittel Tissue-Tek $^{(\mathbb{R}}$ & $\begin{array}{l}\text { Sakura Finetec Europe, Zoeterwoude, } \\
\text { Niederlande }\end{array}$ \\
\hline Einmalhandschuhe & Hartmann, Heidenheim \\
\hline Filterpapier & Whatman, East Sussex, England \\
\hline Geflochtene Seide USP 7/0 & Vömel, Kronberg \\
\hline Gewebekassetten & Klinipath b.v., Duiven, Niederlande \\
\hline Haut-Antiseptikum, Kodan ${ }^{(B)}$ & Schülke \& Mayr, Norderstedt \\
\hline Immobilon-P Membran (PVDF, $0,45 \mu \mathrm{M}$ ) & Millipore, Schwalbach Theissungen \\
\hline Kanülen $27 \mathrm{G}$ und $20 \mathrm{G}$ & B. Braun, Melsungen \\
\hline Kryomikrotom-Klingen 819 & Leica Microsystems, Wetzlar \\
\hline Mikrotom-Klingen N35 & Feather, Köln \\
\hline Nahtmaterial für Mäuse, Seralon 7/0 & Serag Wiessner, Nailer \\
\hline $\begin{array}{l}\text { Objektträger für Gefrierschnitte, Superfrost- } \\
\text { Plus }\end{array}$ & Menzel-GmbH\&Co KG, Braunschweig \\
\hline Objektträger für Paraffinschnitte & Menzel-GmbH\&Co KG, Braunschweig \\
\hline Paraffin, Paraplast Plus & tyco Healthcare, Kendall, USA \\
\hline Petrischalen, Falcon 3003 & $\begin{array}{l}\text { Becton Dickinson, Le Pont De Claix, } \\
\text { Frankreich }\end{array}$ \\
\hline Pipetten $1 \mathrm{ml}, 5 \mathrm{ml}, 10 \mathrm{ml}, 20 \mathrm{ml}$ & Sarstedt, Nümbrecht \\
\hline Pipettenspitzen $10 \mu 1,100 \mu 1,1000 \mu 1$ & Sarstedt, Nümbrecht \\
\hline $\begin{array}{l}\text { Polyethylen- Röhrchen mit } \\
\text { Schraubverschluß } 10 \mathrm{ml}, 50 \mathrm{ml}\end{array}$ & Greiner bio-one, Frickenhausen \\
\hline Reagiergefäße & Sarstedt, Nümbrecht \\
\hline Sephadex G25 & $\begin{array}{l}\text { Pharmacia Fine Chemicals, Uppsala, } \\
\text { Schweden }\end{array}$ \\
\hline Skalpelle & HMD Healthcare Ltd. Norsham, England \\
\hline Spritzen, $1 \mathrm{ml}, 5 \mathrm{ml}$ & $\begin{array}{l}\text { Beckton Dickinson, Le Pont De Claix, } \\
\text { Frankreich }\end{array}$ \\
\hline Sterile Wundkompressen & Hartmann,Heidenheim \\
\hline Sterilfilter, Minisart, $0,2 \mu \mathrm{m}$ & Sartorius, Göttingen \\
\hline
\end{tabular}




\begin{tabular}{|l|l|}
\hline Material & Hersteller \\
\hline U-100 Insulin-Spritzen $0,5 \mathrm{ml}$, Micro-Fine+ & $\begin{array}{l}\text { Beckton Dickinson, Le Pont De Claix, } \\
\text { Frankreich }\end{array}$ \\
\hline $\begin{array}{l}\text { Zellkulturflaschen } 25 \mathrm{~cm}^{2}, 75 \mathrm{~cm}^{2} \text { und } 175 \\
\mathrm{~cm}^{2}\end{array}$ & Greiner bio-one, Frickenhausen \\
\hline Zellstoff, Pehazell & Hartmann, Heidenheim \\
\hline
\end{tabular}

\subsubsection{Medikamente und Chemikalien}

\subsubsection{Alkylglycerine}

Unterschiedliche Derivate von Alkylglycerinen wurden in Zusammenarbeit mit Prof. H. Eibl vom Max-Planck-Institut für biophysikalische Chemie in Göttingen entwickelt. Die Rechte für 2-O-Hexyldiglycerin (HG) hat die Firma Genzyme, Corp. (Cambridge, MA, USA) erworben. Das zur Öffnung der BHS verwendete HG wurde freundlicherweise von der Firma Genzyme, Corp. zur Verfügung gestellt. Dabei handelt es sich um ein amphiphiles Molekül, das einen hydrophilen Kopf an einer hydrophoben Kohlenwasserstoffkette besitzt. Eine gebrauchsfertige Lösung wurde vor Versuchsbeginn immer frisch angesetzt. Um osmotische Effekte zu vermeiden, wurde die HG-Lösung mit Aqua ad injectionem und physiologischer Kochsalzlösung so verdünnt, dass eine isoosmolare Lösung mit einer Osmolarität von etwa 300 mosmol $/ \mathrm{kg}$ entstand.

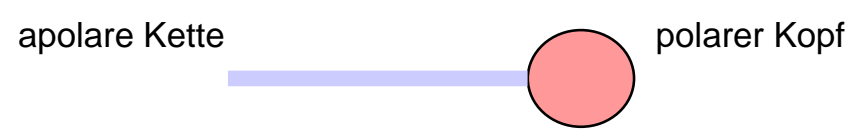

(rac)-2-O-Hexyldiglycerin

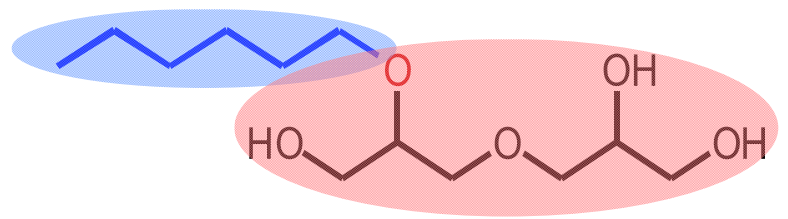

Abbildung 2: Strukturformel von 2-O-Hexyldiglycerin 


\subsubsection{Medikamente}

\begin{tabular}{|l|l|l|}
\hline Medikament & Hersteller & Dosierung \\
\hline $\begin{array}{l}\text { Antisedan } \\
\text { (Atipamezolhydrochlorid) }\end{array}$ & Pfizer & $\begin{array}{l}0,2 \mathrm{mg} \mathrm{kg}^{-1} \text { Körpergewicht } \\
(\mathrm{KG})\end{array}$ \\
\hline $\begin{array}{l}\text { Hostaket } \\
\text { (Ketaminhydrochlorid) }\end{array}$ & Intervent & $85 \mathrm{mg} \mathrm{kg}^{-1} \mathrm{KG}$ \\
\hline Isofluran & Baxter GmbH & $\begin{array}{l}\text { Sauerstoff-Isofluran (1\%) } \\
\text { Gasmix }\end{array}$ \\
\hline Rimadyl $^{(\mathbb{R}}$ & Pfizer & $5 \mathrm{mg} \mathrm{kg}^{-1} \mathrm{KG}$ \\
\hline $\begin{array}{l}\text { Rompun } \\
{ }^{(X)}\end{array}$ & Bayer & $7,5 \mathrm{mg} \mathrm{kg}^{-1} \mathrm{KG}$ \\
\hline
\end{tabular}

\subsubsection{Chemikalien}

\begin{tabular}{|l|l|}
\hline Chemikalie & Hersteller \\
\hline 2-Methylbutan & Riedel-de-Haën, Seelze \\
\hline $\begin{array}{l}\text { 3,3-Diaminobenzidin- } \\
\text { Tetrahydrochlorid (DAB) }\end{array}$ & Roth, Karlsruhe \\
\hline Aceton & Sigma, Deisenhofen \\
\hline Acrylamid-Mix Rotiphorese Gel 30 & Roth, Karlsruhe \\
\hline Agarose AG Plus & Santa Cruz, Heidelberg \\
\hline Ammonium-Nickel-Sulfat & Merck, Darmstadt \\
\hline Ammoniumpersulfat (APS) & Merck, Darmstadt \\
\hline Aqua ad iniectabilia & B. Braun, Melsungen \\
\hline Bromphenolblau & Sigma, Deisenhofen \\
\hline Dimethylsulfoxid (DMSO) & Sigma, Deisenhofen \\
\hline Depex & Sigma, Deisenhofen \\
\hline Eisessig (Essigsäure 100\%) & Roth, Karlsruhe \\
\hline $\begin{array}{l}\text { Entellan-Neu (nicht-wässriges } \\
\text { Eindeckmedium) }\end{array}$ & Merck, Darmstadt \\
\hline Eosin C.I. 45380 & \\
\hline Essigsäure & Roth, Karlsruhe \\
\hline Ethanol 99\% vergällt & Roth, Karlsruhe \\
\hline Extravidin-Peroxidase & Chemie-Vertrieb, Hannover \\
\hline Fetal calf serum (FCS) & Sigma, Deisenhofen \\
\hline $\begin{array}{l}\text { Fluoromount G (wässriges } \\
\text { Eindeckmedium) }\end{array}$ & Biochrom, Berlin \\
\hline Glycin & Biozol, Eching \\
\hline Hämalaun nach Mayer & \\
\hline Isotone Natriumchloridlösung( 0,9\%) & Sigma, Deisenhofen \\
\hline Kernechtrot & Roth, Karlsruhe \\
\hline Methanol 99,9\% & Apraun, Melsungen \\
\hline Milchpulver (non-fat) & Roth, Karlsruhe \\
\hline $\begin{array}{l}\text { N, N, N', N'-Tetramethylethylendiamin } \\
\text { (TEMED) }\end{array}$ & Bio-Rad, München \\
\hline Natriumchlorid & Roth, Karlsruhe \\
\hline Natriumcitrat & Merck, Darmstadt \\
\hline & Sigma, Deisenhofen \\
\hline
\end{tabular}




\begin{tabular}{|l|l|}
\hline Chemikalie & Hersteller \\
\hline Natriumdodecylsulfat (SDS) & Serva, Heidelberg \\
\hline Natronlauge & Merck, Darmstadt \\
\hline Paraformaldehyd & Roth, Karlsruhe \\
\hline Penicillin/Streptamycin (je 5000 U/ml) & Cambrex, Apen \\
\hline Polyethylenglycol MG 20000 & Serva, Heidelberg \\
\hline Ponceau S & Sigma, Deisenhofen \\
\hline $\begin{array}{l}\text { Pospate buffered saline (PBS Dulbecco) } \\
\text { (Pulver) }\end{array}$ & Biochrom, Berlin \\
\hline Rinderserumalbumin (BSA) & Fermentas, St. Leon-Rot \\
\hline Roti-Histol & Roth, Karlsruhe \\
\hline Salzsäure & Merck, Darmstadt \\
\hline Tris X (Base) & Merck, Darmstadt \\
\hline Tween 20 & Calbiochem \\
\hline Wasserstoffperoxid 30\% & Roth, Karlsruhe \\
\hline Xylol & Roth, Karlsruhe \\
\hline Zitronensäure & Merck, Darmstadt \\
\hline$\beta$-Mercaptoethanol & Serva, Heidelberg \\
\hline
\end{tabular}

\subsubsection{Puffer und Medien}

\begin{tabular}{|l|l|l|}
\hline Fertige Puffer/Medium & Verwendung & Hersteller \\
\hline PBS (fertiger Puffer) & $\begin{array}{l}\text { Zellkultur, Perfusion, } \\
\text { Immunfluoreszenz }\end{array}$ & Lonza, Basel, Schweiz \\
\hline RPMI 1640 & Zellkultur & Lonza, Basel, Schweiz \\
\hline MEM-Earle & Zellkultur & Biochrom, Berlin \\
\hline $\begin{array}{l}\text { DMEM 1 g/l Glukose und L- } \\
\text { Glutamin }\end{array}$ & Zellkultur & Biochrom, Berlin \\
\hline $\begin{array}{l}\text { Trypsin 200 mg/l Versene } \\
\text { (EDTA) }\end{array}$ & Zellkultur & Lonza, Basel, Schweiz \\
\hline
\end{tabular}

\begin{tabular}{|l|l|l|}
\hline Selbst hergestellte Puffer & Verwendung & Zusammensetzung \\
\hline Bicarbonatpuffer & $\begin{array}{l}\text { Kopplung von } \\
\text { Farbstoff an Proteine }\end{array}$ & $\begin{array}{l}150 \mathrm{mM} \mathrm{Na}_{2} \mathrm{CO}_{3} \text { in Aqua dest., } \\
\mathrm{pH} \mathrm{9,3}\end{array}$ \\
\hline NaCl-Phosphatpuffer & $\begin{array}{l}\text { Kopplung von } \\
\text { Farbstoff an Proteine }\end{array}$ & $\begin{array}{l}100 \mathrm{mM} \mathrm{NaCl,} \mathrm{50} \mathrm{mM} \\
\mathrm{NaH}_{2} \mathrm{PO}_{4}, 1 \mathrm{mM} \text { EDTA in } \\
\text { Aqua dest., pH 7,5 }\end{array}$ \\
\hline Citratpuffer & Immunhistochemie & $\begin{array}{l}1,8 \mathrm{mM} \text { Zitronensäure + 11 } \\
\text { mM Natriumcitrat in Aqua } \\
\text { dest., pH 6 }\end{array}$ \\
\hline Blockpuffer & $\begin{array}{l}\text { Immunhistochemie } \\
\text { und BSA in PBS, 0,1 \% Tween } \\
\text { Immunfluoreszenz }\end{array}$ & Western-Blot \\
\hline Blockpuffer & $\begin{array}{l}\text { TBS mit 5\% non-fat dry milk, } \\
0,1 \% \text { Tween 20 }\end{array}$ \\
\hline
\end{tabular}




\begin{tabular}{|c|c|c|}
\hline Selbst hergestellte Puffer & Verwendung & Zusammensetzung \\
\hline Blotpuffer & Western-Blot & $\begin{array}{l}48 \text { mMTris, } 39 \mathrm{mM} \text { Glycin, } 20 \\
\% \text { Methanol ( } \mathrm{pH} \sim 9,2 \text {; nicht } \\
\text { einstellen) }\end{array}$ \\
\hline Tris buffered saline (TBS) & Western-Blot & $\begin{array}{l}150 \mathrm{mM} \mathrm{NaCl}, 20 \mathrm{mM} \text { Tris-Cl } \\
(\mathrm{pH} 7,5)\end{array}$ \\
\hline Laufpuffer $(5 x)$ & Western-Blot & $\begin{array}{l}125 \mathrm{mM} \text { Tris, } 1250 \mathrm{mM} \text { Glycin, } \\
0,5 \% \text { SDS }\end{array}$ \\
\hline Waschpuffer & Western-Blot & TBS mit $0,1 \%$ Tween 20 \\
\hline Probenpuffer $(2 \mathrm{x})$ & Western-Blot & $\begin{array}{l}125 \mathrm{mM} \text { Tris-Cl (pH 6,8), } 30 \% \\
\text { Glycerin, } 4 \% \text { SDS, 0,002\% } \\
\text { Bromphenolblau, } 2 \% \beta- \\
\text { Mercaptoethanol (erst vor } \\
\text { Gebrauch zugeben) }\end{array}$ \\
\hline Paraformaldehyd (PFA) 4\% & $\begin{array}{l}\text { Fixierung von } \\
\text { Gewebe }\end{array}$ & $\begin{array}{l}4 \% \text { Paraformaldehyd in PBS, } \\
\text { Lösung durch Zugabe von } \\
\mathrm{NaOH}\end{array}$ \\
\hline
\end{tabular}

\subsubsection{Kommerzielle Kits}

\begin{tabular}{|l|l|}
\hline Kit & Hersteller \\
\hline $\begin{array}{l}\text { PKH2 Green Fluorescent Phagocytic Cell } \\
\text { Linker Kit }\end{array}$ & Sigma-Aldrich, Steinheim \\
\hline Cell Proliferation Reagent WST-1 & Roche, Penzberg \\
\hline $\begin{array}{l}\text { Quantikine }{ }^{\circledR} \text { Human TGF- } \beta 2 \text { Immunoassay } \\
\text { Elisa-Kit }\end{array}$ & R\&D Systems, Wiesbaden \\
\hline $\begin{array}{l}\text { Western blotting detection reagents ECL- } \\
\text { Kit }\end{array}$ & Amersham, Braunschweig \\
\hline
\end{tabular}

\subsubsection{Antikörper und Proteine}

\section{In vivo verwendet}

Bovines $\gamma$-Globulin (Sigma-Aldrich) wurde zur Visualisierung einer unspezifischen Anreicherung großer Proteine im Gehirn und im Gehirntumor verwendet. Dazu wurde es für in vivo-Messungen mit Cy5.5 und für mikroskopische Evaluierung an RB200 gekoppelt.

Als spezifischer therapeutischer Antikörper wurde der, die TGF- $\beta$-Isoformen 1-3 bindende monoklonale IgG1 Antikörper $1 D 11$ (Genzyme, Corp Cambridge, MA, USA) verwendet (Dasch, 1998). 
Als Isotypkontrolle wurde der monoklonale IgG1 Antikörper 13C4 (Genzyme, Corp Cambridge, MA, USA) verwendet, der spezifisch das von E-coli Bakterien sezernierte Shiga Toxin Type1 bindet (Smith, 2006).

Die Antikörper 1D11 und 13C4 wurden freundlicherweise von der Firma Genzyme (Genzyme, Corp Cambridge, MA, USA) zur Verfügung gestellt und mit Fluoreszenzfarbstoffen gekoppelt.

\section{In vitro verwendet}

Für Versuche in der Zellkultur wurde lyophilisiertes, rekombinantes, humanes TGF- $\beta 2$ (R\&D Systems) laut Herstellerempfehlung zur Aktivierung in $4 \mathrm{mM} \mathrm{HCl} \mathrm{mit} \mathrm{0,1 \%} \mathrm{BSA}$ gelöst.

Antikörper für die Immunhistochemie

Primäre Antikörper:

- monoklonaler Maus anti human Ki67 Antikörper MIB 1 (1:500) (Dako) zur Identifizierung von proliferierenden Zellen. Der Antikörper reagiert mit dem in allen Phasen des Zellzyklus exprimierte Antigen Ki67.

- monoklonaler Ratte anti Maus Mac-3 Antikörper (1:300) (BD Biosciences) zur Identifizierung von Makrophagen. Der Isotyp IgG1, $\kappa$ Antikörper reagiert mit dem 110 kDa großen Mac-3 Antigen, das auf der Oberfläche von aktivierten Peritonealmakrophagen expremiert wird.

- monoklonaler Kaninchen anti human aktivierte Caspase-3 Antikörper (1:300) (BD Biosciences) zur Identifizierung apoptotischer Zellen. Der Antikörper reagiert mit dem in apoptotischen Zellen vorhandenen aktiven Fragment der Caspase-3.

- polyklonaler Kaninchen anti humaner Faktor VIII Antikörper (1:300) (Dako) zur Identifizierung von Blutgefäßendothelzellen. Der Antikörper reagiert mit Faktor 8 (oder auch von Willebrand Faktor genannt), der von Endothelzellen der Blutgefäße exprimiert wird.

Sekundäre Antikörper:

- biotinylierter Schaf anti Maus polyklonaler Antikörper (1:500) (Amersham)

- biotinylierter Ziege anti Ratte polyklonaler Antikörper (1:200) (Amersham)

- biotinylierter Esel anti Kaninchen polyklonaler Antikörper (1:200) (Amersham)

- Ziege anti-Kaninchen polyklonaler Antikörper Alexa Fluor 594 (1:300)

(Invitrogen). 


\subsubsection{Fluorezenzfarbstoffe}

- Natrium-Fluorescein (Na-Fl) wurde ungekoppelt als $5 \%$ ige Lösung in 0,9\% $\mathrm{NaCl}$ verwendet.

- Rhodamin B 200 (RB200) wurde an bovines $\gamma$-Globulin gebunden.

- Cy5.5 Mono NHS Ester (Cy5.5) wurde an bovines $\gamma$-Globulin gebunden.

- Alexa Fluor 680 (AF680) wurde von der Firma Genzyme an die Antikörper 1D11 (AF680 1D11) (Markierungsrate: 2,6 Mol Fluorophor/Mol 1D11) und 13C4 (AF680 13C4) gebunden (Markierungsrate: 3,6 Mol Fluorophor/Mol 13C4).

- Alexa Fluor 594 (AF594) wurde von der Firma Genzyme an den Antikörper 1D11 (AF594 1D11) gebunden.

- DAPI wurde ungekoppelt 1:10000 in PBS verdünnt zur Kernfärbung in Immunfluoreszenzschnitten verwendet.

\subsubsection{Tiere}

Ratten und Mäuse wurden von Charles River Laboratories bezogen. Die Haltung der Tiere erfolgte in der Zentralen Tierexperimentellen Einrichtung der Universitätsmedizin Göttingen.

\section{Fischer-Ratten}

(F344/DuCrl)

Diese Albino-Rattenlinie ist seit langem etabliert und hat ihren Ursprung in der 344 Kreuzung eines lokalen Züchters namens Fischer. Die Inzucht begann 1920. Ab der 68. Generation wurde eine Kolonie 1960 bei Charles River gezüchtet.

\section{NMRI-Mäuse}

(Crl:NMRI (Han))

Diese Albino-Mauslinie hat ihren Ursprung in der Nicht-Inzüchtung von Swiss-Mäusen. Nach einer Inzuchtperiode gingen einige „A“-Stamm hybriden Mäuse an das U.S. Naval Medical Research Institute (NMRI), wo sie 9 Jahre ingezüchtet wurden. An der Bundesforschungsanstalt für Viruskrankheiten der Tiere wurden die Mäuse ab 1955 in drei Linien (I-III) gezüchtet. Linie II ging 1958 an das Zentralinstitut für Versuchstierzucht, Hannover, wo sie als geschlossene Auszuchtkolonie gehalten wurde. Seit 1982 wird diese Linie von Charles River gezüchtet. 
$\underline{\text { nu/nu-Mäuse }}$

(Crl:CD1-Foxn1 $\left.{ }^{\mathrm{nu}}\right)$

Diese Mauslinie hat ihren Ursprung in der Nicht-Inzüchtung von Swiss-Mäusen. Über das Rockefeller Institut und das Institute of Cancer Research, Philadelphia kam der AlbinoStamm 1959 zu Charles River, wo er seither als CD-1 Mauslinie gezüchtet wird. CD- ${ }^{\circledR}$ ist ein Markenzeichen von Charles River Laboratories.

Durch eine Serie von Kreuzungen wurde das Nude-Gen auf die CD-1 Maus übertragen. Die Zucht dieses Stammes erfolgt bei Charles River im Isolator (heterozygote nu/+Weibchen x homozygote nu/nu-Männchen).

Das mutante Allel des nude-Locus (Symbol: nu) wird autosomal und rezessiv vererbt. Homozygote Tiere sind haarlos und besitzen keinen Thymus. Daher fehlen die thymusabhängigen T-Lymphozyten und die dadurch vermittelten Immunreaktionen. Bei konventioneller Haltung dominieren chronische Infektionskrankheiten. Die Tiere stellen ein Modell für das DiGeorge-Syndrom des Menschen dar.

\section{Black/6-Mäuse}

(C57/BL/6JCrl)

Diese schwarze Mauslinie hat ihren Ursprung in der Kreuzung eines Bestandes von „Miss Abby Lathrop“. 1937 wurden die Linien 6 und 10 separiert. Die Linie 6 kam über Jackson Lab. 1951 in der 32.Generation zum National Institute of Health und $1974 \mathrm{zu}$ Charles River Laboratories.

\subsubsection{Tumorzelllinien}

\section{Humane Zelllinie U87MG}

(Upsala 87 malignant Glioma)

Diese Zelllinie wurde freundlicherweise von Prof. Bernhardt, Universität Regensburg, zur Verfügung gestellt und stammt ursprünglich von der American Type Culture Collection (ATCC, Rockville, MD). Tumormaterial eines hochmalignen Glioms (WHO-Grad IV) einer 44-jährigen Frau in Kultur genommen (von cell lines service als Grad III deklariert). Es ist eine von mehreren Glioblastomzelllinien, die von J. Ponten und Mitarbeitern 1966 bis 1969 etabliert wurden. In der Zellkultur wurde sie in MEM-Earle* kultiviert.

\section{$\underline{\text { Rattenzelllinie RG2 }}$}

(rat glioma 2)

Diese Zelllinie stammt von der American Type Culture Collection (ATCC, Rockville, MD). Sie wurde aus einem in Fischer-Ratten durch N-Methylnitrosoharnstoff induzierten 
Tumor geklont. Die RG2 Zellen entsprechen der D74 Zelllinie und stimmen in ihren Charakteristika mit humanen Glioblastomzellen überein. Da sie syngen zu Fischer-Ratten sind, sind sie in diese implantiert nicht immunogen. In der Zellkultur wurde sie in RPMI* Medium kultiviert.

\section{Mauszelllinie GL261}

(Glioma 261)

Diese Zelllinie wurde uns freundlicherweise von Prof. van Gool, Universität Leuven, Belgien, zur Verfügung gestellt. Sie wurde aus einem in Black/6 Mäusen durch NMethylnitrosoharnstoff induzierten Tumor geklont. Da sie syngen zu Black 6 Mäusen sind, sind sie in diese implantiert nicht immunogen. In der Zellkultur wurde sie in DMEM* Medium kultiviert.

*Den Medien wurde FCS (10\%) und Penicillin/Streptomycin (1 \%) zugesetzt. Im Folgenden sind immer die Medien mit diesen Zusätzen gemeint, soweit es nicht anders angegeben wird.

\subsubsection{Software}

\begin{tabular}{|l|l|l|}
\hline Programm & Verwendung & Hersteller \\
\hline Word & Textverarbeitung & Microsoft \\
\hline Excel & Diagramme erstellen & Microsoft \\
\hline SigmaStat 3.5 & $\begin{array}{l}\text { Statistik bei } \\
\text { (Student t-Test Daten; } \\
\text { normalverteilten nicht } \\
\text { Mann-Whitney Rank Sum } \\
\text { Test bei noftware Inc. } \\
\text { normalverteilten Daten) }\end{array}$ & \\
\hline Imaging & $\begin{array}{l}\text { Aufnahmen von } \\
\text { Stereomikroskop- und } \\
\text { Mikroskopbildern }\end{array}$ & Leica \\
\hline FW4000 & $\begin{array}{l}\text { Aufnahme und Bearbeitung } \\
\text { von } \\
\text { Fluoreszenzmikroskopbildern }\end{array}$ & Leica \\
\hline OptiView 1.00.00 & $\begin{array}{l}\text { Auswertung der in vivo- } \\
\text { imaging Daten }\end{array}$ & ART, Montreal, Canada \\
\hline
\end{tabular}




\subsection{Methoden}

\subsubsection{Kopplung der Fluoreszenzfarbstoffe RB200 oder Cy5.5 an $\gamma$-Globulin}

Die Markierung erfolgte, wie bei Klein (et al., 1986) beschrieben. Alle Arbeiten mit den Farbstoffen wurden möglichst im Dunkeln, oder in lichtgeschützten Gefäßen durchgeführt, um ein Ausbleichen des Farbstoffs zu vermeiden.

\section{Markieren von $\gamma$-Globulin mit RB200}

Zehn g durch ein Drahtnetz gesiebtes, fein pulverisiertes Phosphorpentachlorid wurde mit 5 g RB200 vorsichtig im Mörser 5 min verrührt. Unter ständigem Rühren wurden $50 \mathrm{ml}$ Aceton dazugegeben und die Mischung anschließend über einen Faltenfilter in einen Messkolben filtriert. $15 \mathrm{ml}$ der filtrierten Lösung wurden in einen Weithalserlenmeyerkolben mit Glasperlen gegeben und bis zum völligen Verdampfen des Acetons und der flüchtigen Säureanteile mit Stickstoff begast. Dieser Vorgang dauerte etwa 12 Stunden $(\mathrm{h})$.

Im Eisbad wurden $5 \mathrm{~g}$-Globulin unter Rühren in $200 \mathrm{ml}$ Bicarbonatpuffer gelöst und die Lösung in den Weithalserlenmeyerkolben auf Eis mit dem getrockneten Farbstoff an den Glasperlen 30 min inkubiert.

\section{Markieren von $\gamma$-Globulin mit Cy5.5}

$120 \mathrm{mg} \gamma$-Globulin wurden auf Eis in $100 \mathrm{ml}$ Bicarbonatpuffer gelöst und $5 \mathrm{mg}$ Cy5.5 bei Raumtemperatur (RT) in $4430 \mu 1$ DMSO. Dann wurden 44 mg $\gamma$-Globulin- und $2215 \mu 1$ Cy5.5-Lösung gemischt und für $2 \mathrm{~h}$ auf Eis inkubiert. Danach wurde das Ganze noch einmal umgerührt und $15 \mathrm{~min}$ bei Raumtemperatur (RT) inkubiert, bevor es $30 \mathrm{~min}$ bei $25^{\circ} \mathrm{C}$ inkubiert wurde. Bis zur Aufreinigung konnte der Ansatz nach Einfrieren in flüssigem Stickstoff bei $-20^{\circ} \mathrm{C}$ zwischengelagert werden.

\section{$\underline{\text { Aufreinigung und Aufkonzentrierung beider Farbstoff- } \gamma \text {-Globuline }}$}

Die Aufreinigung der Farbstoff- $\gamma$-Globuline wurde mittels Gelfiltrations-Chromatographie durchgeführt. Die Farbstofflösung wurde vorsichtig mit einer Pipette (höchstens $30 \%$ des Säulenvolumens) auf die mit Sephadex G25 in NaCl-Phosphatpuffer (1:1) gefüllte Säule gegeben und langsam mit NaCl-Phosphatpuffer als Laufmittel chromatographiert. Dabei trennte sich der gebundene vom ungebundenen Farbstoff, der in die Sephadexkügelchen eindringen kann und deshalb einen weiteren Weg zurücklegen muß. Die erste Fraktion war der gebundene Farbstoff.

Zur Aufkonzentrierung wurde ein Dialyseschlauch in EDTA (10 mM) eingeweicht, ein Ende abgebunden und das andere Ende nach Einfüllen der Farbstofflösung auch fest 
verschlossen. Der Schlauch wurde im Kühlschrank ü.N. in 10 \% PEG 20000 eingelegt. Am nächsten Tag wurde die konzentrierte Farbstoff- $\gamma$-Globulin-Lösung mit einer Spritze herausgesaugt. Der Schlauch wurde dann nochmals mit ein wenig NaCl-Phosphatpuffer ausgespült, um die Ausbeute weiter zu erhöhen.

Die Konzentration des Farbstoffs wurde bestimmt, indem $1 \mathrm{ml}$ Aceton und $100 \mu \mathrm{l}$ Farbstofflösung in ein vorher gewogenes Reagiergefäß pipettiert wurden. Das Gefäß wurde kräftig geschüttelt, damit $\gamma$-Globulin ausfällt und anschließend $5 \mathrm{~min}$ bei $11000 \mathrm{~g}$ zentrifugiert. Das Aceton wurde vorsichtig abpipettiert und das Pellet $1 \mathrm{~h}$ bei $80^{\circ} \mathrm{C}$ getrocknet. Anschließend wurde das Reagiergefäß mit Pellet gewogen und so die Menge an Globulin in der Lösung bestimmt. Die Endkonzentration der Farbstoff- $\gamma$-Globulin-Lösung wurde mit NaCl-Phosphatpuffer auf $8 \%$ eingestellt, in $500 \mu$ Portionen aliquotiert, in flüssigem Stickstoff eingefroren und bis zur Verwendung bei $-20^{\circ} \mathrm{C}$ gelagert. Vor der Benutzung wurde die Farbstofflösung nach dem Auftauen mit einem Filter mit der Porengröße $0,2 \mu \mathrm{m}$ steril filtriert.

\subsubsection{Zellkultur}

\section{Zellen in Kultur nehmen}

Die in flüssigem Stickstoff mit Einfriermedium gelagerten Zellen wurden aufgetaut und der Inhalt des Cryoröhrchens in $10 \mathrm{ml}$ Medium überführt. Das Röhrchen wurde 1 min bei 190 g zentrifugiert, der Überstand abgezogen und die Zellen in $1 \mathrm{ml}$ Medium resuspendiert. Je $500 \mu \mathrm{l}$ der Zellsuspension wurden zum Wachsen in eine $75 \mathrm{~cm}^{2}$ Zellkulturflasche mit $15 \mathrm{ml}$ Medium gegeben und bei $37^{\circ} \mathrm{C} \quad 90 \%$ Lufteuchtigkeit und $5 \% \mathrm{CO}_{2}$-Gehalt im Wärmeschrank inkubiert.

\section{Zellen umsetzen}

Alle 3-4 Tage wurden die Zellen umgesetzt. Dazu wurde das Medium abgesaugt, die adhärenten Zellen $2 \times$ mit $5 \mathrm{ml}$ PBS gespült und dann für 3 Minuten mit $3 \mathrm{ml}$ Trypsin inkubiert, um die Zellen vom Flaschenboden zu lösen. Zum Abstoppen der Reaktion wurden $7 \mathrm{ml}$ Medium zugegeben. Die Zellen wurden nun in ein $5 \mathrm{ml}$ Falcon Röhrchen überführt und bei 280 g 5 min zentrifugiert. Der Überstand wurde wieder abgezogen und die Zellen in $1 \mathrm{ml}$ Medium resuspendiert. Davon wurden $150 \mu \mathrm{l}$ in eine neue Halteflasche mit $15 \mathrm{ml}$ Medium gegeben und für 3 bis 4 Tage im Wärmeschrank inkubiert. Alle übrigen Zellen wurden für Versuche verwendet oder verworfen. 


\section{Zellen zählen}

Suspendierte Zellen wurden für Zellkulturversuche im Beckman Coulter Partikelzähler automatisiert oder für Tumorzellimplantationen mittels einer Neubauer-Zählkammer manuell gezählt.

Zur Zellzahlbestimmung mit dem Partikelzähler wurden $100 \mu 1$ Zellsuspension zu 10 $\mathrm{ml}$ Coulter Isoton II Diluent in eine Küvette pipettiert und die Zellmessung vorgenommen.

Zur manuellen Zellzahlbestimmung wurden $9 \mu 1$ der mit Trypanblau versetzten Zellsuspension luftblasenfrei in die Kammern des sauberen Hemocytometer-Objektträger pipettiert.

Die Zellen in den 16 Quadraten der vier Eckfelder des Objektträgers wurden gezählt, wobei nur die lebenden, nicht blauen Zellen in jedem Quadrat und auf dem oberen und dem linken Rand gezählt wurden. Bei unter 100 Zellen, oder wenn mehr als $10 \%$ der Zellen als Zellklümpchen vorlagen, wurde die Zählung mit erneut gut suspendierten Zellen, bei über 400 Zellen mit stärker verdünnter Zellsuspension wiederholt.

Danach wurden alle in den Quadraten gezählten Zellen addiert und die Durchschnittszellzahl pro Eckfeld (n) errechnet. Die Zellzahl in der Suspension berechnet sich dann nach der Formel: n x 10 $=$ Zellen/ml Zellsuspension.

\subsubsection{WST-1-Test}

Der WST-1-Test ist ein spektrometrisch durchgeführter Test zur Quantifizierung von Zellproliferation und Zellvitalität. Er basiert auf der Spaltung des Tetrazoliumsalzes WST1 durch mitochondriale Dehydrogenasen in lebenden Zellen. Er wird in einer 96-Well Platte durchgeführt und der Farbstoffumschlag durch Absorptionsmessung im Mikrotiterplatten-Lesegerät quantifiziert.

In Vorversuchen wurde ermittelt, wie viele Zellen pro Well ausgesät werden müssen, damit die Zellen in den Wells über den geplanten Messzeitraum nicht konfluent werden. 72 $\mathrm{h}$ bevor die Zellen in 96 Well Platten ausgesät wurden, wurden sie einmalig mit einer definierten Konzentration TGF- $\beta$ oder 1D11 behandelt. Dann wurden sie in $100 \mu 1$ Medium ausgesät und 6 h später einmalig $10 \mu 1$ TGF- $\beta$ oder 1D11 in definierter Konzentration dazu pipettiert. Nach 24, 72 oder 96 h wurden $10 \mu$ des WST-1 Reagenz zu Zellen und Medium in ein Well pipettiert. Als Hintergrund-Kontrolle (Blank) wurde $10 \mu \mathrm{l}$ des Reagenz in ein Well mit entsprechendem Medium ohne Zellen gegeben. Nach $2 \mathrm{~h}$ wurde die Absorption bei $450 \mathrm{~nm}$ gegen eine Referenzwellenlänge von $690 \mathrm{~nm}$ gemessen.

Für Versuchsansätze wurden 10 Replikate gleich behandelt, der Blank-Wert subtrahiert und die mittlere Absorption ermittelt. Jeder Versuch wurde dreimal wiederholt. 


\subsubsection{Gewinnung und Aufkonzentrierung von konditioniertem Medium}

Zur Herstellung konditionierten Mediums wurden Gliomzellen wie beim Umsetzen in einer $75 \mathrm{~mm}^{2}$ Flasche ausgesät. Nach $48 \mathrm{~h}$ wurde das Medium abgesaugt, die Zellen 1x mit PBS gewaschen und $10 \mathrm{ml}$ Zellkulturmedium ohne Zusätze auf die Zellen gegeben. $24 \mathrm{~h}$ später wurde das Medium abgenommen, bei $4^{\circ} \mathrm{C}$ mit 3113 g 10 min zentrifugiert und der Überstand in ein frisches Röhrchen pipettiert. Bis zur Verwendung konnte das Medium bei $-80^{\circ} \mathrm{C}$ zwischengelagert werden. Zur Bestimmung der Zellzahl wurden die Zellen in der Kulturflasche trypsiniert, geerntet und im Partikelzähler gezählt.

Zum Aufkonzentrieren des konditionierten Überstandes wurden $10 \mathrm{ml}$ mit Centricon Konzentrationsfilterröhrchen durch $1,5 \mathrm{~h}$ Zentrifugation bei $4^{\circ} \mathrm{C}$ und $3113 \mathrm{~g}$ aufkonzentriert. Das aufkonzentrierte Medium wurde bis zur Verwendung bei $-80^{\circ} \mathrm{C}$ eingefroren.

\subsubsection{Sphäroide}

In der Mikrowelle wurde 10\%ige Agarose aufgekocht und unter der Sterilbank in eine Wanne auf einer $50^{\circ} \mathrm{C}$ warmen Heizplatte gegossen. Mit der Mehrkanalpipette wurden die Wells einer 96 well Platte mit je $50 \mu$ l Agarose bestückt. Die Platten wurden zum Auskühlen 2 h unter der Sterilbank stehen gelassen.

Die Tumorzellen einer $80 \%$ konfluenten Zellkulturflasche wurden geerntet (s. 2.2.2) und mit dem Partikelzähler gezählt. Dann wurde die Zellzahl auf 500000 Zellen/20 ml Medium eingestellt und davon $100 \mu \mathrm{l}$ mit 2500 Zellen pro Well in die mit Agarose vorbereiteten Platten ausgesät.

Nach vier Tagen, als sich Sphäroide gebildet hatten, wurden 5000 Peritonealmakrophagen in $100 \mu \mathrm{l}$ Medium zu den Sphäroiden pipettiert. In die Wells wurden entweder nur Makrophagen, oder Makrophagen, in deren Medium sich 25 ng TGF$\beta 2 / \mathrm{ml}$ befand, gegeben.

Nach drei Tagen wurde der Zustand der Sphäroide unter dem Auflichtmikroskop begutachtet und dokumentiert.

\subsubsection{Western-Blot-Analyse}

Die Bindung von AF680 1D11 an TGF- $\beta$ wurde mittels Western-Blot getestet. Diese Methode umfasst die Proteingelelektrophorese (SDS-PAGE nach Laemmli), den Transfer der Proteine auf eine Membran sowie die Immundetektion. 


\section{Gießen des Proteingels}

Zuerst wurde das mit Ethanol gereinigte Glasplattenset zusammengebaut. Für ein 15 \%iges Polyacrylamidgel wurden 2,3 ml Aqua dest., $5 \mathrm{ml} 30 \%$ Acrylamid-Mix und 2,5 ml 1,5 M Tris (pH 8,8) zusammen in einen Erlenmeyerkolben gegeben.

Die Lösung wurde 3 min entgast und anschließend 0,1 $\mathrm{ml} 10 \%$ SDS, 0,1 $\mathrm{ml} 10 \%$ APS und $4 \mu \mathrm{l}$ TEMED zugegeben. Das fertige Gel wurde vorsichtig mit Aqua dest. überschichtet und bei $4^{\circ} \mathrm{C}$ im Kühlschrank aufbewahrt. Am nächsten Tag wurde die Lösung für ein $5 \%$ Sammelgel angesetzt (2,1 ml Aqua dest., 0,5 ml 30\% Acrylamid-Mix, $0,38 \mathrm{ml} 1 \mathrm{M}$ Tris (pH 6,8), 0,03 $\mathrm{ml} 10 \%$ SDS, 0,03 $\mathrm{ml} 10 \%$ APS und $3 \mu 1$ TEMED), das Wasser vom Trenngel abgegossen, das Sammelgel vorsichtig auf das Trenngel gegossen und der Kamm eingesetzt. Nach etwa 40 min Polimerisationszeit konnte das Gel in die Gelkammer eingebaut und die Kammer mit 1x Laufpuffer aufgefüllt werden. Unter Puffer wurde der Kamm gezogen und die Taschen gespült.

\section{Proben vorbereiten}

$500 \mu \mathrm{l}$ aufkonzentriertes Medium von U87MG Zellen (s. 2.2.2.2) wurde mit $5 \mu 1$ Agarose AG Plus für $40 \mathrm{~min}$ bei $4^{\circ} \mathrm{C}$ vorinkubiert, um unspezifisch an die Agarose bindende Proteine aus dem Medium zu entfernen. Anschließend wurde zentrifugiert (5 min, $600 \mathrm{~g}$, $\left.4^{\circ} \mathrm{C}\right)$, das überstehende Medium $(450 \mu \mathrm{l})$ in ein frisches Reagiergefäß überführt und $1 \mathrm{~h}$ bei $37^{\circ} \mathrm{C}$ mit $64 \mathrm{ng}$ AF680 1D11 (0,5 $\left.\mu 1,1,27 \mathrm{mg} / \mathrm{ml}\right)$ inkubiert. Dabei wurde von U87MG Zellen ins Medium sezerniertes TGF- $\beta 2$ gebunden. Anschließend wurden erneut $10 \mu 1$ Agarose AG Plus zugegeben und über Nacht (ü.N.) bei $4^{\circ} \mathrm{C}$ im Roller inkubiert, wobei der Antikörper, der zuvor TGF- $\beta$ gebunden hat an die Agarose binden konnte.

Alle weiteren vorbereitenden Schritte wurden auf Eis durchgeführt. Nach Zentrifugation ( 5 min, $600 \mathrm{~g}, 4^{\circ} \mathrm{C}$ ) wurde das Medium abgesaugt, 3 x mit $400 \mu 1$ PBS gewaschen, in $30 \mu 1$ Probenpuffer aufgenommen und 5 min gekocht. Danach wurde sofort auf Eis abgekühlt und kurz zentrifugiert. Durch die Nutzung des Agarose AG Plus-Pellets ist in der Probe nur TGF- $\beta$, dass an den Antikörper gebunden hat.

\section{SDS-Gelelektrophorese}

$15 \mu 1$ der vorbereiteten Probe wurde mit einer Hamilton Spritze auf das Gel aufgetragen. Die Elektrophorese erfolgte in 1x Laufpuffer bei $60 \mathrm{~V}$ bis der Farbmarker im Trenngel angekommen war und anschließend bei $130 \mathrm{~V}$. Nach 1,5 h wurde das Gel vorsichtig aus der Apparatur genommen und 15 min in Blotpuffer äquilibriert.

\section{Transfer auf eine Membran (Semi-Dry Blot)}

Die Immobilan-P Membran wurde auf Gelgröße $(8,5 \mathrm{~cm}$ x 5,5 cm) zugeschnitten. Dann wurde sie zur Benutzung $3 \mathrm{~s}$ in $100 \%$ Methanol eingetaucht und danach $15 \mathrm{~min}$ in 
Blotpuffer äquilibriert. Auch auf Gelgröße geschnittenes Whatman-Filterpapier wurde 15 min in Blotpuffer äquilibriert. Für den Protein-Transfer wurden 3 Lagen Filterpapier auf die untere Platte (Anode) einer Blotkammer gelegt und darüber die Immobilion-P Membran, das Gel und abschließend wieder drei Lagen Filterpapier. Luftblasen zwischen den Schichten wurden durch vorsichtiges Rollen mit einer Pipette über das Sandwich entfernt, der Deckel mit der Deckplatte aufgesetzt und die Apparatur an das Spannungsgerät angeschlossen. Die Proteine wurden $1 \mathrm{~h}$ mit $0,8 \mathrm{~mA} / \mathrm{cm}^{2} \quad(37 \mathrm{~mA} / \mathrm{Gel})$ auf die Membran geblottet.

Immundetektion

Nach dem Transfer wurde die Membran 2 min bei RT in 0,5\% Ponceau S-Lösung $(0,5 \mathrm{~g}$ Ponceau $\mathrm{S}$ in $1 \mathrm{ml}$ Eisessig lösen, ad $100 \mathrm{ml}$ Aqua dest.) inkubiert und anschließend 4x 2 min mit Aqua dest. entfärbt.

Zum Blocken unspezifischer Bindungsstellen wurde die Membran $1 \mathrm{~h}$ bei RT in Blockpuffer geschwenkt, bevor sie ü.N. bei $4^{\circ} \mathrm{C}$ mit dem primären Antikörper (wieder AF680 1D11 -1:250 Verdünnung) in Antikörper-Puffer inkubiert wurde.

Am nächsten Tag wurde die Membran 3x 7 min mit je $12 \mathrm{ml}$ Waschpuffer gewaschen, dann für $1 \mathrm{~h}$ bei RT mit dem sekundären Antikörper (Schaf anti-Maus IgG, 1:7000 Verdünnung) in Block-Puffer inkubiert. Zum Schluss wurde die Membran noch 3x 15 min mit je $12 \mathrm{ml}$ Waschpuffer gewaschen.

Um die mit dem primären Antikörper reagierenden Protein-Banden zu detektieren, wurde die Membran zuerst $1 \mathrm{~min}$ bei RT in $0,125 \mathrm{ml} / \mathrm{cm}^{2}$ frisch angesetztem ECL-Reagenz (Lösungen 1 und 2, western blotting detection reagents; 1:1) inkubiert. Dann wurde sie in Frischhaltefolie eingeschlagen für eine Belichtungszeit von 2 min auf einen Film gelegt, der anschließend entwickelt wurde. Die auf dem Film belichteten Banden repräsentieren das TGF- $\beta$ welches der primäre Antikörper spezifisch gebunden hat.

\subsubsection{ELISA (enzyme-linked immunosorbent assay)}

Der „Human TGF- $\beta 2$ Immunoassay“ Kit wurde eingesetzt, um die Menge des von Zellen ins Medium sezernierten TGF- $\beta 2$ zu ermitteln. Hierzu wurde aufkonzentriertes, konditioniertes Medium (s.2.2.2.2) als Probe verwendet. Zur Hintergrundkontrolle wurde aufkonzentriertes Medium, in dem zuvor keine Zellen inkubiert wurden mitgeführt.

Vorbereitend musste das in den Proben enthaltene TGF- $\beta$ aktiviert werden, um es in die immunoreaktive Form zu bringen. Dies geschah in einem Polypropylen-Reagiergefäß. Dazu wurden zu $125 \mu$ Probenvolumen $25 \mu 11 \mathrm{~N} \mathrm{HCl}$ pipettiert, gut gemischt und $10 \mathrm{~min}$ bei RT inkubiert. Danach wurden erst $25 \mu 1$ 1,2 N NaOH/0,5 M HEPES und nach gutem Mischen $800 \mu \mathrm{l}$ des im Kit enthaltenen Calibrator Diluent RD5I zugegeben. Mit TGF- $\beta 2$ aus dem Kit wurde eine Standard-Eichreihe in Calibrator Diluent RD5I hergestellt. 
Der Kit enthielt alle im Folgenden benötigten Lösungen, Klebefolie, einen in einen Microplate Reader passenden Rahmen und 96 Wells, die in den Rahmen eingespannt werden konnten. Der Boden der Wells war mit monoklonalen TGF- $\beta 2$ spezifischen Antikörpern gecoatet.

Zur Durchführung wurden $100 \mu 1$ Standard oder aktivierte Probe pro Well pipettiert, die Wells mit Klebefolie zugeklebt und $2 \mathrm{~h}$ bei RT inkubiert. In dieser Zeit konnten die Antikörper in der Probe enthaltenes TGF- $\beta 2$ binden. Danach wurden die Proben durch Umdrehen der Platte und leichtes Klopfen auf Zellstoff entfernt und die Wells mit Hilfe einer Mikroplate-Waschapparatur 3x mit Waschpuffer gewaschen.

Nach dem letzten Waschschritt wurde der Waschpuffer auf frischem Zellstoff besonders gründlich abgeklopft, bevor $200 \mu 1$ TGF- $\beta 2$ Conjugat in jedes Well pipettiert wurden. Das Conjugat ist ein mit einem Enzym gekoppelter polyklonaler TGF- $\beta 2$ bindender Antikörper. Dieser sollte an das am Wellboden gebundene TGF- $\beta 2$ binden und so die Enzyme dort befestigen. Wieder wurden die Wells mit Klebefolie zugeklebt und für $2 \mathrm{~h}$ bei RT inkubiert. Anschließend wurde das TGF- $\beta 2$ Conjugat entfernt und die Wells wie zuvor $3 \mathrm{x}$ mit Waschpuffer gewaschen. Von der Substratlösung wurden $200 \mu$ in jedes Well pipettiert und im Dunkeln für 20 min inkubiert. In dieser Zeit wurde das Substrat von den Enzymen am Wellboden in einer Farbreaktion umgesetzt. Die Farbentwicklung ist proportional zur Menge des initial durch den monoklonalen Antikörper gebundenen TGF$\beta 2$ aus der Probe.

Um die Farbreaktion $\mathrm{zu}$ beenden, wurden $50 \mu \mathrm{l}$ Stopplösung $\mathrm{zu}$ den $200 \mu \mathrm{l}$ Substratlösung pipettiert. Danach wurde innerhalb von $30 \mathrm{~min}$ im MikrotiterplattenLesegerät die optische Dichte (OD) bei einer Wellenlänge $450 \mathrm{~nm}$ gegen eine Referenzwellenlänge von $570 \mathrm{~nm}$ gemessen.

Aus den mit der Standard-Eichreihe ermittelten OD-Werten wurde eine Eichgerade erstellt, indem die OD gegen die TGF- $\beta 2$-Konzentration aufgetragen wurde. Mittels der Geradenfunktion konnte die Konzentration der aktivierten Probe berechnet werden (X pg/100 $\mu$ 1). Die Konzentration in der originalen Probe war 7,8 Mal so hoch, da die Proben zur Aktivierung verdünnt wurden $(7,8 \times$ X pg/100 $\mu 1)$. Der ermittelte Hintergrundwert des reinen Mediums wurde nun von den ermittelten Probenwerten subtrahiert. Da es sich um konzentriertes Medium handelte, musste umgerechnet werden, wie viel unkonzentriertes Medium $100 \mu$ konzentriertem Medium entsprechen. Nach der Umrechnung der TGF- $\beta 2-$ Konzentration auf pg/ml wurde ein Bezug zu der Zellzahl hergestellt, die nach Abnahme des Mediums ermittelt worden war. 


\subsubsection{In vivo Experimente}

Um hormonellen Einflüssen auf die Versuchsergebnisse vorzubeugen wurden ausschließlich männliche Tiere für die Versuche eingesetzt. Alle Tierexperimente wurden in Übereinstimmung mit dem deutschen Tierschutzgesetz durchgeführt. Die Tierversuche wurden nach den geltenden Richtlinien durchgeführt und unter den Projektnummern 33.42502/01-50.05 und 33.42502/01-17.03 bei der zuständigen Behörde für Verbraucherschutz und Lebensmittelsicherheit in Braunschweig genehmigt. Ratten wurden einzeln, Mäuse zu viert unter sterilen Bedingungen bei $22^{\circ} \mathrm{C}, 55 \%$ Luftfeuchtigkeit und 12 h Tag-Nacht-Rhythmus in Käfigen unter Filterhauben gehalten. Immundefiziente Mäuse bekamen angesäuertes Wasser ( $\mathrm{pH}$ 2,5). Tiere mit s.c. Tumoren bekamen fluoreszensarmes GLP Nafag feed 890 (Provimi Kliba AG, Kaiseraugst), die übrigen Ratten und Mäuse erhielten Leitungswasser und Standartdiät (V1534-000, Fa. Sniff, Soest, Germany). Käfige, Einstreu und Wasser wurden autoklaviert, das Futter bestrahlt. Während der Versuche wurden die Bedingungen für die Tiere möglichst konstant gehalten. Die Versuchstiere für einen Versuch stammten aus einer Linie und hatten möglichst ähnliche Gewichte. In einem Käfig waren Mäuse aus jeder Versuchsgruppe zusammen. Die operativen Eingriffe und Tumorzellimplantationen wurden so identisch wie möglich durchgeführt.

\subsubsection{Tiere}

Für Versuche zur HG-vermittelten Öffnung der BHS ohne Tumorzellimplantation wurden Ratten und Mäuse verwendet.

- Fischer 344-Ratten

- NMRI-Mäuse

Tumortragende Tiere waren

- Fischer 344-Ratten, die syngene RG2-Glioblastomzellen intrazerebral implantiert bekamen

- Black/6 Mäuse, die syngene GL261-Glioblastomzellen intrazerebral oder s.c. implantiert bekamen

- immundefiziente CD-1 nu/nu Mäuse, die humane U87MG Glioblastomzellen, oder GL261-Glioblastomzellen s.c. implantiert bekamen

Es wurden vier unterschiedliche Versuchsreihen durchgeführt, in denen tumortragende Mäuse mit 1D11 behandelt wurden:

A) S.c. Implantation von humanen U87MG Gliomzellen in immundefiziente CD-1 nu/nu-Mäuse (Xenograft-Modell).

B) S.c. Implantation von murinen GL261 Gliomzellen in immunkompetente Black/6 Mäuse (syngenes Modell). 
C) S.c. Implantation von murinen GL261 Gliomzellen in immundefiziente CD-1 nu/nu-Mäuse (Xenograft-Modell).

D) Intrazerebrale Implantation von murinen GL261 Gliomzellen in immunkompetente Black/6 Mäuse (syngenes Modell).

\subsubsection{Subkutane Tumore}

Für die Versuchsreihen A) bis C) wurden Mäuse in einer kleinen Kammer mit einem 1 \% Isofluoran-Sauerstoff Gasgemisch narkotisiert. Mit Hilfe einer kleinen Maske, über die den Tieren das Gasgemisch zugeführt wurde, wurde die Narkose aufrecht erhalten. Die zuvor geernteten und auf Eis liegenden Zellen wurden gleichmäßig resuspendiert und $1 \times 10^{6}$ Tumorzellen in $100 \mu \mathrm{l}$ PBS mit einer $20 \mathrm{G}$ Kanüle in eine $1 \mathrm{ml}$ Einwegspritze aufgezogen. Die Einstichstelle wurde desinfiziert und die Kanüle unter dem rechten Rippenbogen beginnend unter der Haut Richtung Lende vorgeschoben. Hier wurden die Tumorzellen unter leichtem Druck mit dem Finger auf die Nadel oberhalb der Kanülenöffnung implantiert und anschließend die Nadel vorsichtig wieder gezogen. Der Druck mit dem Finger wurde noch eine Minute aufrecht erhalten, um das Zurückfließen der Tumorzellsuspension im Implantationskanal $\mathrm{zu}$ verhindern. Wenige Minuten nach Entfernen der Maske erwachten die Tiere und wurden noch 30 min unter einer Wärmelampe beobachtet.

Die Tiere der Versuchsreihe A1) mit in vivo-Messung der Anreicherung von AF680 1D11 im Tumor wurden am 7. Tag nach Implantation zufällig in drei Versuchsgruppen aufgeteilt und wie folgt behandelt:

1. i.v.-Behandlung mit 4,8 mg/kg KG 1D11 AF680 1D11 in einem Volumen von $100 \mu \mathrm{NaCl}$ 0,9\% an Tag 7, 11, 14, 18 und 25 nach Implantation.

2. Kontrolle mit i.v.-Behandlung mit 4,8 mg/kg KG 13C4 (oder AF680 1D11) in einem Volumen von $100 \mu \mathrm{NaCl}$ 0,9\% an Tag 7, 11, 14, 18 und 25 nach Implantation.

3. Kontrolle ohne Behandlung.

Die Tiere der Versuchsreihen A2) bis C) wurden am 7. Tag nach Implantation zufällig in drei Versuchsgruppen aufgeteilt und wie folgt behandelt:

1. i.v.-Behandlung mit 4,8 mg/kg KG $1 \mathrm{D} 11$ in einem Volumen von $100 \mu 1 \mathrm{NaCl}$ 0,9\% an Tag 7, 10, 14, 17, 21 und 28 nach Implantation.

2. Kontrolle mit i.v.-Behandlung mit 4,8 mg/kg KG $13 \mathrm{C} 4$ in einem

Volumen von $100 \mu 1 \mathrm{NaCl}$ 0,9\% an Tag 7, 10, 14, 17, 21 und 28 nach Implantation.

3. Kontrolle ohne Behandlung. 
Die Tumorgröße der Mäuse wurde an Tag 7, 10, 14, 17, 21, 24, 28, 31 und 35 nach Implantation gemessen. Dazu wurde mit einer Schiebelehre die Länge, Breite und Höhe des Tumors unter der Haut gemessen. Das Tumorvolumen wurde mittels der Formel: 4/3 $\pi$ abc berechnet, wobei a, b und c die Halbachsen der Länge, Breite und Höhe sind.

Das maximal erlaubte Tumorvolumen s.c. Tumoren ist $1000 \mathrm{~mm}^{3}$. Die Versuchsreihen wurden beendet, sobald die ersten Tumoren dieses Volumen erreicht hatten. Daher wurden die Tiere der Versuchsreihe je nach Wachstumsgeschwindigkeit der Tumoren in den unterschiedlichen Versuchsreihen um Tag 21 oder 35 nach Tumorzellimplantation mittels einer Narkoseüberdosis (Ketamin/Rompun) getötet. Die Tumoren wurden stumpf präpariert, gewogen, fotografiert und durchgeschnitten.

Die eine Hälfte wurde für eine Stunde in Tissue Tec im Kühlschrank inkubiert, bevor sie in frischem Tissue Tec eingebettet, auf flüssigem Stickstoff eingefroren und bei $-20^{\circ} \mathrm{C}$ gelagert wurde. Die andere Hälfte wurde in PFA 4 \% ü.N. fixiert und so für die Einbettung in Paraffin vorbereitet.

\subsubsection{Intrazerebrale Tumoren}

Sowohl Black/6-Mäusen für Versuchsreihe D) als auch Black/6-Mäusen, nu/nu-Mäusen und Fischer-Ratten für Versuche zur BHS-Öffnung wurden Tumorzellen intrazerebral implantiert.

Ratten wurden intraperitoneal mit $90 \mathrm{mg} \mathrm{kg}^{-1} \mathrm{KG} /$ 7,5 $\mathrm{mg} \mathrm{kg}^{-1} \mathrm{KG}$ und Mäuse mit 85 $\mathrm{mg} \mathrm{kg}{ }^{-1} \mathrm{KG} / 7 \mathrm{mg} \mathrm{kg}{ }^{-1} \mathrm{KG}$ eines Ketamin/ Rompun-Gemisches narkotisiert. Narkotisierten Ratten wurde das Fell auf dem Kopf möglichst kurz geschnitten. Behaarte Mäuse wurden mit Hilfe zurechtgeschnittener Stücke von Kaltwachsstreifen im Bereich der Schädeldecke enthaart. Dann wurde die Kopfhaut längs der Sagittalnaht inzidiert. Das Periost wurde auf der rechten Schädelhälfte mit einem Skalpell zur Seite geschoben. Bei Ratten wurde nun unter dem Stereooperationsmikroskop mit einem zahntechnischen Bohrer $1 \mathrm{~mm}$ rostral und $3 \mathrm{~mm}$ lateral rechts des Bregmas, bei Mäusen $1 \mathrm{~mm}$ rostral und 2 mm lateral rechts ein Loch mit einen Durchmesser von $\sim 1 \mathrm{~mm}$ gebohrt. Dabei sollte die Dura mater möglichst unverletzt bleiben. Bei Ratten wurde die Dura mater mit einer spitzen Pinzette vorsichtig eröffnet. Anschließend wurde der Kopf der Tiere in einem Stereotaxiegerät so fixiert, dass die Schädeldecke horizontal lag. Die zuvor geernteten und auf Eis liegenden Zellen wurden gleichmäßig resuspendiert und $10 \mu \mathrm{l}$ luftblasenfrei in einer $10 \mu 1$ Spritze mit einer schräg geschliffenen Kanüle aufgezogen. Diese wurde so in eine Vorrichtung am Mikromanipulator des Stereotaxiegerätes befestigt, dass die Nadel senkrecht zur Schädelfläche, mit der Kanülenöffnung nach rechts lateral steht. Anschließend wurde das ins Gehirn zu bringende Suspensionsvolumen justiert. Die Nadel wurde nun auf die Dura mater abgesenkt und anschließendbei Ratten zunächst $5 \mathrm{~mm}$ und 
bei Mäusen 3,5 mm tief ins Gehirn gebracht, um ein Reservoir zu Schaffen. Dann wurde sie um 0,5 mm zurückgezogen. Nun wurden bei Ratten 7,5 $\mu 1$ und bei Mäusen $5 \mu 1$ Zellsuspension langsam ins Gehirn injiziert. Bei Ratten wie Mäusen wurden 75000 Gliomzellen ins Gehirn eingebracht (

Abbildung 3). Bei Ratten wurde die Kanüle nach 4 min, bei Mäusen nach 3 min unter Spülung der Schädelkalotte mit $\mathrm{NaCl}$ 0,9 \% schnell mit dem Mikromanipulator wieder angehoben. Die Schnittwunde wurde mit 5-7 Einzelknopfnähten verschlossen und desinfiziert. Als Schmerztherapie erhielten die Mäuse s.c. 0,2 $\mathrm{mg} \mathrm{kg}^{-1} \mathrm{KG}$ Rimadyl. Zum schnelleren Erwachen wurde den Tieren $5 \mathrm{mg} \mathrm{kg}^{-1} \mathrm{KG}$ Antisedan $^{\circledR}$ s.c. gespritzt. Anschließend wurden die Tiere 1-2 h unter einer Wärmelampe beobacht. Im weiteren Verlauf wurden die Tiere täglich untersucht.

Die Versuche wurden spätestens beendet, wenn ein Gewichtsverlust von über $20 \%$ zum Ausgangsgewicht oder schwere Krankheitszeichen wie Adynamie, Entzündungen der Nase oder Augen, struppiges Fell oder Apathie (Zeichen eines vermehrten Gehirndrucks durch das Wachstum des Tumors) festgestellt wurden.

Die Tiere der Versuchsreihe D) wurden an Tag 3 nach Implantation zufällig in drei Versuchsgruppen aufgeteilt und wie folgt behandelt:

1. i.v.-Behandlung mit 4,8 mg/kg KG 1D11 (n=4) (oder AF680 1D11, n=4) in einem

Volumen von $100 \mu \mathrm{l} \mathrm{NaCl} 0,9 \%$ an Tag 3, 6, 10, 13 und 17 nach Implantation.

2. Kontrolle mit i.v.-Behandlung mit 4,8 mg/kg KG 13C4 (n=3) (oder AF680 13C4, n=3)

in einem Volumen von $100 \mu \mathrm{NaCl} 0,9 \%$ an Tag 3, 6, 10, 13 und 17 nach Implantation.

3. Kontrolle ohne Behandlung $(n=6)$.

Die Tiere wurden an Tag 25 oder 26 nach Tumorzellimplantation mit einer Narkoseüberdosis in tiefe Narkose gelegt. Kurz vor dem Herzstillstand wurde das Tier auf der Ventralseite aufgeschnitten, der linke Ventrikel des Herzens punktiert, der rechte Vorhof eröffnet und mit geringem Druck ca. $50 \mathrm{ml}$ kaltes PBS infundiert. Das perfundierte Gehirn wurde vom Kleinhirn her frei präpariert, entnommen und 2 Tage in PFA $4 \%$ fixiert.

Bei Versuchen mit HG wurde die BHS geöffnet, wie unter 2.2.3.5 beschrieben. 


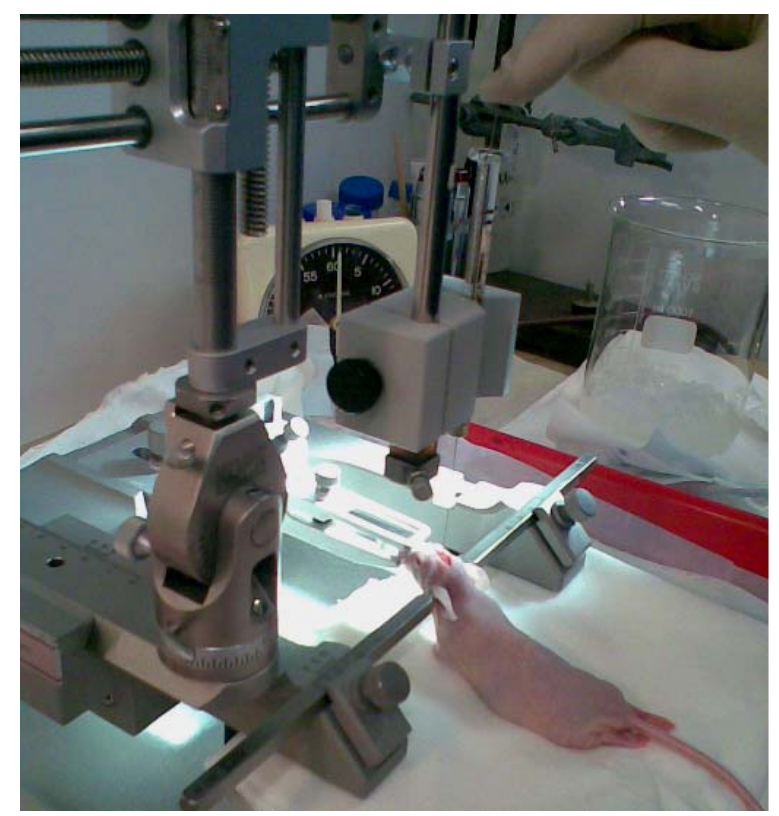

Abbildung 3: Im Stereotaxieaparat eingespannte nu/nu-Maus, der mittels einer Hamilton Spritze U87MG Tumorzellen in die rechte Hemisphäre implantiert werden.

\subsubsection{Intravenöse Applikation}

Die Tiere wurden vor i.v.-Applikation mittels eines 1\%igen Isofluran-SauerstoffGasgemisches narkotisiert und die Schwanzvenen durch Eintauchen des Schwanzes in warmes Wasser geweitet. Dann wurde mit einer 0,5 $\mathrm{ml}$ Insulinspritze die rechte oder linke Schwanzvene punktiert und die zu verabreichende Substanz langsam injiziert.

\subsubsection{Blut-Hirn-Schranken-Öffnung}

Die Mäuse wurden zu Versuchsbeginn durch eine intraperitoneale Gabe eines Ketamin/ Rompun-Gemisches narkotisiert (s. 2.2.2.1). Nach einer halben Stunde wurde die halbe Dosis noch einmal verabreicht. Sobald die Tiere tief in Narkose lagen, wurden sie in Rückenlage auf einem Wärmebett $\left(37^{\circ} \mathrm{C}\right)$ fixiert. Das Fell um die Eingriffsstelle wurde möglichst kurz geschnitten und die Haut desinfiziert. Unter Sicht durch ein Operationsstereomikroskop wurde von ventral her die rechte A. carotis communis im Bereich der Bifurkation mit den Ansätzen der A. carotis interna und der A. carotis externa präpariert. Alle abzweigenden Gefäße der A. carotis externa nahe der Bifurkation wurden ligiert. In die A. carotis externa nahe der Bifurkationsstelle wurde retrograd zum Blutfluss ein selbst gemachter Glaskatheter eingelegt. Dieser wurde mit rückfließendem Blut gefüllt und über ein Anschlussstück luftblasenfrei mit einem PVC-Schlauch verbunden. Dieser wurde zuvor ebenfalls luftblasenfrei mit dem zu verabreichenden Volumen HG-Lösung gefüllt und an eine Hamilton-Pumpe angeschlossen. Über die Pumpe wurden in Ratten 
$1200 \mu 1$ und in Mäusen $300 \mu \mathrm{l}$ isoosmolare HG-Lösung innerhalb von $18 \mathrm{~s}$ gleichmäßig in die A. carotis interna injiziert. Während der Injektion wurde die Blutzufuhr aus der A. carotis communis mit einer Klemme unterhalb der Bifurkation unterbrochen. Somit wurde die HG-Lödung pur in die A. carotis interna gespült. Nach der HG-Gabe wurde der Katheter wieder mit zurückfließendem Blut gefüllt und an einen weiteren Schlauch, der luftblasenfrei mit der ins Gehirn zu bringenden Substanz gefüllt war, angeschlossen. In Ratten waren diese Substanzen in $1000 \mu$, bei Mäusen in $100 \mu 1 \mathrm{PBS}$ oder $\mathrm{NaCl} 0,9 \%$ gelöst. 5 min nach der HG-Applikation wurde die jeweilige Substanz in einer 10 min Kurzinfusion mittels einer Infusionspumpe verabreicht (

Abbildung 4). Am Ende wurde die A. carotis externa abgebunden und der Katheter entfernt. Bei Kurzzeitversuchen wurde etwa 20 min nach Ende der Kurzinfusion eine Narkoseüberdosis verabreicht. Das Gehirn wurde vom Kleinhirn aus frei präpariert, entnommen und sofort in $\sim-50^{\circ} \mathrm{C}$ kaltem, flüssigem 2-Methylbutan eingefroren.

Bei Langzeitversuchen wurde die Operationsstelle mit Einzelknopfnähten geschossen. Zum schnelleren Erwachen wurde den Tieren 5 mg kg-1 KG Antisedan s.c. gespritzt. Anschließend wurden die Tiere 1-2 h unter einer Wärmelampe beobachtet.

Alle Lösungen wurden am Versuchstag frisch angesetzt, steril filtriert und im Wasserbad auf $37^{\circ} \mathrm{C}$ vorgewärmt. Bei Versuchen mit einer mehrtägigen Beobachtungszeit der Tiere erfolgte eine tägliche kurze Untersuchung der Versuchstiere. Behaarte NMRIMäuse, bei denen Fluoreszenzintensitäten im eXplore Optix gemessen werden sollten, wurden unter Narkose vor der Operation mit zurechtgeschnittenen Stücken von Kaltwachsstreifen im Bereich der Schädeldecke enthaart.

Am Versuchsende wurden die Tiere mit einer Narkoseüberdosis getötet. Das Gehirn wurde wie bei Kurzzeitversuchen entnommen und in cirka $-50^{\circ} \mathrm{C}$ kaltem, flüssigem 2Methylbutan eingefroren. 

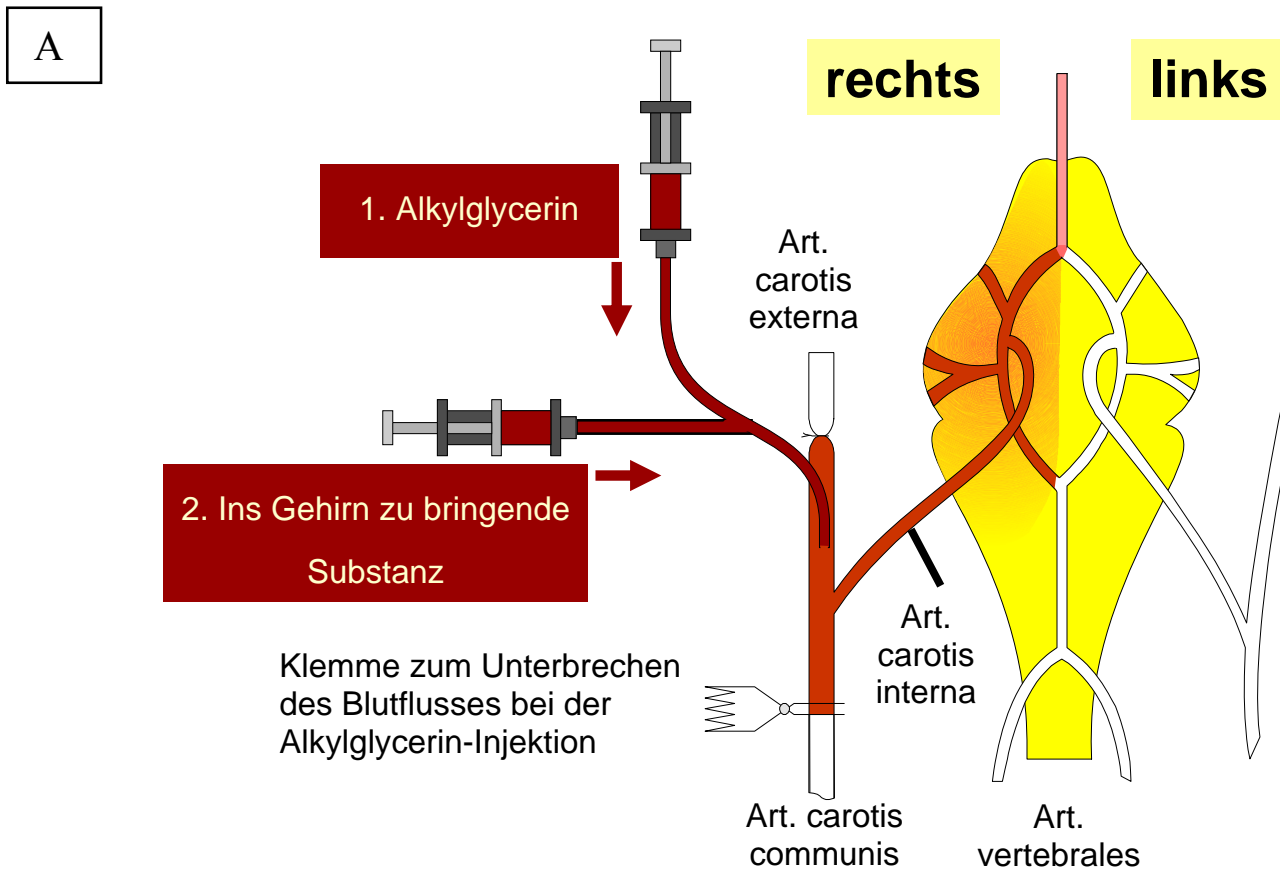

$\mathrm{B}$

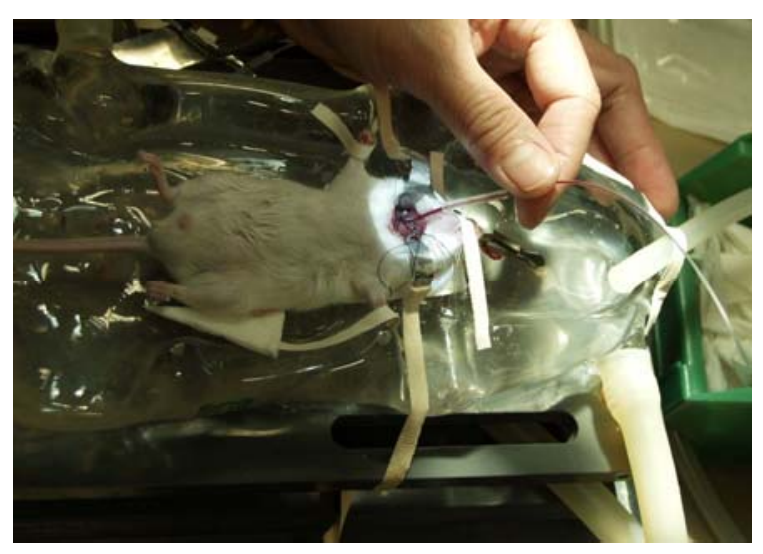

Abbildung 4: A) Foto und B) grafische Darstellung des experimentellen Aufbaus zur Öffnung der BHS. (Abbildung modifiziert nach Takasato et al. 1984)

\subsubsection{Fluoreszenzmessungen mit dem eXplore Optix System}

Mit dem eXplore Optix System (ART) wurden im Nahinfrarotbereich fluoreszierende Chromophore dargestellt. Die verwendeten Fluoreszenzfarbstoffe waren Cy5.5 und AF680. Beide Farbstoffe haben etwa gleiche Anregungs- und Emmissionsmaxima (Abbildung 5). Das Anregungsmaximum liegt für Cy5.5 bei $679 \mathrm{~nm}$ und für AF680 bei $684 \mathrm{~nm}$. Das Emissionsmaximum liegt für Cy5.5 bei $696 \mathrm{~nm}$ und für AF680 bei $707 \mathrm{~nm}$. Die Tiere wurden für die Messungen mittels eines 1\%igen Isofluoran -Sauerstoff-Gasgemisches immobilisiert. Der Tiertisch in dem Gerät war immer so eingestellt, dass der Abstand zwischen Zielgewebe und Detektor gleich war. 
AF680 wurde an die Antikörper 1D11 und 13C4 gekoppelt (s. 2.1.7) und Cy5.5 an $\gamma$ Globulin (s. 2.2.1). Sowohl in lebenden Tieren als auch ex vivo in zuvor entnommenen Gehirnen wurde die Fluoreszenz detektiert.

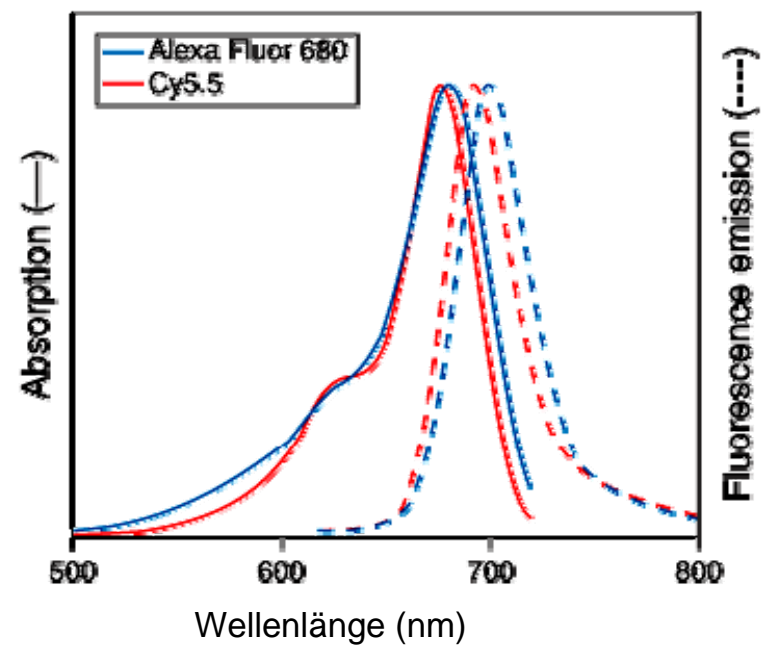

Abbildung 5: Vergleich der Fluoreszenzspektra von AF680 und Cy5.5

Tabelle 2: Filtereinstellungen des eXplore Optix für die Anregung und Messung der Fluoreszenz der Farbstoffe Cy5.5 und AF680

\begin{tabular}{|l|l|l|}
\hline $\begin{array}{l}\text { Filterrad-A } \\
\text { (Anregung) }\end{array}$ & $\begin{array}{l}\text { Filterrad-B } \\
\text { (Detektion) }\end{array}$ & Optimiert für: \\
\hline $665 \mathrm{~nm}-$ BP10 & $693 \mathrm{~nm}-$ LP & Cy5.5 \\
\hline
\end{tabular}

Das „optical imaging“-System scannt im Rastermodus mit einer Distanz von mindestens 0,5 mm zwischen zwei Messpunkten (Abbildung 6, A). Während der Messung wird jeder Messpunkt für eine bestimmte Zeit (Integrationszeit) mit kurzen Laser-Impulsen mit einer Wellenlänge von $670 \mathrm{~nm}$ bestrahlt. Die Zeit zwischen der Anregung und der Detektion des vom Gewebe ausgehenden, durch einen 793 nm Langpass Filter geleiteten Lichts wird mit einem Zeit auflösenden Einzel-Photonen-Zähler gemessen (Abbildung 6, B). Die „temporal point spread" Funktion beinhaltet Informationen über Intensität, Tiefe und Fluoreszensanregungslebensdauer (LT) der Fluoreszenzemmission. Die Fluoreszenzintensität wird in „Counts“ angegeben. LT ist die Zeit bis zum Übergang eines Moleküls von seinem metastabilen, angeregten Zustand in den Grundzustand unter Emission eines Photons. Sie wird in Nanosekunden (ns) angegeben. 


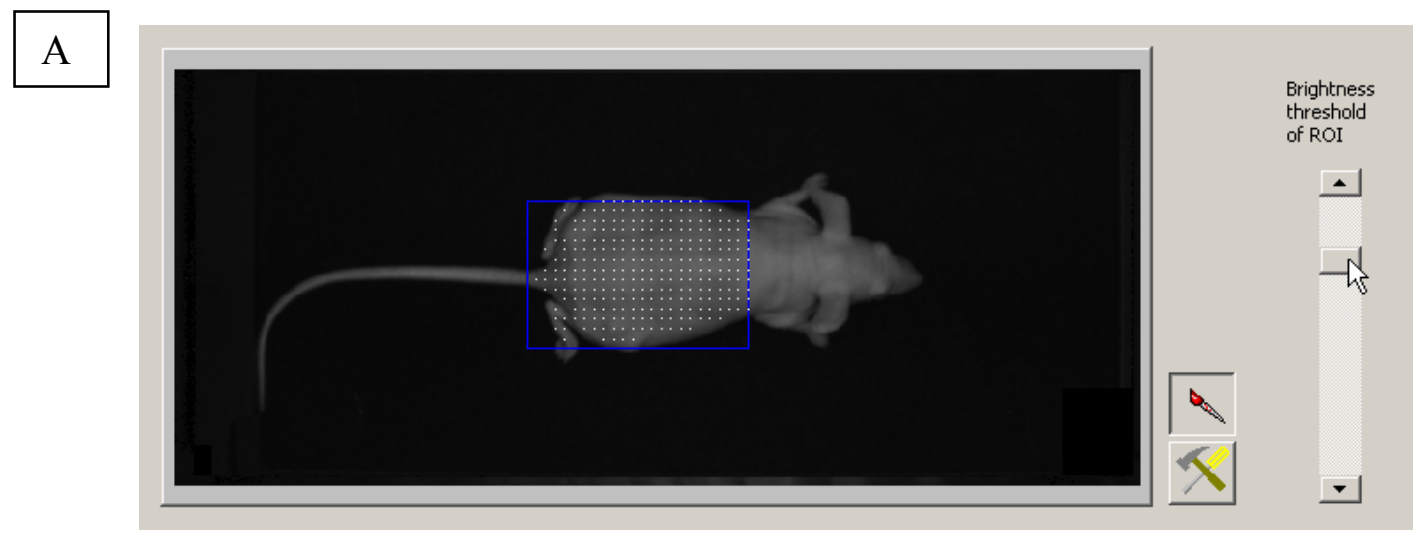

$\mathrm{B}$

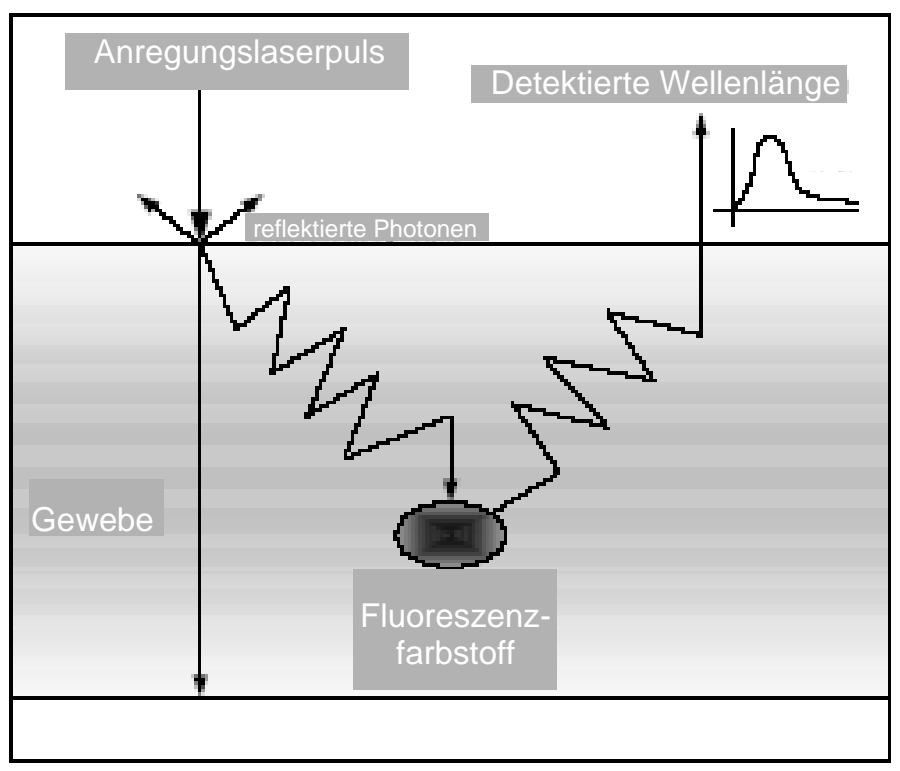

Abbildung 6: Darstellung der Rasterpunkte bei der Fluoreszenzmessung (A) und Prinzip der Messung an jedem Punkt (B).

Es wurde im Nahinfrarotbereich gemessen, da die Eigenfluoreszenz des Gewebes in diesem Lichtbereich geringer ist, als bei geringeren Wellenlängen. Die LT der Fluoreszenz des Gewebes unterscheidet sich deutlich von der des Fluorochroms. Damit kann die dennoch auftretende Autofluoreszenz von der des Fluorochroms unterschieden werden.

Die Fluoreszenz LT kann sich auch für einen Farbstoff in Abhängigkeit von Umgebungsbedingungen und Bindungen ändern.

Für die Messungen wurde die Stärke des Anregungslasers in Anpassung an die Fluoreszenzstärke variiert. Für Messungen von Cy5.5 im Gehirn lag sie zwischen 5 und 10 $\mu \mathrm{W}$, bei AF680 lag sie bei 50-100 $\mu \mathrm{W}$. In s.c. Tumoren lag die Laserstärke zur Messung von AF680 im Durchschnitt bei $150 \mu \mathrm{W}$. Die Integrationszeit blieb bei 1s. Der Abstand zwischen zwei Rasterpunkten war $1 \mathrm{~mm}$.

Die Analyse der gewonnenen Daten wurde mit der optiview 1.00.00 (ART)-Software durchgeführt. Dazu wurden die gemessenen Fluoreszenzsignale für verschiedene 
Laserstärken und Integrationszeiten normalisiert, so dass ein Vergleich der Messwerte zwischen unterschiedlichen Versuchen möglich war.

Die durchschnittliche Fluoreszenzintensität eines Areals wurde als Summe der normalisierten Counts, geteilt durch die Anzahl der Messpunkte, ermittelt. Wenn die durchschnittliche Fluoreszenzintensität über einer Hemisphäre ermittelt wurde, so wurde stets der Mittelwert der Messpunkte eines $7 \mathrm{~mm}$ x $4 \mathrm{~mm}$ großen Areals in Projektion auf der Hemisphäre ermittelt. Diese Auswertungsfläche entsprach in etwa der Größe der Hemisphäre.

\subsubsection{Gewinnung zuvor markierter Peritonealmakrophagen}

Zur selektiven Markierung von phagozytierenden Zellen wie Monozyten, Makrophagen oder Neutrophilen in vivo wurde die PKH2-PCL fluorescent cell linker compound (Zynaxis, Inc.) eingesetzt.

Zunächst wurde eine $50 \mu \mathrm{M}$ Stocklösung mit Ethanol (100\%) angesetzt. $10 \mathrm{ml}$ Diluent B wurden mit $0,05 \mathrm{ml}$ der Stocklösung gut gemischt und mindestens $15 \mathrm{~min}$ bei RT inkubiert. Für eine $30 \mathrm{~g}$ schwere Black/6 Maus wurden dann 0,75 $\mathrm{ml}$ Lösung in eine $1 \mathrm{ml}$ Einwegspritze aufgezogen. Einer Black/6 Maus wurde nach Desinfektion der Unterbauchpartie 0,75 $\mathrm{ml}$ der PKH2-Lösung intraperitoneal gespritzt, um im Tier die Makrophagen zu markieren. Nach ca. $5 \mathrm{~h}$ wurde die Maus mittels einer IsofluranÜberdosis und anschließender zervikalen Dislokation getötet und auf einer Sezierunterlage in Rückenlage fixiert. Daraufhin wurde das abdominale Fell mit 70\% Ethanol gewaschen, die Haut aufgeschnitten, ohne die Bauchmuskeln zu verletzen und diese zu den Seiten und bis zur Schulter frei präpariert. Das Fell wurde an der Seite festgesteckt. Die Bauchdecke wurde nochmals gründlich mit $70 \%$ Ethanol gewaschen.

Dann wurde mit einer $10 \mathrm{ml}$ Spritze etwa $7 \mathrm{ml}$ steriles, eiskaltes PBS in den abdominalen Bauchraum gespritzt. Das Abdomen wurde nun vorsichtig massiert, um die adherenten peritonealen Makrophagen abzulösen und die Flüssigkeit anschließend soweit möglich wieder in die Spritze aufgezogen. Der Inhalt der Spritze wurde in ein steriles 50 $\mathrm{ml}$ Röhrchen überführt und auf Eis gestellt, um das Anlagern der Makrophagen an der Gefäßwand oder Klumpenbildung zu verhindern. Der Vorgang der $7 \mathrm{ml}$ Injektion und anschließender Wiederaufnahme in die Spritze wurde nun 5-6 Mal mit frischem PBS wiederholt.

Anschließend wurden die peritonealen Makrophagen in dem $50 \mathrm{ml}$ Röhrchen bei $4^{\circ} \mathrm{C}$ für 5 min bei $350 \mathrm{x}$ g zentrifugiert, das überstehende PBS abgezogen, die Monozyten in 10 $\mathrm{ml}$ frischem PBS auf Eis resuspendiert und auf Fluoreszenz der Zellen im Auflichtfluoreszenzmikroskop überprüft. Die Zellzahl wurde mit dem Cell Coulter 
bestimmt, wie unter 2.2.2 beschrieben, nochmals zentrifugiert, das PBS abgezogen und mit Medium auf eine Verdünnung von 50000 Monozyten/ml resuspendiert. Von dieser Suspension wurden $100 \mu \mathrm{l} /$ Well mit 5000 Peritonealmakrophagen zu den Sphäroiden (s. 2.2.2.3) pipettiert.

\subsubsection{Gewebeaufbereitung}

\subsubsection{Gehirne}

Die präparierten Gehirne der Versuche zur Öffnung der BHS wurden sofort in gekühltem 2-Methylbutan bei $\sim-50^{\circ} \mathrm{C}$ eingefroren. Sie wurden bei $-20^{\circ} \mathrm{C}$ zwischengelagert und möglichst bald weiter bearbeitet. Gehirne von Tieren mit Hirntumor wurden in PFA $4 \%$ in PBS 2 Tage fixiert. Anschließend wurde das Gehirn in coronare Scheiben geschnitten (Abbildung 7). Dabei wurde der erste Schnitt auf Höhe der Tumorzellimplantationsstelle gesetzt, der zweite auf Höhe der Sehnervenkreuzung und der dritte kurz vor dem Kleinhirn. Danach wurden sie in eine Gewebekassette gelegt, in der sie $30 \mathrm{~min}$ gewässert und in einem Entwässerungsautomaten (TP 1020) ü.N. mit folgenden Schritten entwässert wurden:

$3 \times 60 \min 75 \%$ Ethanol

$2 \times 90$ min $96 \%$ Ethanol

$3 \times 75$ min $100 \%$ Ethanol

2x 120 min Xylol

2x 60 min Paraffin $\left(\mathrm{T}_{\mathrm{M}} 60^{\circ} \mathrm{C}\right)$

Anschließend wurden die Gewebescheiben an einer Ausgießstation in Paraffin eingebettet. Dabei liegt die erste Gehirnscheibe mit der Schnittfläche nach unten, die zweite und dritte Scheibe jeweils mit der rostralen Seite nach unten im Einbettförmchen. Die Anschnittfläche des fertigen Präparateparaffinblocks ist die Unterseite des Einbettförmchens. Im Ergebnisteil dargestellte Schnittbilder zeigen das Gehirn auf Höhe der 1. Schnittebene. 


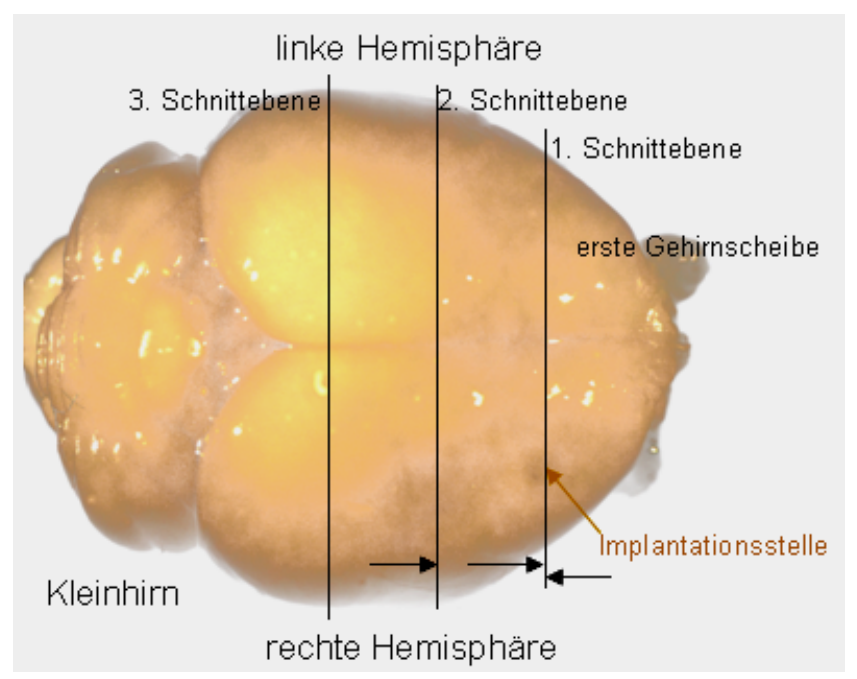

Abbildung 7: Darstellung der coronaren Schnittebenen des Nagergehirns bei der Aufbereitung. Das Gewebe wurde so eingebettet, dass die Schnittebene der Gehirnscheibe, auf die der jeweilige Pfeil zeigt, an der Anschnittfläche des Paraffinblocks liegt.

\subsubsection{Subkutane Tumore}

Die Tumoren wurden mittig geteilt. Eine Hälfte wurde in Tissue Tec im Kühlschrank für 30 - 90 min inkubiert, bevor sie auf flüssigem Stickstoff in Molds in Tissue Tec eingefroren wurde. Die Gewebe wurden bei $-20^{\circ} \mathrm{C}$ gelagert. Die andere Hälfte wurde wie unter 2.2.5.1 beschrieben in PFA 4\% in PBS fixiert und in Paraffin eingebettet.

\subsubsection{Histologie}

\subsubsection{Gefrierschnitte}

Die eingefrorenen Gewebe wurden mit Tissue Tec auf dem Objekthalter des Kryotoms befestigt und $7 \mu \mathrm{m}$ dicke Schnitte angefertigt.

Die Schnitte wurden vorsichtig mit einem Pinsel auf vorgekühlte Objektträger für Gefrierschnitte (Superfrostplus, Menzel Gläser) gelegt und $2 \mathrm{~h}$ bei $-21^{\circ} \mathrm{C}$ in Kryotom getrocknet, bevor sie mit einem Deckglas abgedeckt wurden, dass mit einer Klammer fest gedrückt und mit Klebstoff an den Ecken fest geklebt wurde. Die Schnitte wurden direkt mit einem Fluoreszenzmikroskop begutachtet und einer Mikroskopkamera fotografiert.

Schnitte für Färbungen wurden direkt von der Andruckplatte mit einem warmen Objektträger aufgenommen. Die Schnitte wurden für $2 \mathrm{~h}$ bei RT getrocknet. Anschließend kamen sie bis zur Färbeprozedur in den Kühlschrank, oder für längere Lagerung in den Gefrierschrank bei $-20^{\circ} \mathrm{C}$. 


\subsubsection{Immunfluoreszenzfärbung von Gefrierschnitten}

Zur Faktor VIII-Färbung bedurfte es der folgenden Behandlung:

- 5 min $100 \%$ Ethanol, $4^{\circ} \mathrm{C}$

- 3x mit PBS spülen

- 30 min $1 \%$ BSA in PBS zum Blocken unspezifischer Bindungsstellen

- $1 \mathrm{~h} 100 \mu \mathrm{l} /$ Schnitt 1. Antikörper 1:300 verdünnt in PBS

- 3x mit PBS spülen

- 1 h $100 \mu 1 /$ Schnitt 2. Antikörper mit Fluoreszenzfarbstoff markiert 1:200 verdünnt in PBS

- 10 min DAPI 1:10000 verdünnt in PBS zur Fluoreszenzfärbung der Zellkerne durch Einlagerung in die Nucleinsäureketten

- 4x mit PBS spülen

- eindecken mit Fluoromount $\mathrm{G}$

- einige Minuten trocknen lassen

Begutachtung der Färbung unter dem Durchlichtmikroskop.

\subsubsection{Paraffinschnitte}

Von in Paraffin eingebetteten Geweben wurden mit einem Mikrotom (Leica) 1-5 $\mu$ m dicke Schnitte angefertigt. Diese wurden im Wasserbad gestreckt und auf Objektträger gebracht. Die Schnitte wurden ü.N. im Wärmeschrank bei $37^{\circ} \mathrm{C}$ getrocknet, um die Bindung der Schnitte an den Objektträger zu verbessern und bis zur weiteren Bearbeitung bei RT gelagert.

\subsubsection{Färbungen von Paraffinschnitten}

Für histologische Untersuchungen wurden Paraffinschnitte entweder direkt gefärbt, oder spezielle Strukturen immunhistologisch markiert.

\section{Hämalaun-Eosin Färbung}

Die Hämalaun-Eosin (HE) Färbung von Paraffinschnitten färbt das Gewebe direkt an. Hämalaun färbt Zellkerne blau an, Eosin färbt das Cytoplasma der Zellen rosarot. Dazu werden Paraffinschnitte folgender Prozedur unterzogen:

Entparaffinierung und Rehydrierung:

- 4x 3 min Roti-Histol

- 2x 2 min $100 \%$ Ethanol

- 2 min $96 \%$ Ethanol

- 2 min $70 \%$ Ethanol

- 2 min $50 \%$ Ethanol

- 2 min $30 \%$ Ethanol 
- 3 min Aqua dest.

Färbung:

- 5 min Hämalaun (nach Mayer)

- 10 min fließendes Leitungswasser

- 2 min Aqua dest.

- 3 min $1 \%$ Eosin

- kurz A. dest spülen

Dehydrierung:

- 10 s $70 \%$ Ethanol

- 10 s $80 \%$ Ethanol

- 10 s $90 \%$ Ethanol

- 10 s $96 \%$ Ethanol

- 2x 3 min $100 \%$ Ethanol

- 4x 2 min Roti-Histol

Die Objektträger wurden nacheinander gut abgetropft, unter Verwendung von Entellan mit einem Deckgläschen eingedeckt und ü.N. unter dem Abzug getrocknet. Die Histologie der Schnitte wurde mit Hilfe eines Lichtmikroskops beurteilt.

\section{$\underline{\text { Immunhistologie }}$}

Für immunhistologische Färbungen wurden die Paraffinschnitte zuerst entparaffiniert und rehydriert, wie oben unter HE-Färbung beschrieben. Anschließend wurden die Schnitte wie folgt weiter behandelt:

Zur Ki67-, Active Caspase-3- und zur Mac-3 Färbung bedurfte es der

- Epitopdemaskierung durch Vorbehandlung mit Citratpuffer in der Mikrowelle, 3x 5 min auf höchster Stufe kochen und mit Aqua dest. nachfüllen

- Schnitte bei RT abkühlen lassen

- 3x mit PBS spülen

- 20 min in $100 \%$ Methanol $+600 \mu 1 \mathrm{H}_{2} \mathrm{O}_{2}$ (frisch angesetzt), $4^{\circ} \mathrm{C}$, zur Deaktivierung der endogenen Peroxidase

- 3x mit PBS spülen

- 20 min 10 \% FCS in PBS, RT zum Blocken unspezifischer Bindungsstellen (für Ki67Färbung zusätzlich Blocken mit FAB-Fragmenten)

- ü.N. $110 \mu \mathrm{l} / \mathrm{Schnitt} \mathrm{1.} \mathrm{Antikörper} \mathrm{1:200} \mathrm{verdünnt} \mathrm{in} \mathrm{PBS,} 4^{\circ} \mathrm{C}$

- 3x mit PBS spülen

- 1 h $110 \mu 1 /$ Schnitt 2.Antikörper biotiniliert 1:200 verdünnt in PBS, RT

- 3x mit PBS spülen 
- 1 h Peroxidase konjugiertes Biotin 1:1000 verdünnt mit 10 \% FCS in PBS, RT. Das Enzym Peroxidase setzt DAB zu einem in Alkohol unlöslichen braunen Endprodukt um.

- 3x mit PBS spülen

- 5-8 min Entwicklung in frisch angesetzter DAB-Lösung (DAB-Lösung: $49 \mathrm{ml}$ PBS + 20 $\left.\mu 130 \% \mathrm{H}_{2} \mathrm{O}_{2}+1 \mathrm{ml} \mathrm{DAB}\right)$

- 3x mit Aqua dest. spülen

- 9x in Hämalaun tauchen

- 5 min unter fließendem Leitungswasser bläuen

- kurz $50 \%$ Ethanol

- kurz $70 \%$ Ethanol

- kurz $80 \%$ Ethanol

- kurz $90 \%$ Ethanol

- kurz 96\% Ethanol

- 2x 3 min $100 \%$ Ethanol

- 3x 3 min Xylol

- eindecken mit Depex

- ü.N. unter dem Abzug ausdünsten lassen

Begutachtung der Färbung unter dem Durchlichtmikroskop. 


\section{Ergebnisse}

Zur Verbesserung der Therapie maligner Hirntumoren sind neue Behandlungsansätze dringend erforderlich. In der vorliegenden Arbeit werden Daten vorgestellt, die als Grundlage für innovative Therapieansätze herangezogen werden können.

Es wurden Experimente zur Behandlung von Gliomen mittels eines spezifischen antiTGF- $\beta$-Antikörpers (1D11) durchgeführt. Dazu wurden in vitro die Mengenverhältnisse des von Gliomzellen sezernierten TGF- $\beta$ bestimmt und die Gliomzellen mit dem 1D11Antikörper oder TGF- $\beta$ behandelt. In vivo wurden anhand mehrerer Tiermodelle zunächst Mäuse mit s.c. Gliomen mit dem 1D11-Antikörper therapiert. Anschließend wurden Mäuse mit intrazerebralen Tumoren mit dem Antikörper behandelt, nachdem Vorversuche gezeigt haben, dass der Antikörper über die BHS in den Tumor gelangt. Um die Konzentrationen von antitumorös wirksamen Therapeutika im Gehirn und im Tumor zu erhöhen, wurden zusätzlich Versuche zur Öffnung der BHS mittels HG gemacht und gleichzeitig 1D11 verabreicht.

\subsection{Spezifische Bindung von AF680 1D11 Antiköper an von U87MG Tumorzellen sezerniertes TGF- $\beta$}

Der Antikörper 1D11 bindet die TGF- $\beta$ Isoformen 1, 2 und 3. Um die Verteilung des Antikörpers im Tier sichtbar zu machen, wurde der Antikörper 1D11 zuvor mit den Chromophoren AF680 bzw. AF595 gekoppelt. Nach der Kopplungsreaktion wurde überprüft, ob der gekoppelte Antikörper TGF- $\beta$ noch bindet. Hierzu wurden Western-BlotAnalysen durchgeführt. Eingesetzt wurden Proben von konzentriertem, konditioniertem Medium von U87MG-Zellen, die TGF- $\beta$ ins Medium sezerniert haben und von rekombinantem TGF- $\beta$ (Abbildung 8, A). Als Kontrollen wurden folgende Proben eingesetzt: PBS, Medium, konzentriertes Medium mit AF680 1D11, Agarose A/G plus, konditioniertes, konzentriertes Medium von U87MG-Zellen ohne AF680 1D11 und Agarose A/G plus (Abbildung 8, B). Im Western-Blot zeigten sich für das aufbereitete konditionierte Medium zwei deutliche Banden: Eine ist im Bereich von etwa $25 \mathrm{kDa}$ stark ausgeprägt, was der Größe des aktiven TGF- $\beta$-Dimers entspricht und eine weitere im Bereich von etwa 46 kDa Größe (Abbildung 8, A). Die Banden in der Positivkontrolle mit zugesetztem TGF- $\beta 1$ waren wesentlich schwächer. So konnte die spezifische Bindung von AF680 gekoppeltem und AF594 gekoppeltem 1D11 an TGF- $\beta$ gezeigt werden. 


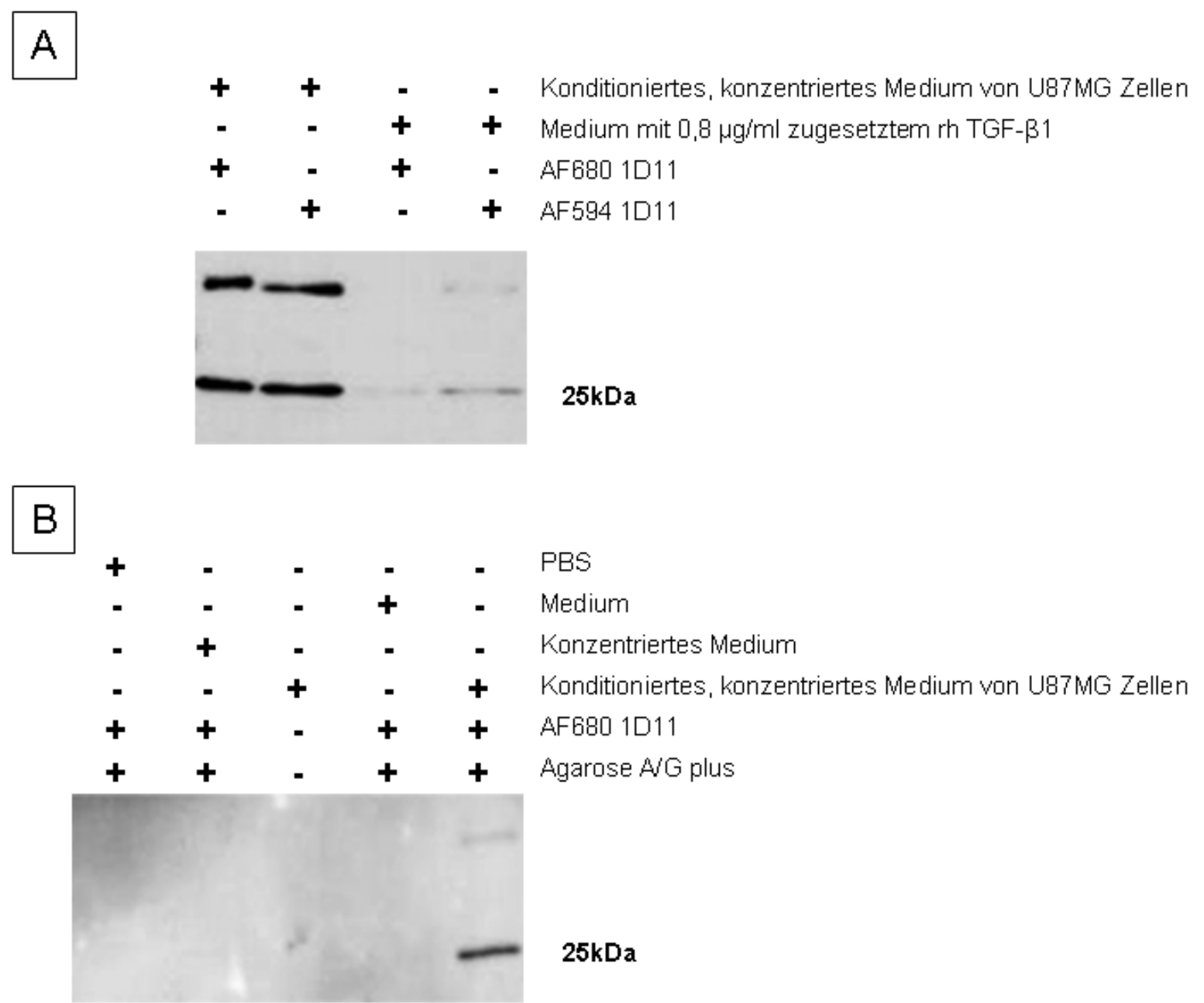

\begin{abstract}
Abbildung 8: Spezifische Bindung von Alexa Fluor gekoppeltem Antikörper 1 D11 an humanes TGF- $\boldsymbol{\beta}$. A) Western Blot-Analyse von immunpräzipitiertem, von U87MG-Zellen sezerniertem TGF- $\beta$ unterschiedlicher Medien unter Verwendung von fluoreszenzgekoppeltem 1D11 für „pull-down“ und Detektion. B) Kontrollansätze und Positivkontrolle.
\end{abstract}

\title{
3.2 TGF- $\beta 2$ Produktion von U87MG und GL261 Zellen
}

Von Gliomzellen ist bekannt, dass sie TGF- $\beta 2$ überexprimieren. Mittels ELISA wurde die Menge des von humanen U87MG Gliomzellen und murinen GL261 Gliomzellen in der Zellkultur sezernierten TGF- $\beta 2$ ermittelt. Dabei stellte sich heraus, dass beide Zelllinien TGF- $\beta 2$ sezernieren. Die Produktion von TGF- $\beta 2$ in U87MG Zellen war etwa 6-mal höher, als die in GL261 Zellen (Abbildung 9). 


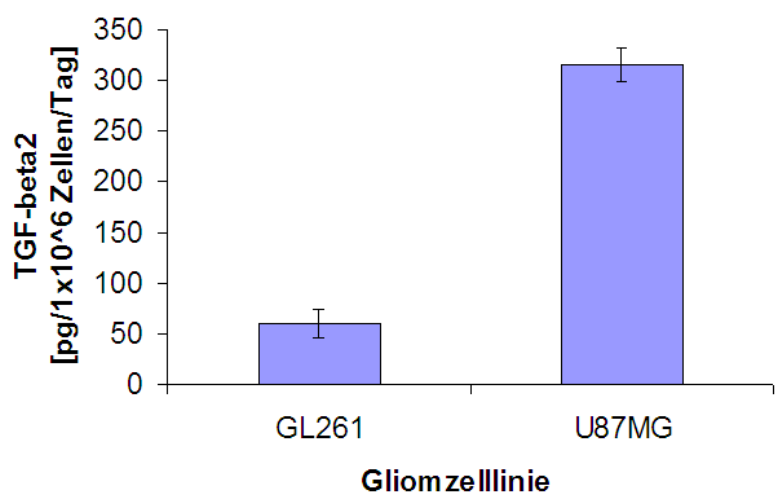

Abbildung 9: Menge von sezerniertem TGF- $\beta 2$ in Gliomzellkulturen. Die Konzentration von TGF- $\beta 2$ im konditionierten Medium wurde $24 \mathrm{~h}$ nach Aussaat von GL261- bzw. U87MG-Gliomzellen mittels ELISA bestimmt $(\mathrm{n}=3)$.

\subsection{Einfluss von TGF- $\beta 2$ auf die Vitalität und Proliferation von Gliomzellen in der Zellkultur}

Der Einfluß von TGF- $\beta$ auf die Proliferation der verwendeten Zelllinien sollte zuerst in der Zellkultur mittels WST-1-Test untersucht werden. In dem Versuch wurde der Einfluss von exogenem TGF- $\beta 2$ auf die Vitalität/Proliferation von U87MG- und GL261-Zellen ermittelt. Dazu wurden die Zellen $72 \mathrm{~h}$ vor der Aussaat mit $0,5 \mathrm{ng} / \mathrm{ml}$ oder $5 \mathrm{ng} / \mathrm{ml}$ rekombinantem TGF- $\beta 2$ vorbehandelt. $6 \mathrm{~h}$ nach Aussaat erfolgte die erneute Behandlung mit TGF- $\beta 2$. Nach 24, 72 und 96 h wurde die Absorption der Zellen gemessen. Nach 96 h zeigte sich ein deutlicher Einfluß von TGF- $\beta 2$ auf die Zellproliferation. Die U87MG-Zellen wurden durch zusätzliches TGF- $\beta 2$ im Medium in ihrem Wachstum gehemmt (Abbildung 10, A), während es auf die GL261-Zellen wachstumsfördernd wirkte (Abbildung 10, B). Dabei fand sich kein Unterschied in den beiden eingesetzten Konzentrationen des zugefügten TGF- $\beta 2$.

Durch die Zugabe von Antikörper (1D11) wird von den Tumorzellen sezerniertes TGF$\beta$ gebunden und die Menge an freiem TGF- $\beta$ reduziert.

GL261 und U87MG Zellen wurden $72 \mathrm{~h}$ vor dem eigentlichen Versuch mit $0,6 \mu \mathrm{g} / \mathrm{ml}$ oder $6 \mu \mathrm{g} / \mathrm{ml}$ 1D11 behandelt. $6 \mathrm{~h}$ nach Aussaat erfolgte die erneute Behandlung mit 1D11. Nach 24, 72 und $96 \mathrm{~h}$ wurde die Absorption der Zellen ermittelt. Inkubation mit 1D11 führte mit keiner Konzentration zu einer Veränderung der Proliferation/Vitalität im Vergleich zur unbehandelten Kontrolle. 

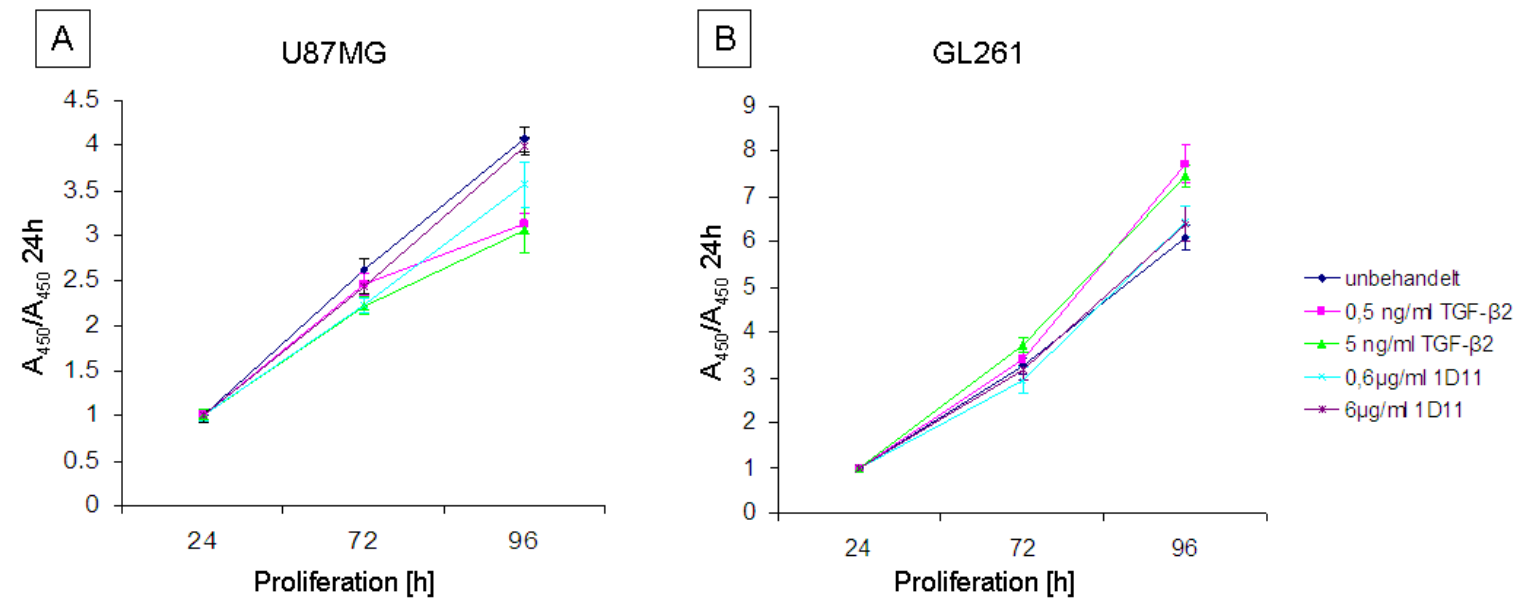

\begin{abstract}
Abbildung 10: Einfluß von TGF-ß2 auf die Proliferation von U87MG- (A) und GL261-Zellen (B) in der Zellkultur. Die Zellen wurden $72 \mathrm{~h}$ vor und auch nach Aussaat in 96-Well Platten mit unterschiedlichen Konzentrationen von humanem, rekombinantem TGF- $\beta 2$ oder 1D11 Antikörper inkubiert. Nach 24, 72 und 96 h wurde mittels WST-1-Test der Farbstoffumsatz (Absorption bei 450 $\mathrm{nm})$ gemessen. Die Absorptionswerte sind als Verhältnis Absorption zu Absorption nach $24 \mathrm{~h}$ über die Zeit aufgetragen. Nach $96 \mathrm{~h}$ unterscheiden sich die unbehandelten Zellen in ihrer Proliferation signifikant von den mit TGF- $\beta 2$ behandelten (t-test: $p<0,001$ (jeweils für beide Zelllinien)), wobei die Gruppen der zwei TGF- $\beta 2$-Konzentrationen sich nicht voneinander unterscheiden (Mann-Whitney Rank Sum Test: $p=0,427$ (für U87MG); $p=0,241$ (für GL261))
\end{abstract}

\title{
3.4 1D11-Behandlung s.c. Tumoren
}

\subsubsection{D11 Antikörper im s.c. Gliom}

Damit der systemisch verabreichte therapeutische Antikörper 1D11 seine lokale Wirkung entfalten kann muß er in den Tumor gelangen. Um zu ermitteln, mit welcher Kinetik sich 1D11 im Tumorgewebe anreichert, wurden Untersuchungen mittels in vivo-Bildgebung im eXplore Optix-System in felllosen tumortragenden nu/nu-Mäusen durchgeführt. Dazu wurde der AF680 1D11 im Vergleich zum nicht spezifisch bindendem Kontrollantikörper AF680 13C4 verwendet.

In Abbildung 11 ist beispielhaft für AF680 1D11, AF680 13C4, und unbehandelte Mäuse ein natives Bild einer Maus mit korrespondierendem Fluoreszenzintensitäts- und LT-Blid dargestellt. Durch Messung der LT kann zwischen der Fluoreszenz des Fluorochroms und unspezifischer Fluoreszenz mit einer erhöhten LT unterschieden werden. AF680 1D11 wies eine LT von 1,45 ns auf. Kontrollmäuse, die keine fluoreszierenden Substanzen erhalten haben zeigten eine geringe Fluoreszenz im Körper. 
Diese Hintergrundsfluoreszenz hatte eine niedrigere LT von $0,51 \mathrm{~ns}$ und konnte daher als nicht AF680-spezifische Fluoreszenz des Gewebes identifiziert werden.

Nach i.v. Gabe von 4,8 mg/kg KG AF680 1D11 zeigte sich in s.c. U87MG-Tumoren bei Messungen mit dem eXplore Optix eine erhöhte Fluoreszenzintensität im Tumor (Abbildung 11). Die LT entspricht dem für AF680 typischen Signal. Auch der mit AF680 markierte Isotypkontrollantikörper $13 \mathrm{C} 4$ zeigte eine erhöhte Fluoreszenzintensität im Tumor. Die hohe Fluoreszenzintensität im Bereich des Magens der Tiere hat eine deutlich höhere LT als die im übrigen Körper und findet sich auch in unbehandelten Kontrolltieren. Daher handelt es sich um ein unspezifisches Signal. Diese Fluoreszenz stammt nicht vom AF680 Fluorophor (Abbildung 11). Die Fluoreszenz (und auch die LT) im Körper der behandelten Mäuse im Vergleich zu unbehandelten Mäusen zeigt neben der Anreicherung im Tumor auch die Verteilung des intravenös verabreichten fluoreszenzmarkierten Antikörpers (Abbildung 11).

In einem mit AF680 13C4 und einem mit AF680 1D11 behandelten Tier wurde anhand der Fluoreszenzintensitäten die Konzentration des jeweiligen Fluorochroms im Tumor in einer dreidimensionalen Rekonstruktion ermittelt. Durch diese Art der Darstellung konnte auch optisch gezeigt werden, dass die Fluoreszenz nicht von der Oberfläche stammt, sondern aus dem Tumorknoten selber. Dabei befand sich im AF680 1D11 behandelten Tumor eine höhere Fluoreszenzintensität, als im AF680 13C4 behandelten Tumor (Abbildung 12).

Bei Gabe von AF594 gekoppeltem 1D11, welches im sichtbaren Bereich fluoreszeiert, konnte fluoreszenzmikroskopisch im Tumor eine erhöhte Fluoreszenz gegenüber einem unbehandelten Tumor gezeigt werden. Hierzu wurde das Tier am Versuchsende perfundiert und der Tumor anschließend im Gefrierschnitt untersucht (Abbildung 13). 


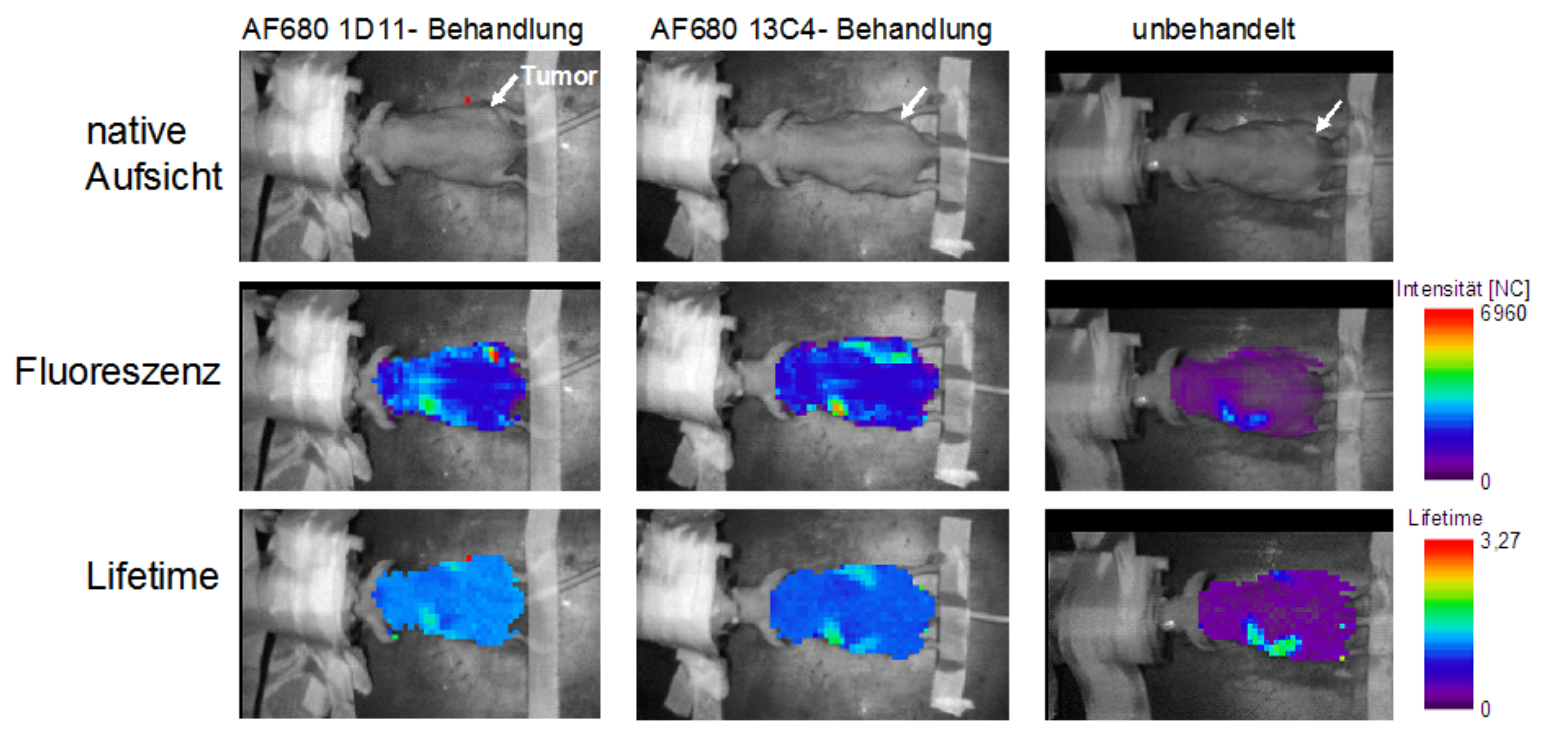

Abbildung 11: Fluoreszintensität und korrespondierende LT in vivo einer $24 \mathrm{~h}$ zuvor i.v. mit AF680 1D11- oder AF680 13C4 Antikörper behandelten oder unbehandelten nu/nu-Maus im eXplore Optix. Der s.c. U87MG-Tumor ist mit einem Pfeil im Bild markiert. Die erhöhte Fluoreszenzintensität über dem Körper im Vergleich zum unbehandelten Tier zeigt, dass sich der jeweilige Antikörper im ganzen Tier verteilt hat. Eine besonders hohe Fluoreszenzintensität findet sich im Tumorbereich. Die hohen Fluoreszenzintensitäten im Bereich bestimmter Organe (z.B. Magen) entspricht einer Autofluoreszenz des Gewebes, was daran zu erkennen ist, dass die LT des Signals höher ist, als die des farbstoffgebundenen Antikörpers. Die Fluoreszenz mit dieser LT findet man auch in unbehandelten Kontrolltieren.

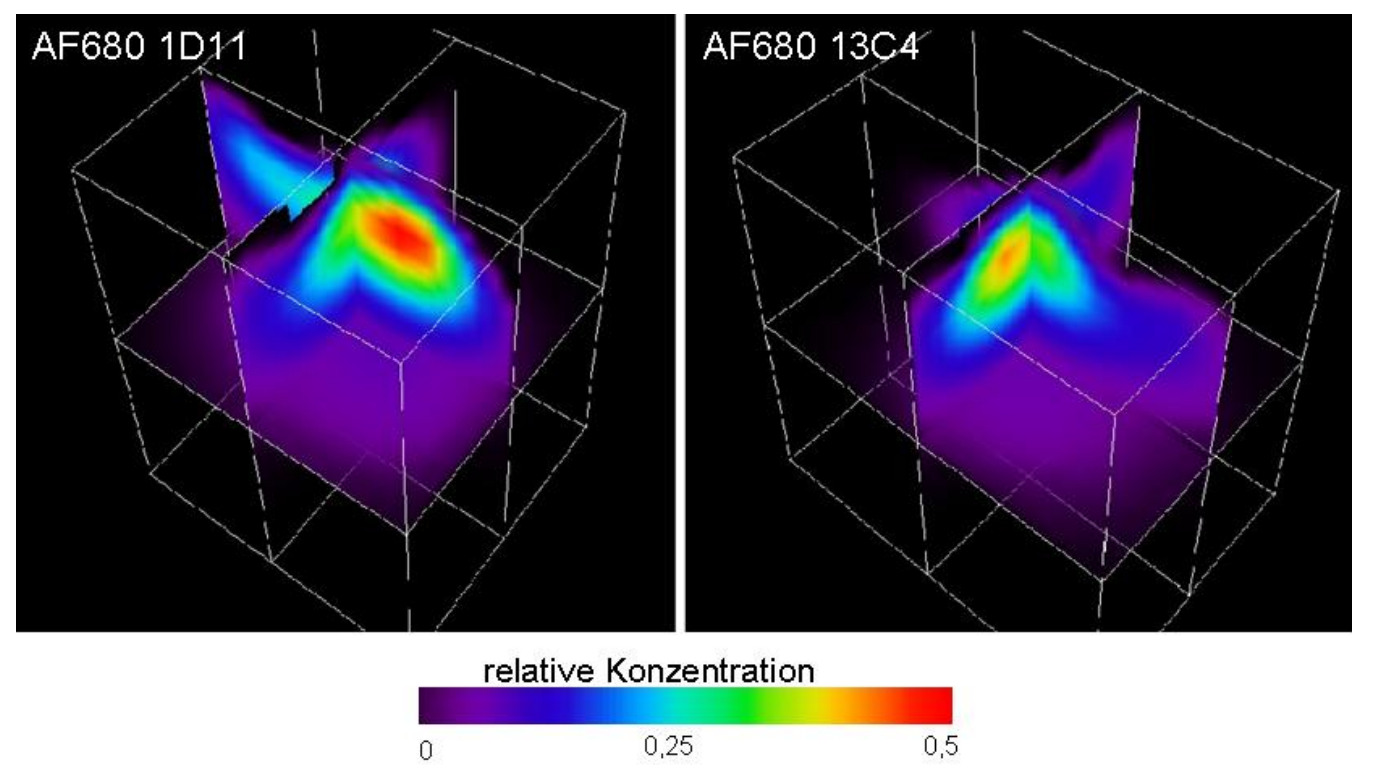

Abbildung 12: Dreidimensionale Darstellung relativer Fluoreszenzkonzentrationen in s.c. U87MG Tumoren. Die Abbildung zeigt im Bereich der Tumoren $24 \mathrm{~h}$ nach der ersten i.v. Injektion von 4,8 mg/kg KG AF680 1D11 oder AF680 13C4 Antikörper, dass die Fluoreszenz aus dm Tumorgewebe stammt. Dabei ist die Konzentration von 1D11 im Tumor größer als die von 13C4. 

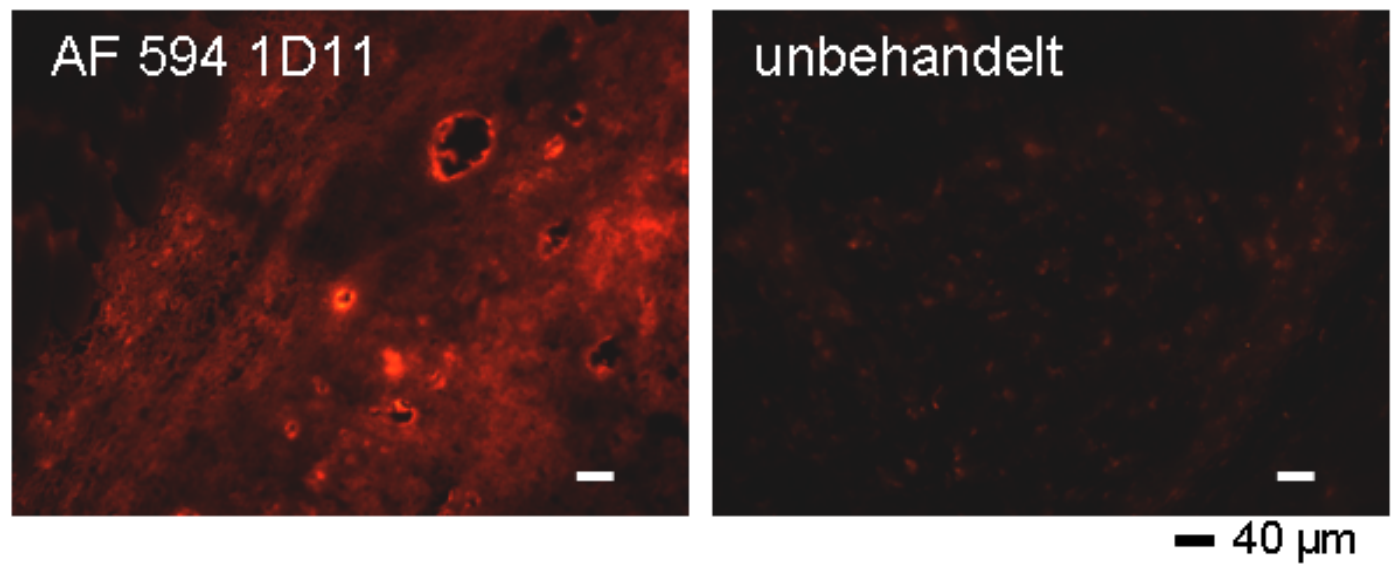

Abbildung 13: AF594 1D11 Antikörper-Fluoreszenz in s.c. U87MG-Tumoren. Die nu/nu-Mäuse wurden $2 \mathrm{~h}$ nach i.v. Gabe von 4,8 $\mathrm{mg} / \mathrm{kg} \mathrm{KG}$ mit PBS Perfundiert bevor die Tumoren entnommen wurden. In den mit AF594 1D11 behandelten Tieren ist in den Schnittnen eine erhöhte Fluorezenzintensität an den Gefäßwänden und im Tumorgewebe zu sehen als im unbehandelten Tier.

\subsubsection{Behandlung subkutaner U87MG-Tumoren in nu/nu-Mäusen (Versuchsreihe A1)}

Um zu untersuchen, wie sich der Antikörper im Tumor unter Therapiebedingungen verhält, wurden die beiden Antikörper AF680 1D11 (anti-TGF $\beta$ ) oder AF680 13C4 (Isotypkontrolle) $2 \mathrm{x}$ wöchentlich - wie unter den Therapiebedingungen - i.v. verabreicht. Die Fluoreszenzintensität in den Tumoren wurde durch tägliches Scannen der Tiere gemessen und über die Zeit aufgetragen (Abbildung 14). Das Areal, in dem die Fluoreszenzintensität gemessen wurde, war immer gleich groß. Nach jeder i.v. Gabe stieg die Fluoreszenzintensität zunächst an, um dann über die Zeit zuerst schneller, dann etwas verlangsamt bis zur nächsten Injektion wieder abzunehmen. Die Fluoreszenz in den Tumoren der mit AF680 1D11 behandelten Mäuse war im Durchschnitt immer höher, als in den mit AF680 13C4 behandelten, die Kinetik war jedoch gleich. Das bedeutet, dass mehr 1D11 in den Tumor gelangte, als 13C4. Die maximale Fluoreszenzintensität nach der Injektion sank von Behandlung zu Behandlung ab. Das galt sowohl für die mit AF680 1D11, als auch für die mit AF680 13C4 behandelten Tiere (Abbildung 14). 


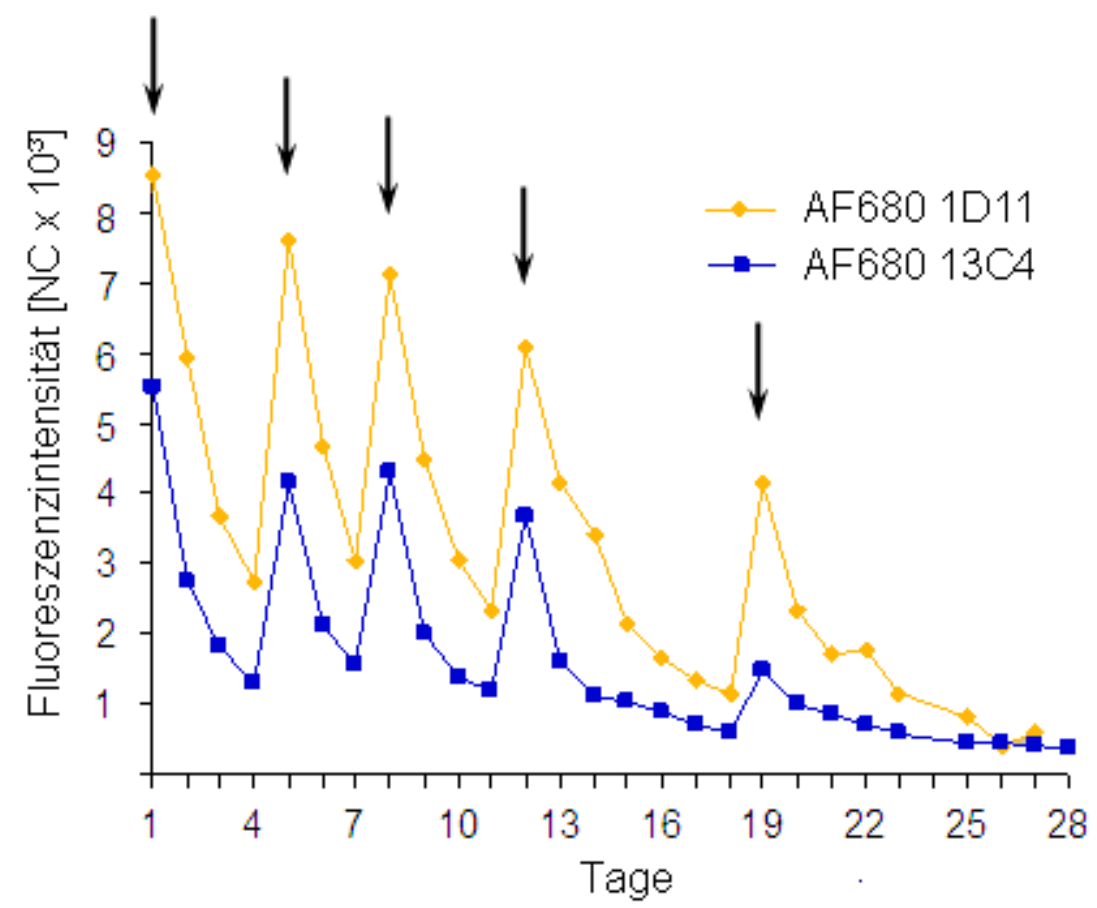

Abbildung 14: Intensität der AF680 1D11- und AF680 13C4 -Fluoreszenz im Zeitverlauf. Die Fluoreszenzintensität in s.c. anwachsenden U87MG-Tumoren in nu/nu-Mäusen wurde nach der 1. Behandlung mit 4,8 mg/kg (hier Tag 1) in vivo über 28 Tage täglich gemessen. Weitere Behandlungen folgten an Tag 5, 8, 12 und 19. (Die Tage sind durch Pfeile markiert.) Die Messungen erfolgten zu identischen Zeitpunkten, an Behandlungstagen $2 \mathrm{~h}$ nach Injektion. Die Fluoreszenzintensität wurde über eine Tumorfläche von $6 \mathrm{~mm}^{2}$ gemittelt.

An Tag 28 nach Tumorzellimplantation wurden die Versuche beendet und die Tumorendgewichte nach Präparation des Tumors bestimmt um zu ermitteln, ob die 1D11Behandlung auf die Tumorendgröße einen Einfluß hat. Zwischen den 13C4-behandelten und den Kontrolltumoren gab es keinen Unterschied in der Tumorgröße (t-Test: $p=0,940)$. Wie Abbildung 15 zeigt, war das Tumorvolumen der 1D11-behandelten Tiere im Durchschnitt um das zweifache höher als bei den 13C4-behandelten und den unbehandelten Tieren. Ein signifikanter Unterschied zwischen den Gruppen bestand jedoch nicht (MannWhitney Rank Sum Test: $\mathrm{p}=0,351)$.

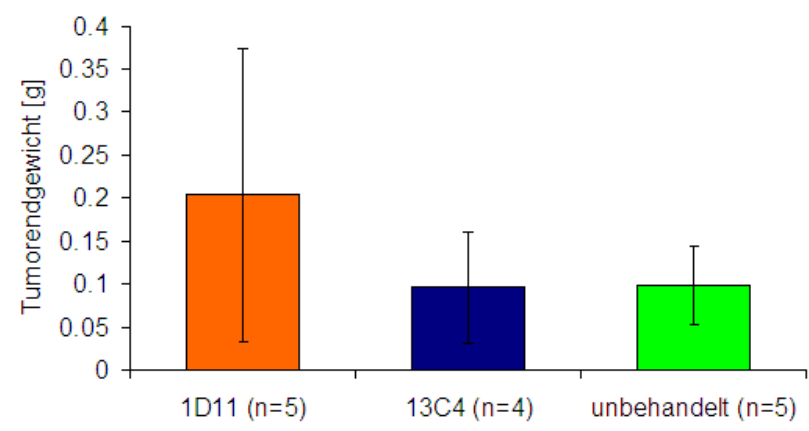

Abbildung 15: Tumorgewichte von AF680 1D11-behandelten Tieren. Für jede Versuchsgruppe ist das mittlere Gewicht für 28 Tage s.c. angewachsener U87MG-Tumoren in nu/nu-Mäusen mit Standardabweichung dargestellt. 


\subsubsection{Behandlung subkutaner U87MG-Tumoren in nu/nu-Mäusen (Versuchsreihe A2)}

Die zuerst durchgeführte Versuchsreihe A1 ergab, dass s.c. anwachsende U87MG Tumoren in nu/nu-Mäusen, die mit AF680 1D11 behandelt wurden sich nicht in ihrem Endgewicht von AF680 13C4 behandelten und unbehandelten Kontrolltumoren unterschieden. Versuchsreihe A2 wurde durchgeführt um zu sehen, ob das an 1D11 gebundene AF680 einen Einfluss auf die Wirkung des 1D11 hat, oder eine tumorsuppressive Wirkung erst später als nach 28 Tagen einsetzt. Die Versuche der Versuchsreihe A2 wurden daher mit nicht an Fluorochome gekoppelten Antikörpern durchgeführt und die Tumoren erst nach 35 Tagen entnommen.

Die mit Isotypkontrollantikörper 13C4 behandelten und unbehandelten Tumoren unterschieden sich nicht signifikant (t-Test: $\mathrm{p}=0,927)$, während die Endgewichte der 1D11-behandelten Tumoren signifikant höher waren als die der unbehandelten Kontrollgruppe (t-Test: $\mathrm{p}<0,001$ ) (Abbildung 16, B). Der Verlauf der Wachstumskurven zeigt, dass die 1D11 behandelten Tumoren schon an Tag 10 nach Implantation, also 3 Tage nach der ersten Behandlung leicht erhöhte mittlere Volumina aufwiesen, als die Kontrollgruppen. Dieser Unterschied wird im weiteren Versuchsverlauf immer deutlicher. An Tag 10 nach Tumorzellimplantation betrug der Quotient der mittleren 1D11 behandelten Tumorgröße zur mittleren Kontrolltumorgröße 1,2, an Tag 21 schon 2,4 und an Tag 35 4,6 (Abbildung 16, A).

Die äußerliche makroskopische Morphologie der Tumoren der verschiedenen Gruppen unterschied sich lediglich durch die Größe (Abbildung 17). Alle Tumoren bestanden aus einem festen Knoten, hatten sichtbar entwickelte Blutgefäßversorgung und wiesen kleinere Einblutungen auf.

Abbildung 18 zeigt den mikroskopischen Aspekt der Tumoren (HE-Färbung der Tumorschnitte). Es ist zu erkennen, dass alle Tumoren aus mäßig dicht gepackten Zellen mit wenigen apoptotischen Bereichen aufgebaut sind. Proliferierende Zellen sind anhand von Mitosefiguren identifizierbar. Im Gegensatz $\mathrm{zu}$ den Kontrolltumoren wiesen die Tumoren nach Behandlung der Mäuse mit 1D11 am Tumorrand Entzündungsreaktionen auf, die durch die Präsenz von Makrophagen in diesem Bereich erkennbar ist. 
A

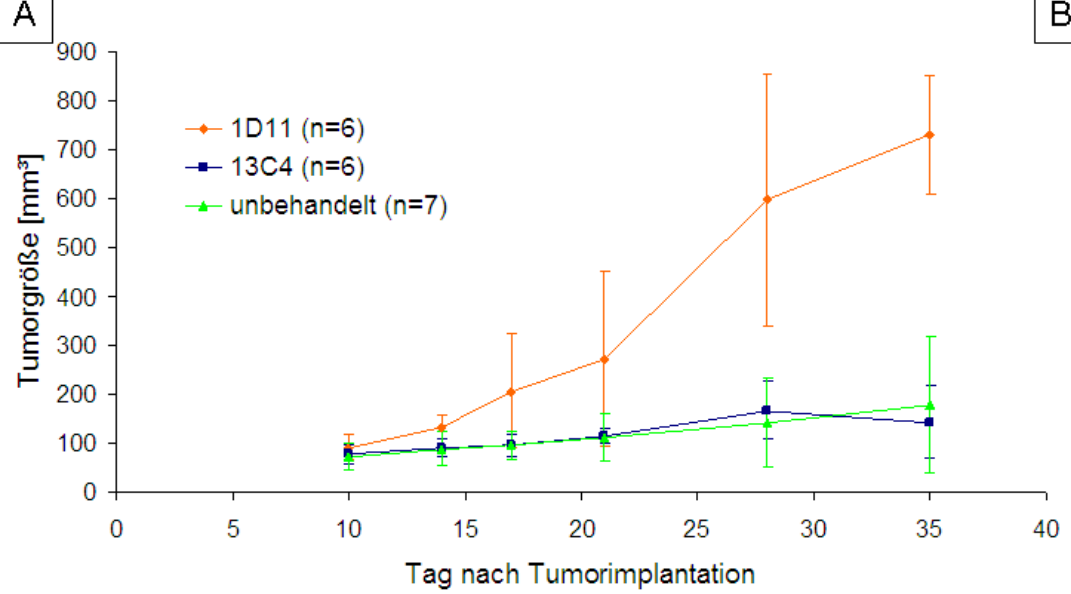

B

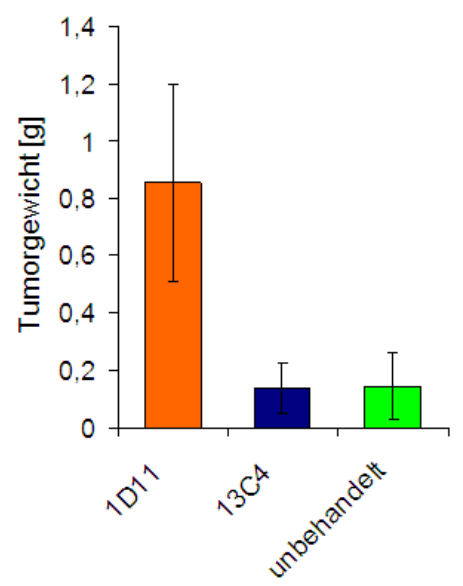

Abbildung 16: Wachstumskurven und Tumorgewichte von U87MG-Tumoren in nu/nu-Mäusen. A) Die Länge, Höhe und Breite der s.c. Tumoren wurde mit der Schiebelehre gemessen und das Volumen näherungsweise nach der Formel $\mathrm{V}=4 / 3 \cdot \pi \cdot a \cdot b \cdot c$ berechnet, wobei $\mathrm{a}, \mathrm{b}$ und $\mathrm{c}$ Halbachsen sind. Die Tumorgröße der Tumoren wurde für jede Versuchsgruppe über die Zeit aufgetragen. B) Für jede Versuchsgruppe ist das mittlere Tumorgewicht mit Standardabweichung dargestellt. Die Tumoren der 1D11-behandelten Mäuse sind signifikant größer, als die der Kontrollgruppen (t-Test $\mathrm{p}<0,001$ ).

1D11

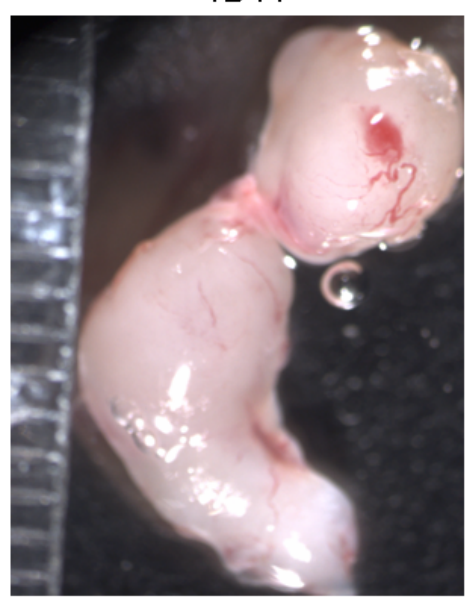

$13 \mathrm{C} 4$

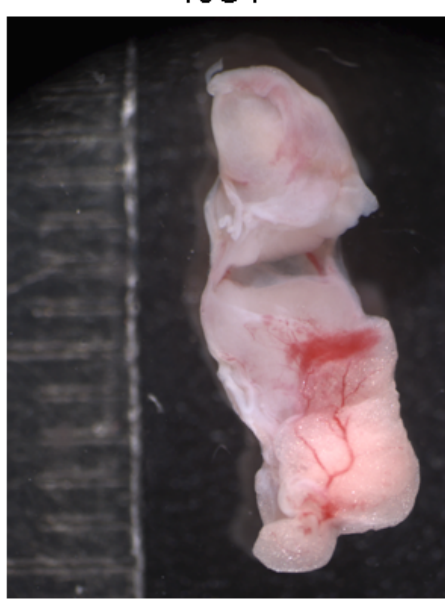

unbehandelt

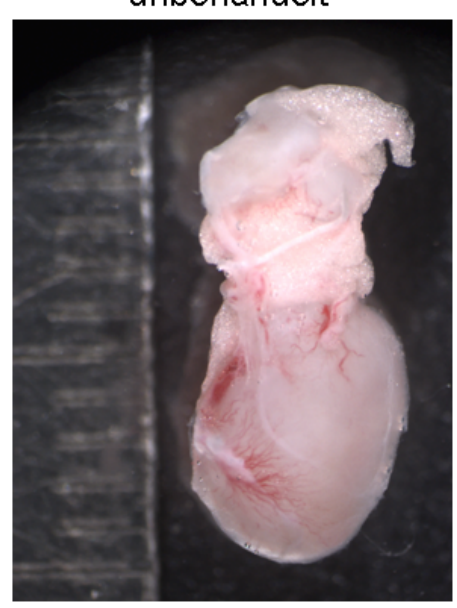

Abbildung 17: Makroskopischer Aspekt der in nu/nu-Mäusen angewachsenen U87MGTumoren. Aus jeder Versuchsgruppe ist ein repräsentativer s.c. Tumor dargestellt. Die Tumoren 1D11-behandelter Mäuse unterscheiden sich von den unbehandelten lediglich durch ihre Größe. 

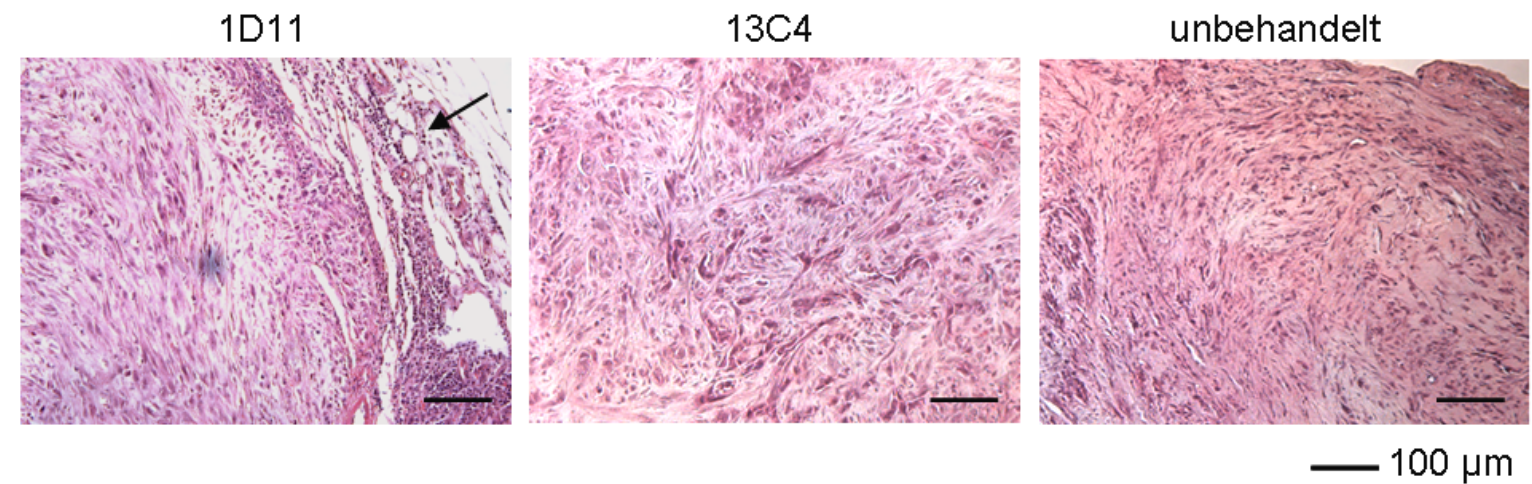

Abbildung 18: Morphologie s.c. in nu/nu-Mäusen angewachsener U87MG-Tumoren. In den HEgefärbten Paraffinschnitten sind Kerne blau und Zytoplasma rosa gefärbt. Entzündungsreaktionen sind mit einem Pfeil gekennzeichnet.

\subsubsection{Behandlung subkutaner GL261-Tumoren in Black/6-Mäusen (Versuchsreihe B)}

Versuchsreihe A wurde in einem Xenograft Mausmodell mit humanen Tumorzellen und immundefizienten Mäusen durchgeführt, weil der Antikörper 1D11 gegen humanes TGF- $\beta$ gerichtet ist und die Bekämpfung humaner Tumoren angestrebt wird. Durch die große Aminosäuresequenz-Homologie bindet der Antikörper auch an Mäuse-TGF- $\beta$ (persönliche Mitteilung von Dr. J. Harper, Genzyme Oncology group). Da das Immunsystem eine große Rolle bei der Tumorbekämpfung unter der Behandlung mit TGF- $\beta$ beeinflussenden Therapeutika spielt (Weller und Fontana, 1995) wurde Versuchsreihe B mit einem syngenen Modell mit immunkompetenten Black/6-Mäusen und Maus GL261 Tumorzellen durchgeführt.

Der Verlauf der Wachstumskurven zeigt, dass die Tumoren 1D11-behandelter Mäuse an Tag 10 nach Implantation, also 3 Tage nach der ersten Behandlung gleiche mittlere Größen aufwiesen, wie die der Kontrollgruppen. Während die Tumore der Kontrollgruppen ab Tag 21 nach Implantation deutlich wuchsen, bildeten sich neun der 1D11-behandelten Tumore ganz zurück. Nur drei Tumoren bildeten sich weiter aus, blieben aber bis zum Versuchsende kleiner als die 13C4 behandelter und unbehandelter Mäuse (Abbildung 19 A). Am Versuchsende nach 35 Tagen hatten neun von zwölf 1D11-behandelten Black/6Mäusen keinen Tumor und drei Mäuse kleine Tumoren entwickelt. Die 13C4 Isotypkontrolle behandelten, sowie die unbehandelten Mäuse wiesen am Versuchsende Tumoren auf, deren mittleres Tumorgewicht signifikant höher war im Vergleich zur 1D11Gruppe (Abbildung 19, B). Die Gruppe der 1D11 behandelten Tumoren unterscheidet sich in ihrem Endgewicht signifikant von der Gruppe unbehandelter Tumoren (t-Test: $\mathrm{p}<$ $0,001)$. 

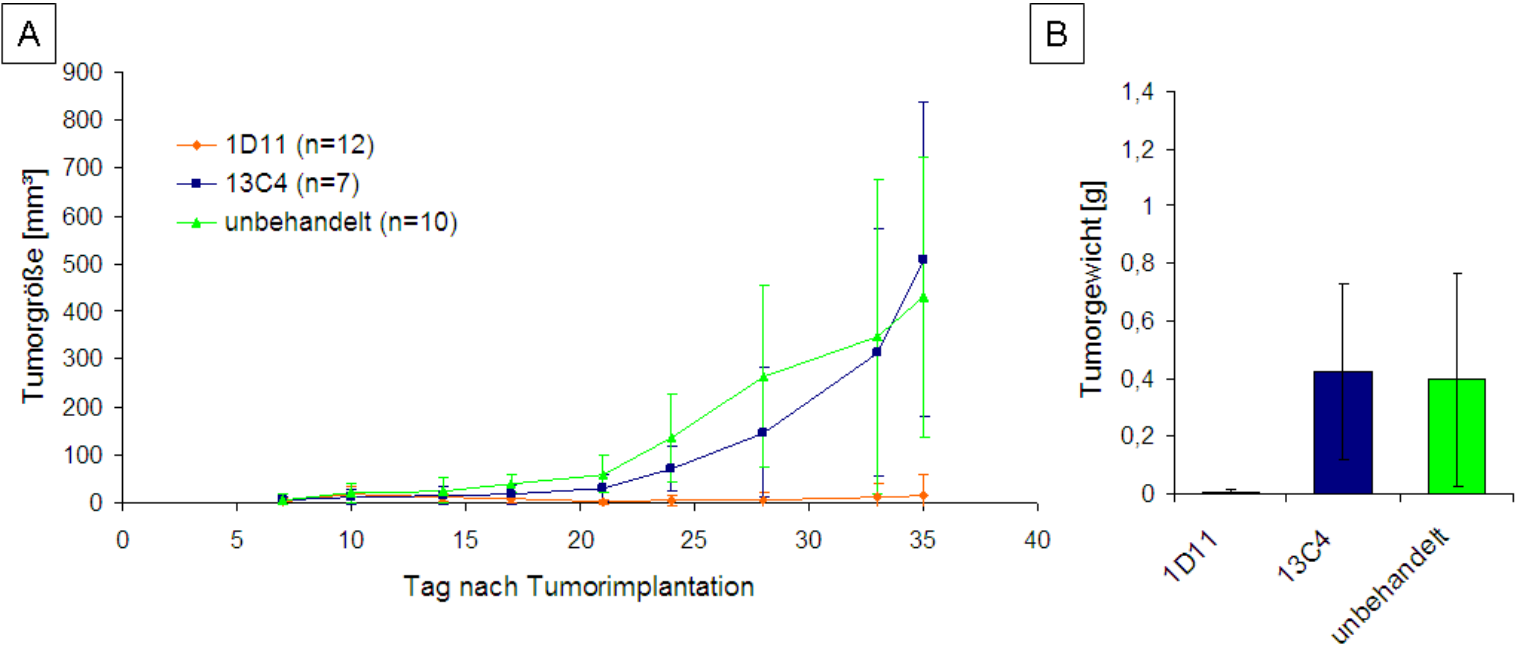

Abbildung 19: Wachstumskurven und Tumorgewichte von GL261-Tumoren in Black/6-Mäusen. A) Die Länge, Höhe und Breite der s.c. Tumoren wurde mit der Schiebelehre gemessen und das Volumen näherungsweise nach der Formel $V=4 / 3 \cdot \pi \cdot a \cdot b \cdot c$ berechnet, wobei $a, b$ und $c$ Halbachsen sind. Die Tumorgröße der Tumoren wurde für jede Versuchsgruppe über die Zeit aufgetragen. B) Für jede Versuchsgruppe ist das mittlere Tumorgewicht mit Standardabweichung dargestellt. Die Tumoren der 1D11-behandelten Mäuse sind signifikant kleiner, als die der Kontrollgruppen (t-Test p < 0,001).

Die makroskopische Morphologie der Tumoren der verschiedenen Versuchsgruppen unterschied sich in Größe und Struktur. Die 1D11-behandelten Tumore waren „kompakter“, hatten weniger sichtbare Blutgefäße und wiesen keine auffälligen Einblutungen auf. Die Kontrolltumoren dagegen bestanden aus festen, sowie größeren weichen Anteilen. Die festen Anteile wiesen gut sichtbare Blutversorgung und Einblutungen auf, die weichen Anteile zeigen teilweise Einblutungen (Abbildung 20). Einige Tumoren infiltrierten umliegendes Haut-, Binde-, oder Muskelgewebe. Der dargestellte 13C4 behandelte Tumor z.B. war so stark mit der Haut verwachsen, dass zwei Tage vor Versuchsende eine offene Wunde entstand (Abbildung 20). 

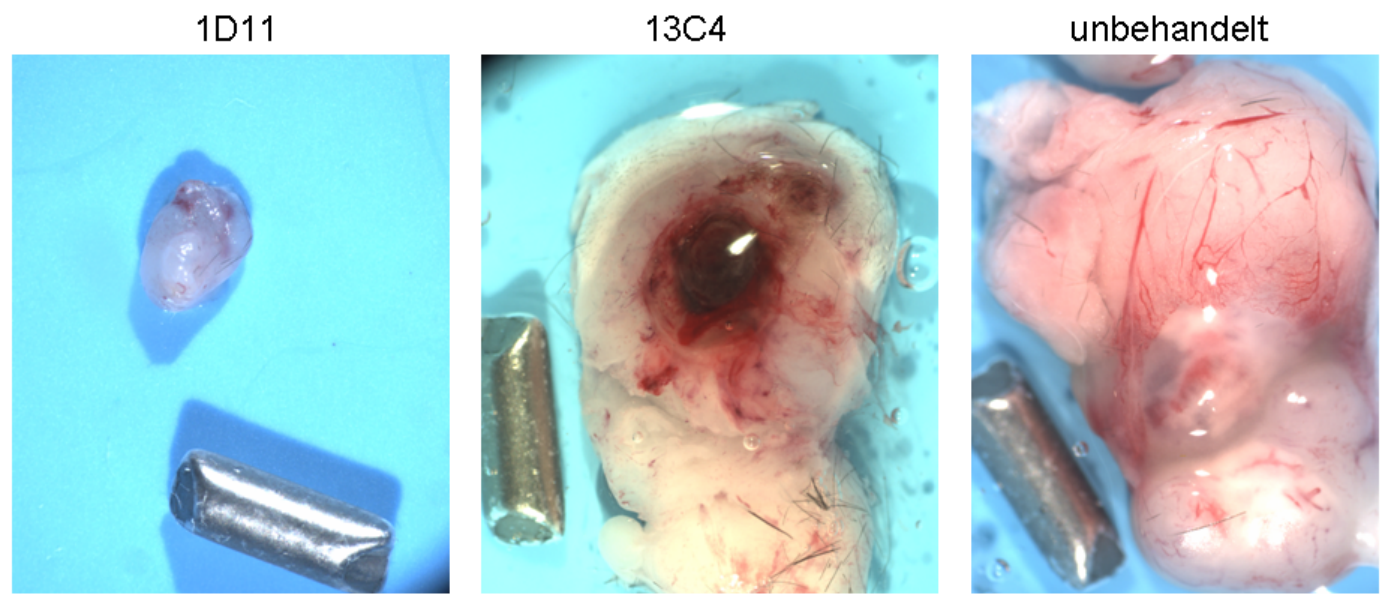

Abbildung 20: Makroskopischer Aspekt der in Black/6-Mäusen angewachsenen GL261Tumoren. Aus jeder Versuchsgruppe ist ein repräsentativer s.c. Tumor dargestellt. Nur bei drei 1D11behandelten Tieren ist am Versuchsende ein Tumor vorhanden. (Der in den Bildern zu sehende Maßstab ist $6 \mathrm{~mm}$ lang.)
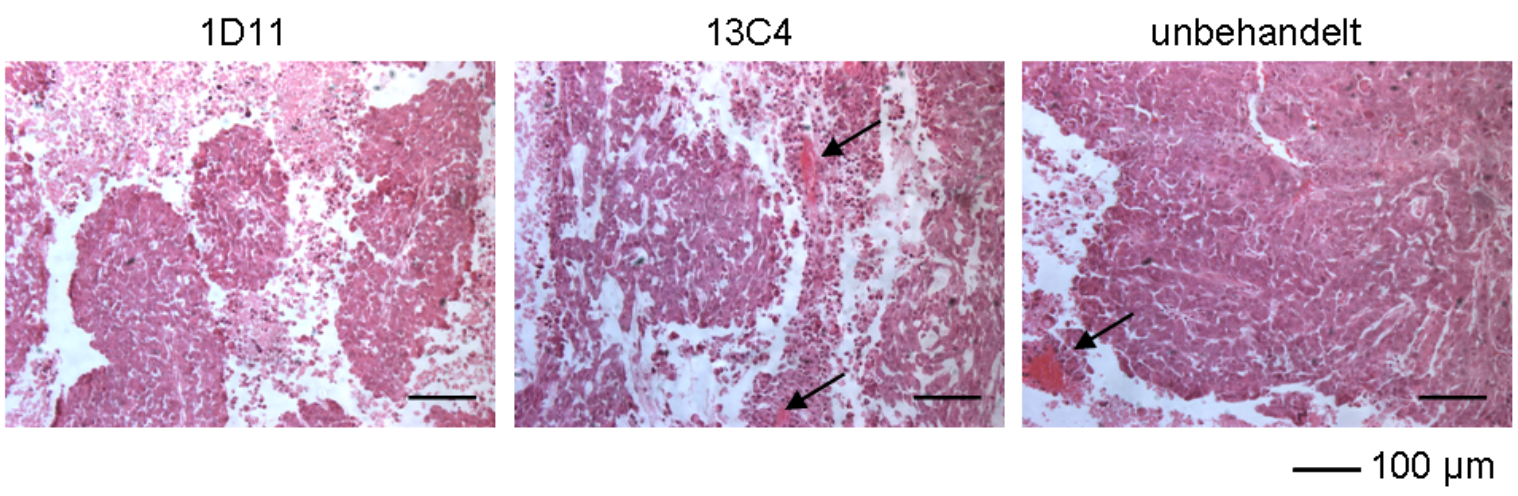

Abbildung 21: Morphologie s.c. in Black/6-Mäusen angewachsener GL261-Tumoren. In den HEgefärbten Paraffinschnitten sind Kerne blau und Zytoplasma rosa gefärbt. Weitlumige Gefäße sind mit einem Pfeil gekennzeichnet.

Die HE-Färbungen von Tumorschnitten aller Versuchsgruppen zeigten Bereiche mit hoher Zelldichte, in denen proliferierende Zellen und Blutgefäße zu finden sind und Bereiche, in denen die Zellen locker in der EZM liegen (Abbildung 21).

Zusammenfassend fand sich in diesem Versuch unter 1D11-Behandlung ein Ansprechen der s.c. GL261-Tumoren.

\subsubsection{Behandlung subkutaner GL261-Tumoren in nu/nu-Mäusen (Versuchsreihe C)}

In immundefizienten nu/nu-Mäusen (Versuchsreihe A) hatten die U87MG-Tumoren der 1D11-behandelten Tiere größere Endgewichte, als die der Kontrolltiere. In immunkompetenten Black/6-Mäusen (Versuchsreihe B) wurde mit der 1D11-Behandlung 
von GL261-Tumoren Tumorrückbildung erreicht. Um zu prüfen, ob der 1D11Behandlungserfolg aus Versuchsreihe B von einem besseren Ansprechen der GL261 Tumorzelllinie auf anti-TGF-beta alleine, oder vom zusätzlichen Effekt des Immunsystems der Black/6-Maus abhing, wurden in der Versuchsreihe C die GL261-Tumorzellen s.c. in nu/nu-Mäuse implantiert.

In diesem Experiment erreichten die Tumoren einiger Mäuse bereits nach 21 Tagen das maximal zulässige Volumen von $1 \mathrm{~cm}^{3}$ für s.c. Tumoren in Mäusen, weshalb die Versuchsreihe bereits nach 3 Wochen beendet werden mußte.

Bei allen Tieren der 1D11-Gruppe wuchsen Tumoren an. Die Wachstumskurven der Versuchsgruppen unterschieden sich nicht signifikant voneinander (Abbildung 22 A). Die Tumorgewichte der 1D11-behandelten Tumoren waren am versuchsende im Mittel zwar größer als die der 13C4-behandelten und der unbehandelten Mäuse, die Werte unterschieden sich aber nicht signifikant voneinander (Mann-Whitney Rank Sum Test: $\mathrm{p}=$ 0,073) (Abbildung 22 B).
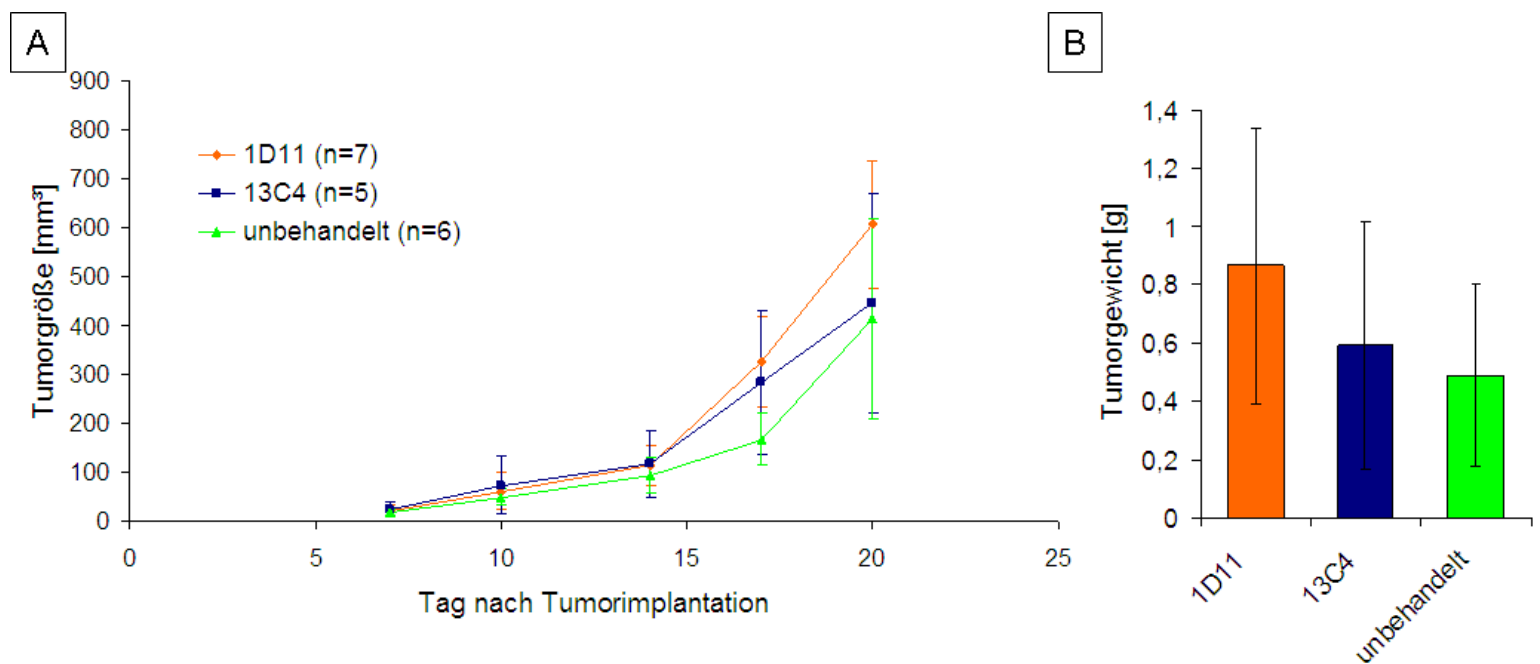

\begin{abstract}
Abbildung 22: Wachstumskurven und Tumorgewichte von GL261-Tumoren in nu/nu-Mäusen. A) Die Länge, Höhe und Breite der s.c. Tumoren wurde mit der Schiebelehre gemessen und das Volumen näherungsweise nach der Formel $V=4 / 3 \cdot \pi \cdot a \cdot b \cdot c$ berechnet, wobei $a, b$ und $c$ Halbachsen sind. Die Tumorgröße der Tumoren wurde für jede Versuchsgruppe über die Zeit aufgetragen. B) Für jede Versuchsgruppe ist das mittlere Tumorgewicht mit Standardabweichung dargestellt. Die Tumoren der 1D11-behandelten Mäuse sind tendenziell größer, aber es gibt keinen signifikanten Unterschied zu den Kontrollgruppen.
\end{abstract}

Die Tumoren der drei Versuchssgruppen unterschieden sich makroskopisch lediglich durch ihre Größe und hatten sowohl feste, als auch weiche, gallertartige Anteile in allen drei Versuchsgruppen (Abbildung 23). Sie waren mit den GL261-Tumoren aus Black/6Mäusen der Versuchsreihe B) vergleichbar, jedoch waren die weichen Anteile in den Tumoren der Versuchsreihe C) blutiger. In Tumoren aller drei Versuchsgruppen waren Gefäße und Einblutungen in allen Bereichen sichtbar. Auch diese Tumoren infiltrierten 
häufig die Muskeln oder die Haut. In manchen Mäusen war der Tumor nicht mit angrenzenden Muskeln verwachsen, hatte in ihm aber schon vermehrte Gefäßbildung induziert.
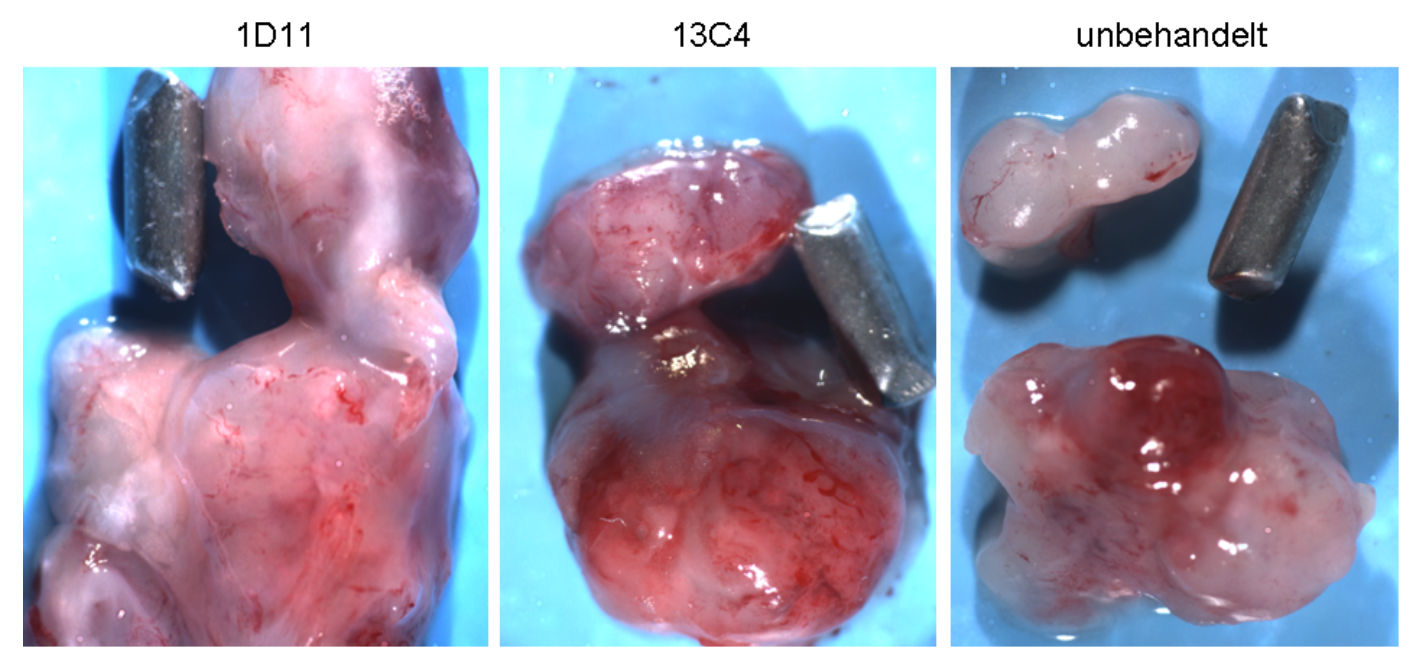

Abbildung 23: Makroskopischer Aspekt der in nu/nu-Mäusen angewachsenen GL261-Tumoren. Aus jeder Versuchsgruppe ist ein repräsentativer s.c. Tumor dargestellt. (Der in den Bildern zu sehende Maßstab ist $6 \mathrm{~mm}$ lang.)

In der histologischen Begutachtung der HE-gefärbten Schnitte der Tumoren waren Bereiche mit dicht gepackten Zellen zu sehen und Bereiche, in denen die Zellen lockerer in der gallertigen Matrix lagen. Es fiel auf, dass die Tumoren große Blutgefäße entwickelt hatten und auch kleinere Einblutungen aufwiesen. Die Blutgefäße fanden sich auch in den lockerer gepackten Bereichen (Abbildung 24). Im Bild des unbehandelten GL261-Tumors ist zu sehen, wie der Tumor Muskelfasern umwachsen hat. Diese Infiltration war typisch für die s.c. GL261-Tumoren und war nur selten bei U87MG-Tumoren zu sehen (Abbildung 24).

Bei den 1D11 behandelten Tieren konnte bis auf die Tendenz zum größeren Endgewicht der Tumoren kein histologischer Unterschied zu 13C4-behandelten und unbehandelten Tieren festgestellt werden. In nu/nu-Mäusen führt die 1D11-Behandlung von GL261Tumoren somit nicht zu Tumorregression. 
$1 \mathrm{D} 11$

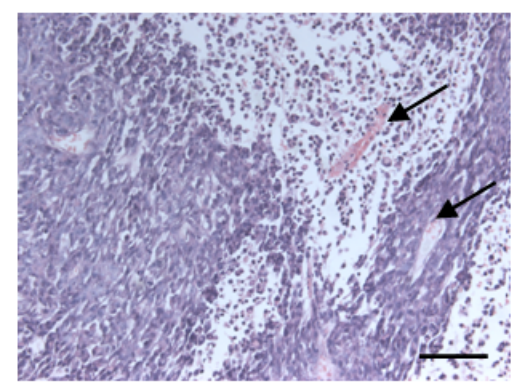

$13 \mathrm{C} 4$

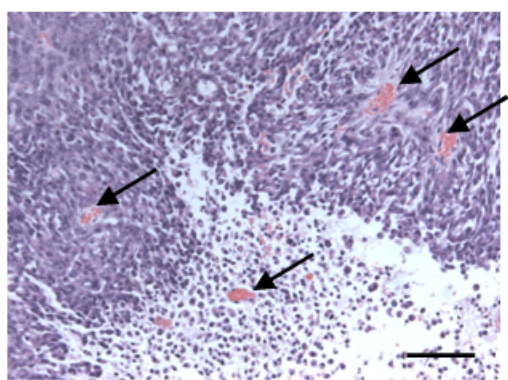

unbehandelt

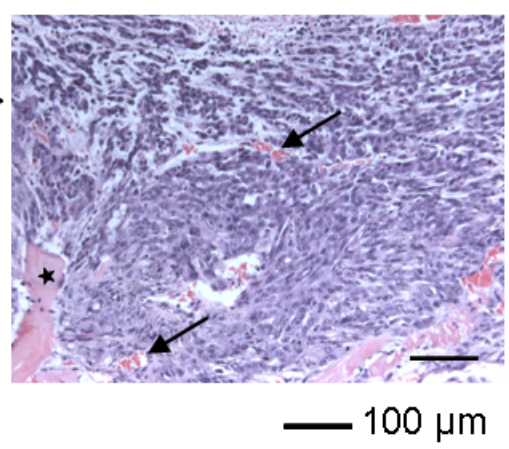

Abbildung 24: Morphologie s.c. in nu/nu-Mäusen angewachsener GL261-Tumoren. In den HEgefärbten Paraffinschnitten sind Kerne blau und Zytoplasma rosa gefärbt. Weitlumige Gefäße sind mit einem Pfeil, umwachsene Muskelfasern mit einem Stern gekennzeichnet.

\subsubsection{Immunhistochemische Färbung s.c. Gliome}

Das Ziel der histopathologischen Untersuchungen war, Veränderungen der Tumoren, die durch die Behandlung der Mäuse mit 1D11 verursacht wurden, näher zu charakterisieren. $\mathrm{Da}$ es im Tumor Unterschiede bezüglich der Proliferation und einwandernden Zellen zwischen Tumorzentrum und Tumorrandbereich geben kann, wurden diese Bereiche getrennt voneinander betrachtet. Für die quantitativen Auswertungen wurde von 5 Tumoren pro Versuchsgruppe jeweils ein Schnitt gefärbt. Die positiven Zellen in je drei Ausschnitten im Randbereich und im Zentrum von einem Tumorschnitt wurden gezählt und Mittelwerte für Tumormitte und Randbereich erstellt.

\subsubsection{Immunhistochemische Färbung proliferierender Zellen}

Proliferierende Zellen exprimieren Ki-67 in allen Phasen des Zellzyklus. Proliferierende Zellen wurden in den U87MG-Tumoren 1D11-behandelter und unbehandelter Mäuse mittels einer immunhistochemischen Färbung mit dem MIB 1 Antikörper der gegen Ki-67 gerichtet ist nachgewiesen. Da es in den Kontrollfärbungen mit dem sekundären Antikörper zur unspezifischen Anfärbung von Zellen in den GL261 Tumoren kam (Abbildung 25), konnten die proliferierenden Zellen in GL261-Tumoren nicht spezifisch angefärbt werden. 
Negativkontrolle

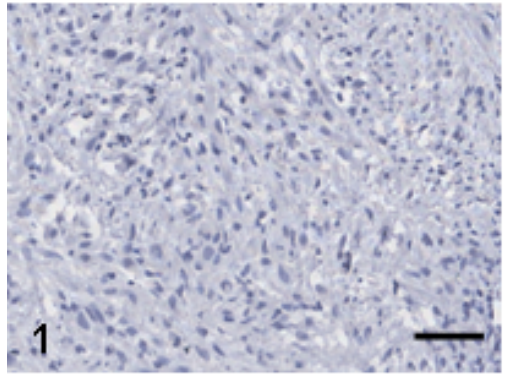

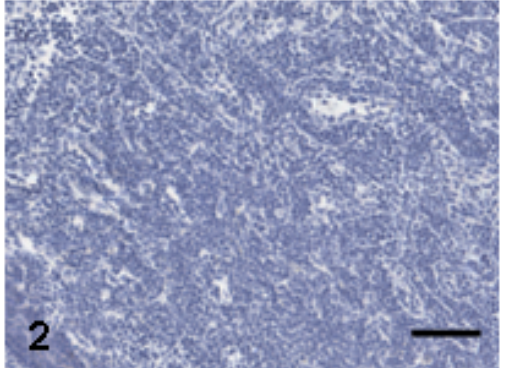

\section{Positivkontrolle}

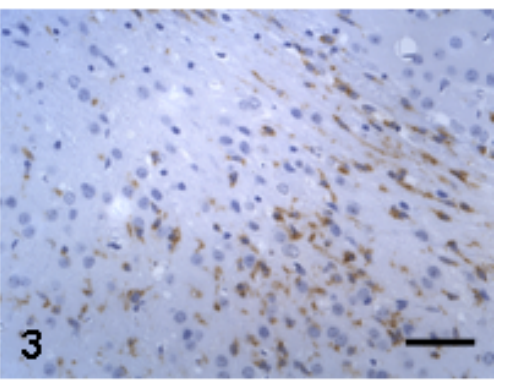

$50 \mu \mathrm{m}$

Abbildung 25: Kontrollen zur immunhistochemischen Detektion von proliferierenden Zellen im Paraffinschnitt von s.c. Gliomen mit MIB 1 monoklonalem Antikörper. 1: Negativkontrolle, Färbung von U87MG-Tumorschnitt nur mit sekundärem Antikörper. 2: Negativkontrolle, Färbung GL261Tumorschnitt nur mit sekundärem Antikörper. Hier zeigten sich unspezifische Färbungen. 3: Positivkontrolle, Färbung von humanem Tonsillenschnitt.

TGF- $\beta$ kann auf Tumorzellen proliferationshemmend wirken. Vermehrte Proliferation in den 1D11-behandelten U87MG-Tumoren würde das größere Volumen erklären. Die Färbung zeigte in der Tumormitte und im Randbereich proliferierende, Ki-67 positive Zellen.

Es zeigte sich keine vermehrte Proliferation in der Umgebung größerer Gefäße (Abbildung 26). In der quantitativen Auswertung zeigte sich kein signifikanter Unterschied in der Anzahl proliferierender Zellen zwischen Tumoren 1D11-behandelter und Tumoren unbehandelter Mäuse (Abbildung 27).

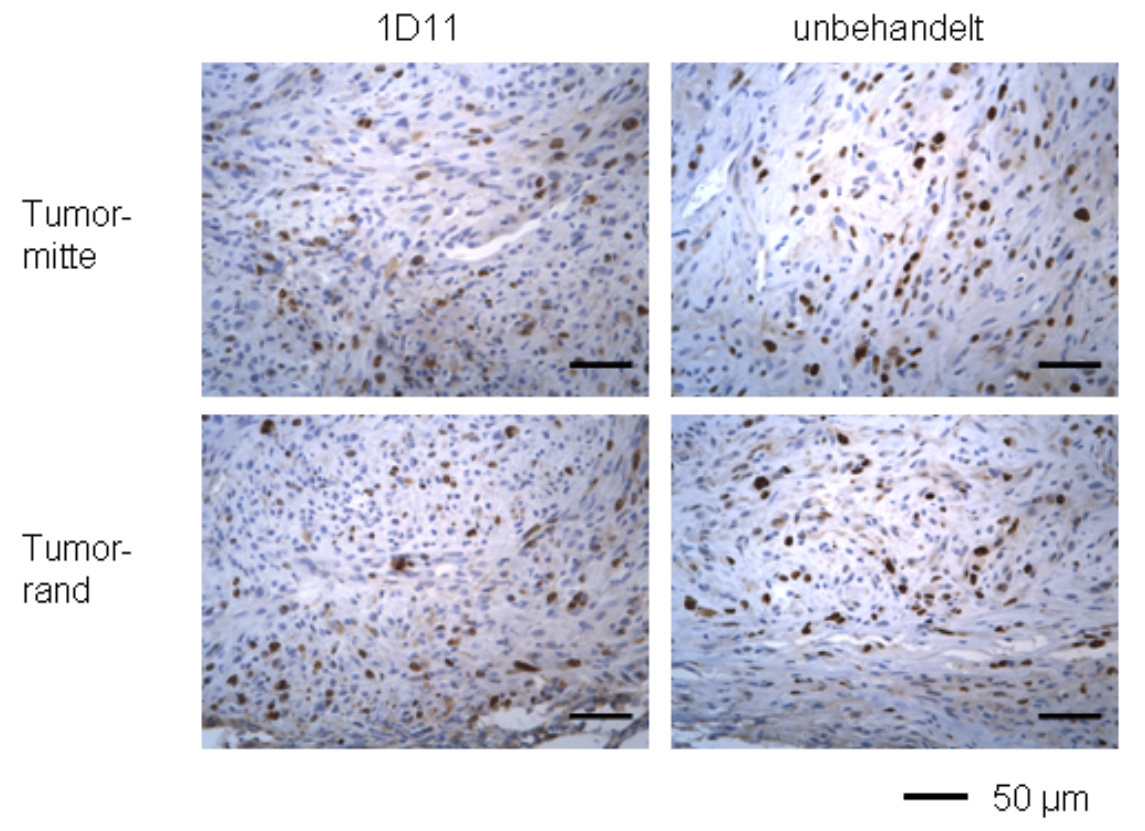

Abbildung 26: Proliferierende Zellen in s.c. U87MG-Tumoren in nu/nu-Mäusen. Die Detektion der proliferierenden Zellen erfolgte mittels MIB 1 Antikörper an Paraffinschnitten. Ki-67 positive Zellen sind braun-schwarz, die blaue Kernfärbung erfolgte mit Hämalaun. 


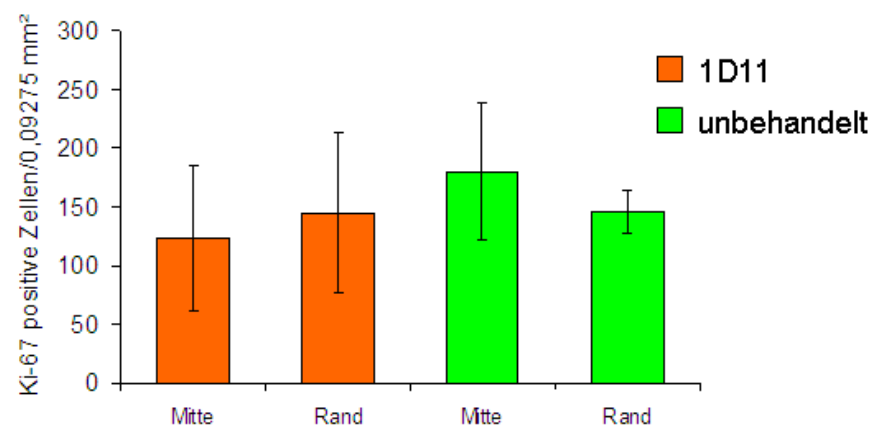

Abbildung 27: Quantitative Auswertung der Ki-67 Färbung s.c. U87MG-Tumoren. Die Anzahl an Ki-67-positiven Zellen in den Gruppen unterscheidet sich nicht signifikant voneinander (One Way Analysis of Variance $\mathrm{p}=0,636)$ ( $\mathrm{n}=5$ für jede Gruppe).

\subsubsection{Immunhistochemische Färbung apoptotischer Zellen}

In Paraffinschnitten wurden Zellen mit einem Antikörper gegen aktive Caspase-3, einer in der Apoptose aktivierten Protease, immunhistochemisch gefärbt. Damit sollte ermittelt werden, ob der Grund für den Größenunterschied der Tumore in vermehrter Apoptose in unbehandelten Tumoren lag. Weder bei humanen U87MG-Tumoren, noch bei murinen GL261-Tumoren zeigte sich dabei unspezifische Wechselwirkung zwischen dem Tumor und dem sekundären Antikörper (Abbildung 28).

\section{Negativkontrolle}
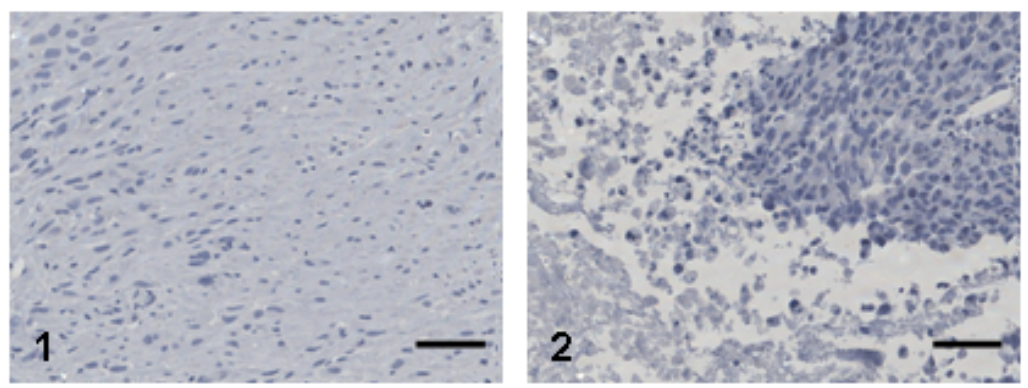

$50 \mu \mathrm{m}$

Abbildung 28: Kontrollen zur immunhistochemischen Detektion apoptotischer Zellen im Paraffinschnitt von s.c. Gliomen mit monoklonalem Antikörper gegen aktive Caspase 3. 1:Negativkontrolle, Färbung von U87MG-Tumorschnitt nur mit sekundärem Antikörper. 2: Negativkontrolle, Färbung von GL261-Tumorschnitt nur mit sekundärem Antikörper. 
Bei U87MG Tumoren waren in allen Versuchsgruppen apoptotische Zellen, sowohl in der Tumormitte als auch im Randbereich zu finden. An größeren Gefäßen fehlten apoptotische Zellen (Abbildung 29).

In Black/6-Mäusen s.c. angewachsene GL261-Tumoren zeigten eine andere Verteilung der apoptotischen Zellen (Abbildung 30). Sie waren in großer Anzahl im Randbereich der kompakten Tumorknoten lokalisiert. Im 1D11-behandelten Tumor gab es im Gegensatz zu den Kontrollen auch in der zelldichten Tumormitte Bereiche mit einer hohen Anzahl apoptotischer Zellen.

In GL261 Tumoren aus nu/nu-Mäusen war die Verteilung apoptotischner Zellen bei 13C4 behandelten und unbehandelten Tumoren ähnlich wie in den unbehandelten, in Black/6-Mäusen angewachsenen Tumoren (Abbildung 31).

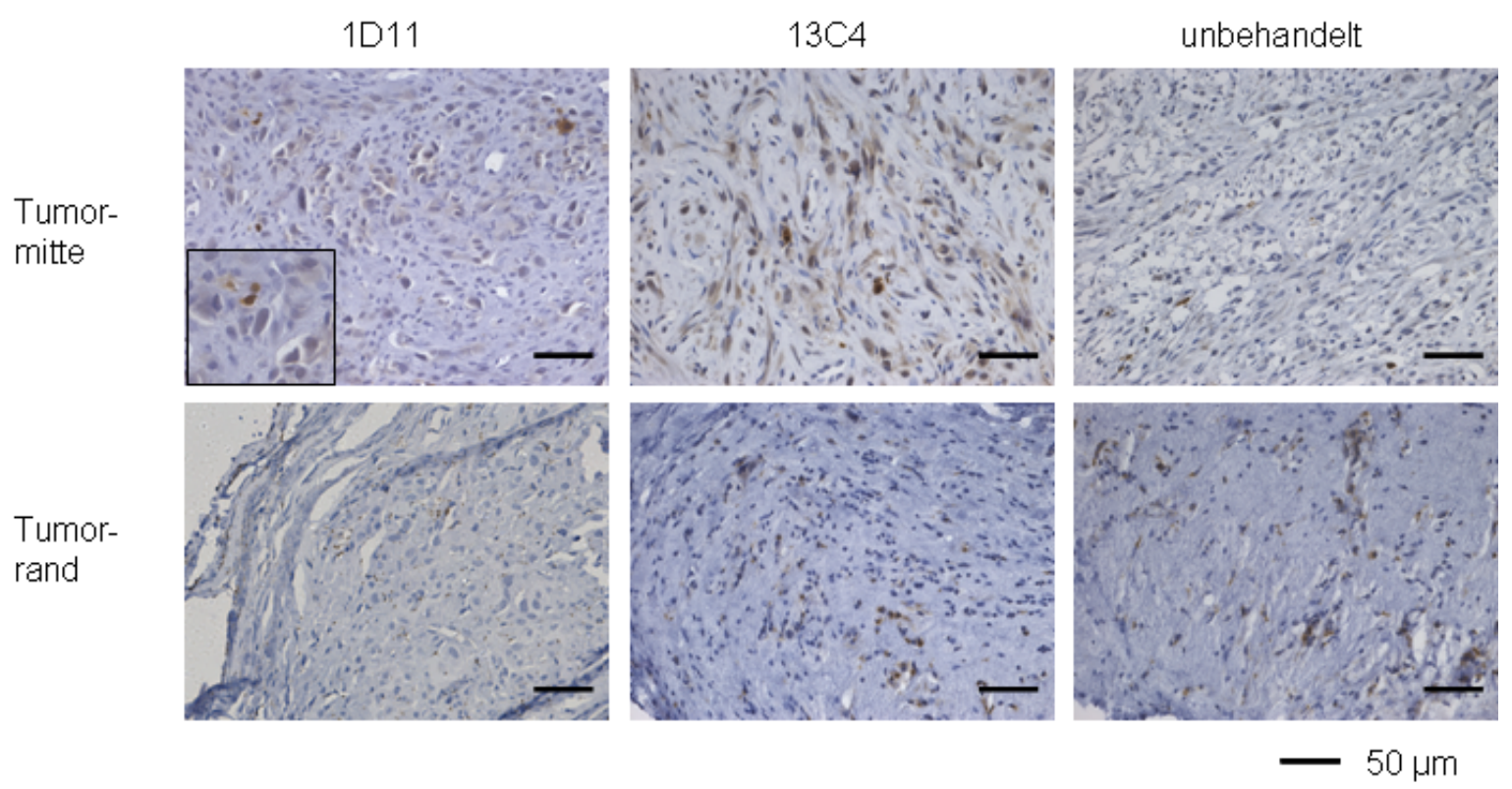

Abbildung 29: Apoptotische Zellen in s.c. U87MG-Tumoren in nu/nu-Mäusen. Die Detektion erfolgte mit einem aktive Caspase-3 Antikörper an Paraffinschnitten. Aktive Caspase-3 positive Zellen sind braun-schwarz, die blaue Kernfärbung erfolgte mit Hämalaun. Der vergrößerte Ausschnitt hat eine Breite von $67 \mu \mathrm{m}$. 
$1 \mathrm{D} 11$

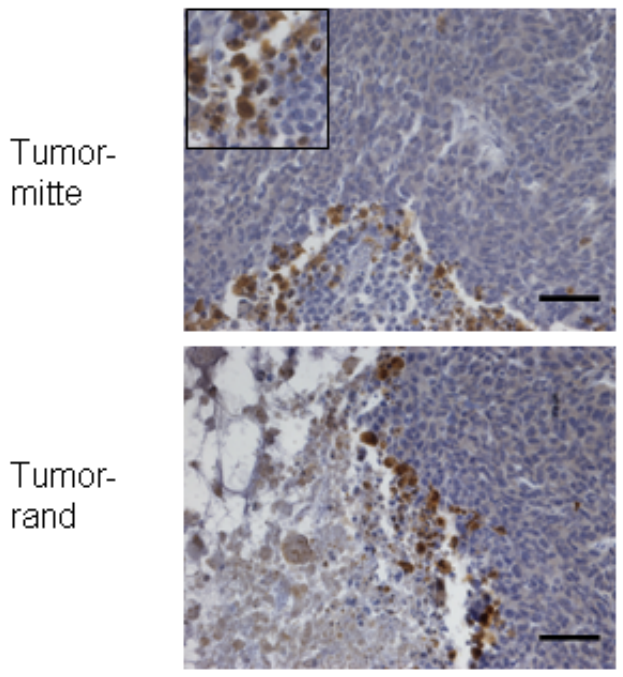

$13 \mathrm{C} 4$
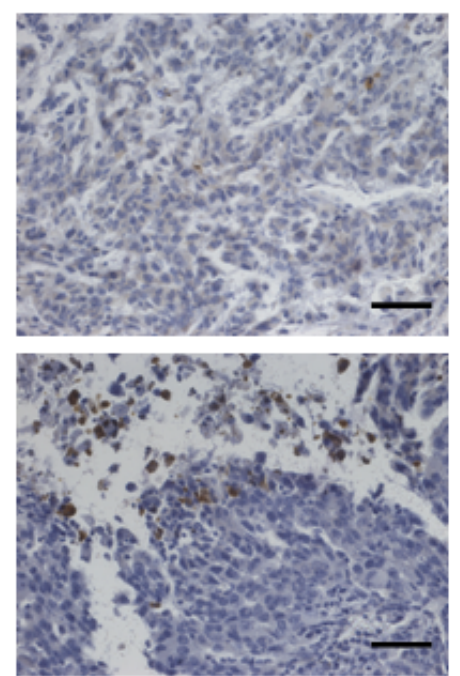

unbehandelt
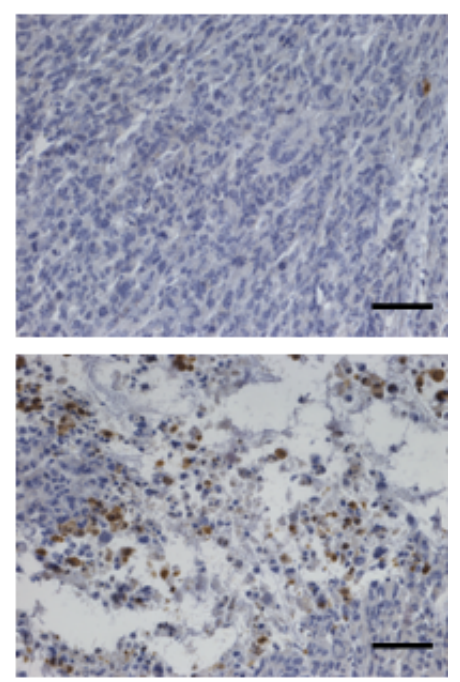

$50 \mu \mathrm{m}$

Abbildung 30: Apoptotische Zellen in s.c. GL261-Tumoren in Black/6-Mäusen. Die Detektion erfolgte mit einem aktive Caspase-3 Antikörper an Paraffinschnitten. Aktive Caspase-3 positive Zellen sind braun-schwarz, die blaue Kernfärbung erfolgte mit Hämalaun. Beachte: hohe Anzahl apoptotischer Zellen in der Mitte von Tumoren der 1D11-behandelten Gruppe. Der vergrößerte Ausschnitt hat eine Breite von $67 \mu \mathrm{m}$.

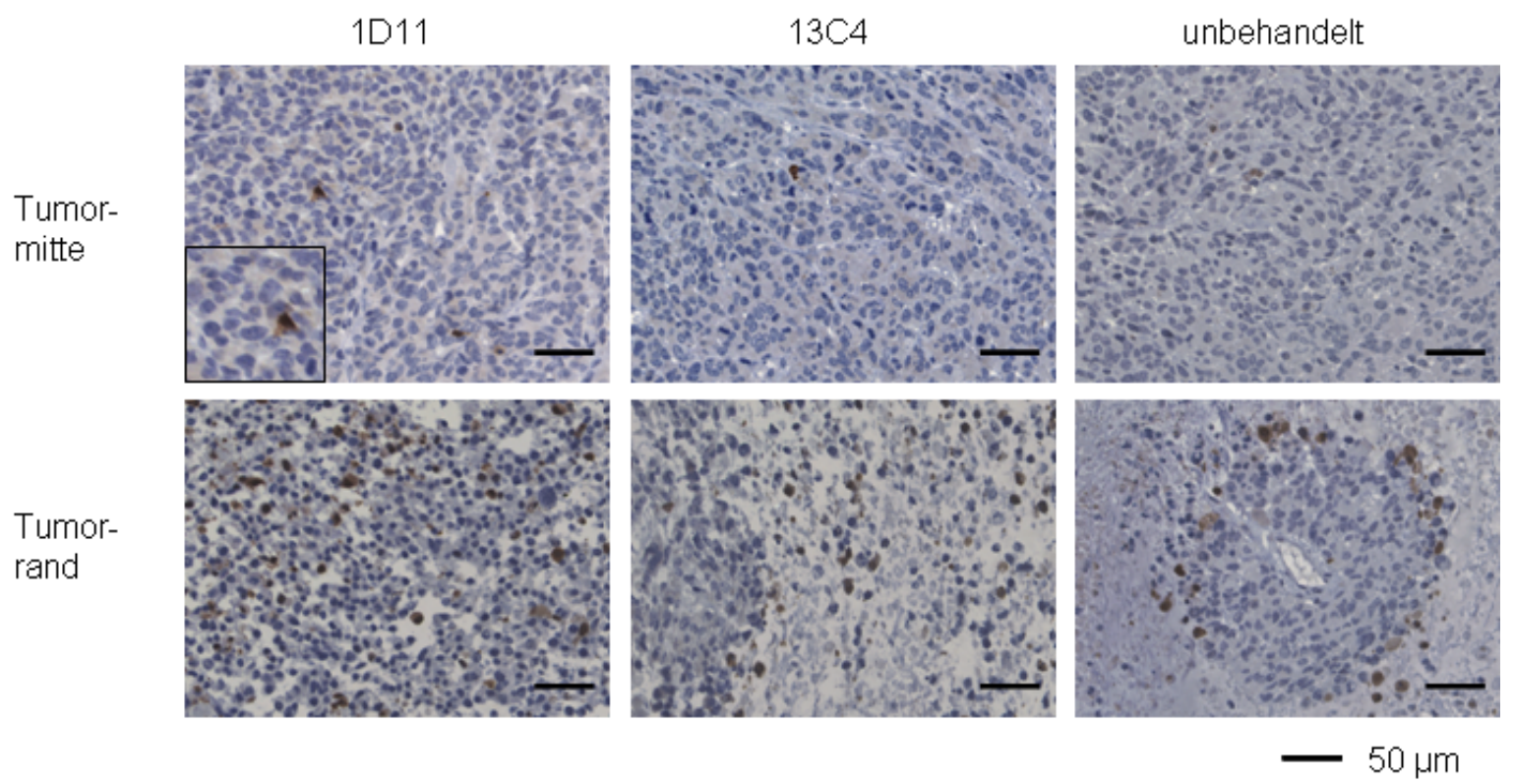

Abbildung 31: Apoptotische Zellen in s.c. GL261-Tumoren in nu/nu-Mäusen. Die Detektion erfolgte mit einem aktive Caspase-3 Antikörper an Paraffinschnitten. Aktive Caspase-3 positive Zellen sind braun-schwarz, die blaue Kernfärbung erfolgte mit Hämalaun. Der vergrößerte Ausschnitt hat eine Breite von $67 \mu \mathrm{m}$.

Die Quantitative Auswertung der Caspase-3 positiven Zellen erfolgte für alle drei Versuchsgruppen der Versuchsreihen A), B) und C) (Abbildung 32). Die Anzahl der apoptotischen Zellen im Tumorrandbereich ist in U87MG Tumoren nicht signifikant höher 
als in der Tumormitte (t-Test: $p=0,163$ für 1D11-behandelte, und $p=0,328$ für unbehandelte). Der Vergleich von Tumoren unbehandelter und 1D11-behandelter Mäuse zeigte keinen Unterschied (t-Test: $\mathrm{p}=0,186$ für Tumormitte, und $\mathrm{p}=0,679$ für Tumorrand).

In GL261 Tumoren 1D11-behandelter Black/6-Mäuse gibt es in der Tumormitte ähnlich viele apoptotische Zellen wie im Randbereich (Whitney Rank Sum Test: $p=0,667$ ) (Abbildung 32). Bei GL261-Tumoren unbehandelter Mäuse gibt es in der Tumormitte eine wesentlich kleinere Anzahl Caspase-3 positiver Zellen, als im Randbereich (Whitney Rank Sum Test: $\mathrm{p}<0,05)$. In der Tumormitte gibt es in den Tumoren 1D11-behandelter Mäuse signifikant mehr apoptotische Zellen als in der Tumormitte von unbehandelten (t-Test: $p<$ 0,05), während die Anzahl im Randbereich der GL261-Tumoren unbehandelter Mäuse mit der von GL261-Tumoren 1D11 behandelter Mäuse vergleichbar ist (t-Test: $p=0,394)$.

$\mathrm{Nu} /$ nu-Mäuse haben in GL261-Tumoren sowohl nach 1D11-Behandlung als auch ohne Behandlung signifikant mehr apoptotische Zellen im Tumorrandbereich als in der Mitte der Tumorknoten (Whitney Rank Sum Test: $p=0,001$ für 1D11 behandelte, Whitney Rank Sum Test: $\mathrm{p}<0,05$ für unbehandelte) (Abbildung 32).

Auch hier gibt es in der Tumormitte signifikant mehr apoptotische Zellen in Tumoren behandelter im Vergleich zu Tumoren unbehandelter Mäuse, während es im Randbereich keinen Unterschied gibt. (Mann-Whitney Rank Sum Test: $\mathrm{p}<0$,05 für Tumormitte, und tTest: $\mathrm{p}=0,815$ für Tumorrand). Der Effekt ist aber wesentlich schwächer ausgeprägt als in GL261-Tumoren 1D11 behandelter Black/6-Mäuse.

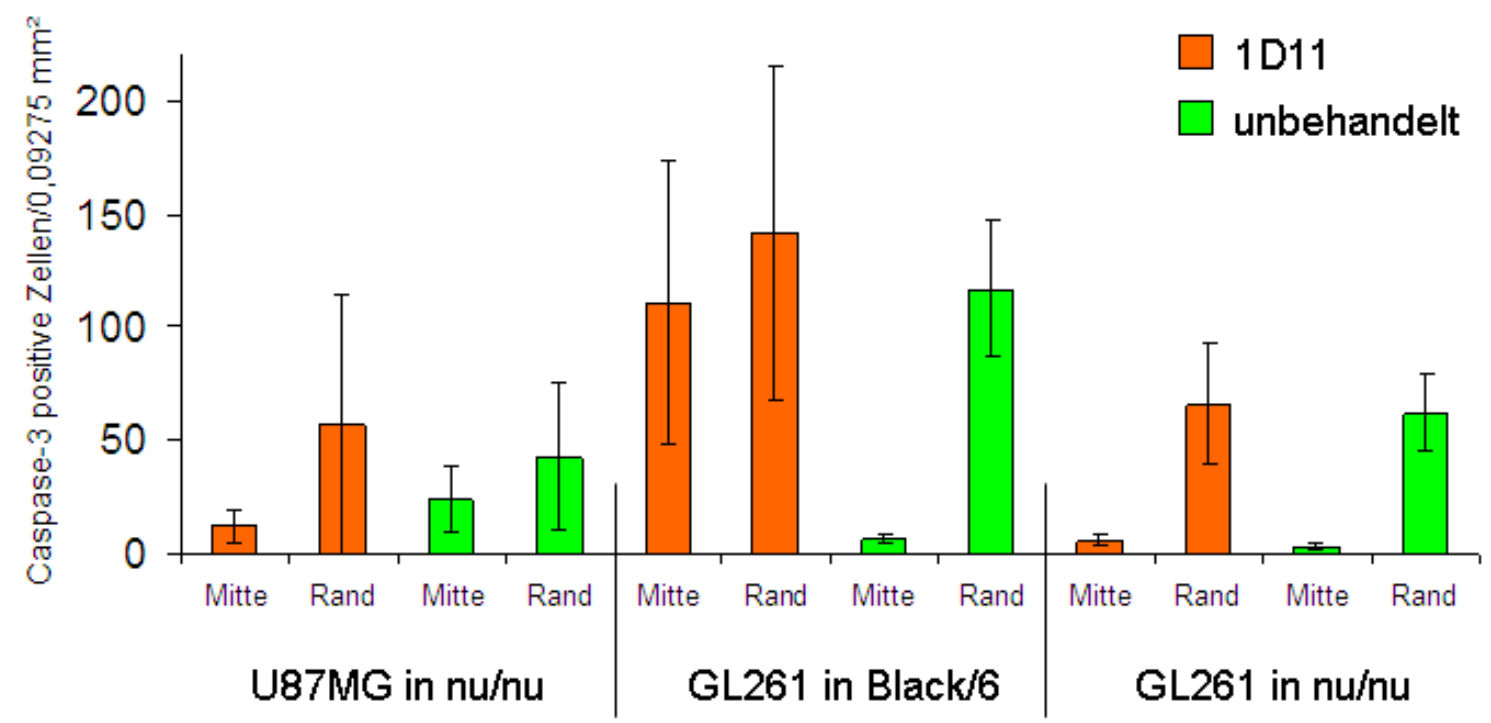

Abbildung 32: Quantitative Auswertung der Caspase-3 Färbungen. Die Anzahl an Caspase-3 positiven Zellen in den Gruppen der U87MG-Tumoren unterscheidet sich nicht signifikant voneinander. In den GL261-Tumoren 1D11-behandelter Black/6-Mäuse gibt es keinen signifikanten Unterschied in der Zahl der apoptotischen Zellen zwischen Tumormitte und Tumorrand. In allen anderen GL261-Tumoren gibt es einen signifikanten Unterschied zwischen Tumormitte und Tumorrand. $n=5$ für jede Gruppe, nur für Tumore 1D11-behandelter Black/6-Mäuse n=2. 


\subsubsection{Immunfluoreszenzfärbung von Gefäßendothelzellen}

TGF-beta wirkt auf Gefäßendothelzellen angiogen. Darum könnte es sein, dass in den Tumoren der 1D11-behandelten Mäuse, in denen weniger TGF- $\beta$ zur Rezeptorbindung zur Verfügung steht, weniger Gefäße neu ausgebildet werden. Diese Hypothese wurde mit Endothelzellfärbung mittels Faktor-VIII Antikörper-Färbung überprüft.

In den Schnitten s.c. U87MG-Tumoren waren verschiedene, angeschittene Gefäßabschnitte gut zu erkennen. Es gab größere und kleinere Gefäßdurchmesser (Abbildung 33).

Die quantitative Auswertung erfolgte durch Zählen der Gefäßanschnitte pro Bild. Für jede der Versuchsgruppen wurde die durchschnittliche Anzahl anhand von Färbungen je eines Schnittes von mindestens 9 Tumoren ermittelt. In humanen U87MG-Tumoren gab es keinen Unterschied in der Gefäßdichte zwischen Tumoren 1D11-behandelter und Tumoren unbehandelter Mäuse (Abbildung 34).
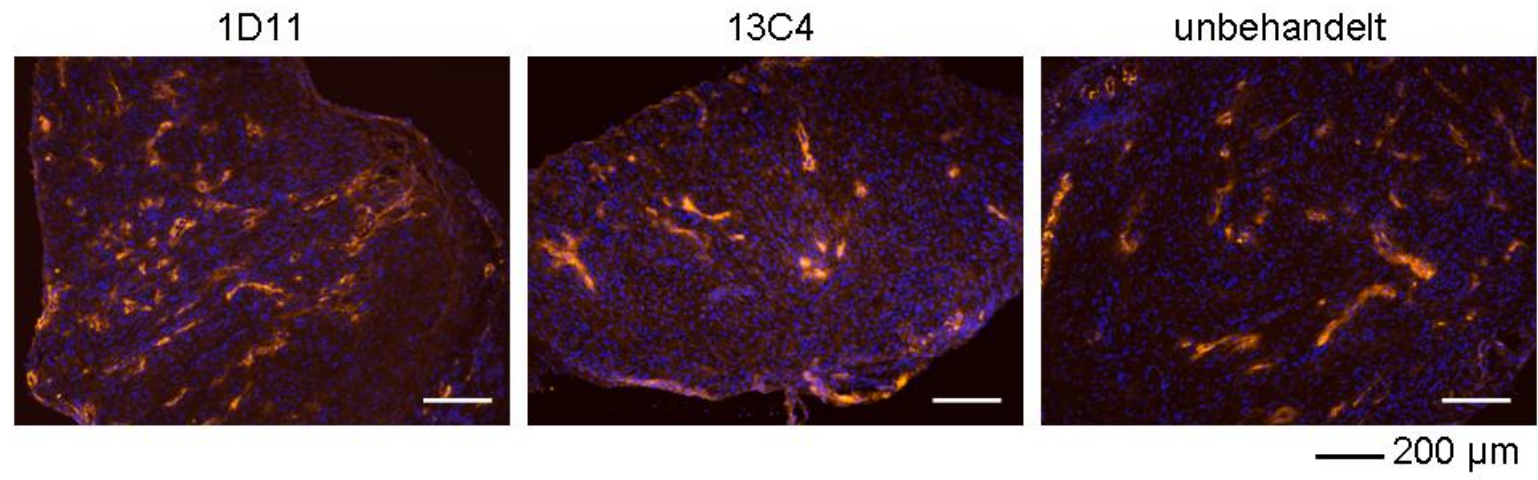

Abbildung 33: Endothelzellen in s.c. U87MG-Tumoren in nu/nu-Mäusen. Die Detektion erfolgte im Gefrierschnitt mittels Faktor-VIII Antikörper. Faktor-VIII positive Zellen sind orange, blaue Kernfärbung erfolgte mit DAPI.

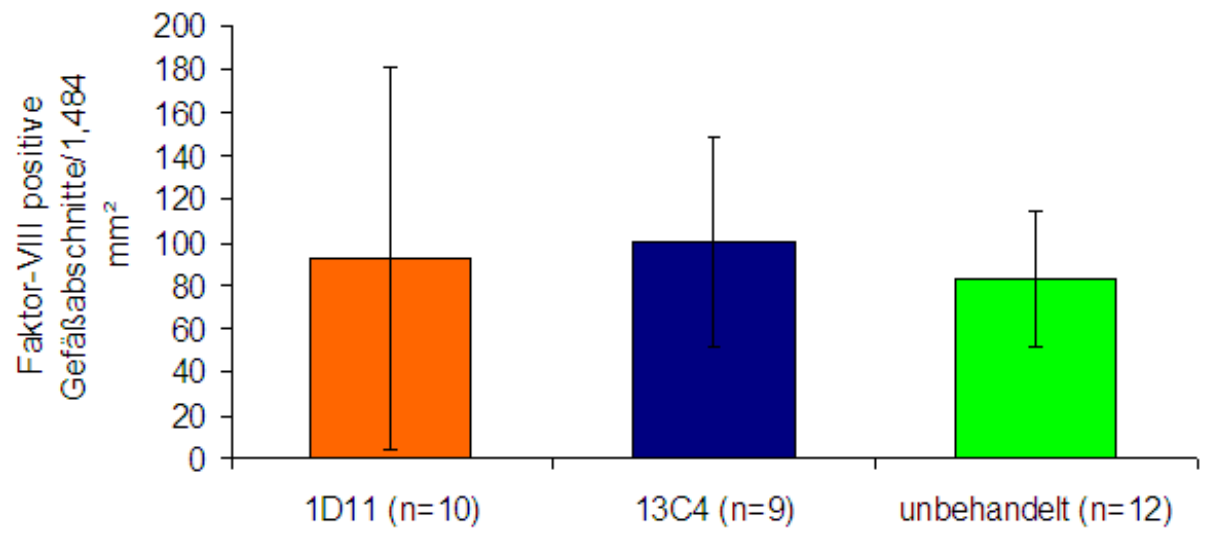

Abbildung 34: Quantitative Auswertung der Endothelzellfärbung durch Bestimmung der Gefäßdichte. Für jeden Faktor-VIII-gefärbten Schnitt s.c. U87MG-Tumoren wurde die Anzahl der Gefäßanschnitte pro Gesichtsfeld ermittelt. Die Anzahl der Gefäßanschnitte in Tumoren 1D11behandelter Mäuse unterscheidet sich nicht von der in Tumoren unbehandelter Mäuse. 
Bei Betrachtung der Gefäßdurchmesser gab es für jede Versuchsgruppe Tumoren, die eher kleine, und solche, die eher größere Gefäßdurchmesser aufwiesen. Hier ließ sich eine Tendenz zu eher kleineren Gefäßen in 1D11-behandelten Tumoren feststellen.

Da in der Versuchsreihe C nur drei kleine GL261-Tumoren 1D11-behandelter Black/6Mäuse angewachsen sind, stand nur einer für die Endothelzellfärbung zur Verfügung. In diesem Tumor gab es nur wenig Gefäße, während die unbehandelten Tumore einige größere und zahlreiche kleine Gefäße aufwiesen (Abbildung 35).
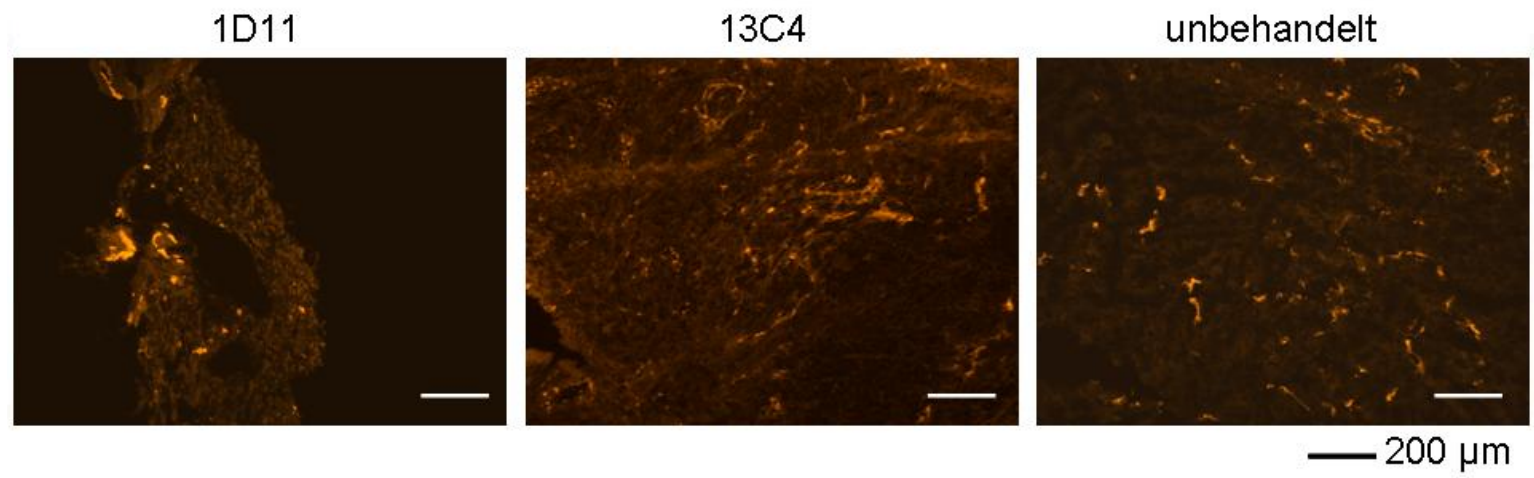

Abbildung 35: : Endothelzellen in s.c. GL261-Tumoren in Black/6-Mäusen. Die Detektion erfolgte im Gefrierschnitt mittels Faktor-VIII Antikörper. Faktor-VIII positive Zellen sind orange.

\subsubsection{Immunhistochemische Färbung von Makrophagen}

Im HE-Schnitt mancher U87MG-Tumore 1D11-behandelter Mäuse sind im Tumorrandbereich eingewanderte Makrophagen sichtbar (Abbildung 18). Die Immunhistochemische Färbung von Makrophagen in Paraffinschnitten der Tumore sollte Aufschluss darüber geben, ob eine verstärkte Immunreaktion in den Tumoren 1D11behandelter Mäuse zu finden ist.

Die Kontrollfärbungen zeigten bei Einsatz des zweiten Antikörpers weder im humanen U87MG-Tumor noch im Maus-Lymphknoten unspezifische Bindungen. In der Positivkontrolle war zu sehen, dass Makrophagen erkannt werden (Abbildung 36). 
Negativkontrolle

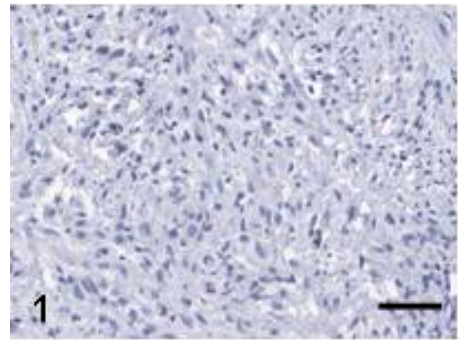

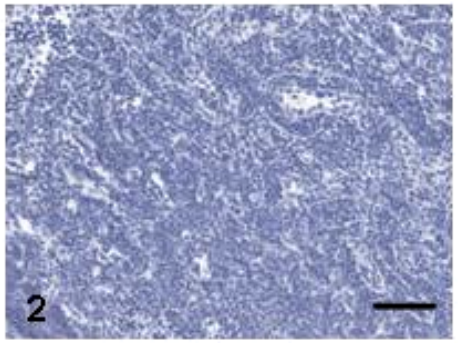

Positivkontrolle

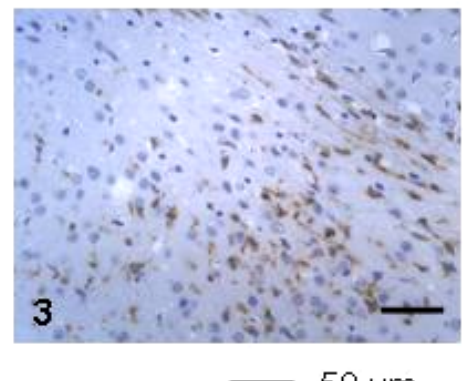

$50 \mu \mathrm{m}$

Abbildung 36: Kontrollen zur immunhistochemischen Detektion aktivierter Makrophagen im Paraffinschnitt von s.c. Gliomen mit Mac-3 monoklonalem Antikörper. 1: Negativkontrolle, Färbung von U87MG-Tumorschnitt nur mit sekundärem Antikörper. 2: Negativkontrolle, Färbung von Black/6Maus Lymphknotenschnitt nur mit sekundärem Antikörper. 3: Positivkontrolle, Färbung von Gehirnschnitt einer Maus mit Inflammationsreaktion im Gehirn (Experimentelle allergische Enzephalomyelitis (EAE)). Kernfärbung mit Hämalaun.

In den U87MG Tumoren waren Makrophagen sowohl in der Tumormitte als auch im Randbereich lokalisiert (Abbildung 37). Oft, wie im Bild der Tumormitte des Tumors einer 1D11-behandelten Maus (Abbildung 37) zu sehen, befanden sich Makrophagen in der Nähe von größeren Blutgefäßen.

$1 \mathrm{D} 11$

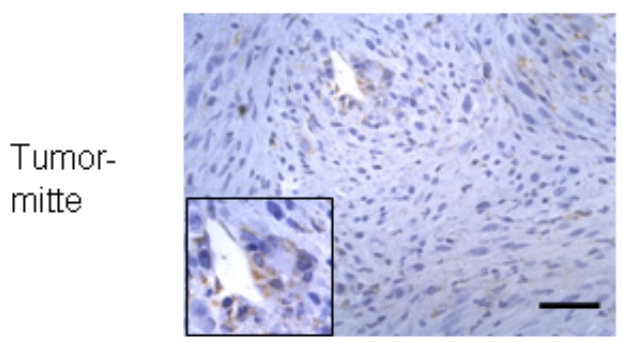

Tumorrand

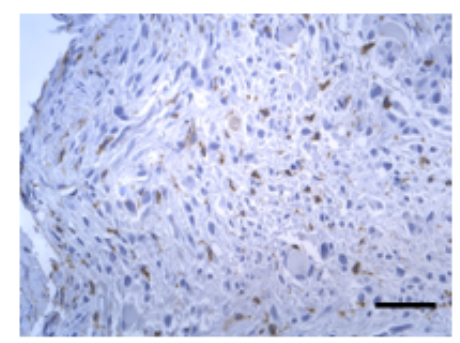

$13 \mathrm{C} 4$
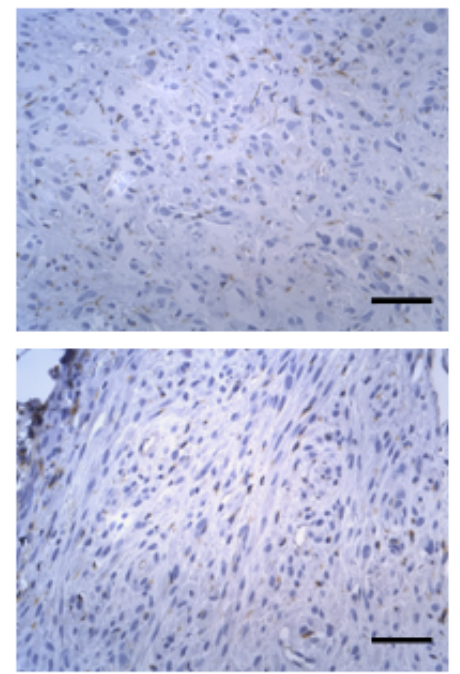

unbehandelt
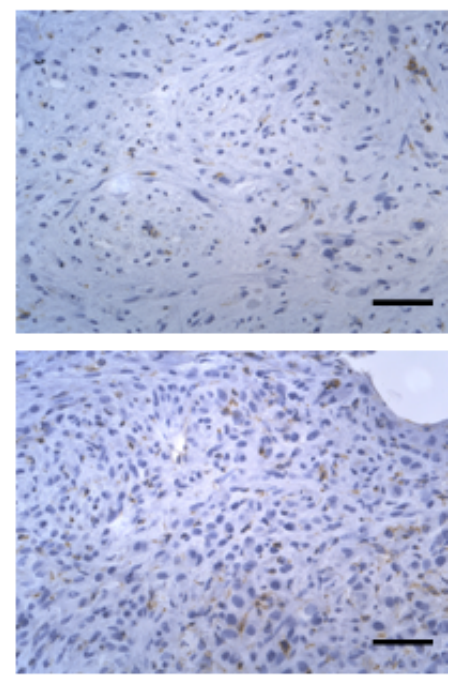

$50 \mu \mathrm{m}$

Abbildung 37: Aktivierte Makrophagen in s.c. U87MG-Tumoren in nu/nu-Mäusen. Die Detektion erfolgte mittels Mac-3 Antikörper an Paraffinschnitten. Mac-3 positive Zellen sind braunschwarz, die blaue Kernfärbung erfolgte mit Hämalaun. Der vergrößerte Ausschnitt hat eine Breite von $67 \mu \mathrm{m}$.

Die quantitative Auswertung der Makrophagenfärbung zeigte im Randbereich des Tumors mehr Makrophagen als in der Tumormitte (Abbildung 38). Außerdem war die 
Zahl der Makrophagen im Randbereich der Tumoren 1D11-behandelter Mäuse tendenziell höher als die der Tumoren unbehandelter Mäuse. Dieser Unterschied war jedoch nicht signifikant (t-Test: $\mathrm{p}=0,421$ für Tumormitte; $\mathrm{p}=0,329$ für Tumorrand).

Die immunhistochmische Färbung von Makrophagen in s.c. in Black/6-Mäusen angewachsenen GL261-Tumoren (Abbildung 39), wie auch die Färbung der in nu/nuMäusen angewachsenen GL261-Tumoren (Abbildung 40) zeigte eine so hohe Makrophagendichte, dass ein Zählen der einzelnen Zellen kaum möglich war. Es ließ sich auch kein Unterschied zwischen Tumoren 1D11-behandelter und unbehandelter Mäuse erkennen. Bei den in nu/nu-Mäusen angewachsenen GL261-Tumoren fielen wieder die großlumigen Gefäße auf, die sowohl in dem Bild der Tumormitte des 1D11 behandelten, als auch in dem Bild der Tumormitte eines unbehandelten Tumors $\mathrm{zu}$ sehen sind (Abbildung 40). Eine vermehrte Präsenz von Makrophagen in Gefäßnähe war hier nicht zu verzeichnen.

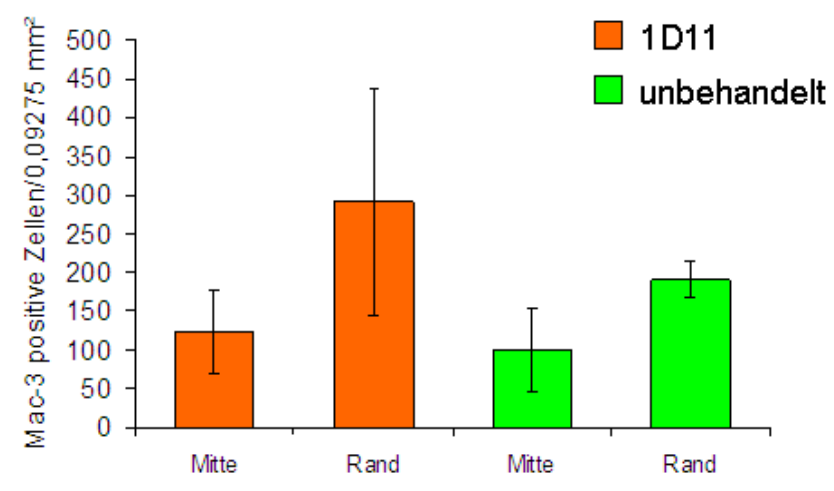

Abbildung 38: Quantitative Auswertungen der Mac-3 Färbungen. Die Anzahl der Makrophagen in s.c. U87MG-Tumoren 1D11-behandelter Mäuse unterscheidet sich weder für die Tumormitte noch für den Tumorrand signifikant von der in Tumoren unbehandelter Mäuse (t-Test: $p=0,421$ für Tumormitte; $\mathrm{p}=0,329$ für Tumorrand). $\mathrm{n}=5$ für jede Gruppe. 
$1 \mathrm{D} 11$
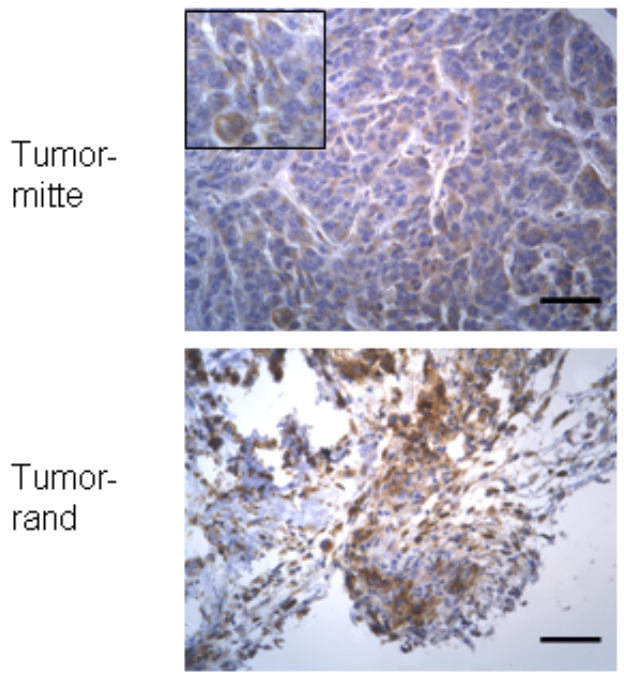

$13 \mathrm{C} 4$
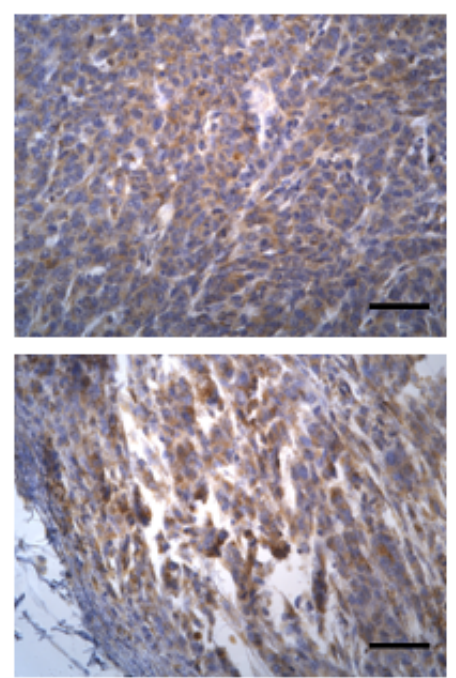

unbehandelt
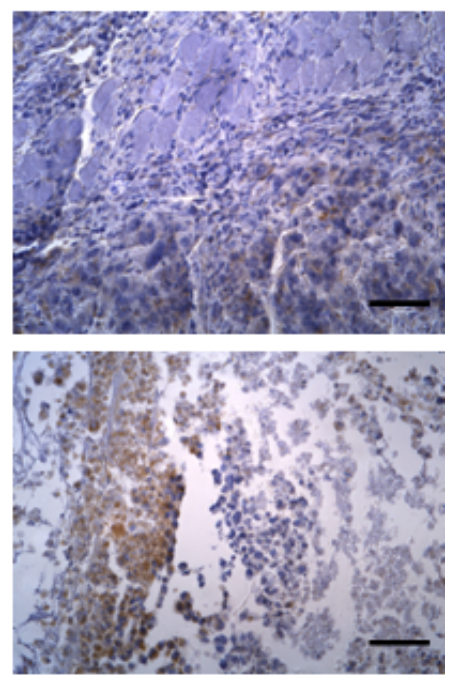

$50 \mu \mathrm{m}$

Abbildung 39: Aktivierte Makrophagen in s.c. GL261-Tumoren in Black/6-Mäusen. Die Detektion erfolgte mittels Mac-3 Antikörper an Paraffinschnitten. Mac-3 positive Zellen sind braunschwarz, die blaue Kernfärbung erfolgte mit Hämalaun. Der vergrößerte Ausschnitt hat eine Breite von $67 \mu \mathrm{m}$.
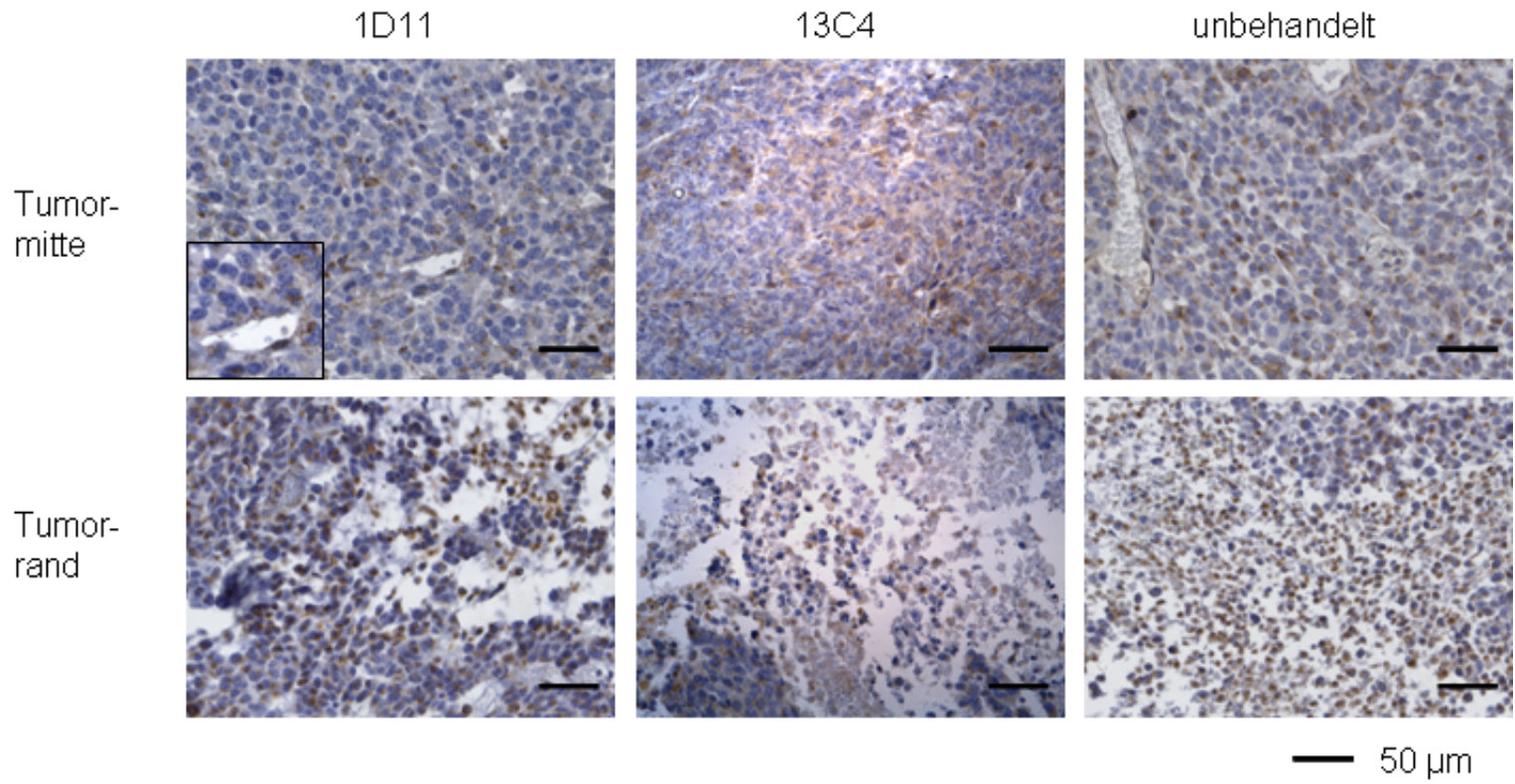

Abbildung 40: Aktivierte Makrophagen in s.c. GL261-Tumoren in nu/nu-Mäusen. Die Detektion erfolgte mittels Mac-3 Antikörper an Paraffinschnitten. Mac-3 positive Zellen sind braun-schwarz, die blaue Kernfärbung erfolgte mit Hämalaun. Der vergrößerte Ausschnitt hat eine Breite von $67 \mu \mathrm{m}$. 


\subsection{Einfluß von humanem, rekombinantem TGF- $\beta$ auf das Einwandern von Peritonealmakrophagen in GL261-Sphäroide}

Da ein Einfluß der Makrophagen in GL261-Tumoren durch Auswertung der immunhistologisch gefärbten Schnitte nicht ermittelt werden konnte, sollte an Sphäroiden aus GL261-Zellen untersucht werden, ob TGF- $\beta$ das Einwandern von Makrophagen beeinflusst. Um die Makrophagen von den Tumorzellen unterscheiden zu können, wurden sie vor der Isolation in vivo mit einem grünen Fluoreszenzfarbstoff markiert. Die Sphäroide wurden in $100 \mu \mathrm{l}$ Medium mit je 5000 Makrophagen und mit 25 ng/ml TGF- $\beta 2$ oder 5000 Makrophagen alleine inkubiert. Nach 60 h waren von 26 Sphäroiden ohne zusätzliches TGF- $\beta 2$ im Medium keine mehr intakt (Abbildung 41, 2). Von den 26 Späroiden die mit zusätzlichem TGF- $\beta 2$ inkubiert waren, waren noch 7 intakt und Makrophagen waren eingewandert (Abbildung 41, 3). Es konnte mit diesem Versuch gezeigt werden, dass zusätzliches TGF- 32 im Medium das Zerstören der Sphäroide durch die Makrophagen verhindern kann.
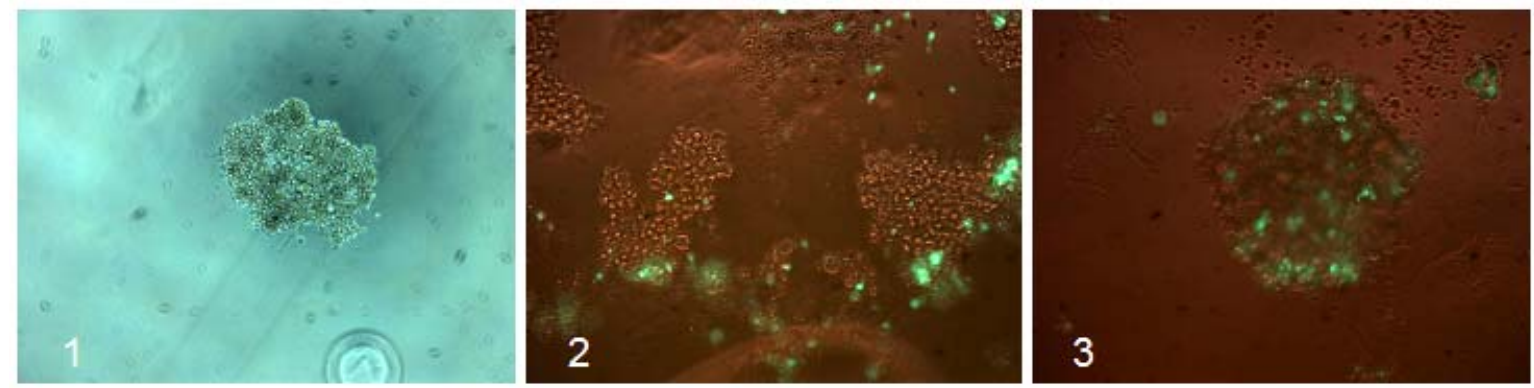

Abbildung 41: GL261 Gliomzellsphäroide 60 h nach Makrophagenbehandlung. 1: GL261Sphäroid ohne Behandlung (100x, Hellfeld), 2: GL261-Sphäroid $60 \mathrm{~h}$ nach Zugabe von Peritonealmakrophagen (200x, Fluoreszenz-Hellfeldkombination), 3: GL261-Sphäroid $60 \mathrm{~h}$ nach Zugabe von Peritonealmakrophagen und $25 \mathrm{ng} / \mathrm{ml}$ rekombinantem, humanem TGF- $\beta 2$ (200x, Fluoreszenz-Hellfeldkombination). Tumorzellen sind nicht fluoreszierend, PKH2-markierte Peritonealmakrophagen der Black/6-Maus fluoreszieren grün.

\subsection{D11 im intrazerebralen Gliom}

Das Wachstum s.c. GL261-Tumoren konnte in Black/6-Mäusen durch Behandlung mit 1D11 gehemmt werden. Daher sollte in diesem Versuchsmodell untersucht werden, ob 1D11 in intrazerebrale Tumoren gelangt und ob dies in vivo erfasst werden kann. Für diese Versuche wurde wie auch für die Versuche zur Anreicherung im s.c. Tumor mit AF680 oder AF594 gekoppeltes 1D11 verwendet. 


\subsubsection{D11 im intrazerebralen Tumor in vivo}

Mit diesem Versuch sollte festgestellt werden, ob eine Anreicherung von AF680 1D11 im Tumor in vivo dargestellt werden kann. Dazu wurden Black/6-Mäuse mit intrazerebralen GL261-Tumoren zu verschiedenen Zeitpunkten nach Implantation einmalig i.v. mit AF680 1D11 behandelt. Die Fluoreszenz im Kopf wurde mit dem eXplore Optix gemessen. Anschließend wurden die Gehirne aus den Mäusen präpariert und ex vivo die Fluoreszenz noch einmal gemessen. Die Gehirne wurden anschließend in PFA 4\% fixiert und aufgeschnitten. In Abbildung 42 ist für eine Behandlung an Tag 8 und eine an Tag 10 nach Tumorzellimplantation zu sehen, dass der Tumor an den Stellen zu finden war, an der die ex vivo gemessenen Gehirne zuvor fluoreszierten. Hier konnte mit dem eXplore OptixSystem ein Eindringen von AF680 1D11 in den Tumor festgestellt werden.

Die Abbildung verdeutlicht zudem, dass die in vivo gemessene Fluoreszenzintensität im Kopf mit zunehmender Versuchsdauer abnimmt. Das liegt wahrscheinlich am nachwachsenden Fell auf dem Kopf, welches vor der intrazerebralen Implantation durch Kaltwachsstreifen entfernt wurde. Aus diesem Grund war es schwierig bei Black/6-Mäusen in vivo die Anreicherung von geringen Mengen an fluoreszenzmarkierten Antikörpern im Gehirntumor zu detektieren. Ex vivo dagegen konnte die Fluoreszenz von Antikörpern im Gehirn problemlos erkannt werden.

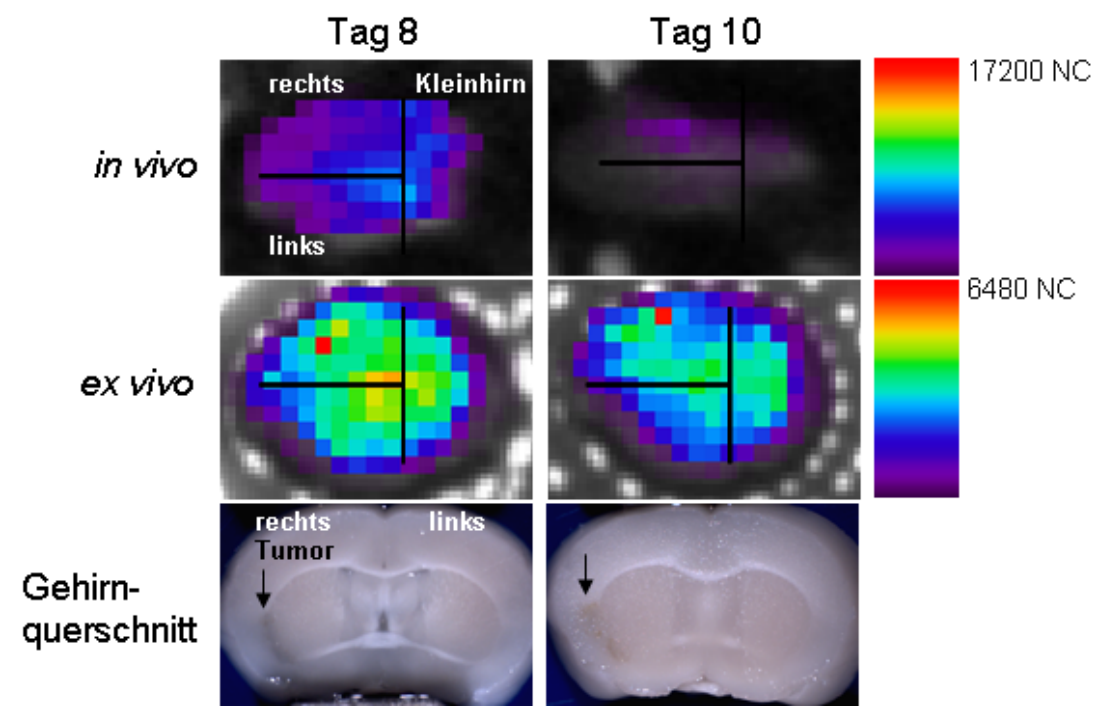

Abbildung 42 : Vergleichende Messung der Fluoreszenzintensität in GL261-Tumoren in Black/6-Mäusen in vivo und in entnommenen Gehirnen ex vivo. Die Messungen erfolgten $3 \mathrm{~h}$ nach i.v. AF680 1D11-Injektion. Ergänzend dazu sind coronare Schnitte der entsprechenden PFA-fixierten Gehirne mit den sich entwickelnden Tumoren gezeigt. 


\subsubsection{D11 im intrazerebralen Tumor in der Fluoreszenzmikroskopie}

Mäusen, bei denen in der rechten Hemisphäre intrazerebrale GL261-Tumoren 20 Tage angewachsen sind, wurde i.v. 4,8 mg/kg AF594 1D11 appliziert. Nach 1,5 h wurden die Tiere getötet und die Gehirne perfundiert. Die Gehirne wurden herauspräpariert und sofort eingefroren. In Gefrierschnitten war die Fluoreszenzintensität im ZNS insgesamt gering und auch im Tumor waren Bereiche erkennbar, in denen keine erhöhte Fluoreszenz zu sehen war (Abbildung 43).

Auch im peritumoralen Hirn der übrigen rechten Hemisphäre und in der linken Hemisphäre war keine erhöhte Fluoreszenz im Gewebe meßbar. Somit war in Gefrierschnitten eine Anreicherung von AF594 1D11 fluoreszenzmikroskopisch nur im Bereich des Tumors detektierbar.

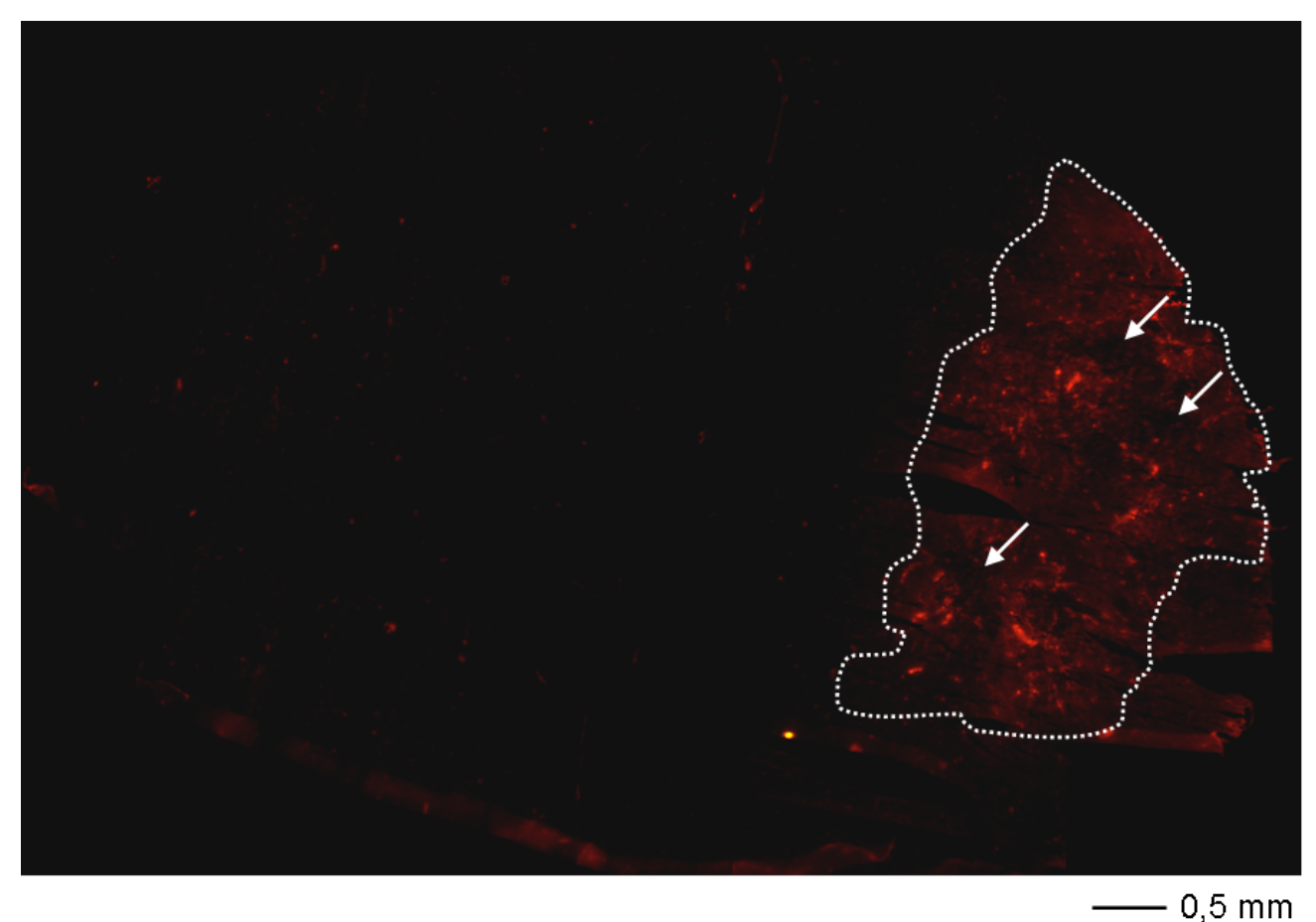

Abbildung 43: Übersicht über die Verteilung von Fluoreszenz in GL261-Tumoren in Black/6Mäusen. Entnahme der Gehirne 1,5 h nach i.v. Injektion von AF594 1D11. Die hellere, umrandete Fläche in der rechten Hemisphäre ist die Region, in der der Tumor zu finden ist. Bereiche in denen keine erhöhte Fluoreszenz im Tumor zu finden ist, sind mit Pfeilen markiert.

\subsubsection{D11-Behandlung intrazerebraler Gliome}

Im nächsten Schritt sollte die Wirksamkeit einer Behandlung intrazerebraler GL261Tumoren in Black/6-Mäusen mit 1D11 untersucht werden. In dieser Versuchsreihe (D) wurden die Tiere ab Tag 3 zwei Mal wöchentlich i.v. mit 4,8 mg/kg KG 1 D11 behandelt. 
Der Versuch wurde zu dem Zeitpunkt, an dem das erste Tier durch Gewichtsverlust auffiel, beendet. Beim Aufschneiden der fixierten Gehirne konnte man sehen, dass die einzelnen Tumoren in ihrer Größe stark variierten. Die Tumorgröße war unabhängig von der jeweiligen Behandlung. In HE-gefärbten seriellen Schnitten wurde der größte Durchmesser für jeden Tumor ermittelt. Abbildung 44 veranschaulicht, dass in Bezug auf den Tumordurchmesser kein Unterschied zwischen den 1D11 behandelten und den unbehandelten Mäusen bestand.

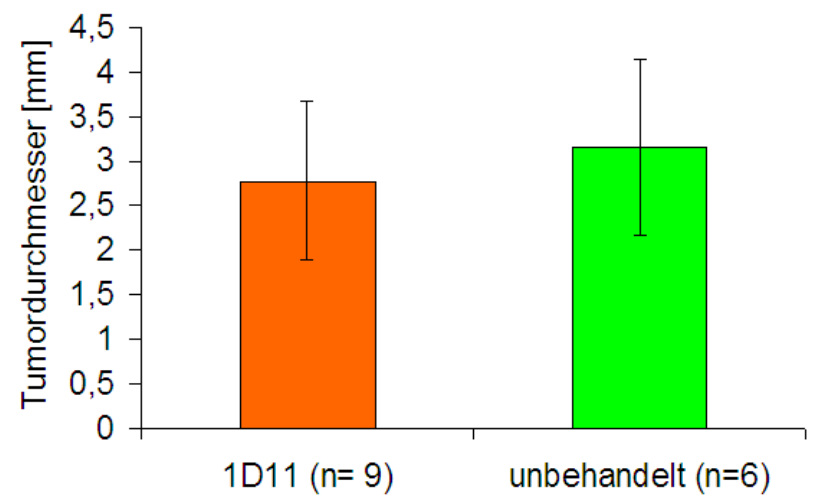

Abbildung 44: Maximaler Durchmesser von GL261-Gliomen. Die Größe wurde an HE-gefärbten Hirnschnitten ermittelt. Die Gehirne wurden an Tag 25 nach Implantation entnommen. Die maximalen Durchmesser der Tumoren der i.v. mit 1D11 behandelten Mäuse unterscheiden sich nicht signifikant von denen unbehandelter Mäuse (t-Test: $\mathrm{p}=0,491)$.

Der histologische Befund der HE-gefärbten Schnitte zeigte eine unterschiedliche Zelldichte im Tumorzentrum. Die Tumoren unbehandelter und die 13C4-behandelter Mäuse waren im Zentrum matrixreicher (Abbildung 45, A 2), während die Tumoren 1D11 behandelter Mäuse weniger Matrix aufwiesen (Abbildung 45, B 1). Eine größere Nekrose fand sich in einem Tumor einer 1D11-behandelten Maus (Abbildung 45, B 1). In Tumoren unbehandelter Tiere fanden sich keine deutlichen nekrotischen Bereiche. Proliferierende Zellen waren in allen Tumoren zu sehen, genauso wie die Umwachsung von Gefäßen außerhalb des Tumorknotens durch Tumorzellen. Ein Beispiel hierfür zeigt Abbildung 45, B 2, bei der ein von Tumorzellen rekrutiertes Gefäß deutlich zu erkennen ist.

Im Tumorrandbereich fiel auf, dass die Tumoren 1D11-behandelter Mäuse verringertes infiltratives Wachstum in gesunde Gehirnbereiche zeigten (Abbildung 45, B 2), während der Randbereich der Tumoren unbehandelter und 13C4-behandelter Mäuse eher „ausgefranst“ wirkte (Abbildung 45, A 1). Die i.v. Behandlung von Mäusen mit intrazerebralen GL261-Tumoren mit 1D11 beeinflußte in diesem Versuch somit zwar die Tumormorphologie, führte aber nicht zur Größenreduktion des Tumors. 

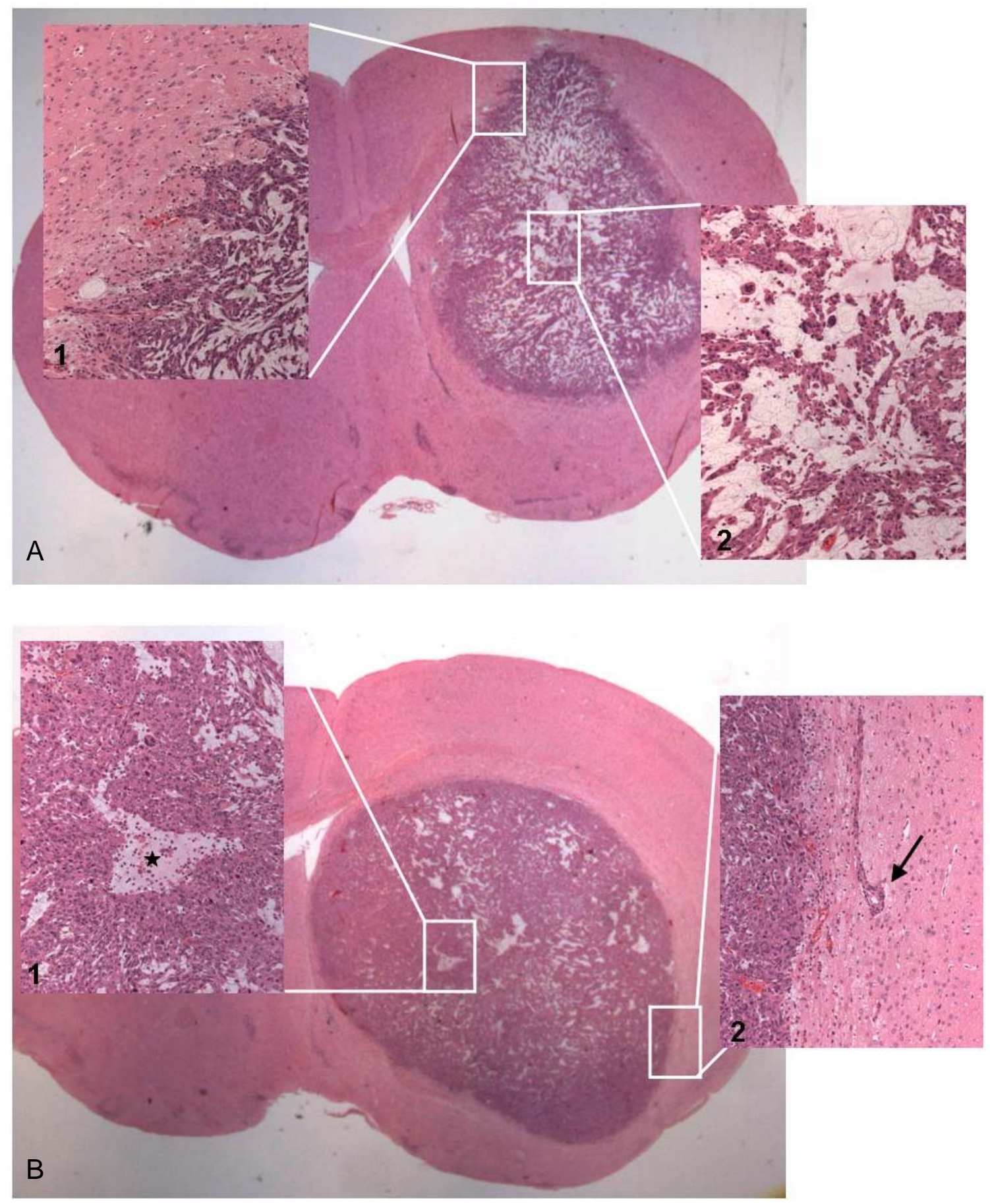

Abbildung 45: Übersicht und Ausschnittsvergrößerungen eines GL261-Tumors einer unbehandelten (A) und einer 1D11-behandelten (B) Maus. Die HE-Färbungen der Paraffinschnitte zeigen je einen 25 Tage im Black/6 Mausgehirn angewachsenen GL261-Tumor. A) Der große Tumor hat im Randbereich eine Infiltrationszone, in der sich Tumorzellen fingerförmig ins umgebende gesunde Hirngewebe ausbreiten (1) und eine matrixreiches Zentrum mit locker angeordneten Zellen (2). B) Der große Tumor hat ein wenig matrixreiches Zentrum mit relativ kompakt angeordneten Zellen. In der Vergrößerung ist eine für Glioblastome typische zentrale Nekrose mit einem Stern gekennzeichnet (1). Im Randbereich gibt es wenig Infiltration ins umgebende gesunde Hirngewebe, ein von Tumorzellen rekrutiertes Gefäß ist mit einem Pfeil gekennzeichnet (2). 


\subsection{Globulin-Anreicherung im Mausgehirn nach Öffnung der BHS}

In den bislang beschriebenen Versuchen wurde der Antikörper i.v. verabreicht. Durch die BHS wird der Übertritt von Antikörpern aus den Blutgefäßen ins ZNS behindert. Eine höhere Konzentration von 1D11 Antikörpern im Gehirn könnte zu deutlicheren Therapieeffekten auf intrazerebrale GL261-Tumoren in der Black/6-Maus führen. Für HG ist beschrieben, dass nach intraarterieller Bolusinjektion in die A. carotis interna dextra die BHS für Substanzen wie Chemotherapeutika aber auch für Albumin in der ipsilateralen rechten Hemisphäre durchlässig wird. Substanzen reichern sich dann in höheren Konzentrationen in der rechten Hemisphäre an, als es ohne vorherige HG-Injektion der Fall ist (Erdlenbruch et al., 2003 a, Erdlenbruch et al., 2003 b, Erdlenbruch et al., 2000). Mit den folgenden Versuchen sollte ermittelt werden, ob sich die Öffnung der BHS durch HG eignet, um große Moleküle wie Antikörper ins Gehirngewebe zu transportieren. Weiterhin sollte geprüft werden, wie lange sich die Antikörper im Gehirn darstellen lassen.

Zur Visualisierung im Gehirn wurden mit Fluorochromen gekoppelte Albumine (RB200 Albumin), Globuline (RB200 $\gamma$-Globulin, Cy5.5 $\gamma$-Globulin) und Antikörper (AF680 1D11) verwendet. Als Positivkontrolle wurde in Versuchen mit fluoreszenzmikroskopischer Auswertung Na-Fl mit einer Molekülgröße von $376 \mathrm{Da}$ gleichzeitig mit Globulinen verabreicht.

Nachdem die BHS in der rechten Hemisphäre durch HG geöffnet wurde, erfolgte die intraarterielle Gabe der fluoreszenzgekoppelten Substanzen. Die Anreicherung der Substanzen im Gehirn wurde dann entweder mittels Fluoreszenzmikroskopie unter Verwendung von Ratten oder NMRI-Mäusen, oder in vivo in auf dem Kopf epilierten NMRI-Mäusen mit dem eXplore-Optix System dargestellt und gemessen. Die ersten Versuche wurden an Ratten durchgeführt, da die Gefäße in diesen Tieren größer sind und sich im Vergleich zu Mäusen leichter präparieren lassen. Die in vivo Fluoreszenzmessung erfolgte im nah-infrarot-Bereich und erforderte wegen der limitierten Eindringtiefe des Lichts die Versuchsdurchführung an Mäusen. Hier wurden zunächst Versuche mit hochkonzentriertem Cy5.5 $\gamma$-Globulin durchgeführt und anschließend Versuche mit AF680 $1 \mathrm{D} 11$.

\subsubsection{Kurzzeitversuche zur Öffnung der BHS mit mikroskopischer Auswertung}

Von den Gehirnen bei denen in Kurzzeitversuchenen nach Öffnung der BHS fluoreszierende Markersubstanzen infundiert wurden, wurden Gefrierschnitte angefertigt, die dann unter dem Mikroskop ausgewertet wurden. 


\subsubsection{HG-Konzentrationsabhängige Öffnung der BHS}

Gesunden Wistar Ratten wurde nach Öffnung der BHS durch intraarterielle Applikation von 75 mM HG, Na-Fl ebenfalls intraarteriell verabreicht. Während wie in Abbildung 46, $1 \mathrm{zu}$ sehen, Na-Fl nach 15 min deutlich in der rechten Hemisphäre nachweisbar war, konnte 66 kDa großes RB200 Albumin die BHS nur in geringem Maße überschreiten (Abbildung 46, 2). Bei der Öffnung der BHS mit 90 mM HG konnten auch Albumin und $\gamma$-Globulin gut detektiert werden. Abbildung 47 zeigt die Fluoreszenz von RB200 Albumin und RB200 $\gamma$-Globulin im Hirngewebe der rechten Hemisphäre.

Die intraarterielle Injektion von HG in die A. carotis interna dextra führte in der rechten Hemisphäre zu einem starken Anstieg von Na-F1 und RB200 Albumin-, oder RB200 $\gamma$ Globulin-Fluoreszenz im Kurzzeitversuch. Die Begutachtung von Serienschnitten zeigte, dass die Fluoreszenz für alle Substanzen hauptsächlich im lateralen Kortex des Vorderhirns zu finden war. In der kontralateralen, linken Hemisphäre war Fluoreszenz nur innerhalb des Lumens der zerebralen Blutgefäße zu erkennen, nicht aber im umgebenden Gewebe (Abbildung 46, 1 und Abbildung 47).
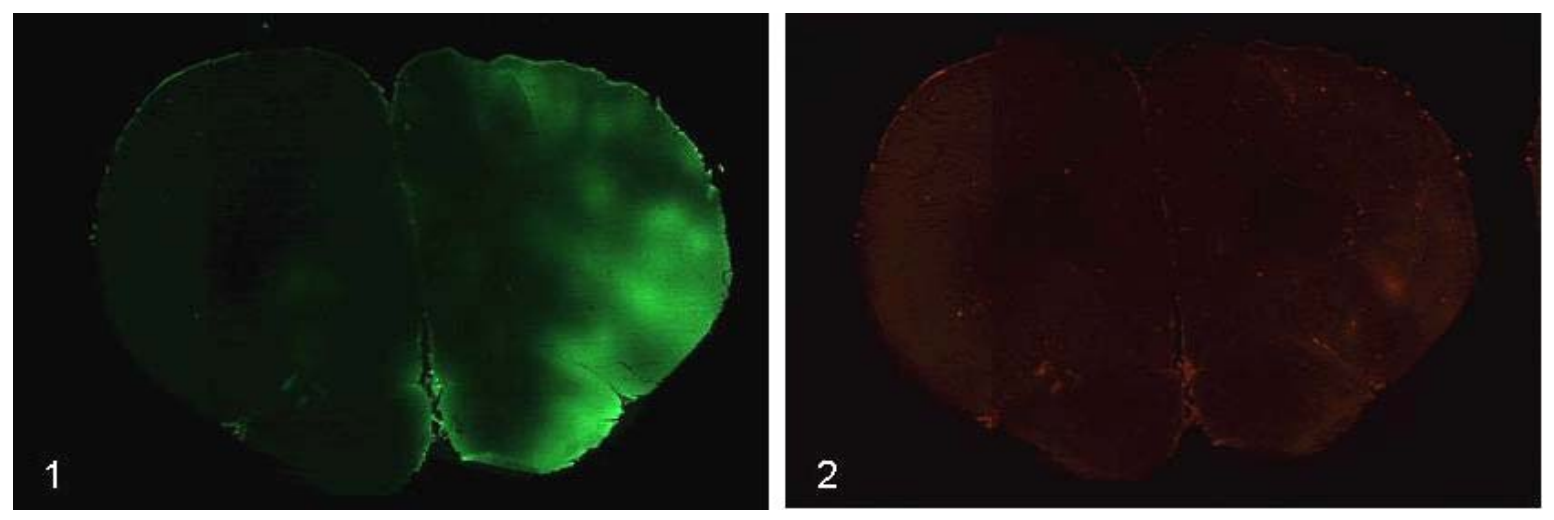

Abbildung 46: Fluoreszenz von Na-Fl (376 Da) (1) und RB200 Albumin (66kDa) (2) im Rattenhirn 15 min nach Öffnung der BHS mit 75 mM HG. Anschließende intraarterielle Infusion der fluoreszierenden Substanzen. In der linken Hemisphäre findet sich keine erhöhte Fluoreszenz. In der rechten Hemisphäre deutlich erhöhte Fluoreszenz von Na-Fl im Gewebe. RB200 Albumin Fluoreszenz ist im Vergleich dazu nur wenig zu sehen. 

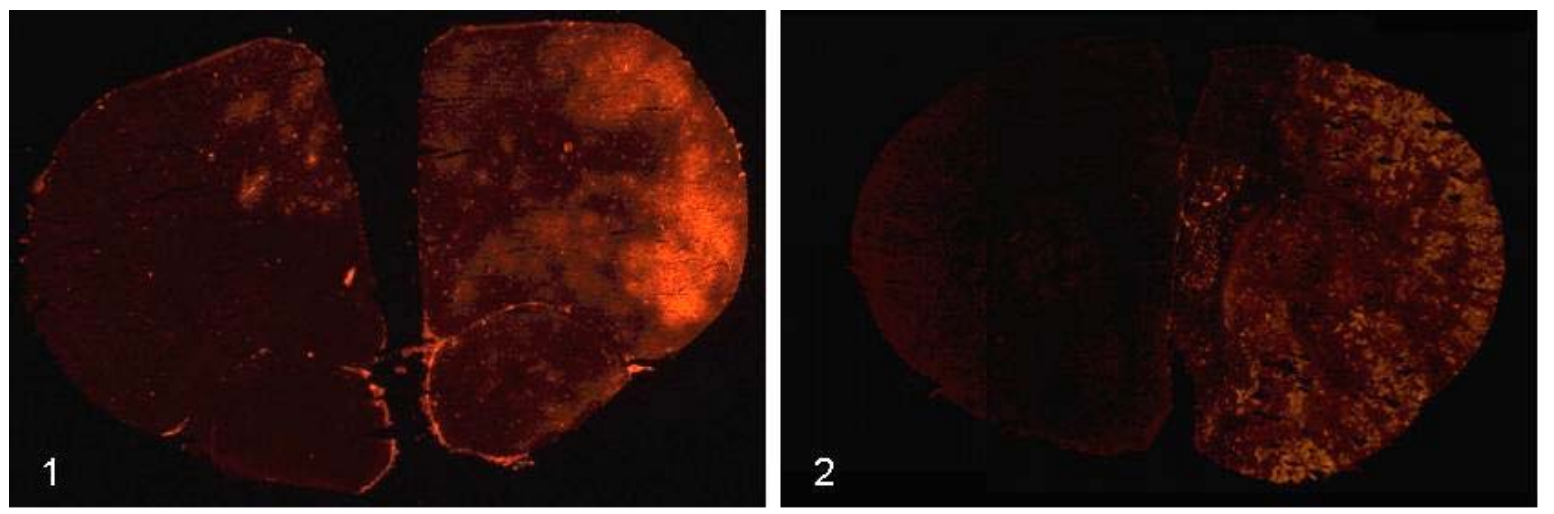

Abbildung 47: Fluoreszenz von RB200 Albumin (66 kDa) (1) und RB200 $\gamma$-Globulin (150 kDa)(2) im Rattenhirn 15 min nach Öffnung der BHS mit 90 mM HG. Anschließende intraarterielle Infusion eines der fluoreszierenden Proteine. In der rechten Hemisphäre ist mit dieser Konzentration von HG auch für diese großen Substanzen eine deutlich erhöhte Fluoreszenz nachweisbar.

\subsubsection{2 Öffnung der BHS mit i.v. Gabe von fluoreszierenden Substanzen}

Die folgenden Versuche wurden durchgeführt, um $\mathrm{zu}$ zeigen, dass nicht die hohe Konzentration der fluoreszierenden Markersubstanzen in den Gehirnkapillaren bei intraarterieller Kurzinfusion, sondern die HG-vermittelte Öffnung der BHS zur Anreicherung in der rechten Hemisphäre führt.

Bei diesen Versuchen wurde Na-Fl und RB200 $\gamma$-Globulin nach i.a. Injektion von 90 mM HG i.v. durch die Schwanzvene verabreicht. Auch hier war eine erhöhte Fluoreszenz von Na-F1 (Abbildung 48, 1) und RB200 $\gamma$-Globulin (Abbildung 48, 2) in der rechten Gehirnhälfte zu finden.

Damit kann ausgeschlossen werden, dass die Anreicherung von Markersubstanzen im Gehirn der rechten Hemisphäre alleine durch die intraarterielle Verabreichung zustande kam. 

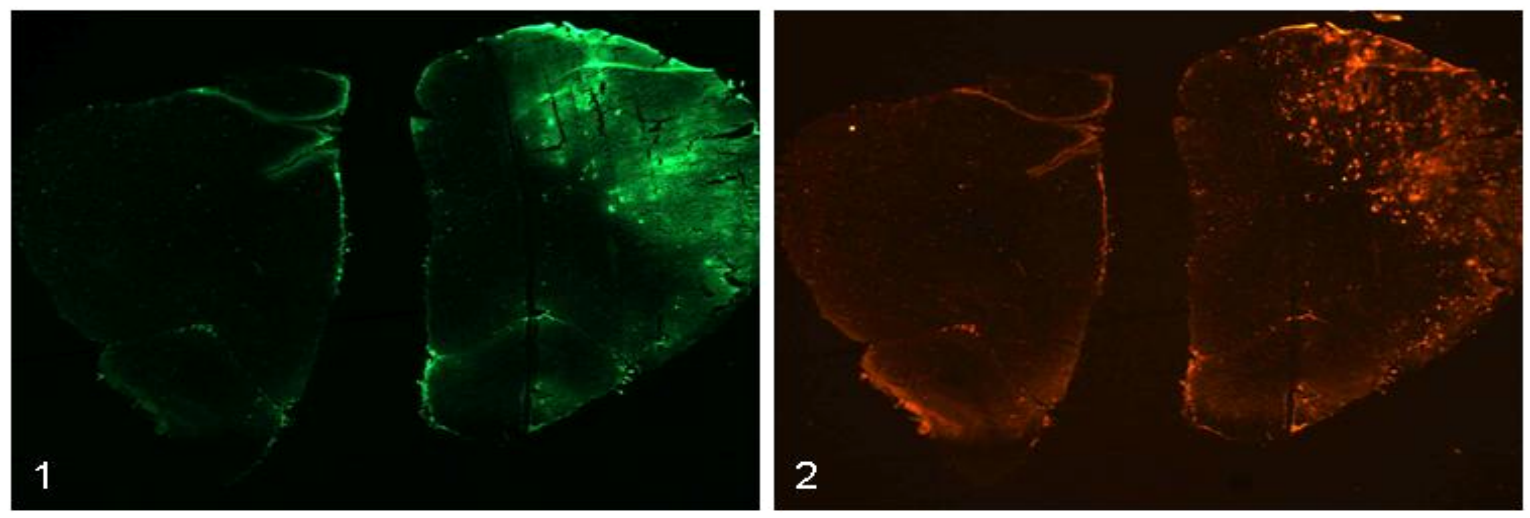

Abbildung 48: Fluoreszenz von Na-Fl (376 Da) (1) und RB200 $\gamma$-Globulin (2) im Maushirn 15 min nach intraarterieller Öffnung der BHS mit 90 mM HG. Anschließende i.v. Injektion der fluoreszierenden Substanzen. In der linken Hemisphäre findet sich keine erhöhte Fluoreszenz. In der rechten Hemisphäre ist eine deutlich erhöhte Fluoreszenz von Na-F1 und RB200 $\gamma$-Globulin zu sehen.

\subsubsection{Langzeitversuche zur Öffnung der BHS mit mikroskopischer Auswertung}

Als nächstes sollte nun die Frage nach dem Verbleib der Substanzen im Gehirn geklärt werden. Hierzu wurden Versuche an Mäusen durchgeführt und die Verteilung der Fluorochrome im Gehirn anhand von Gefrierschnitten analysiert. Für alle folgenden Versuche wurde eine HG-Konzentration von $82,5 \mathrm{mM}$ eingesetzt.

Mit einer Bolusinjektion von $300 \mu 1$ 82,5 mM HG Lösung konnte die BHS auch bei Mäusen für RB200 $\gamma$-Globulin mit guter Verträglichkeit geöffnet werden. So zeigte sich für Na-Fl im Kurzzeitversuch (10 min nach BHS-Öffnung) eine starke und meist homogene Fluoreszenzfärbung des Gewebes der rechten Hemisphäre, wie in Abbildung 49 dargestellt.

Im Gegensatz hierzu war die Fluoreszenzintensität von RB200 $\gamma$-Globulin 10 min nach Öffnung der BHS in der rechten Hemisphäre wesentlich ungleichmäßiger. Coronare Schnitte wiesen in der rechten Hemisphäre eine fleckige Verteilung der Fluoreszenzfärbung auf. In den Bildern der linken Hemisphäre ist Fluoreszenz nur intravaskulär in den Kapillaren der Gefäße zu sehen, nicht aber nicht im Hirngewebe selbst.

Die Auswertung $24 \mathrm{~h}$ nach HG-vermittelter Permeabilitätssteigerung der BHS zeigte demgegenüber eine homogene Verteilung der Fluoreszenz von RB200 $\gamma$-Globulin im Gehirngewebe der rechten Hemisphäre. Dies beweist, dass im Zeitverlauf aus dem initial inhomogenen Übertritt des Globulins mit der Zeit eine homogene Verteilung im Hirngewebe resultiert (Abbildung 50). 

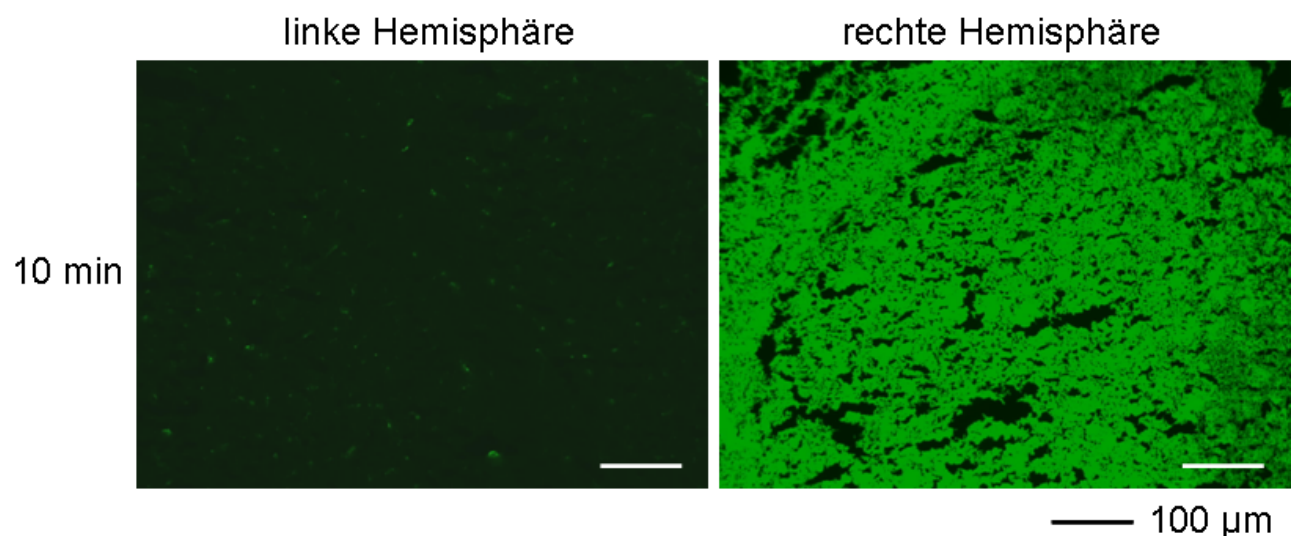

Abbildung 49: Fluoreszenz von Na-FI (376 Da) im NMRI-Maushirn 10 min nach intraarterieller Öffnung der BHS mit 82,5 mM HG. Anschließende intraarterielle Infusion von Na-Fl. In der linken Hemisphäre fand sich kaum Fluoreszenz. In der rechten Hemisphäre war eine deutliche, im Gewebe gleichmäßig verteilte Fluoreszenz zu sehen.

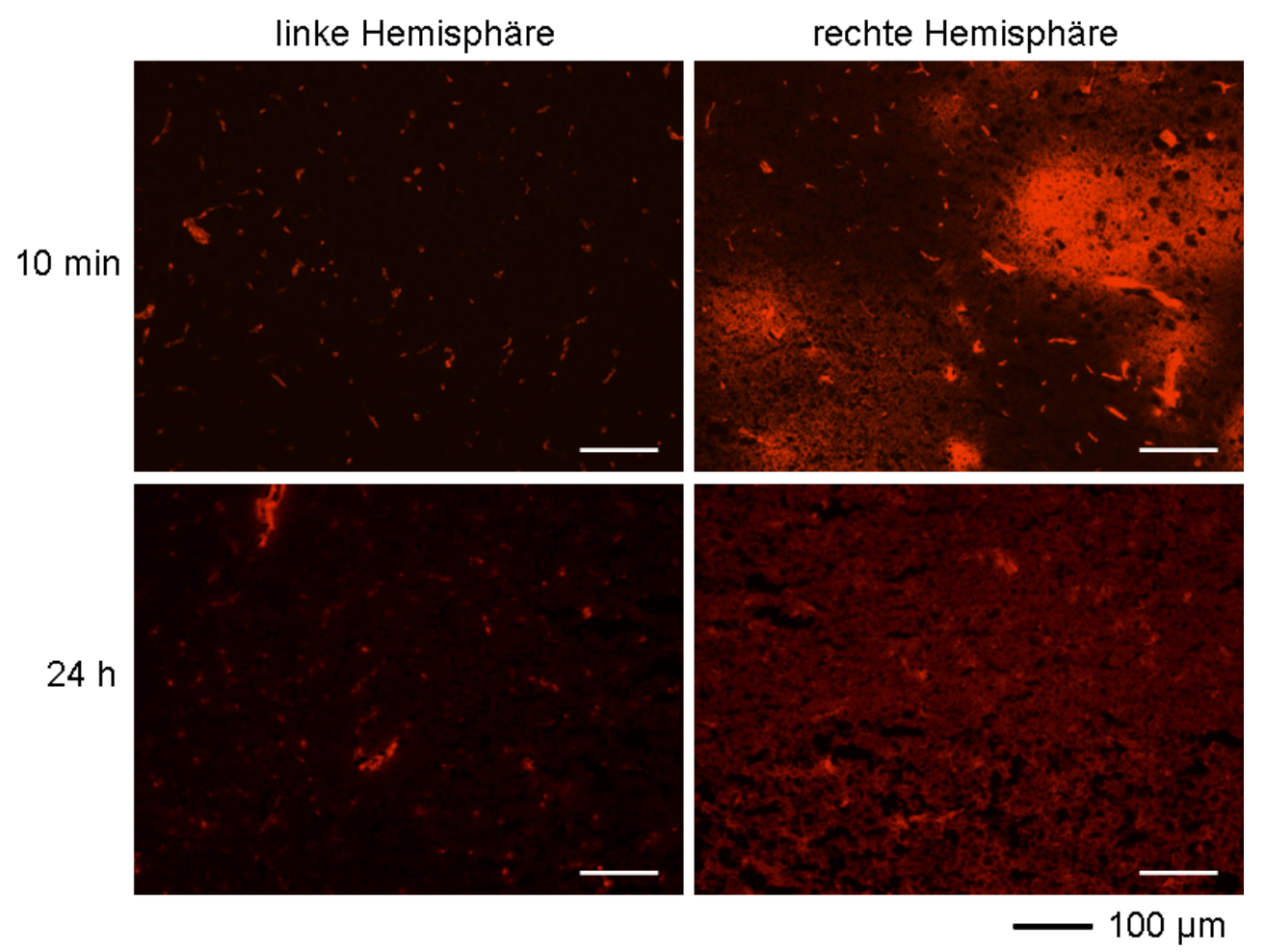

Abbildung 50: Vergleich der RB200 $\gamma$-Globulin (150 kDa) Fluoreszenz 10 min und 24 h nach intraarterieller Öffnung der BHS mit 82,5 mM HG in NMRI-Mäusegehirnen. Es sind Ausschnitte von Gefrierschnitten in coronarer Ebene der rechten und der linken Hemisphäre gezeigt. Die Versuche wurden unter gleichen Bedingungen durchgeführt. 
An repräsentativen Schnitten wurde für beide Gruppen (10 min und 24 h nach Öffnung der BHS und anschließender Gabe von RB200 $\gamma$-Globulin) eine semiquantitative Analyse der Gewebefluoreszenz durchgeführt.

Nach 24 h war die Gewebefluoreszenz in der ipsilateralen Hemisphäre signifikant höher als in der kontralateralen Hemisphäre (Tabelle 3). Die Fluoreszenzintensitäten der kontralateralen Hemisphären galten als Kontrolle ohne Öffnung der BHS. In den linken Hemisphären unterschied sich die gemessene Fluoreszenzintensität 10 min und $24 \mathrm{~h}$ nach Farbstoffgabe nicht. Die Fluoreszenzintensität der rechten Gehirnhälften, die nach $24 \mathrm{~h}$ entnommen wurden, war geringer als nach $10 \mathrm{~min}$. Systemisch verabreichte Globuline gelangten nach der Öffnung der BHS mittels HG also aus dem Blut ins Gehirngewebe. Innerhalb von $24 \mathrm{~h}$ fand sich eine von den Kapillaren ausgehende, gleichmäßige Diffusion der Globuline in das Gehirngewebe.

Tabelle 3: Mittlere Fluoreszenzintensität von RB200 $\gamma$-Globulin in Gefrierschnitten der rechten und linken Hemisphäre nach intraarterieller Öffnung der BHS mit 82,5 mM HG. Die Fluoreszenzintensität in der linken Hemisphäre nach 10 min unterscheidet sich nicht signifikant von der nach 24 h. Die Intensität in der rechten Hemisphäre ist sowohl nach $10 \mathrm{~min}$, als auch nach 24 h signifikant höher als in der linken Hemisphäre (t-test: $\mathrm{p}<0,001$ ). Die Schnitte wurden unter gleichen Belichtungsverhältnissen fotografiert und die Fluoreszenzintensität mit der FW4000 Software ermittelt.

\begin{tabular}{|c|c|c|}
\hline Fluoreszenzintensität & linke Hemisphäre & rechte Hemisphäre \\
\hline $\begin{array}{c}10 \text { min nach Behandlung } \\
(\mathrm{n}=5)\end{array}$ & $49,49(+/-0,58)$ & $95,35(+/-9,34)$ \\
\hline $\begin{array}{c}24 \text { h nach Behandlung } \\
(\mathrm{n}=5)\end{array}$ & $49,12(+/-0,26)$ & $58,08(+/-1,54)$ \\
\hline
\end{tabular}

\subsection{3 $\gamma$-Globulin-Anreicherung im Glioblastom-tragenden Gehirn nach Öffnung der BHS}

Um die Konzentration von systemisch verabreichten Globulinen im Tumor und umgebenden Gehirn zu erhöhen, wurde die BHS zunächst in RG2-Tumor-tragenden Gehirnen in Fischer-Ratten geöffnet. Anschließend wurde auch bei Mäusen mit U87MGTumoren die BHS mit 82,5 mM HG für RB200 $\gamma$-Globulin geöffnet.

15 min nach intraarterieller Öffnung der BHS und anschließender Kurzinfusion von RB200 $\gamma$-Globulin zeigte sich im Gefrierschnitt mit einem 9 Tage in der rechten Hemisphäre angewachsenen RG-2 Gliom eine hohe Fluoreszenzintensität im Tumor und in der rechten Hemisphäre (Abbildung 51).

In Abbildung 52 ist die Fluoreszenz in der rechten Hemisphäre einer Maus mit U87MG-Tumor dargestellt. Nach Öffnung der BHS fand sich eine hohe Fluoreszenz von RB200 $\gamma$-Globulin in der rechten Hemisphäre und im Tumorgewebe. 


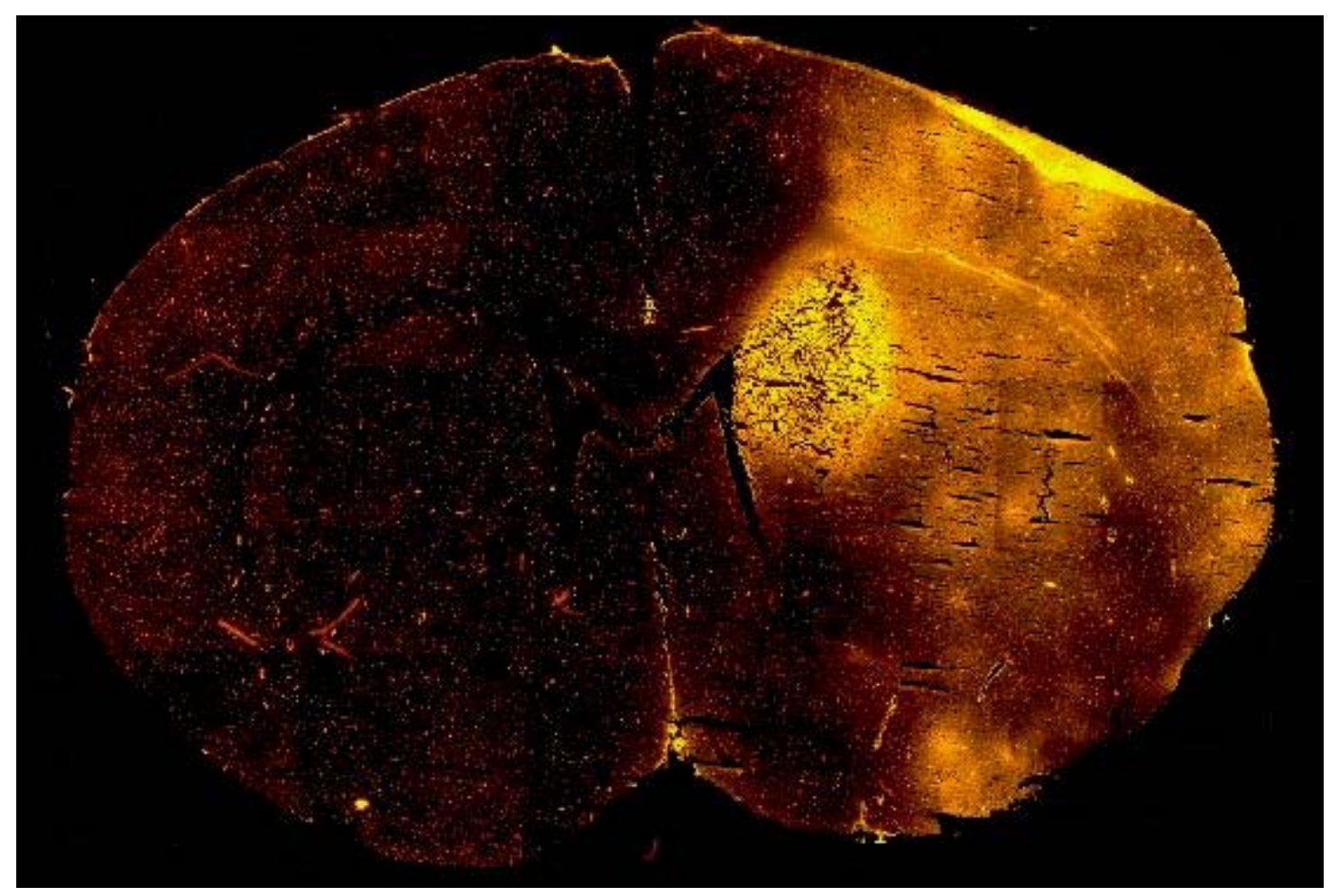

Abbildung 51: Fluoreszenz von RB200 $\gamma$-Globulin (150 kDa) im RG2-Tumor tragenden Rattenhirn 15 min nach Öffnung der BHS mit 82,5 mM HG. Der Tumor ist 9 Tage angewachsen und als besonders helle Region nahe des Ventrikels in der rechten Hemisphäre zu sehen.
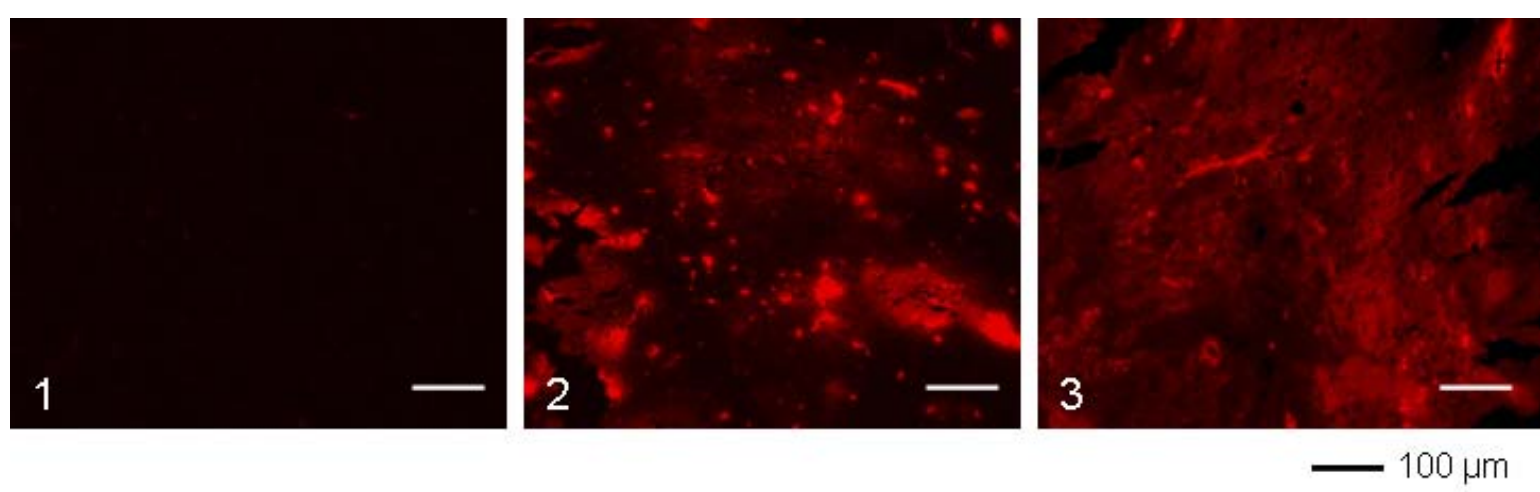

Abbildung 52: Vergleich der RB200 $\gamma$-Globulin Fluoreszenz in der rechten Hemisphäre und im U87MG-Tumor nach intraarterieller Öffnung der BHS mit 82,5 mM HG. Es sind Ausschnitte von Gefrierschnitten des Gehirns in coronarer Ebene der linken (1) und der rechten Hemisphäre (2) und dem Tumor in der rechten Hemisphäre (3) gezeigt.

Die Ergebnisse weisen darauf hin, dass sich mittels Öffnung der BHS durch HG Globuline sowohl in normales Hirngewebe als auch in Hirntumorgewebe transportieren lassen. Der Übertritt von Globulinen über die BHS ins ZNS hängt von der Effektivität der 
Öffnung der BHS ab, das heißt höhere Konzentrationen von HG führen zu einem stärkeren Übertritt der Fluorochrome ins Hirngewebe. Ohne Öffnung der BHS ist die Anreicherung von Globulinen im Gehirn deutlich schwächer ausgeprägt. Eine Behandlung von intrazerbralen GL261-Gliomen in Black/6-Mäusen mit 1D11 unter Öffnung der BHS könnte somit zu einer Erhöhung der Konzentration der Antikörper im Tumor und besonders im umgebenden Gehirngewebe beitragen.

\subsection{4 eXplore Optix-basierte Darstellung von intrazerebralem Cy5.5 $\gamma$-Globulin}

Um den Verbleib von großen Molekülen in der rechten Hemisphäre des Gehirns von Mäusen nach Öffnung der BHS über einen längeren Zeitraum hinweg zu beschreiben, wurde die Intensität der Fluoreszenz nach Gabe von Cy5.5 gekoppeltem Globulin (Cy5.5 $\gamma$ Globulin) mittels ,optical imaging“ im eXplore Optix gemessen.

\subsubsection{In vivo}

Nach Öffnung der BHS mit HG und intraarterieller Infusion von Cy5.5 $\gamma$-Globulin wurden nach $24 \mathrm{~h}$, wie auch nach $72 \mathrm{~h}$ hohe Fluoreszenz-Intensitäten im Bereich der rechten Hemisphäre ermittelt. Diese entsprachen hohen Gewebskonzentrationen von Cy5.5 $\gamma$ Globulin. In Kontrolltieren mit Öffnung der BHS ohne Cy5.5 $\gamma$-Globulin-Gabe wurde keine Fluoreszenz im Gehirn detektiert (Kontrolle 1). Die intraarterielle Kurzinfusion von Cy5.5 $\gamma$-Globulin ohne BHS-Öffnung (Scheinoperation mit Bolusinjektion von $\mathrm{NaCl}$ 0,9\%, $=$ Kontrolle 2) führte zu leicht erhöhter Fluoreszenz im ZNS (Abbildung 53, B). Dies steht im Einklang mit den in der Mikroskopie erhobenen Ergebnissen, bei denen nach Gabe von fluoreszierenden Substanzen eine intravaskuläre Fluoreszenz in Gehirnschnitten zu sehen war (Abbildung 50). Die Fluoreszenzintensität in der rechten Hemisphäre war signifikant höher in HG-behandelten Mäusen ( $\mathrm{t}$-Test $\mathrm{p}<0,05$ ), was dem Anteil an Fluoreszenzmarker entspricht, der die BHS überwunden hat. Zum Zeitpunkt mit maximalen gemessenen Counts nach Behandlung (nach 9 h) betrug die Differenz zur Kontrolle 252400 NC (normalisierte Counts (Fluoreszenzintensität)). Die Halbwertszeit der Fluoreszenzintensität lag bei $46 \mathrm{~h}$ (Abbildung 53, B). Zudem ist in Abbildung 53, B zu erkennen, dass $3 \mathrm{~h}$ nach der BHS-Öffnung die Fluoreszenz in der rechten Hemisphäre der Mäuse erheblich höher war als die der Kontrollmäuse. Die Fluoreszenzintensität im Gehirn erhöhte sich innerhalb der ersten $9 \mathrm{~h}$ nach der Öffnung der BHS noch. Danach nahm die gemessene Fluoreszenzintensität langsam ab.

Langzeitmessungen der Fluoreszenz von intraarteriell verabreichtem Cy5.5 $\gamma$-Globulin nach vorheriger Öffnung der BHS zeigten bis einschließlich $96 \mathrm{~h}$ nach der Behandlung ein erhöhtes Fluoreszenzsignal in der rechten Hemisphäre. 

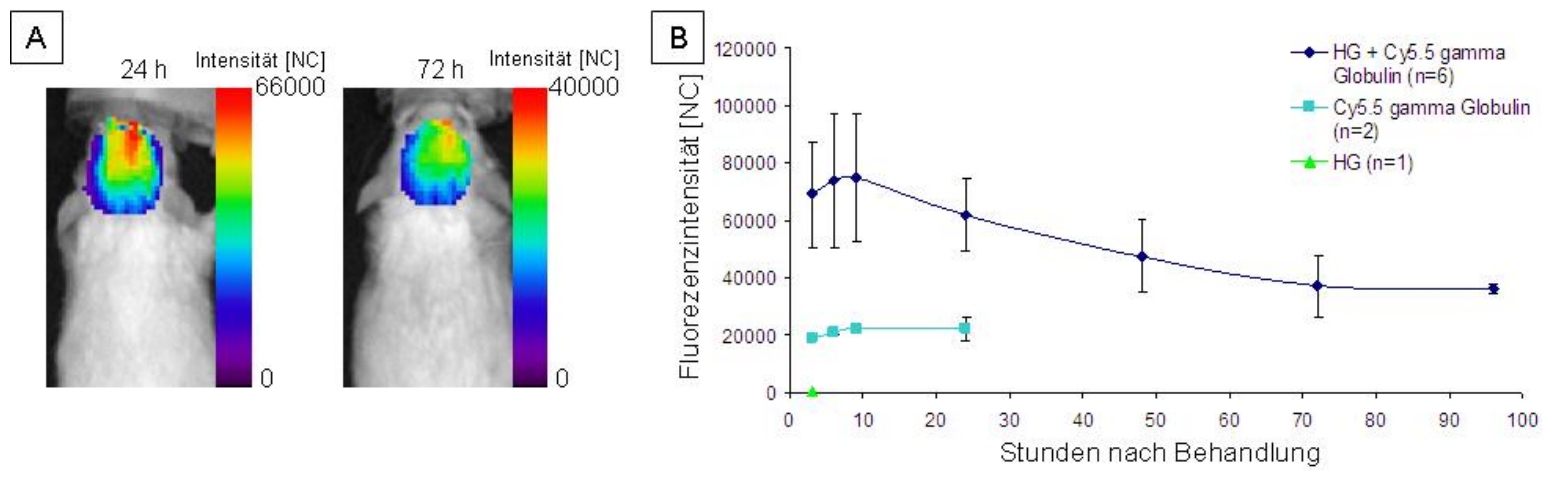

\begin{abstract}
Abbildung 53: Cy5.5 $\gamma$-Globulin Fluoreszenzintensität im Kopf nach intraarterieller Öffnung der BHS mit 82,5 mM HG. A) In vivo-Messungen mit dem eXplore Optix-Gerät detektierten sowohl nach $24 \mathrm{~h}$ als auch nach $72 \mathrm{~h}$ im Bereich der rechten Hemisphäre eine erhöhte Fluoreszenzintensität. Nach $72 \mathrm{~h}$ ist die Intensität geringer als nach $24 \mathrm{~h}$. B) Während die Fluoreszenzintensität im Kopf nach intraarterieller Infusion von Cy5.5 $\gamma$-Globulin ohne Öffnung der BHS nur wenig ansteigt, steigt die Intensität nach HG-vermittelter Öffnung der BHS auf den 4-fachen Wert an. Im unbehandelten Kontrolltier ist nahezu keine Fluoreszenz zu detektieren. Dargestellt ist die mittlere, in der rechten Hemisphäre gemessene Intensität über die Zeit aufgetragen.
\end{abstract}

Die dreidimensionalen Rekonstruktionen der Fluoreszenzverteilung von Cy5.5 $\gamma$ Globulin im Gehirn $6 \mathrm{~h}$ nach Alkylglycerin-vermittelter Öffnung der BHS bzw. nach intraarterieller Infusion ohne Öffnung der BHS beweisen die intrazerebrale Lokalisation der detektierten Fluoreszenz. Die Rekonstruktionen wurden in $1 \mathrm{~mm}$ dicke Schichten zerlegt. Die Konzentration für jede Schicht ist gezeigt (Abbildung 54). Hohe Fluoreszenzintensitäten fanden sich 2-5 $\mathrm{mm}$ tief im Gewebe von Mäusen mit Alkylglycerinn-Behandlung, was der Lokalisation des Gehirns entspricht. In Kontrollexperimenten ohne Öffnung der BHS war eine geringere Konzentration der Fluoreszenz zu finden, die hauptsächlich entlang der Mittellinie lokalisiert war.

Anhand der Darstellung lässt sich zeigen, dass die in vivo gemessene Fluoreszenz aus dem Gehirn und nicht aus Strukturen darüber oder darunter stammt. 


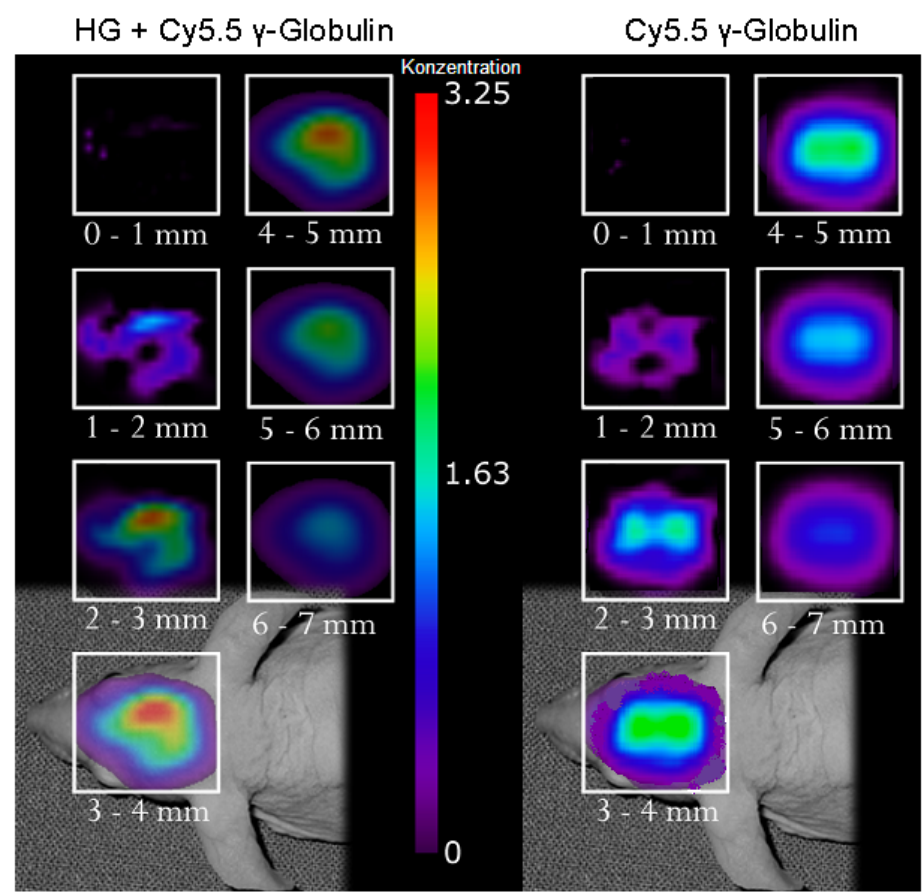

Abbildung 54: Cy5.5 $\gamma$-Globulin-Fluoreszenz in unterschiedlichen Tiefen unter der Kopfoberfläche. $\mathrm{Zu}$ sehen sind Aufsichten auf $1 \mathrm{~mm}$ dicke Scheiben des Gehirns von 0-7 mm Tiefe unter der Oberfläche des Kopfes. Die Messungen wurden 6 h nach HG-vermittelter Öffnung der BHS mit anschließender Gabe von Cy5.5 $\gamma$-Globulin bzw. Cy5.5 $\gamma$-Globulin-Gabe ohne Öffnung der BHS durchgeführt. Zur besseren Orientierung wurde unter die 3-4 mm Schicht das Bild eines Nacktmauskopfes projiziert.

\subsubsection{Ex vivo}

Mittels Untersuchung der Fluoreszenzintensität ex vivo nach Entnahme des Gehirns aus dem knöchernen Schädel, sollte bewiesen werden, dass das Fluoreszenzsignal wirklich vom Gehirngewebe stammt, und ob der Verlauf der in vivo gewonnenen Daten auf die ex vivo Situation übertragen werden kann. Dazu wurde die Fluoreszenz von Cy5.5 $\gamma$-Globulin aller Mausgehirne am Versuchsende ex vivo nachgemessen.

Die höchste Fluoreszenzintensität wurde auch ex vivo in der rechten Hemisphäre von HG-behandelten Mäusen detektiert. Dagegen war die Fluoreszenz in den Gehirnen der Kontrollen 1 und 2 gering. Die Fluoreszenz in den Hirnbereichen der Kontrolle 2 ist durch in den Blutgefäßen befindliches Blut und damit intravaskuläre Fluoreszenz zu erklären (Abbildung 55, A). Das Verhältnis der Intensität zwischen rechter und linker Hemisphäre betrug nach 9 h nach Öffnung der BHS 3,65, nach 24 h 4,63, nach 72 h 5,75 und nach 96 h 3,62 (Abbildung 55, B). Die Intensität der Fluoreszenz in der rechten Hemisphäre ist zu jedem Zeitpunkt signifikant höher als die in der linken Hemisphäre (t-Test $p<0,05)$. 

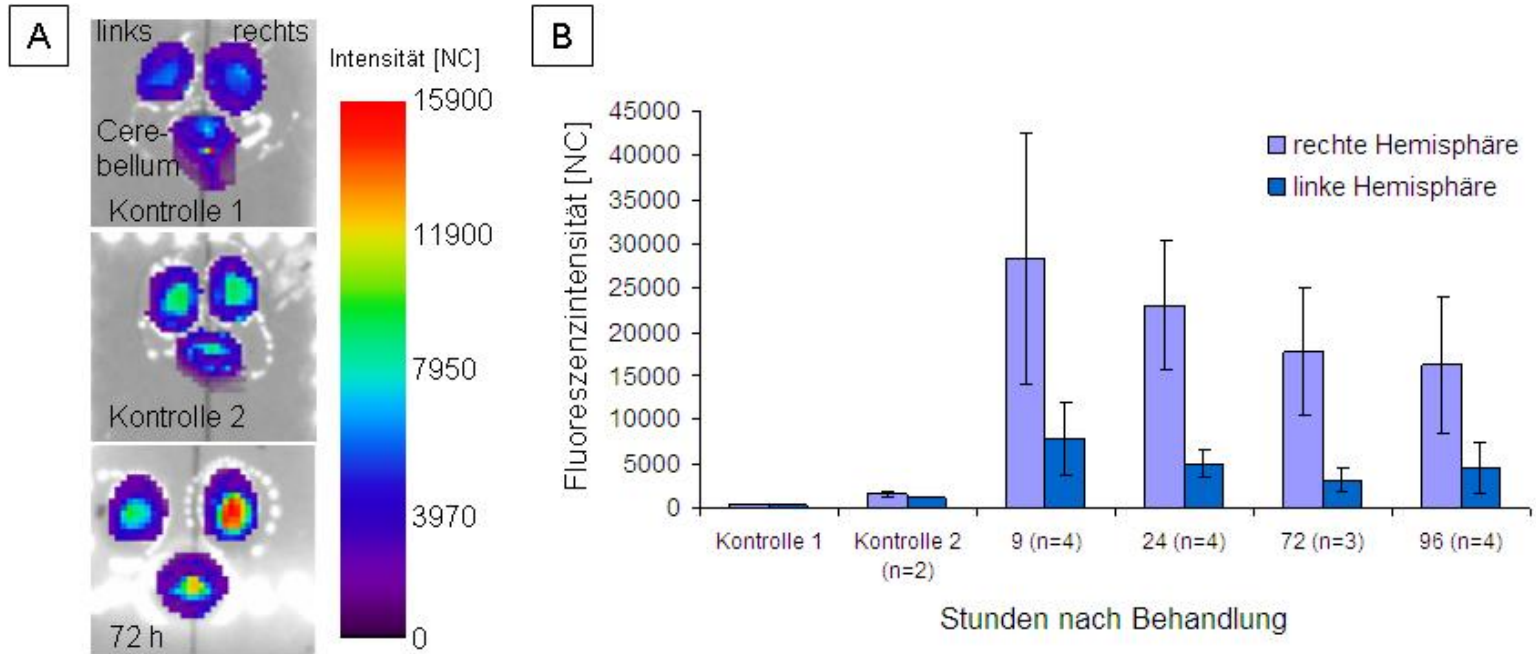

\begin{abstract}
Abbildung 55: Fluoreszenzintensität von Cy5.5 $\gamma$-Globulin im Gehirn ex vivo. Zu verschiedenen Zeitpunkten nach intraarterieller Öffnung der BHS mit 82,5 mM HG, wurde die Fluoreszenzintensität im entnommenen Gehirn mit dem eXplore Optix gemessen. Kontrolle 1: Öffnung der BHS ohne Gabe fluoreszierender Substanzen. Kontrolle 2: $24 \mathrm{~h}$ nach intraarterieller Infusion von Cy5.5 $\gamma$-Globulin ohne Öffnung der BHS. A) Fluoreszenz im entnommenen, zerteilten Hirn in der linken und rechten Hemisphäre und im Cerebellum. Kontrollen 1, 2 und ein Gehirn $72 \mathrm{~h}$ nach Öffnung der BHS und Cy5.5 $\gamma$-Globulin Infusion. B) Fluoreszenzintensitäten ex vivo 9, 24, 72 und 96 h nach Behandlung in der rechten und linken Hemisphäre.
\end{abstract}

Der Ursprung des Fluoreszenzsignals wurde sowohl über die Messung der Fluoreszenzintensität des Gehirns ex vivo, als auch über die dreidimensionale Rekonstruktion der in vivo gewonnenen Daten verifiziert. Die Ergebnisse belegen, dass die mit dem eXplore Optix ermittelten Fluoreszenzsignale von im Gehirn befindlichem Cy5.5 $\gamma$-Globulin stammen. Zudem konnte anhand der gewonnen Daten gezeigt werden, dass die in vivo durchgeführten Messungen den Messungen bei entnommenen Gehirnen entsprechen.

Somit ist es möglich, den Übertritt von Substanzen ins Gehirn im eXplore Optix in vivo zu überwachen.

\title{
3.7.5 eXplore Optix-basierte Darstellung von intrazerebralem AF680 1D11
}

Im nächsten Schritt wurde der AF680 gekoppelte Antikörper 1D11, also ein biologisch aktives Protein, verwendet. Der Antikörper wurde mittels HG-vermittelter Öffnung über die BHS gebracht. Der Verlauf der Fluoreszenzintensität über die Zeit wurde mittels Messungen im eXplore Optix in vivo überwacht. 


\subsubsection{In vivo und ex vivo Fluoreszenzintensitäten}

Die Behandlung von Mäusen mit HG (300 $\mu 1,82,5 \mathrm{mM})$ zur Öffnung der BHS und anschließender intraarterieller Kurzinfusion von AF680 1D11 $(0,2 \mathrm{mg} / 100 \mu \mathrm{l})$ führte zu einem deutlichen Anstieg der Fluoreszenzintensität in der ipsilateralen rechten Hemisphäre (Abbildung 56, A). Die Fluoreszenzintensität, die $6 \mathrm{~h}$ nach der Behandlung ex vivo in der rechten Hemisphäre gemessen wurde, war 1,9-mal so hoch wie in der kontralateralen, linken Hemisphäre (Abbildung 56, B). Nach $72 \mathrm{~h}$ war in vivo im Vergleich zur linken, in der rechten Hemisphäre keine erhöhte AF680-Fluoreszenz mehr zu detektieren. Nach drei Tagen war der Antikörper im Gehirn auch ex vivo nicht mehr detektierbar.
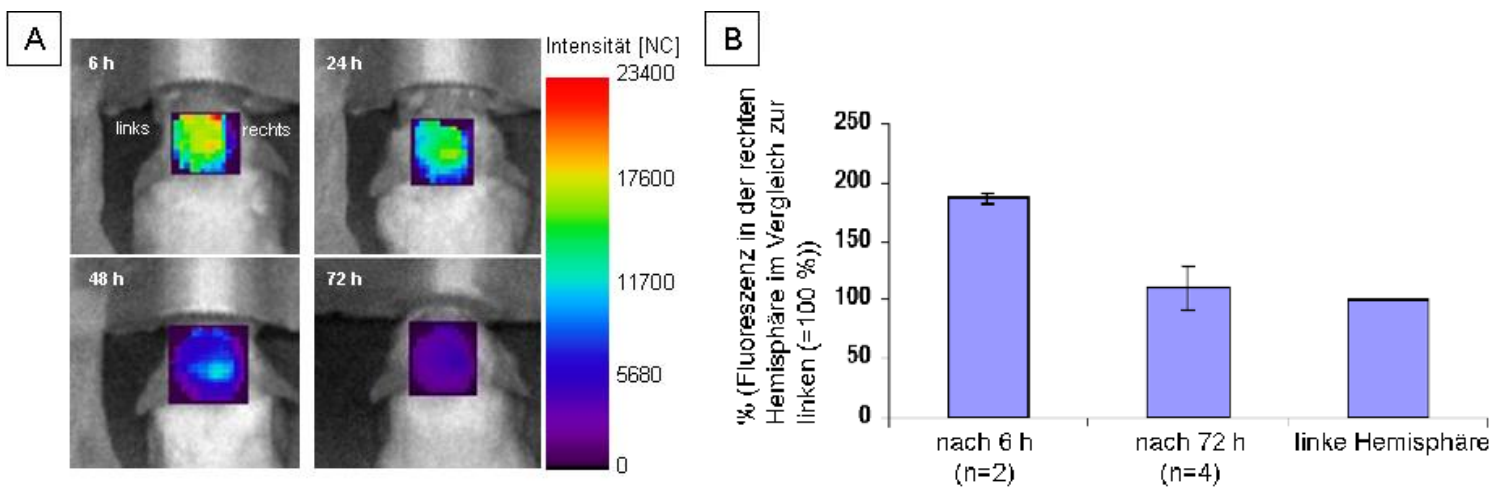

Abbildung 56: AF680 1D11 Fluoreszenzintensität im Kopf nach intraarterieller Öffnung der BHS mit 82,5 mM HG. Verlauf der Fluoreszenzintensität innerhalb von $72 \mathrm{~h}$ nach Öffnung der BHS mit 82,5 mM HG und anschließender Infusion von AF680 1D11. Messungen in vivo (A) und ex vivo (B). Die Fluoreszenz in der linken Hemisphäre wurde auf $100 \%$ gesetzt.

\subsubsection{Fluoreszenzanregungs-Lebensdauer (LT)}

Die in Versuchstieren gemessene LT entsprach der zuvor ermittelten LT von 1D11 gekoppeltem AF680. Im Verlauf der Beobachtungszeit fand sich ein Anstieg der LT der AF680 1D11-Fluoreszenz. Das entnommene Gehirn wies eine im Vergleich zur kurz vorher durchgeführten in vivo-Messung nochmals erhöhte LT auf. Die Erhöhung der LT ex vivo war auch bei der Positivkontrolle, bei der das AF680 1D11 direkt ins Gehirnparenchym gespritzt wurde, zu verzeichnen. Diese LT war identisch zu der von HG und AF680 1D11-behandelten Gehirnen (Abbildung 57, 1-8). Ein nur mit HG behandeltes Kontrolltier wies eine niedrigere LT auf, die sich nach Entnahme nicht erhöhte (Abbildung 57, 9,10). Die LT von AF680 1D11 erhöhte sich auch in vitro nach einer Stunde Inkubation mit rekombinantem humanem TGF- $\beta 1$ signifikant (Abbildung 57, B). 
A
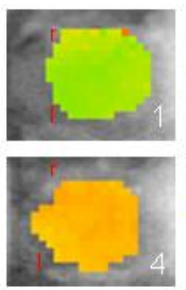

Lifetime [ns]

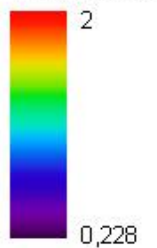

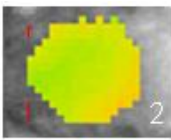
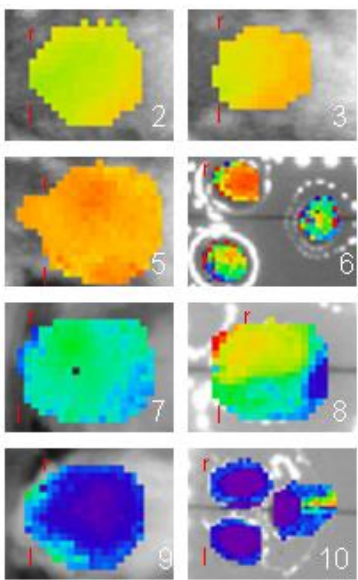

B

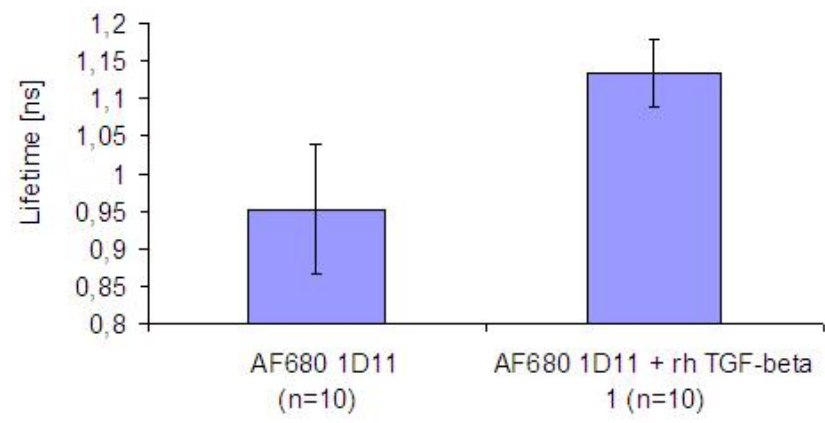

Abbildung 57: LT von AF680 1D11 im Gehirn. A) LT zu verschiedenen Zeitpunkten nach 82,5 mM HG-vermittelter Öffnung der BHS in vivo (1-5) und zum Versuchsende ex vivo (6). Dazu die LT in vivo (7) und ex vivo (8) nach direkter Injektion von AF680 1D11 und die LT einer Negativkontrolle mit Öffnung der BHS ohne AF680 1D11-Infusion in vivo (9) und ex vivo (10) nach $24 \mathrm{~h}$. $\mathrm{r}=$ rechte, l=linke Hemisphäre. B) Die mittlere LT von AF680 1D11 unterscheidet sich signifikant von der LT des $1 \mathrm{~h}$ mit rekombinantem humanen TGF- $\beta 1$ inkubierten AF680 1D11 (t-Test:p < 0,001). Messung in vitro.

Um die Stabilität der Bindung des Antikörpers an das Fluorochrom zu zeigen, wurden die Fluoreszenzintensität (Abbildung 58, B) und die LT der Marker in vitro bei RT bis zu $72 \mathrm{~h}$ im eXplore Optix gemessen. Es gab weder einen Abfall der Fluoreszenzintensität, noch eine Veränderung der LT über diese Zeit (Abbildung 58, A). Somit sind der gemessene Fluoreszenzintensitätsabfall und die Erhöhung der LT nicht durch geringe Stabilität des AF680 1D11 bedingt.

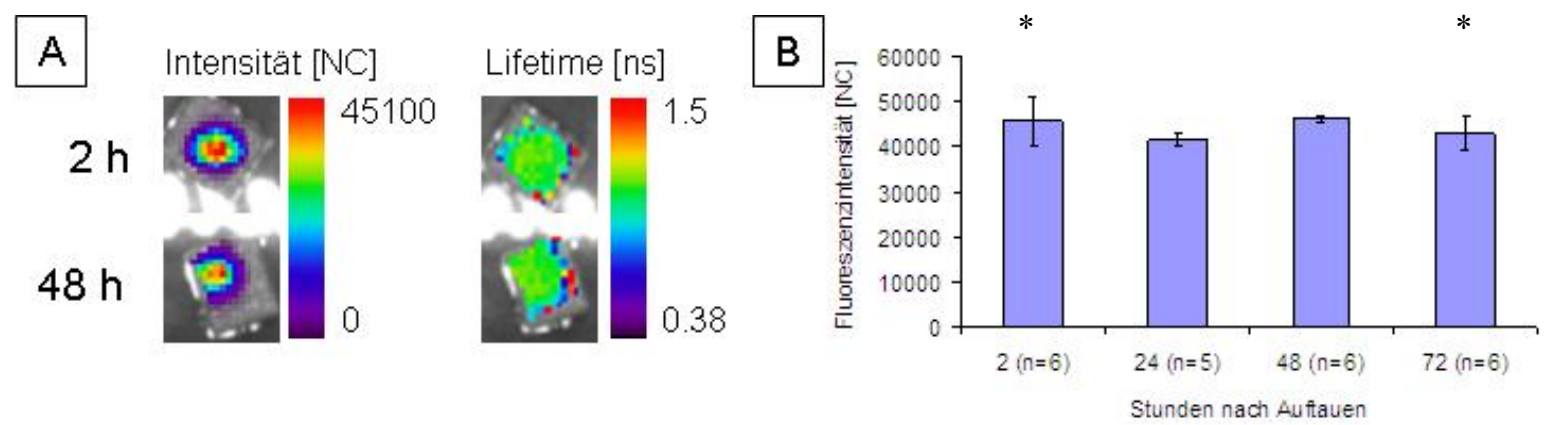

Abbildung 58: Stabilität der Fluoreszenzintensität und der LT des an den $1 D 11$ Antikörper gekoppelten AF680. A) Intensität und LT des AF680 1D11 in vitro, gemessen mit dem eXplore Optix 2 $\mathrm{h}$ und $48 \mathrm{~h}$ nach dem Auftauen. B) Mittlere Fluoreszenzintensität nimmt innerhalb von $72 \mathrm{~h}$ nach dem Auftauen in vitro nicht ab $(* \mathrm{t}$-Test $\mathrm{p}=0,329)$.

Im Gehirn finden somit Veränderungen am AF680 1D11 statt, die eine Änderung der LT des AF680 bewirken. Dies ist wahrscheinlich durch die spezifische Bindung an TGF- $\beta$ bedingt. 


\section{Diskussion}

Maligne Gliome bei Kindern und im Erwachsenenalter haben nach wie vor eine extrem schlechte Prognose. Die Anwendung neuer bildgebender Verfahren sowie verbesserter Methoden in der Neurochirurgie, Radiotherapie, Chemotherapie und Verwendung verschiedener molekularer Therapieansätze konnten die Überlebensrate der Patienten nur geringfügig steigern (Sathornsumetee und Rich 2008, Reardon et al., 2006 a, Stupp et al., 2006, Kalifa und Grill 2005, Khatua und Jalali 2005). Es gibt zahlreiche vielversprechende neue Ansätze molekularer Therapie (Hutterer et al., 2006). Deren Bedeutung ist für Hirntumoren in vivo bislang aber nur unzureichend untersucht.

In der vorliegenden Arbeit sind die möglichen Auswirkungen einer ,molecular targeted“" Therapie mit dem Antikörper 1D11 und der Öffnung der BHS mittels HG für eine Antikörper-basierte Therapie am Mausmodell untersucht worden. Bislang wurden die 1D11 Antikörper noch nicht anderweitig in vivo zur Glioblastombehandlung eingesetzt.

Zunaechst wurde die Kinetik des 1D11 unter Behandlungsbedingungen in s.c. Tumoren mittels optical imaging untersucht. Im Gegensatz zu immundefizienten Mäusen führte die 1D11-Behandlung von immunkompetenten Mäusen mit s.c. Tumoren zum Behandlungserfolg. In intrazerebralen Gliomen konnte keine Tumorregression unter Behandlung mit 1D11 erzielt werden. Die HG-vermittelte Öffnung der BHS scheint eine vielversprechende Methode zu sein, um den Anteil an Antikörper im tumortragenden Gehirn zu erhöhen.

\subsection{Vor- und Nachteile der Implantation von Gliomzellen aus der Zellkultur}

Betrachtet man den tendenziell wachstumsfördenden Effekt einer 1D11-Behandlung auf s.c. U87MG-Tumoren in nu/nu-Mäusen (s. Abbildung 15 und Abbildung 16), dann liegt der Schluss nahe, dass TGF- $\beta$ für diese Tumorzellen in vivo einen tumorsuppressiven Effekt hat. In den dargestellten Versuchen aus der Zellkultur hatte zusätzliches TGF- $\beta 2$ im Medium einen proliferationssteigernden Effekt auf GL261 Zellen (s. Abbildung 10, B). In nu/nu-Mäusen dagegen zeigten die GL261-Tumoren 1D11-behandelter Mäuse, in denen weniger TGF- $\beta$ zur Verfügung stand ein eher schnelleres Wachstum als unbehandelte (s. Abbildung 22). Dies zeigt, dass Ergebnisse aus der Zellkultur nicht unkritisch auf die Situation im Tier übertragen werden dürfen. In einer Studie von Camphausen und Kollegen (2005) wurden in microarray-Analysen Unterschiede des Genexperssionsmusters von U87MG und U251MG in Abhängigkeit von ihrer Umgebung beschrieben. Dabei zeigte 
sich, dass es sowohl Unterschiede zwischen der Zellkultur und dem Anwachsen im Tier, als auch zwischen s.c. und intrazerebral implantierten Zellen gibt. Eine unterschiedliche Genexpression könnte für die unterschiedliche Reaktion der in der vorliegenden Arbeit verwendeten GL261-Zellen - s.c. versus intrazerebral - auf die 1D11-Behandlung verantwortlich sein (s. Abbildung 19 und Abbildung 45). In Studien von Learn et al. (2007) zeigten Expressions-Analysen muriner Gliome die entweder in immunkompetente Mäuse oder in nu/nu-Mäuse intrakraniell implantiert wurden, einen deutlichen Unterschied in der Genexpression. In immunkompetenten Mäusen waren Gene für Zellkommunikation, Wachstum, Adhäsion, katalytische Aktivität, immunmodulatorische Aktivität und Signaltransduktion hochreguliert. Wie in der vorliegenden Arbeit gezeigt wurde, führt die s.c. Implantation der gleichen Tumorzellen in nu/nu-Mäuse und Black/6-Mäuse nicht zu einer veränderten Morphologie der GL261 Tumoren (s. Abbildung 20, Abbildung 21, Abbildung 23 und Abbildung 24). Allerdings gibt es einen Unterschied in der Wachstumsgeschwindigkeit und im Ansprechen auf eine 1D11-Behandlung. Während 1D11 in immundefizienten Mäusen nicht zu einer Tumorreduktion führt, bilden sich in immunkompetenten Mäusen die GL261 Tumoren unter Behandlung komplett zurück. Hier scheint das Immunsystem einen entscheidenden Einfluß auf das Verhalten der Tumoren zu haben (s.4.3.5.2).

Vergleiche zwischen der Zellkultur und der in vivo-Situation sind schwierig. Auch die Daten, die mit implantierten, erst kürzlich in Kultur genommenen Gliomzelllinien erhoben werden sind nicht unbedingt mit endogenen Tumoren zu vergleichen, da die Expression von MHC Klasse I und Klasse II Zelloberflächenmolekülen, sowie B7-2 und Fas Liganden auf der Oberfläche von Gliomzellen durch die in vitro Kultur reduziert werden (Anderson et al., 2002). Auch die Sekretion der Zytokine TGF- $\beta 2$ und IL-10 wird beeinflußt. Nach nur einer Passage von Zellen in vitro wurde TGF- $\beta 2$ deutlich vermehrt und IL-10 gegenüber Zellen die direkt aus dem Tumor stammten deutlich vermindert sezerniert. Ebenfalls nimmt mit zunehmender Passagenzahl die Menge an sezerniertem TGF- $\beta 2$ zu (Anderson et al., 2002). Somit unterscheiden sich die immunologischen Eigenschaften von Gliomzelllinien von denen eines in situ entstandenen Glioms. Authentischer wäre die Behandlung chemisch induzierter Tumoren oder Tumoren in Mauslinien, die genetisch prädestiniert sind für die Entwicklung von Gliomen. Trotz seiner Nachteile wurde auf das Implantationsmodell zurückgegriffen, weil Glioblastome damit s.c. gesetzt werden können und bei intrazerebraler Implantation das Tumorwachstum immer synchron und planbar und die Lokalisation in einer Versuchsgruppe gleich waren. Die Entstehung endogener Tumoren kann man dagegen nicht vorhersagen. 


\subsection{Anreicherung von 1D11 in Gliomen der Maus}

Die Fluoreszenzanreicherung im s.c. U87MG-Tumor bei nu/nu-Mäusen konnte in vivo mittels „optical imaging“ gemessen werden, nachdem mit AF680 Fluoreszenzfarbstoff markierte 1D11 Antikörper i.v. injiziert wurden. In den mehrfach mit AF680 1D11 behandelten s.c. Tumoren wurde von Behandlung zu Behandlung ein geringeres Maximum der Fluoreszenzintensität detektiert, obwohl der Tumor an Größe zunahm (s. Abbildung 14). $\mathrm{Zu}$ keinem Zeitpunkt nach der Behandlung wurde die Fluoreszenzintensität in den Tumoren wieder so gering wie vor der Injektion. Dies zeigt einerseits, dass auch in den fortgeschrittenen Tumor noch AF680 1D11 gelangt und andererseits, dass während einer Phase von 96 h zwischen zwei Behandlungen der Antikörper nicht wieder komplett aus dem Tumor ausgeschieden wird. Somit kann ein Ausbleiben des Therapieerfolges nicht mit der zwischenzeitlichen Abwesenheit des 1D11 im Tumor erkärt werden, sondern höchstens mit einer zu geringen Konzentration.

Die Abnahme des Intensitätsmaximums nach AF680 1D11-Injektion mit zunehmendem Tumorwachstum ist damit erklärbar, dass im Tumor ab einer bestimmten Größe geringer perfundierte Bereiche wie Einblutungen und Nekrosen bestehen, die verabreichte Medikamente nicht aufnehmen (Mendel et al., 2003, Nyati et al., 2002). An diesen Bereichen im Tumor kann folglich keine Fluoreszenz des zuvor verabreichten AF680 1D11 mehr gemessen werden.

Sowohl 1D11 als auch der Kontrollantikörper 13C4 wurden in Tumorgewebe vermehrt aufgenommen, wie die Erhöhung der Fluoreszenzintensität nach Behandlung mit nicht spezifisch bindendem AF680 13C4 in s.c. Tumoren zeigt. Die Fluoreszenzintensität in Tumoren, die mit AF680 1D11 behandelt wurden war zu jedem Zeitpunkt nach i.v. Injektion höher als die in AF680 13C4-behandelten Mäusen (s. Abbildung 14). Diese Erhöhung spricht für eine Mehranreicherung von AF680 1D11 im Tumor nach spezifischer Bindung. (Interindividuelle Unterschiede in der gemessenen Fluoreszenzintensität der Tumoren waren jedoch vorhanden). Der Verlauf der Fluoreszenzintensität im Tumor über die Zeit war nicht unterschiedlich zwischen 1D11-behandelten und 13C4-behandelten Mäusen. Durch die spezifische Bindung des 1D11 im Tumor kommt es nicht zu einer veränderten Kinetik im Vergleich zu dem 13C4. TGF- $\beta$ ist ein frei in der EZM befindliches Protein und unterliegt den gleichen Diffusionsbedingungen, wie auch andere Proteine die nicht gebunden in der extraztellulären Matrix eines Tumors vorliegen. Da TGF- $\beta$ nicht besonders groß ist, scheint es das Diffusionsverhalten des $1 \mathrm{D} 11$ Antikörpers im extrazellulären Millieu nicht wesentlich zu verändern im Vergleich zu dem Antikörper 13C4, der kein Antigen gebunden hat. Wenn der bindende Antikörper an ein zellgebundenes Antigen gebunden hätte, wäre ein Unterschied in der Kinetik zwischen bindendem und nicht bindendem Antikörper zu erwarten gewesen. Die dreidimensionale 
Darstellung bestätigte, dass die gemessene Fluoreszenz im Tumor lokalisiert war und nicht in der Haut darüber (s. Abbildung 12).

In Gefrierschnitten von s.c. Tumoren, wurde die räumliche Verteilung von AF594 1D11 nach i.v. Gabe untersucht. Im Tumorgewebe sieht man eine deutliche Fluoreszenz (s. Abbildung 13). Die inhomogene Verteilung spricht dafür, dass die Fluoreszenz sich langsam, den Druckverhältnissen entsprechend, von den Gefäßen her ausbreitet. In den Gefäßlumina ist aufgrund der vorherigen Perfusion mit PBS keine Fluoreszenz nachweisbar. Allerdings ist eine hohe Fluoreszenz an den Gefäßwänden erkennbar, was ein Hinweis darauf ist, dass sich der Antikörper nahe den Gefäßwänden anreichert. Das ist insofern plausibel, alsdass die ins Blut applizierten Antikörper zuerst nahe den Gefäßen befindliches TGF- $\beta$ erreichen und binden.

Es wäre wünschenswert gewesen, den Antikörper im Tumor mit einer Immunhistochemischen Färbung nachzuweisen. Dies hätte sichergestellt, dass nicht nur freier Farbstoff, der vom 1D11 abgetrennt wurde, den Tumor erreicht Dies war nicht möglich, da es keinen geeigneten Antikörper gegen den 1D11 Antikörper gibt (persönliche Mitteilung von Dr. Jay Harper, Genzyme Oncology). Die in vivo detektierte LT entspricht allerdings der des an 1D11 gebundenen, und nicht dem freien AF680 (s. Abbildung 11). Somit kann man davon ausgehen, dass es nicht zu einer Abspaltung des Farbstoffs vom Antikörper kommt und bei den Bildgebungsverfahren das Konjugat detektiert wird. Die Bereiche hoher Fluoreszenz im Bereich des Magens und der Nieren ist auch erhöhte Fluoreszenzintensität messbar. Aus zwei Gründen kann aber eine Anreicherung des AF680-markierten Antikörpers in diesem Bereich ausgeschlossen werden. Zum Einen ist die Fluoreszenz in diesem Bereich auch in dem Tier zu verzeichnen, welches keine fluoreszenzmarkierten Antikörper bekommen hat und zum Anderen ist die ermittelte LT in diesen Bereichen höher, was für eine Fluoreszenz des Gewebes spricht. Gerade im MagenDarm-Trakt ist das Problem der Fluoreszenz des Futters gegeben. Es wurde versucht zu minimieren, indem die Tiere spezielles fluoreszenzarmes Futter bekamen.

In U87MG-Tumoren kam es nach der Injektion von AF680 $1 \mathrm{D} 11$ zu einer Konzentrationszunahme im Tumor. Bereits 1,5 h nach der Injektion konnte schon eine hohe Fluoreszenzintensität ermittelt werden. In Lymphomen konnte mit einem Cy5.5 gekoppelten chimären Antikörper gegen das B-Zell spezifische Oberflächenantigen CD20, und einer vergleichbaren in vivo Fluoreszensbildgebung im Gegensatz dazu nur eine langsame Anreicherung detektiert werden (Biffi et al., 2008). Die Unterschiede in der Kinetik können sich durch die unterschiedlichen Bindungsorte erklären. Im Falle der Lymphome bindet der Antikörper an zellständige Antigene, während AF680 1D11 an sezerniertes TGF- $\beta$ bindet. Es kann aber auch Unterschiede in der Perfusion der Tumorentitäten geben. In großen Tumoren im Endstadium konnte auch für U87MGTumore eine langsamere Intensitätszunahme beobachtet werden, als für die weniger großen 
zu Anfang der Behandlung. Dies spricht für eine schlechtere Durchblutung in fortgeschrittenen Tumorstadien und steht im Einklang mit den im Verlauf der Behandlungsserie geringer werdenden gemessenen Fluoreszenzintensitätsspitzen nach der Behandlung (s. Abbildung 14). Da die Fluoreszenzintensität immer zum gleichen Zeitpunkt nach i.v.-Injektion gemessen wurde, kann es sein, dass nach der ersten der Behandlung die Intensitätsspitze erfasst wurde, ab der zweiten Messung aber nicht mehr, da das Fluoreszenzmaximum bei jeder folgenden Behandlungen zu einem späteren Zeitpunkt erreicht wurde.

Die Detektion von AF680 1D11-Fluoreszenz in s.c. Glioblastomen bei Black/6- Mäusen war in vivo sehr schwer möglich. Selbst wenn die Tiere vor der Tumorzellimplantation an der Implantationsstelle mit Enthaarungscreme behandelt wurden, wuchs das Fell wieder nach, bevor der Tumor angewachsen war. Durch das nachwachsende Fell wird das Fluoreszenzsignal erheblich abgeschwächt. Bei einer zweiten Anwendung der Creme blieb diese wirkungslos. Durch Rasieren der Tiere vor der Messung konnten die dunklen Haaransätze nicht gleichmäßig entfernt werden.

Für die in vivo-Messung der AF680-1D11-Anreicherung in intrazerebralen GL261 Tumoren bestand das gleiche Problem der Signalabschwächung. Erst nachdem das Gehirn aus dem Schädel herauspräpariert war, konnte eine erhöhte Fluoreszenz an der Stelle des Hirns gemessen werden, an der der Tumor lokalisiert war (s. Abbildung 42). Damit konnte ex vivo gezeigt werden, dass i.v. applizierte Antikörper in Hirntumorgewebe eindringen. Eine in vivo- Darstellung war aber nicht möglich. Auch die Druckverhältnisse im Tumor können unterschiedlich sein, was eine inhomogene Verteilung von Substanzen aus dem Blut im Tumorgewebe verursacht (Michinton u. Tannock, 2006).

Die hohe in vivo Fluoreszenzintensität im Kopfbereich nach AF680 1D11-Injektion an Tag 8 nach Tumorzellimplantation ist durch die Anreicherung des Antikörpers in der durch die Implantationsoperation verletzten Haut zu erklären (s. Abbildung 42). Eine erhöhte Fluoreszenz in Wunden konnte schon für Cy5.5-markiertes Endostatin gezeigt werden (Citrin et al., 2003). Da TGF- $\beta$ auch bei der Wundheilung eine Rolle spielt, ist hier mit erhöhten TGF- $\beta$-Konzentrationen zu rechnen, an die 1D11 spezifisch bindet. Acht Tage nach der Implantation war ex vivo im Hirn erhöhte Fluoreszenz detektierbar. Die BHS war zu diesem Zeitpunkt also geschädigt, sodass AF680 1D11 aus dem Gefäßsystem ins Hirntumorgewebe eindringen konnte. Die Tumorzellen haben zur Beeinträchtigung der BHS geführt. 


\subsection{Einfluß der 1D11-Behandlung auf subkutane Gliome}

In den gezeigten Versuchen zur 1D11-Behandlung s.c. U87MG-Tumoren in immundefizienten nu/nu-Mäusen führte die Inhibierung der TGF- $\beta$-Bindung an seinen Rezeptor zu einem verstärkten Wachstum der Tumoren (s. Abbildung 16). Dieses Ergebnis steht im Einklang mit Ergebnissen von Pan und Kollegen (2006), die zeigen konnten, dass TGF- $\beta 1$-überexprimierende U87MG-Zellen in immundefizienten Ratten kleinere Tumoren entwickelten, als Wildtyp-Zellen.

Sie konnten allerdings in immunhistochemisch gefärbten Schnitten weder für die Angiogenese, noch für die Anzahl apoptotischer Zellen einen Unterschied zwischen den TGF- $\beta 1$-überexprimierenden- und den Wildtyp-U87MG-Tumoren feststellen. Zudem konnten sie keinen Unterschied in der Anzahl an Lymphozyten ermitteln. Auch in der vorliegenden Arbeit konnte in den immunhistochemischen Färbungen weder für Proliferationsmarker noch für Apoptosemarker ein Unterschied zwischen s.c. U87MGTumoren 1D11-behandelter und unbehandelter nu/nu-Mäuse festgestellt werden (s.

Abbildung 26, Abbildung 27, Abbildung 29 und Abbildung 32).

In den GL261-Zellen, (die von sich aus weniger TGF- $\beta 2$ produzieren als die U87MGZellen) bewirkte eine Erhöhung der TGF- $\beta 2$-Konzentration im Medium in der Zellkultur eine Erhöhung der Proliferationsrate (s. Abbildung 10, B). Trotzdem blieben die nicht mit 1D11 behandelten s.c. GL261-Tumoren in der nu/nu-Maus, in denen mehr freies TGF- $\beta$ zur Verfügung stand im Durchschnitt sogar etwas kleiner als die mit 1 D11 behandelten (s. Abbildung 22). Durch das schnelle und aggressive Anwachsen der GL261-Tumoren in nu/nu-Mäusen wurden die Tiere dieser Versuchsreihe C) schon früher aus dem Versuch genommen (Tag 21) als die der Versuchsreichen A) und B) (Tag 35). Hätten die Tumoren noch einige Tage weiter wachsen können, so wäre der Unterschied zwischen den Tumoren der 1D11-behandelten Gruppe und den Kontrollen vermutlich noch deutlicher gewesen. An Tag 21 nach Implantation waren auch die Unterschiede in den Versuchsreihen A) und B) noch nicht so deutlich zu sehen, wie an Tag 35 (s. Abbildung 16, A und Abbildung 19, A).

In frühen Tumorstadien hat TGF- $\beta$ einen tumorsuppressiven Effekt, während es in fortgeschrittenen Stadien ein tumorfördender Faktor ist (Akhurst und Derynck, 2001). Die durch den Smad-Signalweg vermittelten wachstumsinhibierenden Eigenschaften werden dabei von den durch den MAPK-Signalweg induzierten mesenchymalen Eigenschaften abgelöst. Eine Unausgewogenheit zwischen den beiden Signalwegen ist vermutlich für die unterschiedlichen Antworten der Zellen auf TGF- $\beta$ verantwortlich (Nickl-Jockschat et al., 2007). Es scheint, dass sowohl bei U87MG als auch bei GL261 Zellen in nu/nu-Mäusen hauptsächlich der wachstumsinhibierende Smad-Signalweg aktiv ist, wodurch TGF- $\beta$ einen tumorsuppressiven Einfluß ausübt. Eine Behandlung mit 1D11, die die Menge an freiem 
aktiven TGF- $\beta$ reduziert, wirkt sich so wachstumssteigernd aus. Dies zeigt sich in der vorliegenden Arbeit bei s.c. in nu/nu-Mäuse implantierten Tumorzellen.

Die Ergebnisse dieser Arbeit zeigen hingegen aber auch, dass bei s.c. GL261-Tumoren in immunkompetenten Black/6-Mäusen die Behandlung mit 1D11 einen tumorsuppressiven Effekt hatte (s. Abbildung 19). Dies steht im Einklang mit Daten von Uhl und Kollegen (2004), die im syngenen Mausmodell bei Tieren ohne Immunsuppression intrazerebrale Gliome mit SD-208-, einem TGF- $\beta$-RezeptorII-Inhibitor, behandelt haben. In beiden Fällen wurde die TGF- $\beta$-vermittelte Signalkaskade verhindert. Die mittlere Überlebenszeit von behandelten Mäusen betrug 25 Tage, während unbehandelte im Mittel nur 18 Tage überlebten. In immunkompetenten Mäusen scheint TGF- $\beta$ also als Tumorpromotor zu wirken, sodass eine Behandlung, die die Menge an verfügbarem TGF- $\beta$ reduziert, zu verringertem Tumorwachstum führt. In immunhistochemischen Färbungen konnten auch Uhl und Kollegen (2004) keine signifikanten Unterschiede bei der Gefäßbildung, Proliferation oder Apoptose zwischen behandelten und unbehandelten Tieren feststellen. Für s.c. in Black/6-Mäusen angewachsene GL261 Tumoren konnte zwischen 1D11behandelten und Kontrolltumoren auch in der vorliegenden Arbeit kein Unterschied für Gefäßbildung und Proliferation ermittelt werden. Allerdings konnte im Gegensatz zur Arbeit von Uhl und Kollegen (2004) ein Unterschied in der Zahl apoptotischer Zellen von 1D11-behandelten angewachsenen Tumoren im Vergleich $\mathrm{zu}$ 13C4-Isotyp-behandelten festgestellt werden (s. Abbildung 32). Das liegt möglicherweise daran, dass die Untersuchungen von Uhl und Kollegen an intrazerebralen Tumoren durchgeführt wurden, während die 1D11-Behandlung an Mäusen mit s.c. Tumoren stattfand. Die Tatsache, dass es eine erhöhte Zahl apoptotischer Zellen in 1D11-behandelten Tumoren von immunkompetenten Black/6-Mäusen gibt, nicht aber in immundefizienten nu/nu-Mäusen, spricht dafür, dass das Immunsystem einen wachstumshemmenden Einfluss auf den Tumor ausübt, der durch die Reduktion von freiem TGF- $\beta$ in der Tumormatrix vermittelt wird und eine Rolle bei der Einleitung der Apoptose spielt (s. 4.3.5.2). Zu beachten ist allerdings, dass die Statistik für 1D11-behandelte Mäuse nur mit einem n von 2 durchgeführt werden konnte, da bei den Mäusen dieser Behandlungsgruppe nur drei Tumoren angewachsen sind.

Zusammenfassend schreitet das Tumorwachstum in immundefizienten Mäusen schneller voran als in immunkompetenten Mäusen. GL261 Mausgliomzellen zeigten unabhängig von der Mauslinie, in die sie s.c. implantiert wurden, ein anderes Wachstumsbild als humane U87MG-Gliomzellen. Abgesehen von der veränderten Morphologie der Tumoren war bei den GL261 Tumoren häufig die Haut vom Tumor infiltriert, wodurch offene Wunden entstanden, was in zwei Fällen einen frühzeitigen Versuchsabbruch verlangte. Auch waren die GL261-Tumoren stärker in umliegende Muskeln infiltriert als die U87MG-Tumore. Da im syngenen Mausmodell durch Behandlung mit 1D11 eine komplette Reduktion s.c. 
Gliome erreicht werden konnte, ist der Antikörper ein vielversprechendes neues Molekül für eine Therapie.

\subsubsection{Einfluß der 1D11-Behandlung auf die extrazelluläre Matrix}

Im diffus wachsenden Gliom ist der extrazelluläre Raum vergrößert und wird irregulärer (Zamecnik, 2005). Ein vergrößerter extrazellulärer Raum ist in den vorgestellten Versuchen bei intrazerebralen GL261 Tumoren auch zu finden. Die mit 1D11 behandelten Tumoren sind kompakter als die unbehandelten Kontrolltumoren. Somit scheint TGF- $\beta$ einen Einfluß auf die Schaffung eines erweiterten Extrazellularraums zu nehmen. In den letzten Jahren ist die EZM in Gliomen in Hinblick auf das invasive Verhalten von Gliomen intensiv erforscht worden. Im gesunden Gehirn, wie auch im Glioblastom sind die EZMProteine wie Collagen, Laminin und Fibronectin hauptsächlich entlang der Gefäßwände lokalisiert (Gladson, 1999). Die genaue Zusammensetzung der EZM ist noch nicht bekannt, aber im Gehirn sind Hyaluronan, Glycosaminoglykane und Proteoglykane vermutlich die Hauptkomponenten (Bellail et al., 2004, Gladson, 1999). Durch die Synthese der EZMProteine Vitronektin, Tenascin-C und Laminin schafft sich das Glioblastom ein eigenes Mikromilieu (Claes et al., 2007). Für Tenascin-C ist beschrieben, dass es in vitro in U87MG Zellen durch TGF- $\beta$ induziert werden kann und dass die Dichte der EZM in Gliomen mit dem Expressionsgrad von TGF- $\beta$ korrelliert (Hau et al., 2006). Für die Ergbnisse in der vorliegenden Arbeit bedeutet das, dass die Expression von EZMKomponenten im intrazerebralen GL261-Tumor durch die Behandlung mit 1D11 reduziert worden sein könnte.

Im Gewebe stehen die Zellen über Proteine in der Membran in Kontakt miteinander und/oder mit der EZM. Zur Migration müssen Zellen die Kollagenfasern der EZM mittels Matrix-Metalloproteinasen durchtrennen (Lakka et al., 2004, Rao, 2003, Platten et al., 2001). Es konnte gezeigt werden, dass TGF- $\beta$ die Expression von MatrixMetalloproteinasen induziert, während die Expression von Inhibitoren der MatrixMetalloproteinasen reduziert wird, wodurch die Invasivität der Zellen erhöht wird (Nakano et al., 1995; Wick et al., 2001). Dieses invasive Verhalten der Tumorzellen ist auch in HESchnitten der in dieser Arbeit vorgestellten Versuche mit intrazerebralen GL261-Tumoren deutlich zu sehen (s. Abbildung 45, A). Wesolowska und Kollegen (2008) konnten in transfizierten Zellen mit si-RNA die TGF- $\beta$ Rezeptor II Expression in Gliomzellen reduzieren und in vitro zeigen, dass die Invasivität und Migrationsrate dadurch verringert wurde. Das steht im Einklang mit der in HE-Schnitten zu sehenden verringerten Invasivität von 1D11-behandelten intrazerebralen Tumoren (s. Abbildung 45, B). Bei Wesolowska und Kollegen zeichneten sich die s.c. Tumoren der transfizierten Zellen in nu/nu-Mäusen 
allerdings auch durch geringeres Wachstum aus, während die 1D11-behandelten Tumoren in nu/nu-Mäusen in der vorliegenden Arbeit vermehrtes Wachstum aufwiesen. Dieser Unterschied im s.c. Wachstumsverhalten zwischen TGF- $\beta$ Reteptor II ,knock-down“Gliomzellen und 1D11-behandelten Gliomzellen kann seine Ursache darin haben, dass die TGF- $\beta$ Signaltransduktion in den transfizierten Zellen durch weniger TGF- $\beta$ Rezeptor II in der Zellmembran stärker unterbunden ist, als nach 1D11-Behandlung. Dadurch könnte das Gleichgewicht der Signalwege sich für die tranzfizierten im Vergleich zu 1D11 behandelten Zellen zugunsten des proliferationshemmenden Smad-Signalwegs verschieben (s. 4.3). Um diese Phänomene erklären zu können, bedarf es der genauen Analyse der verschiedenen Glioblastomzelllinien und der weiteren Erforschung der komplexen Zusammenhänge und Wirkungen, die TGF- $\beta$ vermittelt.

\subsubsection{Einfluß der 1D11-Behandlung auf die Glykoproteinproduktion}

In Tumoren ist bekannt, dass Glykoproteine die Zelladhäsion modulieren, somit zur Tumormetastasierung beitragen, sowie die Immunantwort und Signalweiterleitung modulieren (Fukuda 2002, Moniaux et al., 2001, Satoh et al., 2000, Fukuda, 1996, Wesseling et al., 1995). Viele Tumore, wie z.B. Colon-, Mamma-, Lungencarcinom und Pankreastumoren exprimieren vermehrt Glykoproteine. Mishima und Kollegen (2006) konnten zeigen, dass fast die Hälfte aller untersuchten humanen Glioblastome Podoplanin, ein Mucin-ähnliches transmembranes Protein überexprimieren und die Podoplaninexpression mit dem Malignitätsgrad von Gliomen korrelliert. Hauptsächlich wurde Podoplanin (nebst Regionen proliferierender Endothelzellen) um nekrotische Bereiche detektiert (Mishima et al., 2006). Diese Beobachtung passt zu den in den s.c. GL261-Tumoren gefundenen Ergebnissen der vorliegenden Arbeit. Hier sind lockere, nekrotische Randbereiche mit hoher Anzahl apoptotischer Zellen von Bereichen hoher Zelldichte mit weniger apoptotischen Zellen zu unterscheiden (s. Abbildung 31). Eine hohe Glykoproteinproduktion kann zu Adhäsionsverlust führen. In den s.c. GL261Tumoren gibt es erhöhte Anzahl an apoptotischen Zellen in matrixreichen Bereich. Die Zellen scheinen einzeln in der Matrix zu liegen. Dazwischen gibt es aber immer noch Zellen, die intakt scheinen. Zellen ohne Kontakt gehen normalerweise in Apoptose. Für Mucin4 ist bekannt, dass es bei Expression in Pankreastumoren auch die durch Kontaktverlust eingeleitete Apoptose (Anoikis) verhindern kann (Chaturvedi et al., 2007). Allerdings gibt es Studien an hochgradigen intraepithelialen Neoplasien im Barrett's Oesophagus, bei denen Mucin4-Expression mit erhöhter Apoptose korrelliert (Bax et al., 2004). In den Versuchen der vorliegenden Arbeit hatte 1D11-Behandlung auf die s.c. angewachsenen GL261-Tumoren in C57/BL6- und in nu/nu-Mäusen zumindest keinen 
erfassbaren Einfluss auf das Ausmaß des Interzellularraumes (s. Abbildung 31). In intrazerebralen Tumoren dagegen hat die 1D11-Behandlung $\mathrm{zu}$ einem reduzierten Interzellularraum und somit kompakteren Tumoren geführt (s. Abbildung 45).

Eine Immunantwort gegen Tumorgewebe wird durch für Immunzellen erkennbare Oberflächenmoleküle auf Tumorzellen ermöglicht. Große Proteine, wie Glykoproteine auf der Oberfläche von Tumorzellen, können die für Immunzellen erkennbaren Oberflächenepitope maskieren. Dadurch können Tumorzellen einer Bekämpfung durch das Immunsystem entgehen (Taylor-Papadimitriou et al., 2002, Taylor-Papadimitriou et al., 1999, Agrawal et al., 1998). In Versuchen mit Ratten konnte gezeigt werden, dass Glykoproteine auf der Oberfläche von Tumorzellen durch sterische Behinderung die Bindung von cytotoxischen T-Zellen und natürlichen Killerzellen verhindert (Komatsu et al., 1999). Dabei war die Länge der einzelnen Glycoproteine und der Glykolysierungsgrad für die effektive Suppression der Immunantwort wichtig (Komatsu et al., 1999).

Wenn in den s.c. GL261-Tumoren, die auf die 1D11-Therapie angesprochenen haben, durch verminderte Glykoproteinproduktion T-Zellen in der Lage gewesen sind, die Tumorzellen $\mathrm{zu}$ erkennen, und eine Immunreaktion einzuleiten, so würde dies die Wirksamkeit erklären. Damit wäre auch das fehlende Ansprechen der Tumoren in nu/nuMäusen auf eine 1D11-Behandlung zu erklären. Hier gibt es keine T-Zellen, die die Tumorzellen erkennen könnten. Zur Klärung müssten weitergehende Untersuchungen zu Komponenten der Matrix erfolgen.

\subsubsection{Einfluß der 1D11-Behandlung auf die Proliferation}

Die Zellkultur ist geeignet die Proliferation von Tumorzellen unter einer bestimmten TGF$\beta 2-K o n z e n t r a t i o n ~ u n t e r$ konstanten Bedingungen zu betrachten.

Auf zugegebenes TGF- $\beta 2$ im Medium reagierten die U87MG-Zellen mit vermindertem Wachstum (s. Abbildung 10, A). Auch andere Arbeitsgruppen konnten sowohl in Astrozyten (Rich et al., 1999, Morganti-Kossmann et al., 1992), als auch in einigen Gliomzelllinien eine Inhibition der Proliferation durch TGF- $\beta$ beobachten (Nickl-Jockschat et al., 2007, Piek et al., 1999, Helseth et al., 1988). Als Wirkung von TGF- $\beta 1$ auf Gliomzellen ist aber auch eine Proliferationssteigerung beschrieben (Piek et al., 1999). Die vorliegende Arbeit zeigt, dass GL261 Zellen auf zusätzliches TGF- 32 im Medium, mit einer Proliferationssteigerung reagieren. Im Gegensatz dazu weisen U87MG-Zellen verminderte Proliferation auf. TGF- $\beta 2$ hat in beiden Zelllinien einen Einfluß auf das

Wachstum. Der Unterschied im Ansprechen der U87MG Zellen im Vergleich zum Ansprechen der GL261-Zellen (s. Abbildung 9) kann in der unterschiedlichen TGF- $\beta 2-$ Sekretion beider Zelllinien begründet sein (Xu und Kapoun 2009). 
In Zellkulturversuchen hatte die 1D11-Behandlung weder einen Effekt auf U87MG Zellen, noch auf GL261-Zellen (s. Abbildung 10). Möglicherweise wird in vitro zugegebenes 1D11 schnell gebunden und das gebundene TGF- $\beta$ durch die hohe Produktion an weiterem TGF- $\beta$ ersetzt.

In den s.c. U87MG-Tumoren bewirkt die Behandlung der Mäuse mit 1D11 ein schnelleres Wachstum und nach gleicher Anwachszeit höhere Endgewichte. Dies lässt vermuten, dass durch Behandlung mit 1D11 die Proliferation in den Zellen erhöht wird. Auf die in vivo Situation in s.c. Mäusen übertragen heißt das, dass die wiederholte Behandlung mit 1D11 die Konzentration an freiem TGF- $\beta$ senkt und eine niedrigere Konzentration eine höhere Proliferation der Tumorzellen zulässt. Im Gegensatz dazu ist in den unbehandelten Tumoren eine höhere TGF- $\beta$-Konzentration vorhanden, was zu einer geringeren Proliferation führt. Allerdings passt diese Hypothese nicht zu den Ergebnissen der immunhistochemischen Färbungen mit Ki67, wo für die Proliferationsrate kein signifikanter Unterschied zwischen behandelten und unbehandelten Tumoren ermittelt werden konnte (s. Abbildung 27) (zum Vergleich mit der Zellkultur s. auch 4.3).

Die Auswirkungen im Tier können durch weitere Einflußfaktoren, die die Proliferation oder die Zellantwort auf TGF- $\beta$ verändern vom Zellkulturergebnis abweichen.

\subsubsection{Einfluß der 1D11-Behandlung auf die Angiogenese}

Gliome bestehen nicht nur aus Tumorzellen, sondern auch noch aus tumorassoziierten Zellen. Gefäßendothelzellen, Glattmuskelzellen und Perizyten, bilden gemeinsam die Gefäße. Zusätzlich finden sich Mikrogliazellen, die durch Cytokine angelockt werden (Platten et al., 2003) und andere einwandernde Immunzellen.

Solide Glioblastome können nur wachsen, wenn sie die Ausbildung neuer Gefäße induzieren. Die Tumoren, die früher Anschluß an das Gefäßsystem bekommen haben gegenüber denen, die diesen Anschluß später bekommen, einen Wachstumsvorsprung. Für die humane Gliomzellinie T98G ist beschrieben, dass der Phänotyp bei schnell anwachsenden Tumoren sich nicht von dem solcher Tumoren unterscheidet, die erst einige Wochen nach Implantation angewachsen sind (Naumov et al., 2006). Das von Gliomzellen sezernierte TGF- $\beta$ wirkt Angiogenese-fördernd auf Endothelzellen (Platten et al., 2001, Akhurst and Derynck, 2001, Dunn et al., 2000).

Insulin-like growth factor-binding protein 7 (IGFBP7) ist ein in Tumorendothelzellen hochreguliertes, Protein, welches die Proliferation beeinflussen kann (Pen et al., 2007). Aktuelle Ergebnisse von Tamura und Kollegen (2009) deuten darauf hin, dass IGFBP7 den Angiogenese-stimulierenden Effekt von VEGF in Endothelzellen modulieren kann. Es konnte gezeigt werden, dass im Tumor weniger Angiogenese stattfindet, je mehr IGFBP7 
vorhanden ist. In menschlichen Gehirnendothelzellen (HBECs), die in konditionierem Medium von U87MG-Zellen gehalten wurden, konnten Pen und Kollegen (2008) durch die Behandlung mit 1D11 die Expression von IGFBP7 niedrig halten (Pen et al., 2008) während sie ohne die Behandlung mit 1D11 anstieg. Dies gibt einen Hinweis darauf, dass in Endothelzellen im U87MG-Tumor die Hochregulierung von IGFBP7 durch TGF- $\beta$ erfolgt. Das wiederum würde bedeuten, dass unbehandelte Tumoren infolge geringerer Angiogenese langsamer wachsen müssten, als 1D11-behandelte. Dieser Effekt konnte in den Versuchen mit U87MG-Tumoren in nu/nu-Mäusen in der vorliegenden Arbeit bestätigt werden. Die 1D11-behandelten Tumoren wuchsen schneller und erreichten zum Versuchsende höhere Endgewichte als die unbehandelten (s. Abbildung 16). Die histopathologische Untersuchung der Gefäßdichte in den U87MG-Tumoren mit Messung der Gefäßanschnitte pro Gesichtsfeld konnte allerdings keinen signifikanten Unterschied zwischen 1D11-behandelten und unbehandelten Tumoren zeigen (s. Abbildung 33 und Abbildung 34). Es gibt aber noch eine andere Möglichkeit den Einfluß von TGF- $\beta$ auf die Angiogenese zu erklären.

In Glioblastomen sind, wie in vielen anderen Tumoren auch die Blutgefäße durch veränderte Histologie charakterisiert. Im Glioblastom haben viele Tumorgefäße keine Basalmembran, eine verminderte Perizytenbedeckung, eine verminderte Anlagerung von Astrozytenendfüßen und eine veränderte Expression von Adhäsionsmolekülen (Baluk et al., 2003, Kleihues et al., 2002, Vitolo et al., 1996, Lossinsky et al., 1995). Diese Veränderungen resultieren in einer erhöhten Zahl sich windender, weitlumiger Gefäße. Im gesunden Gewebe sind proangiogene und antiangiogene Faktoren im Gleichgewicht. Im Glioblastom ist dieses Gleichgewicht zugunsten der proangiogenen Faktoren verschoben. TGF- $\beta$ induziert die Produktion angiogener Substanzen. Die Hemmung von TGF- $\beta$ könnte dazu beitragen, dass weniger angiogene Substanzen von den Tumorzellen exprimiert werden. Dadurch wäre das Gleichgewicht der angiogenen Substanzen soweit wieder hergestellt, dass eine größere Anzahl morphologisch intakter Gefäße entsteht, obwohl die Proliferation der Endothelzellen nicht gesteigert ist. Das vermehrte Wachstum der Tumoren der 1D11 behandelten Mäuse ist dann damit zu erklären, dass die Blutversorgung in diesen Tumoren besser war, als in denen unbehandelter Mäuse, da intakte Gefäße besser perfundiert werden.

Aufgrund der geringen Zahl angewachsener GL261-Tumoren in den Black/6-Mäusen konnte nur ein 1D11-behandelter Tumor eingefroren werden. Dieser eine Tumor hatte eine geringere Gefäßdichte, als die unbehandelten Tumoren. 


\subsubsection{Einfluß der 1D11-Behandlung auf das Immunsystem}

\subsubsection{Makrophagen}

In verschiedenen Studien konnte gezeigt werden, dass Makrophagen die in Gliomen überwiegenden Zellen darstellen (Morimura et al., 1990, Rossi et al., 1987). Die Makrophagenfärbung in der vorliegenden Arbeit sollte Aufschluß darüber geben, ob die s.c. U87MG-Tumoren 1D11-behandelter Mäuse von mehr Makrophagen infiltriert sind, als die der unbehandelten. Dies könnte der Grund sein, weshalb die Tumore größer sind, als die unbehandelten. Es zeigte sich, dass im Randbereich mehr Makrophagen zu finden waren als in der Tumormitte, zwischen 1D11-behandelten und unbehandelten Tumoren gab es jedoch keine Unterschiede (s. Abbildung 37 und Abbildung 38).

In den s.c. GL261-Tumoren gab es im Vergleich zu den U87MG-Tumoren so viele Makrophagen, dass ein Auszählen nicht möglich war (s. Abbildung 39 und Abbildung 40) Diese großen Mengen an Makrophagen fanden sich sowohl in den 1D11-behandelten, als auch in den unbehandelten Tumoren. Interessanterweise war der Effekt auch in nu/nuMäusen zu sehen, so dass die niedrige Zahl an Makrophagen in U87-MG Tumoren nicht vom Tierstamm, sondern durch die Zelllinie bestimmt zu sein scheint.

TGF- $\beta$ wirkt zwar als Immunsuppressor, aber Makrophagen werden nicht am Einwandern in den Tumor gehindert. Es gibt nicht weniger Makrophagen in Tumoren unbehandelter Mäuse als in Tumoren 1D11-behandelter. Sie können aber in ihren Eigenschaften verändert sein. Die in den Tumor infiltrierten Monocyten können unter Einfluß verschiedener Cytokine zu M1- oder M2-Makrophagen differenzieren (Talmadge et al., 2007). Während M1-Makrophagen tumorsuppressiv aktiv sind, sind M2Makrophagen tumorfördernd. GL261-Glioblastome sezernieren Cytokine, die Makrophagen zu Zellen differenzieren, die sowohl M1-, als auch M2-MakrophagenMarker aufweisen (Umemura et al., 2008). Die Eigenschaften dieser M1/M2-Makrophagen sind tumorprogressiv und sie sezernieren relativ große Mengen an TGF- $\beta 1$. Die Behandlung von s.c. GL261-Tumoren mit 1D11 koennte in Black/6-Mäusen dazu geführt haben, dass sich mehr Makrophagen zu M1-Makrophagen differenziert haben, die dann zur Tumorbekämpfung beigetragen haben. Allerdings führte die 1D11-Behandlung von nu/nuMäusen zu verstärktem Tumorwachstum, obwohl diese auch Makrophagen haben.

Makrophagen können zu Gliomzellsphäroiden gegeben werden und die Anzahl der in die Sphäroide einwandernden Makrophagen kann ausgewertet werden (Strik et al., 2006). Die Behandlung von GL261-Sphäroiden mit Makrophagen aus Black/6-Mäusen resultierte in zerstörten Sphäroiden, wogegen die Behandlung mit TGF- $\beta 2$ dazu führte, dass Sphäroide trotz zugegebenen Makrophagen nicht zerstört wurden (s. Abbildung 41). Dies spricht für die Ausdifferenzierung der Makrophagen in einen das Tumorwachstum fördernden Makrophagentyp unter Einfluß von TGF- $\beta 2$. 


\subsubsection{T- und B-Zellen}

Da es im Gehirn kein lymphatisches System gibt, können Zellen des Immunsystems nur über das Blutgefäßsystem einwandern. Daher kommt dem Gefäßendothel im Gehirn bei der Regulierung der Einwanderung von Immunzellen eine besondere Bedeutung zu. Die Expression der Adhäsionsmoleküle ICAM-1 und CD31 auf der luminalen Oberfläche der Endothelzellen erlaubt es T-Zellen hier zu binden und durch die Gefäßwand in das dahinter gelegene Gewebe $\mathrm{zu}$ migrieren. In gesunden Endothelzellen in der Zellkultur hat Fibroblast-Growth-Factor b den größten reduzierenden Effekt auf die Expression von von ICAM-1 und CD31. Dagegen wird bei Endothelzellen aus Glioblastomen die Menge an ICAM-1 und CD31 nach Inkubation mit TGF- $\beta$ am meisten reduziert (Präsentation von J. Lohr, Neurex SEISC Meeting 2009). Somit ist nicht unbedingt ein morphoplogisch verändertes Gefäßsystem ein Indikator für den wachstumsfördernden oder hemmenden Einfluß von TGF- $\beta$, sondern die Funktionalität der Endothelzellen. Durch die Auswertung endothelzell-gefärbter Schnitte von s.c. U87MG-Tumoren konnten keine sicheren Anzeichen für eine veränderte Gefäßmorphologie zwischen 1D11-behandelten und unbehandelten Tumoren festgestellt werden. Funktionelle Unterschiede sind aber nicht auszuschließen (s. auch 4.3.4).

In der vorliegenden Arbeit wuchsen bei immundefizienten Mäusen, die s.c. GL261Tumoren trotz 1D11-Behandlung an, während sie in immunkompetenten Mäusen unter 1D11-Behandlung zurückgebildet wurden (s. Abbildung 19 und Abbildung 22). Mit CD70-überexprimierenden GL261-Zellen konnte von Aulwurm und Kollegen (2006) ein ähnlicher Effekt mit Black/6- und nu/nu-Mäusen erreicht werden. CD70 ist ein Transmembranprotein der Tumor-Nekrosefaktor-Familie, das normalerweise auf aktivierten T- und B-Zellen exprimiert wird. Sein Rezeptor CD27 ist ein Typ-1 Glykoprotein, das konstitutiv von T- und NK-Zellen exprimiert wird. NK-Zellen konnten an die Tumorzellen binden und deren Lyse auslösen. TGF- $\beta$ wirkt inhibierend auf die Proliferation und Aktivität von zytotoxischen T-Zellen und NK-Zellen (Bodmer et al., 1989, Weller und Fontana, 1995). Somit kann die T-Zellantwort durch Bindung von TGF- $\beta$ an 1D11 erhöht werden, was in einer erhöhten Apoptoserate resultiert, die in den GL261Tumoren in 1D11-behandelten Black/6-Mäusen festgestellt wurde. Diese verstärkte Immunantwort kann $\mathrm{zu}$ der in den angewachsenen 1D11-behandelten Tumoren der Versuchsreihe B) gefundenen erhöhten Apoptoserate (s. Abbildung 32, GL261 in Black6) und zur völligen Tumorreduktion geführt haben. 


\subsection{D11-Behandlung intrazerebraler Gliome}

Mit der 1D11-Behandlung intrazerebraler GL261-Tumoren in Black/6-Mäusen wurde der Versuch gemacht, in einem Tiermodell, in dem Mäuse mit s.c. Tumoren mit 1D11 wirksam behandelt werden konnten, nun auch orthotope Glioblastome zu behandeln. Wie die s.c. Tumoren, wurden auch die intrazerebralen Tumoren durch i.v. Gabe von 1D11 behandelt. Da der Raum innerhalb des Schädels begrenzt ist, können die Tumore im Hirn nicht so groß werden, wie unter der Haut. Damit dennoch einige Wochen vergehen in der die Tumoren behandelt werden können, bis die Tiere tumorbedingte Krankheitszeichen aufweisen, wurde die Zahl der implantierten Zellen im Vergleich zu s.c. Implantationen deutlich gesenkt. In Studien von Szatmari und Kollegen (2006) konnte gezeigt werden, dass sich GL261-Zellen vergleichbar $\mathrm{zu}$ anderen Gliomzelllinien verhalten und Charakteristika wie invasives Wachstum zeigen. Sie haben ermittelt, dass bei intrazerebraler Implantation eine Zellzahl von 100.000 Zellen nach durchschnittlich 25 Tagen und eine Zellzahl von 10.000 Zellen nach durchschnittlich 27 Tagen zum Tod der Tiere führt. Für die 1D11-Behandlung wurden in den vorliegenden Versuchen 75.000 Zellen in die rechte Hemisphäre des Großhirns implantiert und die Behandlung startete schon an Tag 3 nach der Implantation, anstelle von Tag 7, wie bei s.c. Tumoren. Nach 25 Tagen hatten sich große, den Großteil der rechten Hemisphäre ausfüllende Tumoren gebildet. Makroskopisch waren an den quergeschnittenen Gehirnen im Gegensatz zu s.c. behandelten GL261-Tumoren in Black/6-Mäusen keine Unterschiede zwischen den 1D11 behandelten und den unbehandelten Tumoren $\mathrm{zu}$ erkennen. Auch die mikroskopisch ermittelten Tumordurchmesser der Versuchsgruppen unterschieden sich nicht signifikant (s. Abbildung 44). Erst die histologische Auswertung der HE-Färbungen zeigte einen Effekt der Behandlung auf die Tumormorphologie. In intrazerebralen GL261-Tumoren finden sich von Tumorzellen kooptierte Gefäße in 1D11-behandelten und in unbehandelten Tumoren. Insgesamt ist die Invasionszone in 1D11-behandelten Tumoren jedoch geringer ausgeprägt, als in unbehandelten, in denen deutlich zu sehen ist, dass die Tumorzellen sich vom Haupttumorknoten aus ins Hirnparenchym ausbreiten (s. Abbildung 45). Für orthotope Gliome wurde im Maus-Modell von anderen gezeigt, dass eine antiangiogene Therapie die Anzahl von kleinen Satellitentumoren und die Invasion der Tumorzellen entlang existierender Gefäße erhöht (Lamszus et al., 2003). Ein Grund für diesen Unterschied zu den Ergebnissen der vorliegenden Arbeit mag sein, dass die Inhibition von TGF- $\beta$-Rezeptor-Bindung nicht nur die Produktion angiogener Faktoren in den Zielzellen herabsetzt, sondern auch die Produktion von Molekülen, die für Tumorzellmigration verantwortlich sind. Tatsächlich konnte von anderen für verschiedene Gliomzelllinien und Primärkulturen in der Zellkultur gezeigt werden, dass exogen zugesetztes TGF- $\beta$ die Migration der Tumorzellen erhöht und eine stabile Transfektion mit TGF- $\beta$-Rezeptor II si 
RNA die Migration verringert. Die transfizierten Gliomzellen zeigten s.c. in nu/nu-Mäuse implantiert ein langsameres Wachstum als Wildtypzellen (Wesolowska et al., 2008). Von Uhl und Kollegen (2004) konnte im Matrigel-Invasionsassay eine verringerte Invasivität von verschiedenen Gliomzelllinien nach Behandlung mit TGF- $\beta$-Rezeptor I KinaseInhibitor SD-208 festgestellt werden. Hier kann die Glykoproteinproduktion der Zellen eine Rolle spielen (s. 4.3.1). Die für die vorliegende Arbeit ausgewerteten unbehandelten Tumore haben einen matrixreichen Tumorknoten, die 1D11 behandelten Tumore haben eine weniger matrixreiche Mitte (s. Abbildung 45). Erhöhte Migration in umgebendes Gehirngewebe konnte in unbehandlten intrazerebralen GL261-Tumoren im Vergleich zu 1D11-behandelten Tumoren auch festgestellt werden. Es scheint, dass die Inhibition des TGF- $\beta$ im intrazerebralen Tumor bewirken konnte, dass weniger Glykoproteine von den Tumorzellen exprimiert wurden. Beispielsweise wird das Proteoglycan Versican von Gliomzellen produziert und ist mit verantwortlich für Adhäsion und Migration. Die Isoformen V0 und V1 werden durch TGF- $\beta 2$ in Gliomzellen induziert was zu erhöhter Migration führt (Arslan et al., 2007).

\section{5 Öffnung der BHS}

Die BHS hat unter anderem die Aufgabe, den Eintritt von potentiell schädigenden Substanzen aus dem Blut ins Hirngewebe zu verhindern (Bradbury, 1979). Die meisten klinisch eingesetzten Zytostatika haben nicht die physiko-chemischen Eigenschaften, um die BHS in für die Therapie ausreichender Menge zu überwinden (Donelli et al., 1992). Dies kann auch der Grund sein, warum 1D11 keinen tumorreduzierenden Effekt zeigte. Die Konzentration an Antikörpern im Gehirn und im Tumor war vielleicht zu gering. Es ist bekannt, dass im Tumorgewebe die Blutversorgung sehr inhomogen ist (Kargiotis et al., 2006, Fischer et al., 2005). Einige Bereiche können zwar eine verstärkte Permeabilität der Gefäße aufweisen, andere Bereiche weisen aber auch geringen Blutfluß auf. Die Bildung von Ödemen im Bereich von Gefäßen mit gestörter BHS führt zu erhöhtem interstitiellem Druck, der die Diffusion von Substanzen aus dem Blut zusätzlich verhindert. Die Behandlung von Tumoren im ZNS wird dadurch erschwert. Auch die in dieser Arbeit intrazerebralen Tumoren wiesen Bereiche auf, in denen der 1D11-Antikörper sich nach i.v. Injektion nicht nachweisen ließ (s. Abbildung 43). Es gibt durch diese Arbeit Hinweise darauf, dass die Behandlung mit 1D11 auch bei intrazerebralen Gliomen einen Einfluß auf den Tumor nimmt. Eine erhöhte Konzentration von 1D11 im Tumor könnte den Einfluß erhöhen und so zu einer Tumorreduktion wie in s.c. GL261-Tumoren führen. 


\subsection{1 Öffnung der BHS für Globuline}

Systemisch verabreichte 1D11-Antikörper gelangen nicht ins Hirnparenchym gesunder Mäuse und Ratten. In dieser Arbeit wurden der Transfer, die lokale Verteilung und die Elimination von $\gamma$-Globulin im Hirn von gesunden Ratten und Mäusen nach Öffnung der BHS mit HG untersucht. HG verursacht vermutlich eine transiente Permeabilisierung der TJ am Gefäßendothel des Gehirns (Erdlenbruch et al., 2003 a, b). Es konnte gezeigt werden, dass nach einer Öffnung der BHS mit HG Substanzuen mit einem Molekulargewicht von 66 kDa ins ZNS übertreten können (Erdlenbruch et.al., 2003 a, b). In der vorliegenden Arbeit fand sich nach Permeabilisierung der BHS mit 82,5 mM HG ein Übertritt von $\gamma$-Globulinen ins Hirngewebe (s. Abbildung 47 und Abbildung 48). Somit lassen sich unter Verwendung von geeigneten Alkylglycerinen systemisch verabreichte Antikörper ins Gehirn gesunder Mäuse und Ratten bringen. Cy5.5 $\gamma$-Globulin wurde in einer hohen Dosis verabreicht, um an Mäusen zu untersuchen, ob in vivo imaging von Proteinen im Hirn möglich ist. Als biologisch aktiver anti-TGF- $\beta$ Antikörper, wurde AF680 1D11 in der Dosis infundiert, in der er auch zur Behandlung s.c. Tumoren eingesetzt wurde. Die Infusion der Markerproteine Cy5.5 $\gamma$-Globulin und AF680 1D11 in die A. carotis nach Öffnung der BHS in Mäusen führte zu einer signifikanten Erhöhung des Übertritts beider Proteine in die ipsilaterale Hemisphäre (Fluoreszenzintensitäten erhöhten sich 2-fach bzw. 4,2-fach). Dies zeigt, dass eine Behandlung von ZNS-Krankheiten mit Hilfe des Modells der Alkylglycerin-induzierten Öffnung der BHS und anschließender Gabe von (therapeutischen) Proteinen möglich ist. Ein Monitoring der Substanzen in vivo wird durch den Einsatz von im nahen Infrarotbereich fluoreszierenden Proben ermöglicht. Das eXplore Optix System ist in den beschriebenen Experimenten für die Anregung und Detektion von Cy5.5 Fluoreszenz optimiert worden. AF680 hat ein vergleichbares Absorptions- und Emissionsspektrum und kann daher mit der gleichen Einstellung genutzt werden. Dennoch können die Fluoreszenzintensitäten zwischen Versuchen mit den unterschiedlichen Fluorochromen nicht quantitativ miteinander verglichen werden.

Die Fluoreszenzintensität und LT von Cy5.5 $\gamma$-Globulin und AF680 1 D11 wurden jeweils in vivo durch Messung mit dem eXplore Optix-System in der Maus bestimmt. Die simultane Messung von Fluoreszenz und LT belegte, dass detektierte Fluoreszenz von den fluoreszenzgekoppelten Globulinen, bzw. Antikörpern stammte (s. Abbildung 57). Die Analyse der Fluoreszenzintensität der Markerproteine in vivo bestätigte die Daten, die bereits mittels Fluoreszenzmikroskopie ermittelt wurden. Auch in vivo konnte eine starke Alkylglycerin-vermittelte Anreicherung der fluoreszierenden $\gamma$-Globuline und von 1D11 in der rechten Hemisphäre, also ipsilateral zur Öffnung der BHS, gefunden werden (s. Abbildung 53 und Abbildung 56). 
In vorherigen Studien konnte gezeigt werden, dass Albumin nach Co-Applikation mit 1O-Pentylglycerin ins Gehirngewebe eindringen kann (Erdlenbruch et al., 2003 b). Verglichen mit 1-O-Pentylglycerin und weiteren kurzkettigen Alkylglycerinen, bietet HG bessere pharmakodynamische Eigenschaften, da es ein gut definiertes Zeitfenster von etwa 15 bis 30 Minuten für eine effektive Öffnung der BHS gibt (Erdlenbruch et al., 2003 a). Verwendet man HG für die BHS-Öffnung, können die ins Gehirn zu bringenden Moleküle als Kurzinfusion über ca. 15 Minuten nach Injektion von $\mathrm{HG}$ infundiert werden (Erdlenbruch et al., 2003 b). Das ist für die intraarterielle Gabe von Therapeutika sowohl im Tiermodell als auch für eine potentielle Anwendung beim Menschen von Bedeutung, da die meisten Medikamente als Kurzinfusion in der Regel besser verträglich sind und die Therapeutika nicht mit HG gemischt werden müssen. Eine Mischung könnte zu Wechselwirkungen zwischen Medikament und Alkylglycerin führen. Die in der Arbeit gezeigte effektive und über $96 \mathrm{~h}$ anhaltende Anreicherung von Antikörpern verdeutlicht das große therapeutische Potential des beschriebenen Behandlungsansatzes. Mithilfe von HG kann die BHS berechenbar permeabilisiert werden. Eine intraarterielle Kurzinfusion biologisch aktiver Proteine im Anschluß an die Öffnung der BHS ermöglicht den Übertritt dieser Makromoleküle ins Gehirn und somit eine Behandlung von ZNS-Erkrankungen.

Der Übertritt der fluoreszenzgekoppelten Globuline aus dem Gefäßendothel ins Gewebe fand sich bei der Auswertung mit konventioneller Fluoreszenzmikroskopie ex vivo, wie auch in vivo und ex vivo bei Messungen mit dem eXplore Optix-Gerät (s. Abbildung 53 und Abbildung 55). Mit der hochauflösenden Fluoreszenzmikroskopie konnte die lokale Verteilung der fluoreszenzmarkierten Globuline im Hirn untersucht werden. Kurz nach der Injektion der hochmolekularen Marker unter geöffneter BHS war die Fluoreszenz hauptsächlich um die Hirnkapillaren zu finden, während sie $24 \mathrm{~h}$ nach der Gabe gleichmäßig im Gehirngewebe verteilt war (s. Abbildung 50). Kleinere Farbstoffmoleküle zeigten im gleichen Versuchsansatz dagegen eine sehr rasche Verteilung im Hirngewebe. Schon 15 Minuten nach der Kurzinfusion fand sich eine gleichmäßige Na-Fl-Verteilung (s. Abbildung 49). Wie vermutet scheinen sich größere Moleküle langsamer im Gehirngewebe zu verteilen als die kleineren Moleküle. Die fluoreszenzmikroskopischen Bilder bestätigten zudem, dass die in vivo mit Hilfe des eXplore Optix detektierte Fluoreszenz tatsächlich von den fluoreszierenden Globulinen im Hirngewebe stammt.

In den HG-behandelten Tieren konnte über den gesamten Versuchszeitraum von $96 \mathrm{~h}$ eine erhöhte Cy5.5 $\gamma$-Globulin-Fluoreszenz detektiert werden. Die Werte waren im Vergleich zu Kontrollen mit Cy5.5 $\gamma$-Globulin ohne Öffnung der BHS durchgehend höher. Dies konnte auch in den ex vivo-Messungen bestätigt werden.

Interessanterweise fand sich nach Öffnung der BHS jedoch eine große interindividuelle Schwankung der Fluoreszenzintensität in der rechten Hemisphäre. Die Unterschiedliche Anreicherung der fluoreszenzmarkierten Substanzen sind wahrscheinlich Folge der 
individuell unterschiedlich starken Effektivität von HG. Dieses Phänomen des unterschiedlichen Ausmaßes der Öffnung der BHS wurde auch schon in früheren Arbeiten beschrieben (Erdlenbruch, 2003, a und b). Die linke Hemisphäre und das Kleinhirn weisen dagegen stets nur geringe Fluoreszenzintensitäten auf.

Erhöhte Gewebefluoreszenz im Gehirn zeigte sich bis zu 72 h nach der AF680 1D11Applikation in Verbindung mit einer Öffnung der BHS, obwohl eine wesentlich geringere Proteinmenge verabreicht wurde als bei Cy5.5 $\gamma$-Globulin (nur 1,5\% der verabreichten Cy5.5 $\gamma$-Globulin-Dosis) (s. Abbildung 56). Mit HG-vermittelter BHS-Öffnung ist ein Anstieg der Fluoreszenz im Gehirn bis $9 \mathrm{~h}$ nach der Behandlung und ein anschließender langsamer Abfall bis zu 96 h nach Behandlung ermittelt worden (s. Abbildung 53). Die Halbwertszeit lag bei 48 h. Daten zur Halbwertszeit von $\gamma$-Globulinen im Gehirn wurden bereits vor über 20 Jahren beschrieben (Neuwelt et al., 1988). Nach intraarterieller Bolusinjektion hochmolarer Mannitollösungen konnten anschließend verabreichte $\gamma$ Globuline ins ZNS gelangen. In Experimenten mit 25 \%iger Mannitollösung und anschließender Kurzinfusion von ${ }^{125} \mathrm{I}$ radioaktiv markierten $\gamma$-Globulinen stieg die Radioaktivität im Gehirn in der ersten Stunde an und blieb während der nächsten $23 \mathrm{~h}$ erhöht. Danach war ein rapider Abfall bis $72 \mathrm{~h}$ nach Injektion zu beobachten (Neuwelt et al., 1988). Diese Daten weichen von den in dieser Arbeit gezeigten etwas ab. Allerdings gibt es auch Daten in der Literatur, denen zufolge Proteine auch deutlich länger in erhöhter Menge im Gehirn bleiben. In Hunden konnte noch 52 Tage nach Mannitol-vermittelter osmotischer Öffnung der BHS gleichzeitig verabreichtes Evans blue (960 Da) im Gehirn gefunden werden (Neuwelt et al., 1983). Der Mechanismus der osmotischen Öffnung der BHS ist allerdings ein völlig anderer als der der HG-vermittelten, was die Unterschiede erklären könnte.

In der Vergangenheit wurden auch zahlreiche andere Substanzen untersucht, um eine Öffnung der BHS für therapeutische Zwecke zu erzielen. Jüngeren Datums sind Versuche in denen die reversible, intraarterielle BHS-Öffnung mittels Natriumcaprylat in vitro (Sugibayashi et al., 2008) und in vivo (Preston et al., 2008) gezeigt wurde. Allerdings wurden für eine Wirksame BHS-Öffnung hohe Dosen benötigt, die bei intraarterieller Gabe Hirnödeme verursachten. Zudem kam es bei Gabe von Natriumcaprylat zu vorübergehendem Bluthochdruck, was den Einsatz als BHS-permeabilisierende Substanz erschwerte (Preston et al., 2008). Die Versuche mit HG zeigten im Dosisbereich, der zu einer deutlichen Öffnung der BHS führte keine Nebenwirkungen. Bislang steht keine Möglichkeit zur Verfügung, die die BHS für systemisch applizierte Substanzen überwindbar macht, die genauso effizient und untoxisch ist, wie die intraarterielle Bolusgabe von Alkylglycerinen. Fluoreszenzmessung im Tier konnte nach i.v. Gabe eine Anreicherung von mit Cy5.5 markierten myristoilierten Polyargininpeptiden im Gehirn von Mäusen in vivo gezeigt werden (Pham et al., 2005). Allerdings ist diese Anreicherung 
hauptsächlich basal am Übergang zum Hirnstamm lokalisiert. Hier kann man sich fragen, ob die Anreicherung stressbedingt war (Esposito et al., 2001). Bei der HG-vermittelten Öffnung der BHS handelt es sich dagegen um eine Anreicherung von Substanzen vor allem im Cortex. Dies ist eine Folge der bevorzugten Perfusion dieser Regionen während der intraarteriellen Injektion der Alkylglycerine. Daher ist der permeabilisierende Effekt des HG in dieser Region am Größten.

\subsubsection{Bewertung der Lebensdauer der Fluorochromanregung}

Nach der Kopplung an Proteine hat AF680 eine höhere Fluoreszenzintensität als Cy5.5 (Berlier et al., 2008). Die spezifische LT von Fluorochromen erhöht sich nach der Kopplung an Proteine (Bushman et al., 2003). Auch die Änderung der LT von Fluorochromen in Abhängigkeit von der Bindung an Proteine in vivo wurde schon beschrieben (Raymond et al., 2008). In vitro ließ sich für AF680 1D11 Antikörper eine Erhöhung der LT feststellen, nachdem er mit TGF- $\beta 1$ inkubiert wurde (s. Abbildung 58, A). Almutairi und Kollegen konnten zeigen, dass in vitro eine Inkubation des NIRFarbstoffs Cypate mit Albumin zu einer Erhöhung der LT führt (Almutairi et al., 2008 b). Möglicherweise kann die Bindung von TGF- $\beta 1$ an den AF680 gekoppelten Antikörper auch die LT erhöhen. Auch für Temperaturdifferenzen ist ein Einfluß auf die LT von Protein-gebundenen Fluorochromen beschrieben (Salsbury et al., 2003). Dies kann allerdings nicht der Grund für die LT-Erhöhung in vitro sein, da die Messungen unter identischen Temperaturbedingungen stattfanden.

Interessanterweise konnte in vivo im zeitlichen Verlauf nach BHS-Öffnung eine Erhöhung der LT von AF680 1D11 Fluoreszenz in der rechten Hemisphäre festgestellt werden (s. Abbildung 57). Eine LT-Veränderung kann grundsätzlich daher rühren, dass die spezifische Fluoreszenzintensität von AF680 abnimmt, während die Intensität der Hintergrundfluoreszenz gleich bleibt. So nimmt der Anteil der Hintergrund- an der Gesamtfluoreszenz zu. Die LT des Hintergrundes ist geringer, als die von AF680 1D11. Somit würde auch die gemessene LT sich in Richtung des Wertes für die Hintergrundfluoreszenz-LT verschieben. Demnach müsste die LT über die Zeit abnehmen. In den in vivo 1D11-Versuchen kann dies also nicht der Grund für die LT-Änderung sein, da die LT zunahm. Veränderungen der LT sind auch schon als Konsequenz von Veränderungen im umgebenden Mikromillieu, wie z.B. Änderungen des pH-Werts beschrieben worden (Hassan et al., 2007). In ischämischen Nieren konnte ex vivo nach Injektion von Cy5.5 eine Erhöhung der LT im Vergleich zu nicht ischämischen Nieren gefunden werden (Abulrob et al., 2007). Es ist aber unwahrscheinlich, dass Änderungen des $\mathrm{pH}$-Wertes oder eine Ischämie im Gehirn für die Erhöhung der LT verantwortlich 
waren, da für die Methode beschrieben ist, dass keine Schäden im Hirn hervorgerufen werden (Erdlenbruch et al., 2003 a). In den Kontrollhirnen, bei denen die BHS ohne anschließende Infusion von AF680 1D11 geöffnet wurde, war keine Erhöhung der LT feststellbar. Zudem wurde in ischämischen Nieren auch ohne Cy5.5-Injektion eine entsprechende LT-Erhöhung festgestellt (Abulrob et al., 2007). Da die Erhöhung der LT von AF680 1D11 in vitro nach Inkubation von AF680 1D11 mit TGF- $\beta 1$ sichtbar war, ist vielleicht die Bindung von Antikörpern möglicherweise auch in vivo für die Änderung der LT verantwortlich. Almutairi und Kollegen konnten mit eXplore Optix-Messungen zeigen, dass Obsonisierung von Fluorochromen in vivo $\mathrm{zu}$ einer Veränderung der LT führt (Almutairi et al., 2008 a).

Zusammenfassend kann festgehalten werden, dass in vivo optical imaging von AF680 1D11 und Cy5.5 $\gamma$-Globulin im nahen Infrarot-Fluoreszenzbereich im Gehirn nach BHSÖffnung mit dem eXplore Optix-Gerät möglich ist. Es konnte gezeigt werden, dass HG die Option bietet, Antikörper aus dem Blut über die BHS ins Gehirn zu bringen. Dies erlaubt die Behandlung von Krankheiten des ZNS, wie malignen Gliomen mit spezifischen, systemisch applizierten Antikörpern. Der HG-vermittelte Übertritt von Proteinen ins ZNS und deren Konzentrationsabnahme über die Zeit kann mittels eXplore Optix gemessen werden. Somit ist die Möglichkeit gegeben, pharmakokinetische Langzeit-Studien für Proteine im Gehirn von Mäusen durchzuführen. Durch Messung der LT-Veränderung können pharmakodynamische Prozesse in vivo verfolgt werden.

Das experimentelle Modell ist allerdings auf die Nutzung fellloser oder weißfelliger Mäuse beschränkt und lässt sich nicht für Untersuchungen an Black/6-Mäusen verwenden.

\subsection{3 Öffnung der BHS im Glioblastom-tragenden Gehirn}

In Gefrierschnitten wurde die Verteilung von AF594 1D11 nach i.v. Gabe betrachtet. Im intrazerebralen Tumor sieht man eine, nicht alle Regionen des Tumors erfassende Fluoreszenz. Im umgebenden Gehirngewebe ist keine erhöhte Fluoreszenz feststellbar (s.

\section{Abbildung 43).}

Ausserhalb des Tumors verhindert die BHS den Übertritt von Fluoreszenzmarkern ins ZNS. Auch im Tumor gibt es die Bereiche, in denen die BHS noch intakt ist und in denen deshalb keine Fluoreszenzmarker ins Tumorgewebe gelangen können. Zusätzlich spielt bei fortgeschrittenen Glioblastomen der Druck der interstitiellen Flüssigkeit im Tumor für den Übertritt von Substanzen eine große Rolle (Michinton u. Tannock, 2006). Wenn man den interstitiellen Druck in Hirntumoren senkt, kann eine höhere Konzentration von Therapeutika im Tumor erreicht werden (Navalitloha et al., 2006). Somit sind ohne Beeinflussung des Hirndrucks auch Bereiche hohen interstitiellen Drucks trotz durch den 
Tumor eingeschränkter BHS von der Visualisierung durch anreichernde Fluoreszenzmarker ausgenommen. Zusätzlich erschweren die schon für die s.c. Tumoren diskutierten Faktoren (Nekrosen und Einblutungen) einen Eintritt von Molekülen. Bereiche ohne AF594 1D11Anreicherung wurden durch fluoreszenzmikroskopische Ermittlung der Verteilung der Fluoreszenz im intrazerebralen Tumor für dieses Modell bestätigt.

Nach Öffnung der BHS in der tumortragenden rechten Hemisphäre von Ratten zeigt sich im Gegensatz zur Infusion ohne BHS-Öffnung Fluoreszenz von anschließend infundierem RB200 $\gamma$-Globulin im gesamten Tumor und in weiten Teilen des Hirnparenchyms (s. Abbildung 51). Auch in Mausgehirnen zeigte sich eine Anreicherung von RB200 $\gamma$ Globulin im Bereich des Tumors und in der rechten Hemisphäre (s. Abbildung 52). Die Öffnung der BHS erlaubt es also höhere Konzentrationen im Tumor und im Tumorrandbereich zu erreichen als mit intraarterieller Gabe alleine. Somit gelangt im Falle einer Tumorbehandlung mit Antikörpern unter gleichzeitiger Öffnung der BHS mehr Wirkstoff an den Wirkort.

\subsection{4 Öffnung der BHS im Vergleich zu convection enhanced delivery}

Um die Konzentration an Antikörpern im tumortragenden Gehirn zu erhöhen, könnte man eine Behandlung durchführen, bei der die Antikörper direkt ins Gehirn appliziert werden. Dies ist möglich über einen Zugang wie einen Dauerkatheter und eine osmotische Pumpe oder eine fest implantierte Kanüle. Dieser Eingriff kann allerdings Entzündungsreaktionen auslösen. Ein weiterer Aspekt ist, dass ein Katheter an einer bestimmten Stelle endet und die Konzentration an Antikörpern hier am höchsten wäre. Es ist zwar durch Mikromanipulator und Einspannen des Tiers in den stereotaktischen Rahmen möglich, Katheterende und Tumorzellimplantation aufeinander abzustimmen, aber in welche Richtung sich der Tumor letztendlich ausbreitet, ist nicht mehr beeinflussbar. Liu und Kollegen (2007 b) haben im Rattenmodell TGF- $\beta 2$-Antisense-Oligonucleotide über eine fest implantierte Kanüle, durch die 10 Tage zuvor die Tumorzellen injiziert wurde, verabreicht und ihre Verteilung im Gehirn gezeigt. Dabei war zu sehen, dass sich die Antisense-Moleküle bis zum Rand des Tumorknotens ausgebreitet hatten, nicht aber in das umgebende, möglicherweise vom Tumor infiltrierte Gehirn. Tiere, die so behandelt wurden, lebten länger als Kontrolltiere, generierten aber letztendlich doch einen lethalen Tumor. Im gezeigten HE-Schnitt sieht es so aus, als ob der Tumor nach medial verlagert angewachsen ist. Das kann Zufall sein, kann aber auch einen Hinweis darauf geben, dass hier Zellen die Therapie überstanden haben, die von den Oligonucleotiden nicht erreicht wurden. Im menschlichen Gehirn ist dieser Effekt unter Umständen noch ausgeprägter, da es größer ist als ein Mausgehirn. Hier gelangen Wirkstoffe durch Diffusion relativ zum 
Gehirnvolumen gesehen nur in ein kleineres Areal. Der Vorteil der HG-vermittelten Öffnung der BHS im Vergleich zum Katheter liegt darin, dass das Medikament über die Blutgefäße überall im Gehirn ankommt und sich nicht nur lokal verteilt.

\subsection{Ausblick}

In dieser Arbeit konnte, wie auch von anderen Gruppen gezeigt werden, dass die Beeinflussung des TGF- $\beta$-Signalwegs eine Summe von Veränderungen im Gliom hervorruft. Daher ist TGF- $\beta$ ein hoch interessantes Zielmolekül für die Behandlung von Gliomen. Durch weitere Untersuchungen kann der Einfluss der Behandlung auf die Tumoren weiter aufgeklärt werden. So können Färbungen aktivierter T-Zellen von Schnitten intrazerebraler Tumoren von 1D11-behandelten sowie von Kontrollmäusen ausgewertet werden und der Einfluß des Immunsystems -insbesondere der T-Zellen- auf die Behandlung genauer untersucht werden. Durch immunhistochemische Färbung von Matrixkomponenten könnte spezifiziet werden, ob die 1D11-Behandlung Einfluß auf eine bestimmte Matrixkomponente des Tumors nimmt.

Eine Möglichkeit das Ansprechen von intrazerebralen Tumoren auf 1D11-Therapie zu steigern wäre eine Kombinationstherapie mit Substanzen die additiv oder sogar synergistisch zur Behandlung mit 1D11 tumorreduzierend wirken. Durch Impfung von Tieren mit bestrahlten Tumorzellen zusätzlich zur TGF- $\beta 2-A n t i s e n s e-O l i g o n u c l e o t i d-$ Behandlung von intrazerebralen Gliomen in der Ratte konnte zum Beispiel eine Verlängerung des Überlebens der Tiere im Vergleich zur Antisense-Oligonucleotide Behandlung alleine erreicht werden (Liu et al., 2007 b).

Leider ist es im Nagermodell bisher nicht gelungen, eine wiederholte Öffnung der BHS am selben Tier für die vorliegende Arbeit durchzuführen, da die Gefäße sowohl in der Maus als auch in der Ratte zu klein sind, um mehrmals einen Katheter einlegen zu können. Bei Versuchen zur Mehrfachbehandlung war nach dem Legen eines Dauerkatheters dieser trotz Spülung mit Heparin nach kurzer Zeit verstopft. Der Versuch einer wiederholten Katheterisierung der A. carotis über die Femoralgefäße scheiterte ebenfalls. Daher liegt ein Ziel für die Zukunft darin, eine Methode zu etablieren, die mehrfache 1D11-Behandlung von intrazerebralen Tumoren unter HG-vermittelter Öffnung der BHS zulässt.

Zhu und Kollegen (1994) konnten zeigen, dass in Mäusen nach Öffnung der BHS mit Mannitol ein mit Doxorubicin gekoppelter Antikörper im intrazerebralen Tumor und im umliegenden Gehirn angereichert wird. S.c. Tumore zeigten ein geringeres Tumorwachstum unter viermaliger Behandlung mit dem Antikörper, der das Therapeutikum Doxorubizin durch spezifische Bindung im Tumor anreichern konnte. Auch 
in dieser Studie wurde keine wiederholte Behandlung unter Öffnung der BHS durchgeführt.

Kürzlich wurde von Chen et al. (2009) eine neue Methode zur Dauerkatheterisierung der Carotis externa beschrieben. Die Anwendung dieser Technik könnte eine mehrfache Alkylglycerin-vermittelte Öffnung der BHS im Mausmodell ermöglichen.

Eine Anwendung der Alkylglycerine zur Öffnung der BHS an größeren Tieren, z.B. Hunden könnte die Applikation erleichtern und wuerde eine repetitive Behandlung ermöglichen. So könnte dann erstmals auch die Verträglichkeit einer Mehrfachgabe von Alkylglycerinen untersucht werden.

Im Menschen ist die mehrfache Katheterisierung der A. carotis über die Femoralarterie möglich. 


\section{Zusammenfassung}

Hochmaligne Gliome (z.B. Glioblastome) sind mit einer durchschnittlichen Überlebenszeit von etwa einem Jahr einer der aggressivsten soliden Tumoren. Trotz der Fortschritte in der Neuroonkologie sind sie nur unzureichend behandelbar. Die Ursachen hierfür sind das infiltrative Wachstum und die starke Migrationsfähigkeit hoch maligner Hirntumoren, die ausgeprägte Chemoresistenz und die unzureichenden Penetration systemisch verabreichter therapeutischer Substanzen über die Blut-Hirn-Schranke. Innovative Behandlungsmethoden sind daher unabdingbar, um die Heilungschancen für Gliompatienten zu verbessern. Das bessere molekulare Verständnis maligner Hirntumoren in den letzten Jahren lieferte die Grundlage zur Entwicklung neuer Substanzen und therapeutischer Konzepte, deren antitumoröse Wirksamkeit im Hirn im Tiermodell untersucht werden muss.

Das Zytokin TGF- $\beta$ spielt in der Progression des Glioblastoms eine entscheidende Rolle bei der Induktion von Wachstum, Angiogenese, Invasion und Immunsuppression. Daher ist es ein vielversprechendes Molekül für eine gezielte molekulare Therapie maligner Gliome. Der Antikörper 1D11 bindet spezifisch die aktiven TGF- $\beta$ Isoformen 1-3 und inhibiert so deren Bindung an die Rezeptoren.

Für s.c. Glioblastome in Mäusen wurde die spezifische Anreicherung i.v. injizierter Fluoreszenzfarbstoff-gekoppelter anti-TGF- $\beta$-Antikörper (1D11) mittels Fluoreszenzmessung in vivo über 28 Tage wiederholt gemessen. Dabei zeigte sich eine erhöhte Fluoreszenzintensität im Tumor. Die i.v. Behandlung s.c. Gliome (humane U87MG-Zellen oder murine GL261-Zellen) in immundefizienten nu/nu-Mäusen mit 1D11 führte $\mathrm{zu}$ einer Tumorprogression im Vergleich $\mathrm{zu}$ einer mit einem Kontrollantikörper (13C4) behandelten und einer unbehandelten Kontrollgruppe. Im Gegensatz dazu führte die 1D11-Behandlung von s.c. GL261-Tumoren im syngenen Modell mit immunkompetenten Black/6-Mäusen $\mathrm{zu}$ einer Wachstumsverringerung bei $25 \%$ der behandelten, und $\mathrm{zu}$ kompletter Remission bei 75\% der behandelten Mäuse.

Charakteristisch für GL261-Tumoren waren weiche, matrixreiche, sowie feste Anteile und viele Einblutungen. Dabei unterschied sich die Morphologie der GL261-Tumoren aus Black/6-Mäusen nicht von derjenigen aus nu/nu-Mäusen. Die U87MG-Tumoren dagegen bestanden aus festen Tumorknoten mit nur kleinen Einblutungen. Histologische und immunhistochemische Untersuchungen der Tumore 1D11-behandelter Tiere zeigten zu den jeweiligen Kontrollgruppen keine Unterschiede hinsichtlich der Morphologie, der Proliferation (Ki 67), der Gefäßdichte (F VIII) und der Infiltration tumorassoziierter Makrophagen (MAC-3). Die Anzahl apoptotischer Zellen in GL261-Tumoren 1D11behandelter Black/6-Mäuse war im Vergleich zu Kontrolltieren erhöht. In der nu/nu-Maus 
war dieser Effekt nicht nachweisbar. Dies lässt darauf schließen, dass das Immunsystem in Abhängigkeit der TGF- $\beta$-Konzentration im Glioblastom Apoptose auslösen kann.

Auch in intrazerebralen GL261-Tumoren in Black/6-Mäusen zeigte sich in vivo und ex vivo durch „optical imaging“, sowie in Gefrierschnittanalysen eine Anreicherung von Fluoreszenzfarbstoff-gekoppeltem 1D11. Die intrazerebralen GL261-Tumoren zeigten im Gegensatz zu den s.c. Tumoren unter 1D11-Behandlung keine Größenreduktion. Allerdings wurde festgestellt, dass sie bei gleicher Tumorgröße kompakter waren und weniger invasiv wuchsen als die Kontrolltumoren. Somit konnten die TGF- $\beta$-vermittelten invasiven Eigenschaften bei den intrazerebralen, also orthotop gelegenen Gliomen durch 1D11 gehemmt werden. Wahrscheinlich waren die 1D11-Konzentrationen in den intrazerebralen Tumoren infolge der Blut-Hirn-Schranke zu gering, um die bei s.c. Tumoren beobachtete Tumorremission auszulösen.

Nach intraarterieller Bolusinjektion von 2-O-Hexyldiglycerin, einer Substanz, die die Permeabilität der Blut-Hirn-Schranke erhöht, konnte sowohl die Anreicherung systemisch applizierter $\gamma$-Globuline, als auch die von 1D11 im Ratten- und Mausgehirn erzielt werden. Mit Hilfe dieser Methode konnte die BHS für die Zeit der Antikörperapplikation ohne größere Nebenwirkungen geöffnet werden. Dies wurde durch Fluoreszensintesitätsmessungen in vivo und ex vivo an Mäusen, wie auch anhand von Gefrierschnitten vom Gehirn gesunder Ratten, gezeigt. Die Antikörper verteilten sich von den Kapillaren aus gleichmäßig im Gehirnparenchym und waren dort bis zu $96 \mathrm{~h}$ in vivo detektierbar. Gleichzeitig wurde die Anregungslebensdauer des Fluorochroms detektiert. Für mit Fluoreszensfarbstoff gekoppelte 1D11-Antikörper zeigte sich über mehrere Tage eine stete Erhöhung der Fluoreszenzanregungslebensdauer im Gehirn. Dies bedeutet, dass das Molekül im Gehirn Konformationsänderungen erfahren hat, was für eine AntikörperAntigen-Bindung im Gehirn spricht.

Im Gliommodell konnte durch die Öffnung der Blut-Hirn-Schranke mittels 2-OHexyldiglycerin in intrazerebralen Glioblastomen und im Gehirngewebe in der Peripherie des Tumors die Konzentration von Globulinen deutlich erhöht werden.

Diese Ergebnisse zeigen, dass der Antikörper 1D11 eine mögliche neue Substanz für die Behandlung von Glioblastomen darstellt, die mittels 2-O-Hexyldiglycerin in deutlich erhöhter Konzentration in allen vitalen, durchbluteten Bereichen des Tumors, des Tumorrandgebiets und im umgebenden Hirnparenchym angereichert werden kann. Somit werden auch infiltrierende, maligne Zellen um das solide Tumorgewebe herum von der Substanz erreicht.

Künftige Untersuchungen müssen zeigen, ob mit einer Öffnung der Blut-Hirn-Schranke und gleichzeitiger Therapie mit 1D11 eine Tumorregression erzielt werden kann. 


\section{Literaturverzeichnis}

Abbott NJ: The bipolar astrocyte. In: Blood-Brain Interfaces-From Ontology to Artificial Barriers. 189-208. Ed. Dermietzel R, Spray D, Nedergaard M, Wiley-VCH, Weinheim, 2006.

Abulrob A, Brunette E, Slinn J, Baumann E, Stanimirovic D (2007): In vivo time domain optical imaging of renal ischemia-reperfusion injury: discrimination based on fluorescence lifetime. Mol Imaging 6: 304-314.

Agrawal B, Krantz MJ, Parker J, Longenecker BM (1998): Expression of MUC1 mucin on activated human T cells: implications for a role of MUC1 in normal immune regulation. Cancer Res 58: 4079-4081.

Akhurst RJ, Derynck R (2001): TGF-beta signaling in cancer - a double-edged sword. Trends Cell Biol 11: 44-51.

Almutairi A, Akers WJ, Berezin MY, Achilefu S, Fréchet JM. (2008 a): Monitoring the Biodegradation of Dendritic Near-Infrared Nanoprobes by in vivo Fluorescence Imaging. Mol Pharm 5(6): 1103-1110.

Almutairi A, Guillaudeu SJ, Berezin MY, Achilefu S, Fréchet JM (2008 b): Biodegradable $\mathrm{pH}$-sensing dendritic nanoprobes for near-infrared fluorescence lifetime and intensity imaging. J Am Chem Soc 130: 444-445.

Anderson RC, Elder JB, Brown MD, Mandigo CE, Parsa AT, Kim PD, Senatus P, Anderson DE, Bruce JN (2002): Changes in the Immunologic Phenotype of Human Malignant Glioma Cells after Passaging in Vitro. Clinical Immunology 102(1): 84-95.

Arismendi-Morillo G, Castellano A (2005): Tumoral micro-blood vessels and vascular microenvironment in human astrocytic tumors. A transmission electron microscopy study. J Neurooncol 73(3): 211-217.

Armstrong TS, Cohen MZ, Eriksen LR Hickey JV (2004): Symptom clusters in oncology patients and implications for symptom research in people with primary brain tumors. $\mathrm{J}$ Nurs Scholarsh 36(3): 197-206.

Arslan F, Bosserhoff A-K, Nickl-Jockschat T, Doerfelt A, Bogdahn U, Hau P (2007): The role of versican isoforms $\mathrm{V} 0 / \mathrm{V} 1$ in glioma migration mediated by transforming growth factor-b2. Br J Cancer 96: 1560-1568.

Arslan F, Bosserhoff A-K, Nickl-Jockschat T, Doerfelt A, Bogdahn U, Hau P (2007): The role of versican isoforms $\mathrm{V} 0 / \mathrm{V} 1$ in glioma migration mediated by transforming growth factor-b2. Br J Cancer 96: 1560-1568.

Arteaga CL (2001): The epidermal growth factor receptor: from mutant oncogene in nonhuman cancers to therapeutic target in human neoplasia. J Clin Oncol 19 (18): 3240 . 
Aulwurm S, Wischhusen J, Friese M, Borst J, Weller M (2006): Immune stimulatory effects of CD70 override CD70-mediated immune cell apoptosis in rodent glioma models and confer long-lasting antiglioma immunity in vivo. Int. J. Cancer: 118: 17281735.

Baluk P, Morikawa S, Haskell A, Mancuso M, McDonald DM (2003): Abnormalities of basement membrane on blood vessels and endothelial sprouts in tumors. Am J Pathol 163(5): 1801-1815.

Banks WA (2008): Delivery of peptides to the brain: emphasis on therapeutic development. Biopolymers 90: 589-594.

Barrios-Rodiles M, Brown KR, Ozdamar B, Bose R, Liu Z, Donovan RS, Shinjo F, Liu Y, Dembowy J, Taylor IW, Luga V, Przulj N, Robinson M, Suzuki H, Hayashizaki Y, Jurisica I, Wrana JL (2005): Highthroughput mapping of a dynamic signaling network in mammalian cells. Science 307: 1621-1625.

Baselga J (2001): The EGFR as a target for anticancer therapy - focus on cetuximab. Eur J Cancer 37(4): 16-22.

Bax DA, Haringsma J, Einerhand AW, van Dekken H, Blok P, Siersema PD, Kuipers EJ, Kusters JG (2004): MUC4 is increased in high grade intraepithelial neoplasia in Barrett's oesophagus and is associated with a proapoptotic Bax to Bcl-2 ratio. J Clin Pathol 57: 1267-1272.

Bellail AC, Hunter SB, Brat DJ, Tan C, Van Meir EG (2004): Microregional extracellular matrix heterogeneity in brain modulates glioma cell invasion. Int $\mathrm{J}$ Biochem Cell Biol 36: 1046-1069.

Berlier JE, Rothe A, Buller G, Bradford J, Gray DR, Filanoski BJ, Telford WG, Yue S, Liu J, Cheung CY, Chang W, Hirsch JD, Beechem JM, Haugland RP, Haugland RP (2003): Quantitative comparison of long-wavelength Alexa Fluor dyes to Cy dyes: fluorescence of the dyes and their bioconjugates. J Histochem Cytochem 51: 1699-1712.

Biffi S, Garrovo C, Macor P, Tripodo C, Zorzet S, Secco E, Tedesco F, Lorusso V (2008): In vivo biodistribution and lifetime analysis of cy5.5-conjugated rituximab in mice bearing lymphoid tumor xenograft using time-domain near-infrared optical imaging. Mol Imaging 7(6): 272-82.

Bleyer WA (1999): Epidemiologic impact of children with brain tumors. Childs Nerv Syst 15: 758-763.

Bloch S, Lesage F, McIntosh L, Gandjbakhche A, Liang K, Achilefu S (2005): Wholebody fluorescence lifetime imaging of a tumor-targeted near-infrared molecular probe in mice. J Biomed Opt 10(5): 054003.

Bodmer S, Strommer K, Frei K, Spiel C, de Tribolet N, Heid I, Fontana A (1989): Immunosuppression and transforming growth factor-beta in glioblastoma. Preferential production of transforming growth factor-beta 2. J Immunol 143: 3222-3229. 
Bogdahn U, Mahapatra A, Olyushin VE, Mouli C, Parfenov VE, Stockhammer G, Ludwig S, Wuerth G, Heinrichs H, Schlingensiepen K (2007): A phase IIb actively controlled study with the TGF-beta-2 inhibitor AP 12009 for recurrent or refractory anaplastic astrocytoma. J Clin Oncol, ASCO Annual Meeting Proceedings Part I 25(18S): 2025.

Boiardi A, Silvani A, Ruffini PA, Rivoltini L, Parmiani G, Broggi G, Salmaggi A (1994): Loco-regional immunotherapy with recombinant interleukin-2 and adherent lymphokine-activated killer cells (A-LAK) in recurrent glioblastoma patients. Cancer Immunol Immunother 39(3): 193-197.

Borlongan CV, Emerich DF (2003): Fascilitation of drug entry into the CNS via transient permeation of blood brain barrier: laboratory and preliminary clinical evidence from bradikinin receptor agonist, Cereport. Brain Res Bull 60: 297-306.

Bouffet E (2000): Common brain tumors in children. Paediatr Drugs 2: 57-66.

Bradbury MWB: The Concept of a Blood-Brain Barrier. John Wiley \&Sons, Chichester, 1979.

Brandes AA, Franceschi E, Tosoni A, Hegi ME, Stupp R (2008): Epidermal Growth Factor Receptor Inhibitors in Neuro-oncology: Hopes and Disappointments. Clin Cancer Res 14(4): 957-960.

Bredel M (2001): Anticancer drug resistance in primary human brain tumors. Brain Res Brain Res Rev 35: 161-204.

Bushmann V, Weston KD, Sauer M (2003): Spectroscopic Study and Evaluation of RedAbsorbing Fluorescent Dyes. Bioconjugate Chem 14: 195-204.

Camphausen K, Purow B, Sproull M, Scott T, Ozawa T, Deen DF, Tofilon PJ (2005): Influence of in vivo groeth on human glioma cell line gene expression: Convergent profiles under orthotopic conditions. PNAS 102(23): 8287-8292.

Catalaa I, Henry R, Dillon WP, Graves EE, McKnight TR, Lu Y, Vigneron DB, Nelson SJ (2006): Perfusion, diffusion and spectroscopy values in newly diagnosed zerebral gliomas. NMR Biomed 19: 463-475.

Chaturvedi P, Singh AP, Moniaux N, Senapati S, Chakraborty S, Meza JL, Batra SK (2007): MUC4 mucin potentiates pancreatic tumor cell proliferation, survival, and invasive properties and interferes with its interaction to extracellular matrix proteins. Mol Cancer Res 5: 309-320.

Chen L, Swartz KR, Toborek M (2009): Vessel microport technique for applications in cerebrovascular research. J Neurosci Res 87(7): 1718-1727.

Chozick BS, Pezzullo JC, Epstein MH, Finch PW (1994): Prognostic implications of p53 overexpression in supratentorial astrocytic tumors. Neurosurgery 35: 831-838.

Christensen HC, Kosteljanetz M, Johansen C (2003): Incidences of gliomas and meningiomas in Denmark, 1943 to 1997. Neurosurgery 52: 1327-1334.

Citron D, Lee AK, Scott T, Sproull M, Menard C, Tofilon PJ, Camphausen K (2004): In vivo tumor imaging in mice with near-infrared labeled endostatin. Mol Cancer Ther 3(4): 481-488. 
Claes A, Idema AJ, Wesseling P (2007): Diffuse glioma growth: a guerilla war. Acta Neuropathol 114(5): 443-458.

Cloughesy TF, Kuhn J, Robins HI, Abrey L, Wen P, Fink K, Lieberman FS, Mehta M, Chang S, Yung A, DeAngelis L, Schiff D, Junck L, Groves M, Paquette S, Wright J, Lamborn K, Sebti SM, Prados M (2005): Phase I trial of tipifarnib in patients with recurrent malignant glioma taking enzyme-inducing antiepileptic drugs: a North American Brain Tumor Consortium Study. J Clin Oncol 23(27): 6647-6656.

Dasch JR, Pace DR, Waegell W, Inenaga D, Ellingsworth L (1998): Monoclonal Antibodies Recognizing Transforming Growth Factor- $\beta$, Bioactivity Neutralization and Transforming Growth Factor 82 Affinity Purification. J immunol 142: 1536-1541.

De Vleeschouwer S, Fieuws S, Rutkowski S, Van Calenbergh F, Van Loon J, Goffin J, Sciot R, Wilms G, Demaerel P, Warmuth-Metz M, Soerensen N, Wolff JE, Wagner S, Kaempgen E, Van Gool SW (2008): Postoperative adjuvant dendritic cell-based immunotherapy in patients with relapsed glioblastoma multiforme. Clin Cancer Res 14(10): 3098-3104.

De Vleeschouwer S, Van Gool SW, Van Calenbergh F (2005): Immunotherapy for malignant gliomas: emphasis of strategies of active specific immunotherapy using autologous dendritic cells. Childs Nerve Syst 21: 7-18.

Deli MA (2009): Potential use of tight junction modulators to reversibly open membranous barriers and improve drug delivery. Biochem Biophys Acta 1788(4): 892-910.

Demeule M, Regina A, Che C, Poirier J, Nguyen T, Gabathuler R, Castaigne J-P, Beliveau R (2008): Identification and Design of Peptides as a New Drug Delivery System for the Brain. JPET 324:1064-1072.

Derynck R, Zhang YE (2003): Smad-dependent and Smadindependent pathways in TGFbeta family signaling. Nature 425: 577-584.

Dhanikula RS, Argaw A, Bouchard J-F, Hildgen P (2007): Methotrexate Loaded PolyetherCopolyester Dendrimers for the Treatment of Gliomas: Enhanced Efficacy and Intratumoral Transport Capability. Molecular Pharmaceutics 5(1): 105-116.

Donelli MG, Zucchetti M, D'Inalci M (1992): Do anticancer agents reach the tumour target in the human brain? Cancer Chemother Pharmacol 30: 251-260.

Doolittle ND, Abrey LE, Bleyer WA, Brem S, Davis TP, Dore-Duffy P, Drewes LR, Hall WA, Hoffmann JM, Korfel A, Martuza R, Muldoon LL, Peereboom D, Peterson DR, Rabkin SD, Smith Q, Stevens GH, Neuwelt EA (2005): New frontiers in translational research in neuro-oncology and the blood-brain barrier:report of the tenth annual BloodBrain Barrier Disruption Consortium Meeting. Clin Cancer Res 15(11(2 Pt 1)): 421-428.

Doolittle ND, Miner ME, Hall WA, Siegal T, Jerome E, Osztie E, Mc Allister LD, Bubalo JS, Kraemer DF, Fortin D, Nixon R, Muldoon LL, Neuwelt EA (2000): Safety and efficacy of a multicenter study using intraarterial chemotherapy in conjunction with osmotic opening of the blood-brain barrier for the treatment of patients with malignant brain tumors. Cancer 88: 637-647. 
Dubois CM, Laprise MH, Blanchette F, Gentry LE, Leduc R (1995): Processing of transforming growth factor beta 1 precursor by human furin convertase. J Biol Chem 270: 10618-10624.

Dunn IF, Heese O, Black PM (2000): Growth factors in glioma angiogenesis: FGFs, PDGF, EGF, and TGFs. J Neurooncol 50: 121-137.

Ehrlich P. Das Sauerstoffbedürfnis des Organismus. Eine farbenanalytische Studie. Berlin, Hirschwald, 1885.

Erdlenbruch B, Alipour M, Fricker G, Miller DS, Kugler W, Eibl H, Lakomek M (2003 b): Alkylglycerol opening of the blood-brain barrier to small and large fluorescence markers in normal and C6 glioma-bearing rats and isolated rat brain caplillaries. $\mathrm{Br} \mathrm{J}$ Pharmacol 139:685-694.

Erdlenbruch B, Jendrossek V, Eibl H, Lakomek M (2000): Transient and controllable opening of the blood-brain barrier to cytostatic and antibiotic agents by alkylglycerols in rats. Exp Brain Res 135: 417-422.

Erdlenbruch B, Kugler W, Schinkhof C, Neurath H, Eibl H, Lakomek M (2005): Bloodbrain barrier opening with alkylglycerols: Biodistribution of 1-O-pentylglycerol after intravenous and intracarotid administration in rats. J Drug Target 13(3): 143-150.

Erdlenbruch B, Schinkhof C, Kugler W, Heinemann DEH, Herms J, Eibl H, Lakomek M (2003a). Increased administration of short-chain alkylglycerols for increased delivery of methotrexate to the rat brain. British Journal of Pharmacology 139: 685-694.

Ermoian RP, Kaprealian T, Lamborn KR, Yang X, Jelluma N, Arvold ND, Zeidman R, Berger MS, Stokoe D, Haas-Kogan DA. (2009): Signal transduction molecules in gliomas of all grades. J Neurooncol 91: 19-26.

Esposito P, Gheorghe D, Kandere K, Pang X, Connolly R, Jacobson S, Theoharides TC (2001): Acute stress increases permeability of the blood-brain-barrier through activation of brain mast cells. Brain Res 888(1): 117-127.

Fan KJ, Pezeshkpour GH (1992): Ethnic distribution of primary central nervous system tumors in Washington, DC, 1971 to 1985. J Natl Med Assoc 84: 858-863.

Farkkila M, Jaaskelainen J, Kallio M, Blomstedt G, Raininko R, Virkkunen P, Paetau A, Sarelin H, Mantyla M. (1994): Randomised, controlled study of intratumoral recombinant gamma-interferon treatment in newly diagnosed glioblastoma. Brt J Cancer 70: $138-141$.

Fellner F, Bauer B, Miller DS, Schaffrik M, Fankhänel M, Spruß T, Bernhardt G, Graeff C, Färber L, Gschaidmeier H, Buschauer A, Fricker G (2002): Transport of paclitaxel (Taxol) across the blood-brain barrier in vitro and in vivo. J Clin Invest 110: 1309-1318.

Finlay JL, Zacharoulis S (2005): The treatment of high grade gliomas and diffuse intrinsic pontine tumors of childhood and adolescence: a historical-and futuristic-perspective. $\mathrm{J}$ Neurooncol 75(3): 253-266.

Fischer I, Gagner J-P, Law M, Newcomb EW, Zagzag D (2005): Angiogenesis in Gliomas: Biology and molecular Pathophysiology. Brain Pathology 15: 297-310. 
Fogh J, Fogh JM, Orfeo T (1977): One hundred and twenty-seven cultured human tumor cell lines producing tumors in nude mice. J Natl Cancer Inst 59: 221-226.

Folkman, J (1990): What is the evidence that tumors are angiogenesis dependent? J Natl Cancer Inst 82: 4-6.

Forsyth PA, Posner JB (1993): Headaches in patients with brain tumors: a study of 111 patients. Neurology 43: 1678-1683.

Freije WA, Castro-Vargas FE, Fang Z, Horvath S, Cloughesy T, Liau LM, Mischel PS, Nelson SF (2004): Gene Expression Profiling of Gliomas Strongly Predicts Survival. Cancer Res 64: 6503-6510.

Friese MA, Platten M, Lutz SZ, Naumann U, Aulwurm S, Bischof F, Buhring HJ, Dichgans J, Rammensee HG, Steinle A, Weller M (2003): MICA/NKG2D-mediated immunogene therapy of experimental gliomas. Cancer Res 63: 8996-9006.

Friese MA, Steinle A, Weller M (2004): The innate immune response in the central nervous system and ist role in glioma immune surveillance. Onkologie 27: 487-491.

Fukuda M (1996): Possible roles of tumor-associated carbohydrate antigens. Cancer Res 56: $2237-2244$.

Fukuda M. (2002): Roles of mucin-type O-glycans in cell adhesion. Biochim Biophys Acta 1573: 394-405.

Furnari FB, Fenton T, Bachoo RM, Mukasa A, Stommel JM, Stegh A, Hahn WC, Ligon KL, Louis DN, Brennan C, Chin L, DePinho RA, Cavenee WK (2007): Malignant astrocytic glioma: genetics, biology, and paths to treatment. Genes Dev 21(21): 26832710.

Furuse M, Hirase T, Itoh M, Nagafuchi A, Yonemura S, Tsukita S, Tsukita S (1993): Occludin: a novel integral membrane protein localizing at tight junctions. J Cell Biol 123(6Pt2): 1777-1788.

Galanis E, Buckner JC, Maurer MJ, Kreisberg JI, Ballman K, Boni J, Peralba JM, Jenkins RB, Dakhil SR, Morton RF, Jaeckle KA, Scheithauer BW, Dancey J, Hidalgo M, Walsh DJ; North Central Cancer Treatment Group (2005): Phase II trial of temsirolimus (CCI779) in recurrent glioblastoma multiforme: a North Central Cancer Treatment Group Study. J Clin Oncol 23(23): 5294-5304.

Gass A, Hirsch JG, Behrens S, Szabo K, Gaa J Hennerici MG (2000): Diffusions- und Perfusionsgewichtete Magnetresonanztomografie bei neurologischen Erkrankungen. Electromedica 68.

Gladson CL (1999): The extracellular matrix of gliomas: modulation of cell function. J Neuropathol Exp Neurol 58: 1029-1040.

Glinsky GV, Berezovska O, Glinskii AB (2005): Microarray analysis identifies a deathfrom-cancer signature predicting therapy failure in patients with multiple types of cancer. J Clin Invest 115: 1503-1521.

Gold LI (1999): The role for transforming growth factor-beta (TGF-beta) in human cancer. Crit Rev Oncog 10(4): 303-360. 
Golden PL, Pollack GM. (2003): Blood-brain barrier efflux transport. J Pharm Sci 92: 1739-53.

Goumans MJ, Valdimarsdottir G, Itoh S, Rosendahl A, Sideras P, ten Dijke P (2002): Balancing the activation state of the endothelium via two distinct TGF- $\beta$ type I receptors. EMBO J 21: 1743-1753.

Gurfinkel M, Ke S, Wen X, Li C, Sevick-Muraca EM (2003): Near-infrared fluorescence optical imaging and tomography. Dis Markers 19:1 07-21.

Hassan M, Riley J, Chernomordik V, Smith P, Pursley R, Lee SB, Capala J, Gandjbakhche AH (2007): Fluorescence lifetime imaging system for in vivo studies. Mol Imaging 6: 229-236.

Hau P, Kunz-Schughart LA, Rümmele P, Arslan F, Dörfelt A, Koch H, Lohmeier A, Hirschmann B, Müller A, Bogdahn U, Bosserhoff AK (2006): Tenascin-C protein is induced by transforming growth factor-betal but does not correlate with time to tumor progression in high-grade gliomas. J Neurooncol 77(1): 1-7.

Hegi ME, Diserens AC, Gorlia T, Hamou MF, de Tribolet N, Weller M, Kros JM, Hainfellner JA, Mason W, Mariani L, Bromberg JE, Hau P, Mirimanoff RO, Cairncross JG, Janzer RC, Stupp R (2005): MGMT gene silencing and benefit from temozolomide in glioblastoma. N Engl J Med 352: 997-1003.

Heldin C-H, Miyazono K, ten Dijke P (1997): TGF- $\beta$ signalling from cell membrane to nucleus through SMAD proteins. Nature 390: 465-471.

Helseth E. Unsgaard G, Dalen A, Vik R (1988): The effects of type beta transforming growth factor on proliferation and epidermal growth factor receptor expression in a human glioblastoma cell line. J Neuro-Oncol 6: 269-276.

Hirabayashi S, Tajima M, Yao I, Nishimura W, Mori H, Hata Y (2003): JAM4, a junctional cell adhesion molecule interacting with a tight junction protein, MAGI-1. Mol Cell Biol 23(12): 4267-4282.

Hollingworth W, Medina LS, Lenkinski RE, Shibata DK, Bernal B, Zurakowski D, Comstock B, Jarvik JG (2006): A systematic literature rewiew of magnetic resonance spectroscopy for the characterization of brain tumors. Am J Neuroradiol 27(7): 14041411.

Hulshof MC, Koot RW, Schimmel EC, Dekker F, Bosch DA, Gonzalez Gonzalez D (2001): Prognostic factors in glioblastoma multiforme. 10 years experience of a single institution. Strahlenther Onkol 177: 283-290.

Hutterer M, Gunsilius E, Stockhammer G (2006): Molecular therapies for malignant glioma. Wien Med Wochenschr 156(11-12): 351-363.

Ichimura K, Ohgaki H, Kleihues P, Collins VP (2004): Molecular pathogenesis of astrocytic tumours. J Neurooncol 70: 137-160. 
Jachimczak P, Bogdahn U, Schneider J, Behl C, Meixensberger J, Apfel R, Dorries R, Schlingensiepen KH, Brysch W (1993): The effect of transforming growth factor-beta 2specific phosphorothioate-anti-sense oligodeoxynucleotides in reversing cellular immunosuppression in malignant glioma. J Neurosurg 78: 944-951.

Jachimczak P, Hessdorfer B, Fabel-Schulte K, Wismeth C, Brysch W, Schlingensiepen KH, Bauer A, Blesch A, Bogdahn U (1996): Transforming growth factor-beta-mediated autocrine growth regulation of gliomas as detected with phosphorothioate antisense oligonucleotides. Int J Cancer 65: 332-337.

Jackson EL, Garcia-Verdugo JM, Gil-Perotin S, Roy M, Quinones-Hinojosa A, VandenBerg S, Alvarez-Buylla A (2006): PDGFR alpha-positive B cells are neural stem cells in the adult SVZ that form glioma-like growths in response to increased PDGF signaling. Neuron 51(2): 187-199.

Jain RK (1990): Vaskular and interstitial barriers to delivery of therapeutic agents in tumors. Cancer Metastasis Rev 9: 253-266.

Jong A, Huang SH (2005): Blood-brain barrier drug discovery for central nervous system infections. Curr Drug Targets Infect Disord 5(1): 65-72.

Jung V, Romeike BF, Henn W, Feiden W, Moringlane JR, Zang KD, Urbschat S (1999): Evidence of focal genetic microheterogeneity in glioblastoma multiforme by areaspecific CGH on microdissected tumor cells. J Neuropathol Exp Neurol 58(9): 993-999.

Kaatsch P, Rickert CH, Kühl J, Schütz J, Michaelis J (2001): Population-based epidemiologic data on brain tumors in German children. Cancer 92(12): 3155-3164.

Kalifa C, Grill J (2005): The therapy of infantile malignant brain tumors: current status? J Neurooncol 75(3): 279-285.

Kargiotis O, Rao JS, Kyritsis AP (2006): Mechanisms of angiogenesis in gliomas. J Neurooncol 78(3): 281-93.

Kelli SJ (1999): Chemotherapy of central nervous system tumours in infants. Child`s Nerve Syst 15: 592-612.

Kemper EM, Boogerd W, Thuis E, Beijnen JH, van Tellingen O (2004): Modulation of the blood-brain barrier in oncology: Therapeutic opportunities for the treatment of brain tumors? Cancer Treat Rev 30: 415-423.

Keren S, Gheysens O, Levin CS, Gambhir SS (2008): A Comparison Between a Time Domain and Continuous Wave Small Animal Optical Imaging System. IEEE Transactions on Medical Imagigng 27(1): 58-63.

Khatua S, Jalali R (2005): Recent advances in the treatment of childhood brain tumors. Pediatr Hematol Oncol 22(5): 361-371.

Kjellman C, Olofson SP, Hansson O, von Schantz T, Lindvall M, Nilsson I, Salford LG, Sjogren HO, Widegren B (2000): Expression of TGF-beta isoforms, TGF-beta receptors, and SMAD molecules at different stages of human glioma. Int J Cancer 89: 251-258. 
Kleihues P, Cavenee WK. Pathology and genetics of tumours of the nervous system. IARC Press, Lyon, 2000 (a).

Kleihues P, Cavenee WK. World Health Organization classification of tumours of the nervous system. IARC/WHO, Lyon, 2000 (b).

Kleihues P, Louis DN, Scheithauer BW, Rorke LB, Reifenberger G, Burger PC, Cavenee WK (2002): The WHO classification of tumors in the nervous system. J Neuropathol Exp Neurol 60(3): 215-225.

Kleihues P, Ohgaki H (1999): Primary and secondary glioblastomas: From concept to clinical diagnosis. Neuro-oncol 1: 44-51.

Kleihues P, Scheithauer BW, Burger PC. Histological typing of tumours of the nervous system $\left(2^{\text {nd }}\right.$ ed). Springer, Stuttgart, 1993

Klein B, Kuschinsky W, Schröck H, Vetterlein F (1986): Interdependency of local capillary density, blood flow, and metabolism in rat brains Am J Physiol 251(6 Pt 2): H1333-340.

Komatsu M, Yee L, Carraway KL (1999): Overexpression of sialomucin complex, a rat homologue of MUC4, inhibits tumor killing by lymphokine-activated killer cells. Cancer Res 59: 2229-2236.

Koochekpour S, Merzak A, Pilkington GJ (1996): Vascular endothelial growth factor production is stimulated by gangliosites and TGF-beta isoforms in human glioma cells in vitro. Cancer Lett 102: 209-215.

Kreuter J (2004). Influence of the surface properties on nanoparticle-mediated transport of drugs to the brain. J Nanosci Nanotechnol 4: 484-488.

Kuan CT, Wikstrand CJ, Bigner DD. (2001): EGF mutant receptor vIII as a molecular target in cancer therapy. Endocr Relat Cancer 8: 83-96.

Lai CH, Kuo KH (2005): The critical component to establish in vitro BBB model: Pericyte. Brain Res Brain Res Rev 50(2): 258-265.

Lakka SS, Gondi CS, Yanamandra N, Olivero WC, Dinh DH, Gujrati M, Rao JS (2004): Inhibition of cathepsin B and MMP-9 gene expression in glioblastoma cell line via RNA interference reduces tumor cell invasion, tumor growth and angiogenesis. Oncogene 23: 4681-4689.

Lamszus K, Kunkel P, Westphal M (2003): Invasion as limitation to anti-angiogenic glioma therapy. Acta Neurochir Suppl 88: 169-177.

Laperriere NJ, Leung PM, McKenzie S, Milosevic M, Wong S, Glen J, Pintilie M, Bernstein M (1998): Randomized study of brachytherapy in the initial management of patients with malignant astrocytoma. Int J Radiat Oncol Biol Phys 41(5): 1005-1011.

Learn CA, Grossi PM, Schmittling RJ, Xie W, Mitchell DA, Karikari I, Wei ZZ, Dressman H, Sampson JH (2007): Genetic Analysis of Intracranial Tumors in a Murine Model of Glioma Demonstrate a Shift in Gene Expression in Response to Host Immunity. J Neuroimmunol 182(1-2): 63-72. 
Lee JM, Dedhar S, Kalluri R, Thompson EW. (2006): The epithelialmesenchymal transition: new insights in signaling, development, and disease. J Cell Biol 172:973-981.

Leon SP, Folkerth RD, Black PM. (1996): Microvessel density is a prognostic indicator for patients with astroglial brain tumors. Cancer 77: 362-372.

Lidar Z, Mardor Y, Jonas T, Pfeffer R, Faibel M, Nass D, Hadani M, Ram Z (2004): Convection enhanced delivery of paclitaxel for the treatment of recurrent malignant glioma: A phase I/II clinical study. J Neurosurg 100: 472-479.

Liu VC, Wong LY, Jang T, Shah AH, Park I, Yang X, Zhang Q, Lonning S, Teicher BA, Lee C (2007 a): Tumor Evasion of the Immune System by Converting CD4 ${ }^{+} \mathrm{CD} 25^{-} \mathrm{T}$ Cells into $\mathrm{CD} 4{ }^{+} \mathrm{CD} 25^{+} \mathrm{T}$ Regulatory Cells: Role of Tumor-Derived TGF- $\beta$. J Immunol 178: 2883-2892.

Liu Y, Wang Q, Kleinschmidt-DeMasters BK, Franzusoff A, Ng K-Y, Lillehei KO (2007 b): TGF- $\beta 2$ inhibition augments the effect of tumor vaccine and improves the survival of animals with pre-established brain tumors. J Neurooncol 81: 149-162.

Löscher W, Potschka H (2005): Role of drug efflux transporters in the brain for drug disposition and treatment of brain diseases. Prog Neurobiol 76(1): 22-76.

Lossinsky AS, Mossakowski MJ, Pluta R, Wisniewski HM (1995): Intercellular adhesion molecule-1 (ICAM-1) upregulation in human brain tumors as an expression of increased blood-brain barrier permeability. Brain Pathol 5(4): 339-344.

Louis DN, Ohgaki H, Wiestler OD, Cavenee WK (eds). WHO classification of tumours of the central nervous system. IARC, Lyon, 2007.

Maher EA, Furnari FB, Bachoo RM, Rowitch DH, Lousi DN, Cavenee WK, DePinho RA (2001): Malignant glioma: genetics and biology of a grave matter. Genes Dev 15: 13111333.

Martin-Padura I, Lostaglio S, Schneemann M, Williams L, Romano M, Fruscella P, Panzeri C, Stoppacciaro A, Ruco L, Villa A, Simmons D, Dejana E (1998): Junctional adhesion molecule, a novel member of the immunoglobulin superfamily that distributes at intercellular junctions and modulates monocyte transmigration. J Cell Biol 142(1): 117-127.

Massague J (1998): TGF-beta signal transduction. Annu Rev Biochem 67: 753-791.

McAllister MS, Krizanac-Bengez L, Macchia F, NaftalinnR J, Pedley KC, Mayberg MR, Marroni M, Leaman S, Stanness KA, Janigro D (2001): Mechanisms of glucose transport at the blood-brain barrier: an in vitro study. Brain Res 409: 20-30.

Mecha M, Rabadan MA, Pena-Melian A, Valencia M, Mondejar T, Blanco MJ (2008): Expression of TGF- $\beta$ s in the Embryonic Nervous System: Analysis of Interbalance Between Isoforms. Dev Dyn 237(6): 1709-1717. 
Mendel DB, Laird AD, Xin X, Louie SG, Christensen JG, Li G, Schreck RE, Abrams TJ, Ngai TJ, Lee LB, Murray LJ, Carver J, Chan E, Moss KG, Haznedar JO, Sukbuntherng J, Blake RA, Sun L, Tang C, Miller T, Shirazian S, McMahon G, Cherrington JM (2003): In vivo antitumor activity of SU11248, a novel tyrosine kinase inhibitor targeting vascular endothelial growth factor and platelet-derived growth factor receptors: determination of a pharmacokinetic/pharmacodynamic relationship. Clin Cancer Res 9: 327-337.

Merchant RE, Ellison MD, Young HF. (1990): Immunotherapy for malignant glioma using human recombinant interleukin-2 and activated autologous lymphocytes. A revive of pre-clinical and clinical investigations. J Neurooncol 8: 173-188.

Michinton AI, Tannock IF (2006): Drug penetration in solid tumours. Nat Rev Cancer 6(8): 583-592.

Mishima K, Kato Y, Kaneko MK, Nishikawa R, Hirose T, Matsutani M (2006): Increased expression of podoplanin in malignant astrocytic tumors as a novel molecular marker of malignant progression. Acta Neuropathol 111(5):483-488.

Moniaux N, Escande F, Porchet N, Aubert JP, Batra SK (2001): Structural organization and classification of the human mucin genes. Front Biosci 6: 1192-1206.

Moolten FL (1986): Tumor chemosensitivity conferred by inserted herpes thymidine kinase genes: paradigm for a prospective cancer control strategy. Cancer Res 46(10): 52765281.

Morganti-Kossmann MC, Kossmann T, Brandes ME, Mergenhagen SE, Wahl SM (1992): Autocrine and paracrine regulation of astrocyte function by transforming growth factor13. J Neuroimmunol 39: 163-174.

Morimura T, Neuchrist C, Kitz K, Budka H, Schneiner O, Kraft D, Lassmann H (1990): Monocyte subpopulations in human gliomas: expression of $\mathrm{Fc}$ and complement receptors and correlation with tumor proliferation. Acta Neuropathol 80: 287-294.

Moskowitz SI, Jin T, Prayson RA (2006): Role of MIB1 in predicting survival in patients with glioblastomas. J Neurooncol 76: 193-200.

Nakano A, Tani E, Miyazaki K, Yamamoto Y, Furuyama J (1995): Matrix metalloproteinases and tissue inhibitors of metalloproteinases in human gliomas. $\mathrm{J}$ Neurosurg 83: 298-307.

Nam JS, Terabe M, Mamura M, Kang MJ, Chae H, Stuelten C, Kohn E, Tang B, Sabzevari H, Anver MR, Lawrence S, Danielpour D, Lonning S, Berzofsky JA, Wakefield LM (2008): An anti-transforming growth factor beta antibody suppresses metastasis via cooperative effects on multiple cell compartments. Cancer Res 68(10): 3835-3843.

Naumov GN, Bender E, Zurakowski D, Kang S-Y, Sampson D, Flynn E, Watnick RS, Straume O, Akslen LA, Folkman J, Almog N (2006): A Model of Human Tumor Dormancy: An Angiogenic Switch From the Nonangiogenic Phenotype. Journal of the National Cancer Institute 98(5): 316-325. 
Navalitloha Y, Schwartz ES, Groothuis EN, Allen CV, Levy RM, Groothuis DR (2006): Therapeutic implications of tumor interstitial fluid pressure in subcutaneous RG-2 tumors. Neuro Oncol 8(3): 227-233.

Neuwelt EA, Abbott NJ, Drewes L, Smith QR, Couraud PO, Chiocca EA, Audus KL, Greig NH, Doolittle ND (1999): Cerebrovascular biology and the various neural barriers: Challenges and future directions. Neurosurgery 44: 604-609.

Neuwelt EA, Barnett EA, Mc Cormick CI, Ferenkel EP, Minna DJ (1985). Osmotic bloodbrain barrier modification: monoclonal antibody, albumin, and methotrexate delivery to cerebrospinal fluid and brain. Neurosurgery 17: 419-423.

Neuwelt EA, Barnett PA, Hellström I, Hellström KE, Beaumier P, McCormick CI, Weigel RM (1988): Delivery of melanoma-associated immunoglobulin monoclonal antibody and Fab fragments to normal brain utilizing osmotic blood-brain barrier modification. Cancer Res 48: 4725-4729.

Neuwelt EA, Glasberg M, Frenkel E, Barnett P (1983): Neurotoxicity of chemotherapeutic agents after blood-brain barrier modification: neuropathological studies. Ann Neurol 14: 316-324.

Newton HB (2003): Molecular neuro-oncology and development of targeted therapeutic strategies for brain tumors. Part 1: Growth factor and Ras signaling pathways. Expert Rev Anticancer Ther 3(5): 595-614.

Nickl-Jockschat T, Arslan F, Doerfelt A, Bogdahn U, Hau P (2007): An imbalance between Smad and MAPK pathways is responsible for TGF- $\beta$ tumor promoting effects in highgrade gliomas. International Journal of Oncology 30: 499-507.

Nitta T, Hata M, Gotoh S, Seo Y, Sasaki H, Hashimoto N, Furuse M, Tsukita S (2003): Size-selective loosening of the blood-brain barrier in claudin-5-deficient mice. J Cell Biol 161(3): 653-660.

Norden AD, Drappatz J, Wen PY (2008): Novel anti-angiogenic therapies for malignant gliomas. Lancet Neurol 7: 1152-1160.

Nyati MK, Symon Z, Kievit E, Dornfeld KJ, Rynkiewicz SD, Ross BD, Rehemtulla A, Lawrence TS (2002): The potential of 5-fluorocytosine/cytosine deaminase enzyme prodrug gene therapy in an intrahepatic colon cancer model. Gene Ther 9: 844-849.

Oehring RD, Miletic M, Valter MM, Pietsch T, Neumann J, Fimmers R, Schlegel U. (1999): Vascular endothelial growth factor (VEGF) in astrocytic gliomas-a prognostic factor? J Neurooncol 45: 117-125.

Oh SP, Seki T, Goss KA, Imamura T, Yi Y, Donahoe PK, Li L, Miyazono K, ten Dijke P, Kim S, Li E (2000): Activin receptor-like kinase 1 modulates transforming growth factor- $\beta 1$ signaling in the regulation of angiogenesis. Proc Natl Acad Sci USA 97: 26262631. 
Ohgaki H, Dessen P, Jourde B, Horstmann S, Nishikawa T, Di Patre PL, Burkhard C, Schuler D, Probst-Hensch NM, Maiorka PC, Baeza N, Pisani P, Yonekawa Y, Yasargil MG, Lutolf UM, Kleihues P (2004): Genetic pathways to glioblastoma: a populationbased study. Cancer Res 64: 6892-6899.

Ohgaki H, Kleihues P (2005, a): Epidemiology and etiology of gliomas. Acta Neuropathol 109: 93-108.

Ohgaki H, Kleihues P (2005, b): Population-based studies on incidence, survival rates, and genetic alterations in astrocytic and oligodendroglial gliomas. Neuropathol Exp Neurol 64: 479-489.

Okada H, Kohanbash G, Zhu X, Kastenhuber ER, Hoji A, Ueda R, Fujita M (2009): Immunotherapeutic approaches for glioma. Crit Rev Immunol 29(1): 1-42.

Packer RJ (1999): Brain tumors in children. Arch Neurol 56: 421-425.

Pan JJ, Chang WJ, Barone TA, Plunkett RJ, Ostrow PT, Greenberg SJ (2006): Increased expression of TGF-betal reduces tumor growth of human U-87 Glioblastoma Cells in vivo. Cancer Immunol Immunother 55(8): 918-927.

Pardridge W, Boado R, Farrell C (1990): Brain-type glucose transporter (GLUT-1) is selectively localized to the blood-brain barrier. Studies with quantitative western blotting and in situ hybridization. J Biol Chem 265: 18035-18040.

Parney IF, Kunwar S, McDermott M, Berger M, Prados M, Cha S, Croteau D, Puri RK, Chang SM (2005): Neuroradiographic changes following convection enhanced delivery of the recombinant cytotoxin interleukin 13-PE38QQR for recurrent malignant glioma. J Neurosurg 102: 267-275.

Patel MM, Goyal BR, Bhadada SV, Bhatt JS, Amin AF. (2009): Getting into the Brain: Approaches to Enhance Brain Drug Delivery. CNS Drugs (23): 35-58.

Pen A, Moreno MJ, Martin J, Stanimirovic DB (2007): Molecular markers of extracellular matrix remodeling in glioblastoma vessels: microarray study of laser-captured glioblastoma vessels. Glia 55(6): 559-572.

Pen A, Moreno1 MJ, Durocher Y, Deb-Rinker P, Stanimirovic DB (2008): Glioblastomasecreted factors induce IGFBP7 and angiogenesis by modulating Smad-2-dependent TGF-b signalling. Oncogene 27: 6834-6844.

Pepper MS (1997): Transforming growth factor-beta: vasculogenesis, angiogenesis, and vessel wall integrity. Cytokine Growth Factor Rev 8: 21-43.

Peppiatt CM, Howarth C, Mobbs P, Attwell D (2006): Bidirectional controls of CNS capillary diameter by pericytes. Nature 443: 700-704.

Perry JR, Louis DN, Carincross JG (1999): Current treatment of oligodendrogliomas. Arch Neurol 56: 434-436.

Pham W, Zhao B-Q, Lo EH, Medarova Z, Rosen B, Moorea A (2005): Crossing the bloodbrain barrier: A potential application of myristoylated polyarginine for in vivo neuroimaging. NeuroImage 28: 287-292. 
Phillips HS, Kharbanda S, Chen R, Forrest WF, Soriano RH, Wu TD, Misra A, Nigro JM, Colman H, Soroceanu L, Williams PM, Modrusan Z, Feuerstein BG, Aldape K (2006): Molecular subclasses of high-grade glioma predict prognosis, delineate a pattern of disease progression, and resemble stages in neurogenesis. Cancer Cell 9: 157-173.

Piek E, Westermark U, Kastemar M, Heldin CH, van Zoelen EJ, Nistér M, Ten Dijke P (1999): Expression of transforming-growth-factor (TGF)-beta receptors and Smad proteins in glioblastoma cell lines with distinct responses to TGF-beta1. Int $\mathrm{J}$ Cancer 80(5): 756-763.

Platten M, Kretz A, Naumann U, Aulwurm S, Egashira K, Isenmann S, Weller M (2003): Monocyte Chemoattractant Protein-1 Increases Microglial Infiltration and Aggressiveness of Gliomas. Ann Neurol 54: 388-392.

Platten M, Wick W, Weller M (2001): Malignant glioma biology: role of TGF-beta in growth, motility, angiogenesis, and immune escape. Microsc Res Tech 52: 401-410.

Plautz GE, Yang ZY, Wu BY, Gao X, Huang L, Nabel GJ (1993): Immunotherapy of malignancy by in vivo gene transfer into tumors. Proc Natl Acad Sci USA 90: 46454649.

Ponten J, Macintyre EH (1968): Long term culture of normal and neoplastic human glia. Acta Path Microbiol Scand 74: 465-486.

Pöpperl G, Kreth FW, Herms J, Koch W, Mehrkens JH, Gildehaus FJ, Kretzschmar HA, Tonn JC, Tatsch K. (2006): Analysis of 18F-FET PET for Grading of Recurrent Gliomas: Is Evaluation of Uptake Kinetics Superior to Standard Methods? J Nucl Med 47: 393-403.

Preston E, Slinn J, Vinokourov I, Stanimirovic D (2008): Graded reversibile opening of the rat blood-brain barrier by intracarotid infusion of sodium caprate. $\mathrm{J}$ Neurosci Methods 168: 443-449.

Rainov NG (2000): A phase III clinical evaluation of herpes simplex virus type 1 thymidine kinase and ganciclovir gene therapy as an adjuvant to surgical resection and radiation in adults with previously untreated glioblastoma multiforme. Hum Gene Ther 11(17): 2389-2401.

Ramsauer M, Krause D, Dermietzel R (2002): Angiogenesis of the blood-brain barrier in vitro and the function of zerebral pericytes. FASEB J 16: 1274-1278.

Rao JS (2003): Molecular mechanisms of glioma invasiveness: the role of proteases. Nat Rev Cancer 3: 489-501.

Rapoport SI (2000): Osmotic opening of the blood-brain barrier: principles, mechanisms, and therapeutic applications. Cell Mol Neurobiol 20: 217-230.

Raymond SB, Skoch J, Hills ID, Nesterov EE, Swager TM, Bacskai BJ (2008): Smart optical probes for near-infrared fluorescence imaging of Alzheimer`s disease pathology. Eur J Nucl Med Mol Imaging 35: 93-98. 
Reardon DA, Akabani G, Coleman RE, Friedman AH, Friedman HS, Herndon JE 2nd, McLendon RE, Pegram CN, Provenzale JM, Quinn JA, Rich JN, Vredenburgh JJ, Desjardins A, Gururangan S, Badruddoja M, Dowell JM, Wong TZ, Zhao XG, Zalutsky MR, Bigner DD (2006 b): Salvage radioimmunotherapy with murine iodine-131-labeled antitenascin monoclonal antibody $81 \mathrm{C} 6$ for patients withrecurrent primary and metastatic malignant brain tumors: phase II study results. J Clin Oncol 24: 115-122.

Reardon DA, Akabani G, Coleman RE, Friedman AH, Friedman HS, Herndon JE, Cokgor I, McLendon RE, Pegram CN, Provenzale JM, Quinn JA, Rich JN, Regalado LV, Sampson JH, Shafman TD, Wikstrand CJ, Wong TZ, Zhao XG, Zalutsky MR, Bigner DD (2002): Phase II trial of murine (131)I-labeled antitenascin monoclonal antibody 81C6 administered into surgically created resection cavities of patients with newly diagnosed malignant gliomas. J Clin Oncol 20: 1389-1397.

Reardon DA, Rich JN, Friedman HS, Bigner DD (2006 a): Recent advances in the treatment of malignant astrocytoma. J Clin Oncol 24(8): 1253-1265.

Regina A, Demeule M, Laplante A, Jodoin J, Dagenais C, Berthelet F, Moghrabi A, Beliveau R (2001) Multidrug resistance in brain tumors: roles of the blood-brain barrier. Cancer Metastasis Rev 20(1-2): 13-25.

Reifenberger G, Collins VP (2004): Pathology and molecular genetics of astrocytic gliomas. J Mol Med 82: 656-670.

Reya T, Morrison SJ, Clarke MF, Weissman IL (2001): Stem cells, cancer, and cancer stem cells. Nature 414: 105-111.

Rich J, Borton A, Wang X, Platten M, Wick W and Weller M (2001): Transforming growth factor-beta signaling in cancer. Microsc Res Tech 52: 363-373.

Rich JN, Zhang M, Datto MB, Bigneri DD, Xiao-Fan Wang X-F (1999): Transforming Growth Factor-b-mediated $\mathrm{p} 15^{\mathrm{INK} 4 \mathrm{~B}}$ Induction and Growth Inhibition in Astrocytes Is SMAD3-dependent and a Pathway Prominently Altered in Human Glioma Cell Lines. J Biol Chem 274(49): 35053-35058.

Rifkin DB (2005): Latent transforming growth factor-beta (TGF-beta) binding proteins: orchestrators of TGF-beta availability. J Biol Chem 280(9): 7409-7412.

Rossi ML, Hughes JT, Esiri MM, Coakham HB, Brownell DB (1987): Immunohistological study of mononuclear cell infiltrate in malignant gliomas. Acta Neuropathol 74: 269277.

Ruzek MC, Hawes M, Pratt B, McPherson J, Ledbetter S, Richards SM, Garman RD (2003): Minimal effects on immune parameters following chronic anti-TGF-beta monoclonal antibody administration to normal mice. Immunopharmacol Immunotoxicol. 25(2): 235-57.

Salsbury FR, Han WG, Noodleman L, Brooks CL (2003): Temperature-Dependent Behavior of Protein-Chromophore Interactions: A Theoretical Study of a Blue Fluorescent Antibody. Chemphyschem 4: 848-855. 
Sankar S, Mahooti-Brooks N, Centrella M, McCarthy TL, Madri JA (1995): Expression of transforming growth factor type III receptor in vascular endothelial cells increases their responsiveness to transforming growth factor $\beta 2$. J Biol Chem 270: 13567-13572.

Sartor K, Hartmann M, Fiebach J, Harting I, Wilhelm T, Heiland S (2003): Normal and Abnormal Water Diffusion in Brain. Fortschr Röntgenstr 175:1317-1329.

Sathornsumetee S, Rich JN (2007): Antiangiogenic therapy in malignant glioma: promise and challenge. Curr Pharm Des 13: 3545-3558.

Sathornsumetee S, Rich JN (2008): Designer Therapies for Glioblastoma Multiforme. Ann NY Acad Sci 1142: 108-132.

Satoh S, Hinoda Y, Hayashi T, Burdick MD, Imai K, Hollingsworth MA (2000): Enhancement of metastatic properties of pancreatic cancer cells by MUC1 gene encoding an anti-adhesion molecule. Int J Cancer 88: 507-518.

Schinkel AH, Smit JJ, van Telligen O, Beijnen JH, Wagenaar E, van Deemter L, Mol CA, van der Valk MA, Robanus-Maandag EC, De Riele HPJ, Berns AJM, Borst P (1994): Disruption of the mouse mdrla P-glycoprotein gene leads to a deficiency in the bloodbrain barrier and to increased sensitivity to drugs. Cell 77(4): 491-502.

Schlingensiepen KH, Schlingensiepen R, Steinbrecher A, Hau P, Bogdahn U, Fischer-Blass B, Jachimczak P (2006): Targeted tumor therapy with the TGF-beta2 antisense compound AP 12009. Cytokine Growth Factor Rev 17(1-2): 129-139.

Schmid I, Peraud A, Pöllinger B. Hirntumoren und Spinale Tumoren, 3.Auflage. Kapitel: Kindliche Tumoren. Zuckschwerdt Verlag, München (2007)

Schmierer B, Hill CS (2007): TGF $\beta$-SMAD signal transduction: molecular specificity and functional flexibility. Nat Rev Mol Cell Biol 8: 970-982.

Schuz J, Kaletsch U, Kaatsch P, Meinert R, Michaelis J (2001): Risk factors for pediatric tumors of the central nervous system: results from German population- based casecontrol study. Med Pediatr Oncol 36(2): 274-282.

Schweitzer T, Vince GH, Herbold C, Roosen K, Tonn JC (2001): Extraneural metastases of primary brain tumors. J Neurooncol 53: 107-114.

Selker RG, Shapiro WR, Burger P, Blackwood MS, Arena VC, Gilder JC, Malkin MG, Mealey JJ Jr, Neal JH, Olson J, Robertson JT, Barnett GH, Bloomfield S, Albright R, Hochberg FH, Hiesiger E, Green S (2002): The Brain Tumor Cooperative Group NIH Trial 87-01: a randomized comparison of surgery, external radiotherapy, and carmustine versus surgery, interstitial radiotherapy boost, external radiation therapy, and carmustine. Neurosurgery 51(2): 343-357.

Seoane J (2006): Escaping from the TGF-beta anti-proliferative control. Carcinogenesis 27: 2148-2156.

Shi Y, Massagué J (2003): Mechanisms of TGF- $\beta$ signaling from cell membrane to the nucleus. Cell 113: 685-700.

Sibtain NA, Howe FA, Saunders DE (2007): The clinical value of proton magnetic resonance spectroscopy in adult brain tumours. Clin Radiol 62(2): 109-119. 
Siegal T, Rubinstein R, Bokstein F, Schwartz A, Lossos A, Shalom E, Chisin R, and Gomori JM (2000): In vivo assessment of the window of barrier opening after osmotic blood-brain barrier disruption in humans. J Neurosurg 92: 599-605.

Skultetyova I, Tokarev D, Jezova D (1998): Stress-induced increase in blood-brain barrier permeability in control and monosodium glutamate-treated rats. Brain Res Bull 45(2): 175-178.

Smith MJ, Carvalho HM, Melton-Celsa AR, O’Brien AD (2006): The 13C4 Monoclonal Antibody That Neutralizes Shiga Toxin Type 1 (Stx1) Recognizes Three Regions on the Stx1 B Subunit and Prevents Stx1 from Binding to Its Eukaryotic Receptor Globotriaosylceramide. Infection and Immunity 74(12): 6992-6998.

Solan A, Dansey R, Zamorano L, Barger G, Hamm C, Diaz F, Baynes R, Wood G (2000): Adoptive immunotherapy in patients with recurrent malignant glioma: preliminary results of using autologous whole-tumor vaccine plus granulocyte-macrophage colony stimulating factor and adoptive transfer of Anti CD3-activated lymphocytes. Neurosurg Focus 9(6): article 9.

Song K, Wang H, Krebs TL, Danielpour D (2006): Novel roles of Akt and mTOR in suppressing TGF-beta/ALK5-mediated Smad3 activation. EMBO J 25: 58-69.

Stern JI, Raizer JJ (2006): Chemotherapy in the treatment of malignant gliomas. Expert Rev Anticancer Ther 6(5): 755-767.

Stevenson BR, Siliciano JD, Mooseker MS, Goodenough DA (1986): Identification of ZO1: a high molecular weight polypeptide associated with the tight junction (zonula occludens) in a variety of epithelia. J Cell Biol 103(3): 755-766.

Stockhammer G, Brotchi J, Leblanc R, Bernstein M, Schackert G, Weber F, Ostertag C, Mulder NH, Mellstedt H, Seiler R, Yonekawa Y, Twerdy K, Kostron H, De Witte O, Lambermont M, Velu T, Laneuville P, Villemure JG, Rutka JT, Warnke P, Laseur M, Mooij JJ, Boëthius J, Mariani L, Gianella-Borradori A, et al. (1997): Gene therapy for glioblastoma [correction of gliobestome] multiform: in vivo tumor transduction with the herpes simplex thymidine kinase gene followed by ganciclovir. J Mol Med 75(4): 300304.

Stummer W, Pichlmeier U, Meinel T, Wiestler OD, Zanella F, Reulen HJ (2006): ALAGlioma Study Group. Fluorescence-guided surgery with 5-aminolevulinic acid for resection of malignant glioma: a randomised controlled multicentre phase III trial. Lancet Oncol 7: 392-401.

Stupp R, Hegi ME, van den Bent MJ, Mason WP, Weller M, Mirimanoff RO, Cairncross JG (2006): Changing paradigms- an update on the multidisciplinary management of malignant glioma. Oncologist 11(2): 165-180.

Sugibayashi K, Onuki Y, Takayama K (2009): Displacement of tight junction proteins from detergent-resistant membrane domains by treatment with sodium caprate. Eur $\mathrm{J}$ Pharm Sci 36(2-3): 246-253. 
Szatmari T, Lumniczky K, Desaknai S, Trajcevski S, Hídvegi EJ, Hamada H, Safrany H (2006): Blackwell Publishing Asia Detailed characterization of the mouse glioma 261 tumor model for experimental glioblastoma therapy. Cancer Sci 97(6): 546-553.

Takasato Y, Rapoport SI, Smith QR (1984): An in situ brain perfusion technique to study cerebrovascular transport in the rat. Am J Physiol 247(3 Pt 2): H484-493.

Talmadge JE, Donkor M, Scholar E (2007): Inflammatory cell infiltration of tumors: Jekyll or Hyde. Cancer Metastasis Rev 26: 373-400.

Tamura K, Hashimoto K, Suzuki K, Yoshie M, Kutsukake M, Sakurai T (2009): Insulinlike growth factor binding protein-7 (IGFBP7) blocks vascular endothelial cell growth factor (VEGF)-induced angiogenesis in human vascular endothelial cells. Eur J Pharmacol 610(1-3): 61-67.

Taylor-Papadimitriou J, Burchell J, Miles DW, Dalziel M (1999): MUC1 and cancer. Biochim Biophys Acta 1455: 301-313.

Taylor-Papadimitriou J, Burchell JM, Plunkett T, Graham R, Correa I, Miles D, Smith M (2002): MUC1 and the immunobiology of Cancer. J Mammary Gland Biol Neoplasia 7: 209-221.

Teicher BA (2001): Malignant cells, directors of the malignant process: role of transforming growth factor-beta. Cancer Metastasis Rev 20: 133-143.

ten Dijke P, Arthur HM (2007): Extracellular control of TGF $\beta$ signalling in vascular development and disease. Nat Rev Mol Cell Biol 8: 857-869.

ten Dijke P, Goumans MJ, Pardali E (2008): Endoglin in angiogenesis and vascular diseases. Angiogenesis 11: 79-89.

Thiery JP (2003): Epithelial-mesenchymal transitions in development and pathologies. Curr Opin Cell Biol 15: 740-746.

Tonn JC, Goetzl C, Grabenbauer GG, Wiestler OD (2004): Ependymome. Der Onkologe 9(7): 721-728.

Tso CL, Freije WA, Day A, Chen Z, Merriman B, Perlina A, Lee Y, Dia EQ, Yoshimoto K, Mischel PS, Liau LM, Cloughesy TF, Nelson SF (2006): Distinct Transcription Profiles of Primary and Secondary Glioblastoma Subgroups. Cancer Res 66: 159-167.

Uhl M, Aulwurm S, Wischhusen J, Weiler M, Ma JY, Almirez R, Mangadu R, Liu Y-W, Platten M, Herrlinger U, Murphy A, Wong DH, Wick W, Higgins LS, Weller M (2004): SD-208, a Novel Transforming Growth Factor $\beta$ Receptor I Kinase Inhibitor, Inhibits Growth and Invasiveness and Enhances Immunogenicity of Murine and Human Glioma Cells In vitro and In vivo. Cancer Res 64: 7954-7961.

Uhrbom L, Dai C, Celestino JC, Rosenblum MK, Fuller GN, Holland EC (2002): Ink4aArf loss cooperates with KRas activation in astrocytes and neural progenitors to generate glioblastomas of various morphologies depending on activated Akt. Cancer Res 62: 5551-5558. 
Umemura N, Saio M, Suwa T, Kitoh Y, Bai J, Nonaka K, Ouyang G-F, Okada M, Balazs M, Adany R, Shibata T, Takami T (2008): Tumor-infiltrating myeloid-derived suppressor cells are pleiotropic-inflamed monocytes/macrophages that bear M1- and M2-type characteristics. J Leukoc Biol 83(5): 1136-1144.

Unger C, Eibl H, von Heyden H-W, Kirsch B, Nagel GA (1985): Blut-Hirn-Schranke und Penetration von Zytostatika. Klein Wochenschr 63: 565-571.

Unsicker K, Strelau J. (2000): Functions of transforming growth factor-beta isoforms in the nervous system. Cues based on localization and experimental in vitro and in vivo evidence. Eur J Biochem 267: 6972-6975.

Urbach H, Solymosi L. Neuroonkologie, 2. erweit. Auflage. Stuttgart. Thieme, 2003.

van Breemen MS, Wilms EB, Vecht CJ (2007): Epilepsy in patients with brain tumours: epidemiology, mechanisms, and management. Lancet Neurol 6: 421-430.

Vitolo D, Paradiso P, Uccini S, Ruco LP, Baroni CD (1996): Expression of adhesion molecules and extracellular matrix proteins in glioblastomas: relation to angiogenesis and spread. Histopathology 28(6): 521-528.

Voges J, Reszka R, Gossmann A, Dittmar C, Richter R, Garlip G, Kracht L, Coenen HH, Sturm V, Wienhard K, Heiss WD, Jacobs AH (2003): Imaging-guided convectionenhanced delivery and gene therapy of glioblastoma. Ann Neurol 54: 479-487.

Walker MD, Alexander E Jr, Hunt WE, MacCarty CS, Mahaley MS Jr, Mealey J Jr, Norrell HA, Owens G, Ransohoff J, Wilson CB, Gehan EA, Strike TA (1978): Evaluation of BCNU and/or radiotherapy in the treatment of anaplastic gliomas. A cooperative clinical trial. J Neurosurg 49: 333-343.

Walker PR, Calzascia T, de Tribolet N, Dietrich PY (2003): T-cell immune responses in the brain and their relevance for zerebral malignancies. Brain Res Brain Res Rev 42(2): 97-122.

Walshe TE, Saint-Geniez M, Maharaj AS, Sekiyama E, Maldonado AE, D'Amore PA (2009): TGF-beta is required for vascular barrier function, endothelial survival and homeostasis of the adult microvasculature. PloS ONE 4(4): 5149.

Warren K, Jakacki R, Widemann B, Aikin A, Libucha M, Packer R, Vezina G, Reaman G, Shaw D, Krailo M, Osborne C, Cehelsky J, Caldwell D, Stanwood J, Steinberg SM, Balis FM (2006): Phase II trial of intravenous lobradimil and carboplatin in childhood brain tumors: a report from the Children's Oncology Group. Cancer Chemother Pharmacol 58(3): 343-347.

Weller M, Fontana A (1995): The failure of current immunotherapy for malignant glioma. Tumor-derived TGF-beta, T-cell apoptosis, and the immune privilege of the brain. Brain Res Brain Res Rev 21: 128-151. 
Wen PY, Yung WK, Lamborn KR, Dahia PL, Wang Y, Peng B, Abrey LE, Raizer J, Cloughesy TF, Fink K, Gilbert M, Chang S, Junck L, Schiff D, Lieberman F, Fine HA, Mehta M, Robins HI, DeAngelis LM, Groves MD, Puduvalli VK, Levin V, Conrad C, Maher EA, Aldape K, Hayes M, Letvak L, Egorin MJ, Capdeville R, Kaplan R, Murgo AJ, Stiles C, Prados MD. (2006): Phase I/II study of imatinib mesylate for recurrent malignant gliomas: North American Brain Tumor Consortium Study 99-08. Clin Cancer Res 12: 4899-4907.

Wesolowska A, Kwiatkowska A, Slomnicki L, Dembinski M, Master A, Sliwa M, Franciszkiewicz K, Chouaib S, Kaminska B (2008): Microglia-derived TGF-b as an important regulator of glioblastoma invasion - an inhibition of TGF-b-dependent effects by shRNA against human TGF-b type II receptor. Oncogene 27: 918-930.

Wesseling J, van der Valk SW, Vos HL, Sonnenberg A, Hilkens J (1995): Episialin (MUC1) overexpression inhibits integrin-mediated cell adhesion to extracellular matrix components. J Cell Biol 129: 255-265.

Wessels JT, Busse AC, Mahrt J, Dullin C, Grabbe E, Mueller GA. (2007): In Vivo Imaging in Experimental Preclinical Tumor Research-A Review. Cytometry A 71: 542-549.

Westphal M, Hilt DC, Bortey E, Delavault P, Olivares R, Warnke PC, Whittle IR, Jaaskelainen J, Ram Z (2003): A phase III trial of local chemotherapy with biodegradable carmustine (BCNU) wafers (Gliadel wafers) in patients with primary malignant glioma. Neuro-oncol 5: 3276-3284.

Wick W, Naumann U, Weller M (2006): Transforming Growth Factor- $\beta$ : A Molecular Target fort he Future Therapy of Glioblastoma. Current Pharmaceutical Design 12: 341349.

Wick W, Platten M, Weller M (2001): Glioma cell invasion: regulation of metalloproteinase activity by TGF-beta. J Neurooncol 53: 177-185.

Wischusen J, Jung G, Radovanovic I, Beier C, Steinbach JP, Rimner A, Huang H, Schulz JB, Ohgaki H, Aguzzi A, Rammensee HG, Weller M (2002): Identification of CD70mediated apoptosis of immune effector cells as a novel immune escape pathway of human glioblastoma. Cancer Res 62: 2592-2599.

Wolburg H, Wolburg-Buchholz K, Kraus J, Rascher-Eggstein G, Liebner S, Hamm S, Duffner F, Grote E-H, Risau W, Engelhardt B (2003): Localization of claudin-3 in tight junctions of the blood-brain barrier is selectively lost during experimental autoimmune encephalomyelitis and human glioblastoma multiforme. Acta Neuropathol 105: 586592.

Wolburg H: The endothelial frontier. In: Blood-Brain Interfaces - from Ontology to Artificial Barriers. 77-107. Ed. Dermietzel R, Spray D, Nedergaard M, Wiley-VCH, Weinheim, 2006

Wolff JAE, Wagner S, Reinert C, Gnekow A, Kortmann R-D, Kühl J, Van Gool SW (2006): Maintenance treatment with interferon-gamma and low-dose cyclophosphamide for pediatric high-grade glioma. J Neurooncol 79: 315-321. 
Wrann M, Bodmer S, de Martin R, Siepl C, Hofer-Warbinek R, Frei K, Hofer E, Fontana A (1987): $\mathrm{T}$ cell suppressor factor from human glioblastoma cells is a 12.5-kd protein closely related to transforming growth factor-beta. Embo J 6:1633-1636.

$\mathrm{Xu} \mathrm{XL}$, Kapoun AM (2009): Heterogeneous activation of the TGFbeta pathway in glioblastomas identified by gene expression-based classification using TGFbetaresponsive genes. J Transl Med 7: 12.

Yamashita M, Fatyol K, Jin C, Wang X, Liu Z, Zhang YE (2008): TRAF6 mediates Smadindependentbactivation of JNK and p38 by TGF-beta. Mol Cell 31: 918-924.

Yuan X, Curtin J, Xiong Y, Liu G, Waschsmann-Hogiu S, Farkas DL, Black KL, Yu JS (2004): Isolation of cancer stem cells from adult glioblastoma multiforme. Oncogene 23:9392-9400.

Zamecnik J (2005): The extracellular space and matrix of gliomas. Acta Neuropathol (Berl) 110: $435-442$.

Zeltzer PM, Moilanen B, Yu JS, Black KL (1999): Immunotherapy of malignant brain tumors in children and adults: fron theoretical principles to clinical application. Childs Nerv Syst 15: 514-528.

Zhu J, Takahashi H, Nakazawa S (1994): Human Monoclonal Antibody-Drug Conjugates in the Experimental Treatment of Malignant Gliomas. Neurol Med Chir (Tokyo) 34(5): 279-285. 


\section{Anhang}

\subsection{Abkürzungen}

\begin{tabular}{|l|l|}
\hline$\mu$ & Mikro- \\
\hline A. & Arteria \\
\hline AF594 & Alexa Fluor 594 \\
\hline AF680 & Alexa Fluor 680 \\
\hline BHS & Blut-Hirn-Schranke \\
\hline BSA & Bovines Serumalbumin \\
\hline Cy5.5 & Cy5.5 Mono NHS Ester \\
\hline DAB & 3,3-Diaminobenzidin Tetrahydrochlorid \\
\hline DNA & Desoxyribonucleinsäure \\
\hline EZM & extrazelluläre Matrix \\
\hline FCS & Fetales Kälberserum \\
\hline g & Gramm \\
\hline h & Stunde \\
\hline HE & Hämalaun-Eosin \\
\hline HG & 2-O-Hexyldiglicerin \\
\hline i.v. & intravenös \\
\hline KG & Körpergewicht \\
\hline l & Liter \\
\hline LT & Lifetime (Fluoreszenzanregungslebensdauer) \\
\hline m & Milli- \\
\hline min & Minute \\
\hline mm & Millimeter \\
\hline n & Nano- \\
\hline NaCl 0,9\% & Isotonische Kochsalzlösung \\
\hline Na-F1 & Natrium-Fluorescein \\
\hline PBS & Phosphate buffered saline \\
\hline PFA & Paraformaldehyd \\
\hline RB200 & Rhodamin B200 \\
\hline & \\
\hline
\end{tabular}




\begin{tabular}{|l|l|}
\hline RT & Raumtemperatur \\
\hline S & Sekunde \\
\hline s.c. & subkutan \\
\hline SDS & Natriumdodecylsulfat \\
\hline TEMED & N, N, N', N'-Tetramethylethylendiamin \\
\hline TGF- $\beta$ & Transforming Growth Factor- beta \\
\hline TJ & Tight Junction \\
\hline Ü.N. & über Nacht \\
\hline VEGF & Vascular endothelial growth factor \\
\hline WHO & World Health Organization \\
\hline ZNS & Zentrales Nevensystem \\
\hline
\end{tabular}




\section{Danksagung}

Mein besonderer Dank gilt Herrn Prof. Dr. M. Lakomek für die Überlassung des interessanten Themas.

Herrn Prof. Dr. E. A. Wimmer danke ich für die freundliche Übernahme des Erstreferats. Herrn Prof. Dr. R. Heinrich danke ich für die freundliche Übernahme des Koreferats.

Frau Prof. Dr. S. Hoyer-Fender, Herrn Prof. Dr. A. Stumpner, Herrn PD Dr. W. Kramer und Herrn Prof. Dr. U. Groß danke ich für die Bereitschaft die Prüfungskommission zu bilden.

Großen Dank schulde ich Herrn PD Dr. B. Erdlenbruch für die Einführung in die Thematik und die stete Diskussionsbereitschaft und PD Dr. W. Kugler für alle Anregungen und Diskussionen.

Herrn PD Dr. Schulz-Schaeffer aus der Abteilung Neuropathologie danke ich für die freundliche Unterstützung bei der Auswertung der histologischen Präparate.

Ein großes Dankeschön auch an Dr. Jürgen Becker aus der Abteilung Anatomie und Zellbiologie für die Anregungen zum Manuskript dieser Arbeit.

Regina, Rita, den Julias und allen anderen Kollegen im Labor danke ich für die gute Zusammenarbeit und stete Hilfsbereitschaft. Ganz besonders möchte ich mich an dieser Stelle bei Hoa Nguyen bedanken, die mir bis vor zwei Jahren als sie schwer erkrankte eine große Hilfe bei der Einarbeitung und Durchführung der Tierversuche war.

Meiner Mutter danke ich dafür, dass sie immer ein offenes Ohr für meine Sorgen hatte.

Ganz herzlich möchte ich mich bei Alexander bedanken, der immer für mich da war und mir auch in schlechten Zeiten immer wieder Mut gemacht hat. Einen ganz lieben Dank auch an Isabell und Julia, die alle Entbehrungen tapfer ertragen und mich während meiner Arbeit immer wieder aufgemuntert haben. 


\section{Lebenslauf}

- Persönliche Daten:

- Schulbildung:

1981 - 1984

$1984-1986$

$1986-1994$

- Studium:

$1994-2003$

Seit WS 2006/07

Geb. 31. August 1974 in Emden

Grundschule Westerburg in Emden

Orientierungsstufe Osterburgschule in Emden

Gymnasium am Treckfahrtstief in Emden

Abschluss: Allg. Hochschulreife

Biologiestudium an der

Georg-August-Universität zu Göttingen

Abschluss: Diplombiologin

Anfertigung der Diplomarbeit am Albrecht-vonHaller-Institut für Pflanzenwissenschaften bei Prof. Dr. C.Gatz mit dem Thema:

Identifizierung von Protein-Interaktionspartnern des bZIP-Transkriptionsfaktors TGA2.2 aus Nicotiana tabacum

Wissenschaftliche Mitarbeiterin der Universitätsklinik Göttingen im

Zentrum für Kinderheilkunde und Jugendmedizin in der Arbeitsgruppe Neuroonkologie der Abteilung Pädiatrie I

Forschung zum Thema Blut-Hirn-Schranke und Gehirntumor unter der Leitung von Prof. Dr. M. Lakomek

Anfertigung der vorliegenden Dissertation in der selben Abteilung 


\section{Poster}

Hülper P, Kugler W, Lakomek M, Erdlenbruch B

TGF-beta antibody treatment of subcutaneous gliomas in mice.

8th Meeting of the European Association of NeuroOncology (EANO)

11th -14th September 2008, Barcelona/Spain

Hülper P, Kugler W, Lakomek M, Erdlenbruch B

Alterations of blood vessels in malignant gliomas.

10. Blut-Hirn Schranke Expertentreffen (blood-brain barrier expert meeting)

20th-21th May 2008, Bad Herrenalb/Germany

Hülper P, Preusse A-C, Kugler W, Eibl H, Lakomek M, Erdlenbruch B

Increased transfer of TGF-beta antibody to the CNS after BBB opening with 2-O-

hexyldiglycerol: Visualisation of drug transfer using optical imaging.

10th International Symposium "Signal transduction in the blood-brain barriers"

13th - 16th September 2007, Potsdam/Germany

Manuskript zur Veröffentlichung in der Zeitschrift „Molecular Imaging and Biology“ eingereicht:

Petra Hülper, Christian Dullin, Wilfried Kugler, Max Lakomek, Bernhard Erdlenbruch.

Monitoring proteins using in vivo near infrared time domain optical imaging after 2-Ohexyldiglycerol-mediated transfer to the brain. 